\title{
Open Government Data as a Reform and Ecosystem - A conceptual framework for evolution and health
}

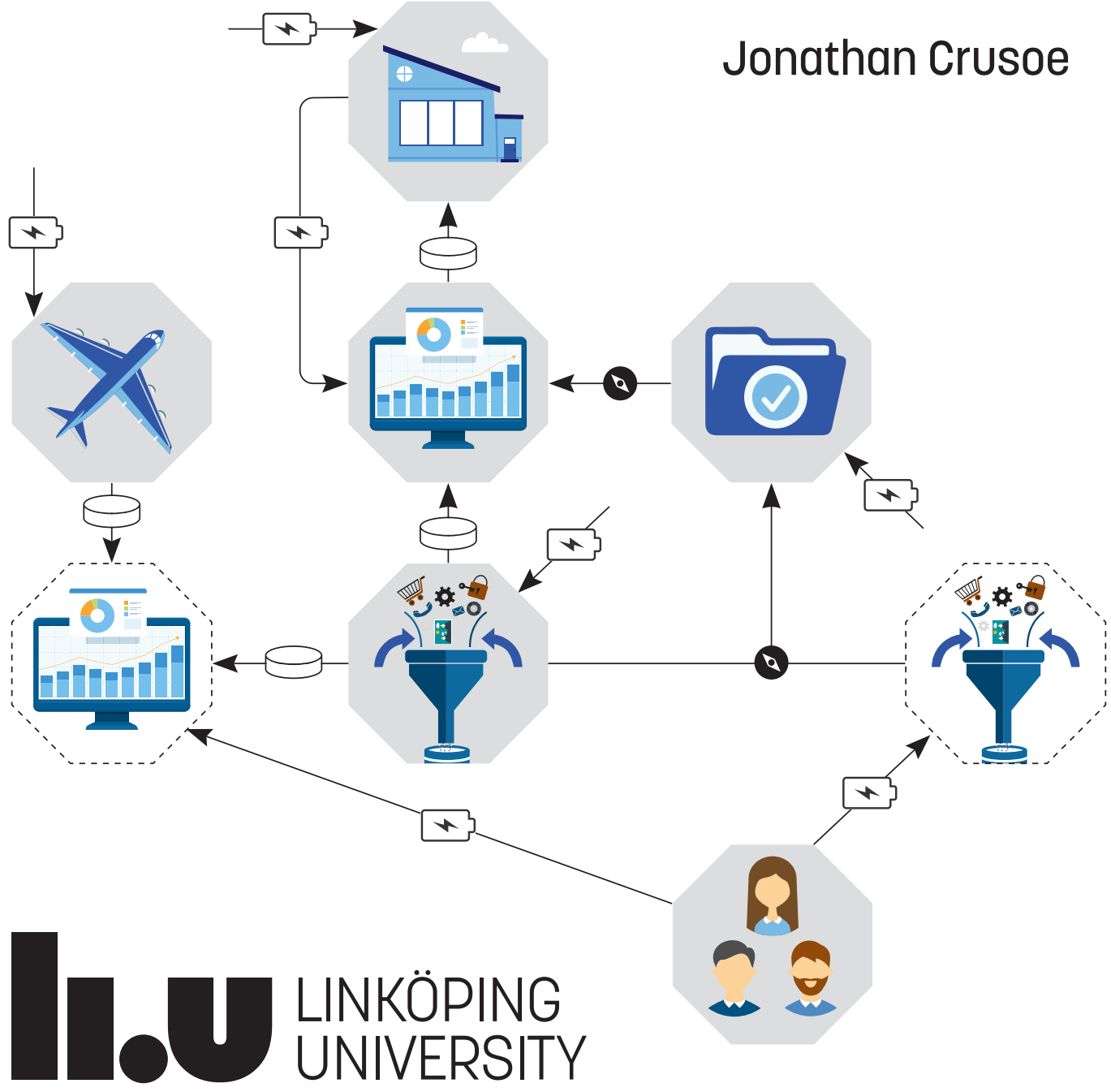





\title{
Open Government Data as a Reform and Ecosystem - A conceptual framework for evolution and health
}

\author{
Jonathan Crusoe
}

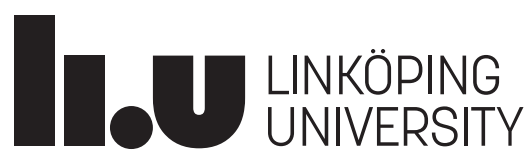

Linköping University

Department of Management and Engineering

Division of Information Systems and Digitalization

SE-581 83 Linköping, Sweden

Linköping 2021 


\section{Open Government Data as a Reform and Ecosystem - A conceptual framework for evolution and health}

(oc) EY This work is licensed under a Creative Commons Attribution 4.0 International License.

https://creativecommons.org/licenses/by/4.0/

Edition 1:0

(C) Jonathan Crusoe, 2021

ISBN 978-91-7929-000-9

ISSN 0282-9800

URL http://urn.kb.se/resolve?urn=urn:nbn:se:liu:diva-10.3384

Published articles have been reprinted with permission from the respective copyright holder.

Typeset using [ATEX

Printed by LiU-Tryck, Linköping 2021 


\section{POPULÄRVETENSKAPLIG SAMMANFATTNING}

Introduktion: Öppna data är data som tillgängliggörs av offentliga organisationer (eng. open government data [OGD]) enligt vissa principer för att låta vem som helst återanvända data. I denna doktorsavhandling inom ämnet informationssystem undersöker jag samspelet mellan en OGD-reform och ett OGD-ekosystem samt olika typer av roller för aktörer. En OGD-reform förändrar delar av ett samhälle så att ett OGD-ekosystem kan organiseras för att realisera olika fördelar (till exempel ekonomisk tillväxt eller transparens). Ett OGD-ekosystem består i att aktörer delar data (tillhandahållare [eng. providers]) och vem som helst använder data. Rollen berikare (eng. enrichers) använder data för att utveckla produkter eller tjänster och sökare (eng. seekers) använder data, produkterna eller tjänsterna för att tillgodose deras behov.

Problem och Syfte: Tidigare OGD-forskning tenderar att inkludera en OGD-reform i ett OGDekosystem, vilket kan begränsa möjligheterna att förstå ett ekosystems evolution och dess hälsa. Därför att en OGD-reform är tillfälliga förvandlingar, medan ett OGD-ekosystem är återkommande processer för ett mera specifikt ändamål. Denna situation kan dölja hur samspelet mellan en OGD-reform och ett OGD-ekosystem kan påverka OGD-ekosystemets hälsa. Hälsa är ett OGD-ekosystems förmåga att uppnå ett högre ändamål samtidigt som det gynnar dess aktörer utan att skada andra. Reform relaterar till evolution då båda berör förändringar av aktörer. Denna avhandling syftar till att reda ut detta samspel för att förstå hur samspelet kan påverka OGD-ekosysemets hälsa.

Forskningsdesign: I avhandlingen studerades det svenska OGD-ekosystemet mellan 2016 och 2019, vilket senare utvidgades till internationella samarbeten mellan 2019 och 2021. Forskningen är kvalitativ och avhandlingen består av en kappa med fem artiklar: (1) en jämförelse mellan två organisationer som tillhandahåller öppna data, (2) ett ramverk som beskriver berikares arbete, (3) en diagnos av det svenska OGD-ekosystemet, (4) lärdomar från allmännyttiga tjänster (t.ex. vatten, el och kollektivtrafik) och (5) hur tillhandahållare och berikare kan beakta sökare i sitt arbete. Ett centralt, och syntetiserande, resultat i kappan är ett konceptuellt ramverk;reformekosystem (RE-EKO) ramverket.

Resultat: RE-ECO-ramverket beskriver samspelet mellan en OGD-reform och ett OGDekosystem samt hur det kan påverka ekosystemets hälsa. En OGD-reform är konceptualiserad som ett spelbräde och ett OGD-ekosystem som ett havsekosystem. OGD-aktörer förändrar en ömsesidig struktur för att organisera ett OGD-ekosystem genom aktiviteter så som övertala, samarbeta, förändra och utvärdera. OGD-ekosystemet består av datacykler och identifieringsnoder som arbetar för att förverkliga vissa fördelar. OGD-aktörerna kan påverka hälsan hos ett OGD-ekosystem genom att omvandla deras lokala förhållanden, kliva mellan en OGD-reform och ett OGD-ekosystem och lastningar av mutationer.

Bidrag: Doktorsavhandlingens teoretiska bidrag är RE-ECO-ramverket samt slutsatserna att (1) ett OGD-ekosystem är ett stödjande, symbiotiskt ekosystem; (2) lastningar av mutationer kan styra och driva förändringar; (3) OGD-aktörer kan röra sig mellan en OGD-reform, ett OGDekosystem och andra ekosystem; (4) landskapsmetaforen kan användas för att avslöja hur en OGD-reform kan begränsa ett OGD-ekosystems hälsa; och (5) hur aktörer kan uppleva spänningar mellan en OGD-reform och ett OGD-ekosystem. Förslag till vidare forskning ges i form av fördjupade studier av samspelet mellan en OGD-reform och ett OGD-ekosystem. Vidare diskuteras också principer för praktiker inom området för att nå god nytta av OGD. 


\begin{abstract}
Introduction: This doctoral thesis in Information Systems disentangles the interplay of an OGD reform and an OGD ecosystem. Open government data (OGD) refers to data shared by public organizations, in the role of providers, following certain principles for anyone to reuse. An OGD reform transforms parts of society so that an OGD ecosystem can coalesce and realize benefits (e.g., economic growth or transparency). An OGD ecosystem consists of providers sharing data, enrichers developing products or services on this data, and seekers using the data, products, or services to satisfy their needs.

Problem and Purpose: Previous OGD research tends to encompass an OGD reform into an OGD ecosystem, which can restrict the possibilities to understand the evolution and health of an OGD ecosystem. Because, an OGD reform is a temporary transformation, while an OGD ecosystem includes sustained processes for a purpose. It obfuscates the possible interplay between an OGD reform and an OGD ecosystem, which could affect the health of the ecosystem. Health is an OGD ecosystem's ability to achieve its higher purpose while benefiting its actors without harming others. Reform and evolution are related since both refer to the change of actors. The purpose of my doctoral thesis is to disentangle the interplay between an OGD reform and an OGD ecosystem to understand how it can affect the health of an OGD ecosystem.
\end{abstract}

Research Design: I set out to explore the Swedish OGD ecosystem from 2016 to 2019. The research expanded to international explorations between 2019 and 2021. My research is qualitative and encompasses an introductory part and five articles. The papers include (1) a comparison between two providers, (2) an enricher framework, (3) diagnosis of the Swedish OGD ecosystem, (4) lessons drawn from public utilities, and (5) how providers and enrichers can consider seekers in their work. I then revisited my empirical material to perform additional analysis to synthesize a conceptual framework called reform-ecosystem (RE-ECO) framework.

Findings: The RE-ECO framework depicts the interplay between an OGD reform and an OGD ecosystem and how it could affect the ecosystem's health. An OGD reform is conceptualized as a checkerboard and an OGD ecosystem as an ocean ecosystem. OGD actors transform a reciprocal structure to coalesce an OGD ecosystem through persuasion, collaboration, transformation, and evaluation. The OGD ecosystem consists of strands of data-information cycles and identification nodes, which work to realize certain benefits. The OGD actors can transform local conditions, step between ecosystems, and mutation-load to affect the health of an OGD ecosystem.

Contribution: The theoretical contribution of this doctoral thesis is the RE-ECO framework. The thesis also concludes that an OGD ecosystem is an ancillary, symbiotic ecosystem; mutationloading can control and fuel the change of actors; OGD actors can step between their OGD reform, their OGD ecosystem, and other ecosystems; the landscape metaphor reveals how an OGD reform can constrain the health of an OGD ecosystem; and actors can experience tensions between an OGD reform and an OGD ecosystem. OGD researchers are suggested to further study the interplay between an OGD reform and an OGD ecosystem. OGD practitioners should follow "high-value, high-impact" and "publish with purpose" principles rather than "open by default" or "raw data now" principles. 


\section{Acknowledgments}

Ten years ago, I changed from computer science to innovative programming because I wanted to become a game programmer, and a computer science degree was too mathematical. I participated in SCRUM and Agile development with an Agile coach course at the end of my bachelor's degree. The course awoke a spark and questions about the surroundings of software development, such as "What do project managers do?" and "How can organizations use computers?" Honestly, when I reached the last year of my bachelor's, I did not feel I was finished with academia. So, I decided to apply to the master's program of IT and management and specialize in the softer sides of IT. It must have been one of the first times I encountered social researchers who spoke about human needs and interactions supported by the hard rules of technology. Hard rules that are made by the softness of these people and the trudging momentum of reality. They lived within this borderland of the hard and the soft; objectivity and subjectivity. It nibbled on my horizons drawn by my childhood. I grew up reading various fact-books bought by my parents. The books often treated topics about technology and biology (often engineering and dinosaurs). I guess it left my brain half empty since the social sciences revealed a gap to fill with knowledge about philosophy, psychology, humans, societies, and organizations. Therefore, my doctoral process is not just a five-year process for a degree or a stack of papers. It has been a journey of character development as much as a journey of maturity. It made me into something I could never have dreamt of when I first applied for a bachelor's in computer science.

I am grateful to my colleagues who have shown support and shared their insights. You have contributed to my doctoral research with feedback, guidance, advice, and comments. I am equally grateful to my research participants, who have taken their time to share their experiences and knowledge about open government data. I hope to hear more about them. Especially, I want to thank my family, my colleagues in the Netherlands and Belgium, Karin Ahlin, Björn Lundell, and my supervisors.

My family has shown support in various ways through my doctoral research. My father, Stellan Crusoe, and my mother, Pia Crusoe, have provided me with warm meals in the winters and offered places to relax in the summers. Without you, I would never have become. As such, I am eternally grateful for the childhood you have provided me. I am also grateful to have Simon as a brother, an inspiration in the handy craft. Similarly, like my parents, I am about to set out on a journey to found a 
family. Elisabeth, your support and care have been a blessing, difficult to measure in words. I am lucky to have you.

I am grateful to Marijn and Anneke from the Delft University of Technology, the Netherlands. I had a good stay at your university and Delft with its many birds, bikes, channels, and brick houses. Marijn, you have provided essential feedback and ideas for my research, which contributed to the idea of reform and ecosystem for open government data. Anneke, it was fantastic to work with you and amazing to explore public utilities. Your thoughts and comments have helped to increase the quality of my work. Our collaboration has been a keystone in my doctoral research.

I am indebted to Anthony and Antoine from the University of Namur, Belgium. You have helped me to evaluate my research in another country but also introduced me to Elisabeth. You have also taken me on adventures through the streets of Namur and Brussels. You have made our collaborative studies about open government data a benchmark for good research (at least, in my opinion).

I appreciate having met and worked with Karin Ahlin; you have stuck with me through dry, wet, warm, and cold. You have been supportive and guiding. Our long discussions about research and even longer working hours are valued.

I am honored to have had Björn Lundell as my pre-seminar opponent. You have shown a keen eye for details and sharp, precise feedback, instrumental in finishing my doctoral thesis. You also were my opponent for my licentiate thesis, and you did a fantastic job. I am grateful for the time you dedicated to help me and ensure quality in my research.

I am lucky to have had Sofie and Fredrik as my sub-supervisors. You have provided support and humor at an equal level with rich feedback and comments. In addition, you have contributed to making my doctoral research memorable and enjoyable.

I am fortunate to have had Ulf as my supervisor. You have gone above and beyond your duty as a supervisor. You have stood with me through calm and storm. You have supported my growth of character and been a role model. You have been patient with my escapades and adventures. But, on the other hand, for some adventures, you have been a catalyst. You have reawoken my curiosity, which you have guided and nurtured. It is, as such, difficult to capture the gratitude and honor I feel for you and the role you have had in my doctoral research. I am honored and humbled to have been your Ph.D. student.

Jonathan Crusoe

Linköping, June 2021 


\section{Preface}

Information Systems (IS) is a research discipline within the Faculty of Arts and Sciences at Linköping University (LiU), Linköping Sweden. IS is a discipline studying human work with developing and changing different kinds of IT systems in organisational and societal settings. The research discipline includes theories, strategies and policies, models, methods, co-working principles and artefacts related to information systems development. Different development and change situations can be studied as planning, analysis, specification, design, implementation, maintenance, evaluation and redesign of information systems. Focus is also on the interplay with other forms of organizational development, processes of digitalization and innovation. The discipline also includes the study of prerequisites for and results from information systems development, as e.g. institutional settings, studies of usage and consequences of information systems on individual, group, organizational and societal levels.

The IS research at LiU is conducted in collaboration with private and public organizations. Collaboration also includes national and international research partners in the information systems research field. The research has a clear ambition to give distinct theoretical contributions within the information systems research field and relevant focus areas. Simultaneously, the research aims to contribute with practically needed and useful knowledge.

This work, Open Government Data as a Reform and Ecosystem - A conceptual framework for evolution and health, is written by Jonathan Crusoe, Linköping University. He presents this work as his $\mathrm{PhD}$ thesis in Information Systems, Division of Information Systems and Digitalization, Department of Management and Engineering, Linköping University, Sweden.

Linköping, June 2021

\author{
Karin Axelsson \\ Professor
}

\author{
Ulf Melin \\ Professor
}

Sofie Pilemalm

Professor 



\section{Doctoral dissertations in information systems ${ }^{1}$}

1. Karin Axelsson (1998) Metodisk systemstrukturering - att skapa samstämmighet mellan informationssystemarkitektur och verksamhet

2. Stefan Cronholm (1998) Metodverktyg och användbarhet - en studie av datorstödd metodbaserad systemutveckling

3. Anders Avdic (1999) Användare och utvecklare - om anveckling med kalkylprogram

4. Owen Eriksson (2000) Kommunikationskvalitet hos informationssystem och affärsprocesser

5. Mikael Lind (2001) Från system till process - kriterier för processbestämning vid verksamhetsanalys

6. Ulf Melin (2002) Koordination och informationssystem i företag och nätverk

7. Pär J. Ågerfalk (2003) Information Systems Actability: Understanding Information Technology as a Tool for Business Action and Communication

8. Ulf Seigerroth (2003) Att förstå och förändra systemutvecklingsverksamheter - en taxonomi för metautveckling

9. Karin Hedström (2004) Spår av datoriseringens värden - effekter av IT i äldreomsorg

10. Ewa Braf (2004) Knowledge Demanded for Action - Studies of Knowledge Mediation in Organisations

11. Fredrik Karlsson (2005) Method Configuration - method and computerized tool support

12. Malin Nordström (2005) Styrbar systemförvaltning - Att organisera systemförvaltningsverksamhet med hjälp av effektiva förvaltningsobjekt

13. Stefan Holgersson (2005) Yrke: Polis - yrkeskunskaper, motivation, IT-system och andra förutsättningar för polisarbete

14. Marie-Therese Christiansson \& Benneth Christiansson (2006) Mötet mellan process och komponent - mot ett ramverk för en verksamhetsnära kravspecifikation vid anskaffning av komponentbaserade informationssystem

15. Britt-Marie Johansson (2007) Kundkommunikation vid distanshandel. En studie om kommunikationsmediers möjligheter och hinder

16. Göran Hultgren (2007) eTjänster som social interaktion via användning av ITsystem - en praktisk teori

17. Björn Johansson (2007) Deciding on Sourcing Option for Hosting of Software Applications in Organisations

18. Per Oscarson (2007) Actual and perceived information systems security

\footnotetext{
${ }^{1}$ The label was changed (to Information Systems) from Information Systems Development in May 2019.
} 
19. Hanna Broberg (2009) DEVIS: Design av verksamhetsstödjande IT-system - En designteori och metod

20. Anders Hjalmarsson (2009) Behovet av struktur och frihet - en avhandling om situationsanpassad facilitering vid samarbetsinriktad modellering

21. Jenny Lagsten (2009) Utvärdera informationssystem - Pragmatiskt perspektiv och metod

22. Ida Lindgren (2013) Public e-Service Stakeholders - On who matters for public e-service development and implementation

23. Malin Granath (2016) The Smart City - how smart can 'IT' be? Discourses on digitalisation in policy and planning of urban development

24. Fredrik Söderström (2016) Introducing public sector eIDs - the power of actors' translations and institutional barriers

25. Sten-Erik Öhlund (2017) Interoperability. Capability to interoperate in a shared work practice using information infrastructures - studies in ePrescribing

26. Yousefi Mojir, Kayvan (2018) Information Systems Development for Emerging Public Sector Cross-sector Collaborations: The Case of Swedish Emergency Response

27. Johan Petersson (2019) Elektroniska marknadsplatser - IT-stöd för små- och medelstora leverantörer

28. Elina Ramsell (2021) Toward ICT-enabled Co-production for Effective Crisis and Emergency Response

29. Jonathan Crusoe (2021) Open Government Data as a Reform and Ecosystem - A conceptual framework for evolution and health

\section{Licentiate theses in information systems}

1. Owen Eriksson (1994) Informationssystem med verksamhetskvalitet - utvärdering baserat på ett verksamhetsinriktat och samskapande synsätt

2. Karin Pettersson (1994) Informationssystemstrukturering, ansvarsfördelning och användarinflytande - en komparativ studie med utgångspunkt i två informationssystemstrategier

3. Stefan Cronholm (1994) Varför CASE-verktyg i systemutveckling? - En motivoch konsekvensstudie avseende arbetssätt och arbetsformer

4. Anders Avdic (1995) Arbetsintegrerad systemutveckling med kalkylprogram

5. Dan Fristedt (1995) Metoder i användning - mot förbättring av systemutveckling genom situationell metodkunskap och metodanalys

6. Malin Bergvall (1995) Systemförvaltning i praktiken - en kvalitativ studie avseende centrala begrepp, aktiviteter och ansvarsroller

7. Mikael Lind (1996) Affärsprocessinriktad förändringsanalys - utveckling och tillämpning av synsätt och metod 
8. Carita Åbom (1997) Videomötesteknik i olika affärssituationer - möjligheter och hinder

9. Tommy Wedlund (1997) Att skapa en företagsanpassad systemutvecklingsmodell - genom rekonstruktion, värdering och vidareutveckling i T50-bolag inom ABB

10. Boris Karlsson (1997) Metodanalys för förståelse och utveckling av systemutvecklingsverksamhet - analys och värdering av systemutvecklingsmodeller och dess användning

11. Ulf Melin (1998) Informationssystem vid ökad affärs- och processorientering egenskaper, strategier och utveckling

12. Marie-Therese Christiansson (1998) Inter-organisatorisk verksamhetsutveckling metoder som stöd vid utveckling av partnerskap och informationssystem

13. Fredrik Öberg (1998) Object-oriented frameworks - a new strategy for CASE tool development

14. Ulf Seigerroth (1998) Integration av förändringsmetoder - en modell för välgrundad metodintegration

15. Bengt EW Andersson (1999) Samverkande informationssystem mellan aktörer i offentliga åtaganden - en teori om aktörsarenor i samverkan om utbyte av information

16. Pär J. Ågerfalk (1999) Pragmatization of information systems - a theoretical and methodological outline

17. Karin Hedström (2000) Kunskapsanvändning och kunskapsutveckling hos verksamhetskonsulter - erfarenheter från ett FoU-samarbete

18. Göran Hultgren (2000) Nätverksinriktad förändringsanalys - perspektiv och metoder som stöd för förståelse och utveckling av affärsrelationer och informationssystem

19. Ewa Braf (2000) Organisationers kunskapsverksamheter - en kritisk studie av "knowledge management"

20. Henrik Lindberg (2000) Webbaserade affärsprocesser - möjligheter och begränsningar

21. Benneth Christiansson (2000) Att komponentbasera informationssystem - Vad säger teori och praktik?

22. Per-Arne Segerkvist (2001) Webbaserade imaginära organisationers samverkansformer - Informationssystemarkitektur och aktörssamverkan som förutsättningar för affärsprocesser

23. Stefan Holgersson (2001) IT-system och filtrering av verksamhetskunskap kvalitetsproblem vid analyser och beslutsfattande som bygger på uppgifter hämtade från polisens IT-system

24. Per Oscarson (2001) Informationssäkerhet i verksamheter - begrepp och modeller som stöd för förståelse av informationssäkerhet och dess hantering i verksamheter 
25. Johan Petersson (2002) Lokala elektroniska marknadsplatser informationssystem för platsbundna affärer

26. Fredrik Karlsson (2002) Meta-method for Method Configuration - A Rational Unified Process Case

27. Lennart Ljung (2003) Utveckling av en projektivitetsmodell - om organisationers förmåga att tillämpa projektarbetsformen

28. Britt-Marie Johansson (2003) Kundkommunikation på distans - en studie om kommunikationsmediets betydelse i affärstransaktioner

29. Fredrik Ericsson (2003) Information Technology for Learning and Acquiring Work Knowledge among Production Workers

30. Emma Eliason (2003) Effektanalys av IT-systems handlingsutrymme

31. Anders Hjalmarsson (2004) Att etablera och vidmakthålla förbättringsverksamhet. Behovet av koordination och interaktion vid förändring av systemutvecklingsverksamheter

32. Björn Johansson (2004) Deciding on Using Application Service Provision in SMEs

33. Ulf Larsson (2004) Designarbete i dialog - karaktärisering av interaktionen mellan användare och utvecklare i en systemutvecklingsprocess

34. Anders Forsman (2005) Standardisering som grund för informationssamverkan och IT-tjänster - En fallstudie baserad på trafikinformationstjänsten RDS-TMC

35. Jenny Lagsten (2005) Verksamhetsutvecklande utvärdering i informationssystemprojekt

36. Jan Olausson (2005) Att modellera uppdrag - grunder för förståelse av processinriktade informationssystem i transaktionsintensiva verksamheter

37. Amra Halilovic (2006) Ett praktikperspektiv på hantering av mjukvarukomponenter

38. Hanna Broberg (2006) Verksamhetsanpassade IT-stöd - designteori och metod

39. Sandra Haraldson (2008) Designprinciper för handlingskvalitet i samverkan - ett multiorganisatoriskt perspektiv på tredjepartslogistik

40. Jonas Sjöström (2008) Making Sense of the IT artefact - A socio-pragmatic inquiry into IS use qualities

41. Anders Persson (2009) Förutsättningar för sammanhållen kommunal eFörvaltning

42. Ann-Margreth Hammar (2011) Från projektorganisation till förvaltningsorganisation - en studie av överlämningsarenan

43. Eva Karlsson (2012) Systemutveckling för riskbaserad tillsyn - Hur verksamhetsanalys på praktikteoretisk grund kan användas för kravfångst

44. Hannes Göbel (2014) IT Service Management - Designprinciper för informationssystemsartefakter 
45. Kayvan Yousefi Mojir (2016) New Forms of Collaboration in Emergency Response Systems: A framework for participatory design of information systems

46. Siri Wassrin (2018) Why is it difficult to design innovative IT? An agential realist study of designing IT for healthcare innovation

47. Jonathan Crusoe (2019) Why is it so difficult to cultivate open government data? Understanding impediments from an ecosystem perspective

48. Maria Murphy (2021) Digital Transformation for Crisis Volunteerism: A Study in the Aftermath of the Swedish Forest Fires Crisis in 2018. 



\section{Contents}

$\begin{array}{lll}\text { Abstract } & \text { iii }\end{array}$

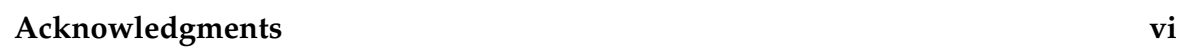

Preface viii

Dissertations in information systems $\quad$ xiv

\begin{tabular}{lll}
\hline Contents & xv \\
\hline
\end{tabular}

List of Figures $\quad$ xvii

List of Tables $\quad$ xix

\begin{tabular}{lll}
\hline & Introduction & 1
\end{tabular}

1.1 The Knowledge Gaps . . . . . . . . . . . . . . . . . . . . . 3

1.2 Purpose and Research Questions . . . . . . . . . . . . . . . . . . . 6

$1.3 \quad$ Expected Contribution and Audience . . . . . . . . . . . . . . 8

1.4 Delimitations $\ldots \ldots \ldots \ldots \ldots$

1.5 Thesis Outline . . . . . . . . . . . . . . . . . . . . . . . . . 10

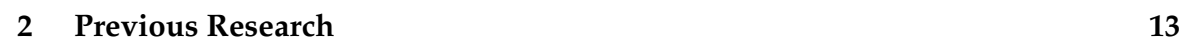

$2.1 \quad$ Information Systems $\ldots \ldots \ldots$. . . . . . . . . . . . . . . . . . 13

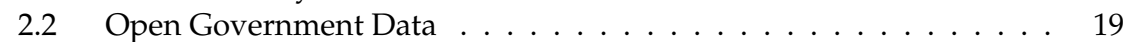

2.3 Reform . . . . . . . . . . . . . . . . . . . . . . . . . . . . . . . . .

$2.4 \quad$ An Ecosystem Perspective . . . . . . . . . . . . . . . . . . . . . . . . . . . . . . . . . . . . .

2.5 Data and Information Society . . . . . . . . . . . . . . . . . . . . . . . . . 44

$2.6 \quad$ A Summary of the Previous Research Section . . . . . . . . . . . . . . 55

\begin{tabular}{|lll}
\hline 3 & Paradigmatic Worldview & 57
\end{tabular}

3.1 Paradigmatic Worldviews and Elements . . . . . . . . . . . . . . 57

$3.2 \quad$ My View on Reality . . . . . . . . . . . . . . . . . . . . . . . . . . . . . . . . . . 59

3.3 My View on Humans . . . . . . . . . . . . . . . . . . . . . . . . . . . . . 60

$3.4 \quad$ My View on Social Systems . . . . . . . . . . . . . . . . . . . . . . . . . . . . . . . . . . . . . . . .

$3.5 \quad$ My View on Artifacts $\ldots \ldots \ldots$. . . . . . . . . . . . 62 
$3.6 \quad$ My Paradigmatic Worldview's Influence on my Research . . . . . . . 66

\begin{tabular}{|lll}
\hline Doctoral Research Process & 69 \\
\hline
\end{tabular}

4.1 Overview of my Doctoral Research Process . . . . . . . . . . . . . . . 70

$4.2 \quad$ Research Questions and Articles $\ldots \ldots \ldots$. . . . . . . . . . . 71

4.3 The Methods of my Five Included Articles and Other Works . . . . . 72

4.4 Synthesizing the RE-ECO Framework . . . . . . . . . . . . . . . . . . . . . . . . . . . . . . . 81

$4.5 \quad$ Limitations . . . . . . . . . . . . . . . . . . 82

5 The RE-ECO Framework for Open Government Data 85

5.1 A Reciprocal Structure of an OGD Reform and an OGD Ecosystem . 86

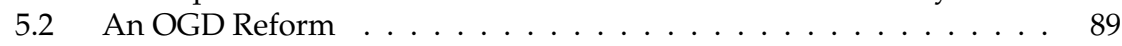

5.3 An OGD Ecosystem . . . . . . . . . . . . . . . . . . . . . . . 103

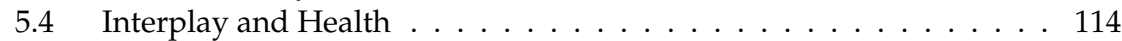

5.5 A Summary of the RE-ECO Framework . . . . . . . . . . . . . . . . . 121

\begin{tabular}{lll}
\hline & Discussion & 125
\end{tabular}

6.1 My Disentanglement of an OGD Reform and an OGD Ecosystem . . 125

6.2 OGD Actors as Tension Points . . . . . . . . . . . . . . . . . . . 128

6.3 Cycles and Flows . . . . . . . . . . . . . . . . . . . . . . . . . . . . . . . . 129

$6.4 \quad$ Interplay and Health $\ldots \ldots \ldots$. . . . . . . . . . . . . . . . . . . . . . . . . . . . . . . . . . . . . . . . . .

6.5 Summary of Discussion . . . . . . . . . . . . . . . . . 133

7 Conclusions and Implications 135

7.1 How can the Interplay Between an OGD Reform and an OGD Ecosystem Affect the Health of an OGD Ecosystem? . . . . . . . . . . 135

7.2 Theoretical Contribution and Recommendations . . . . . . . . . . . 137

$7.3 \quad$ Implications and Recommendations for Practice . . . . . . . . . . . . . . 138

$7.4 \quad$ Reflections . . . . . . . . . . . . . . . . . . . . . . . . . 139

7.5 Future Research . . . . . . . . . . . . . . . . . . . . . . . . . . . . . . 149

\begin{tabular}{ll}
\hline References & 153
\end{tabular}

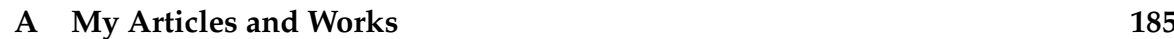

A.1 Included Articles . . . . . . . . . . . . . . . . . . . . . . . . 185

A.2 Additional Articles . . . . . . . . . . . . . . . . . . . . . . 186

\begin{tabular}{ll}
\hline Paper A & 191
\end{tabular}

\begin{tabular}{lr}
\hline Paper B & 205 \\
\hline
\end{tabular}

\begin{tabular}{ll}
\hline Paper C & 231
\end{tabular}

\begin{tabular}{lr}
\hline Paper D & 267
\end{tabular}

\begin{tabular}{ll}
\hline Paper E & 285
\end{tabular} 


\section{List of Figures}

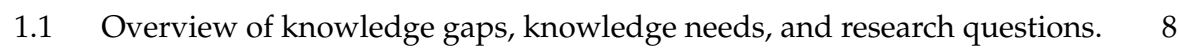

$2.1 \quad$ An overview of the general stages of an OGD reform. . . . . . . . . . . . . 36

$2.2 \quad$ A data-information society with its sectors and sphere. . . . . . . . . . . . 47

4.1 My research questions connected to the five included articles. . . . . . . . 73

5.1 An overview of the RE-ECO framework. . . . . . . . . . . . . . . 86

5.2 A reciprocal structure of an OGD reform and an OGD ecosystem. . . . . 90

5.3 A movement-game of an OGD reform. . . . . . . . . . . . . . . . 94

5.4 An overview of an OGD ecosystem $\ldots \ldots \ldots \ldots$. . . . . . . . 104

5.5 An overview of the interplay between an OGD reform and an OGD ecosystem that can affect the health of an OGD ecosystem. $\quad \ldots \ldots$. . . . 115

6.1 A representation of an OGD actor step between nodes of its OGD reform, its OGD ecosystem, and other ecosystems. . . . . . . . . . . . . 133 



\section{List of Tables}

$3.1 \quad$ My paradigmatic worldview's influence on my research. . . . . . . . . 66 



\section{Introduction}

This thesis is a compilation doctoral thesis in the discipline of information systems and field of e-governmen ${ }^{1}$ that encompasses five articles about open government data (OGD). In the thesis, I develop the OGD ecosystem, OGD reform, and health concepts, which are introduced below. In my research, I have observed that OGD is a new socio-technical phenomenon introduced by reformists to societies around the 2010s (e.g., Huijboom and Broek, 2011. Ubaldi, 2013. Heimstädt, Saunderson, and Heath, 2014). OGD refers to data shared by providers following certain principles for anyone to reuse (e.g., Tauberer and Lessig, 2007; Open Data Charter, 2015: Open Data Handbook, 2015). While previous OGD research has used the term reform and sometimes approached OGD as a driver of reform (e.g., Davies, 2010: Ubaldi, 2013. Hartog, Mulder, Spée, Visser, and Gribnau, 2014), I have been unable to identify previous OGD research that has approached OGD as a reform. I believe the concept of reform could clarify the work of OGD actors (people and organizations) and its scope by differentiating between temporary and permanent work. Thus, I introduce and develop an approach to understand OGD as a reform in this thesis. Reformists are actors who have identified needs for improvements in societies and are propagating reforms, which are purposive and artificial transformations to satisfy these needs (Caiden, 2017). OGD has given rise to reforms where public organizations are (expected to be) transformed into providers of data, actors who develop products or services on the data become enrichers, and actors who use the data, products, or services become seekers (Lee, 2014 Janssen and Zuiderwijk, 2014. Safarov, Meijer, and Grimmelikhuijsen, 2017). Enrichers could be developers, journalists, researchers, or students, while seekers are often considered to be citizens (Janssen and Zuiderwijk, 2014. Safarov, Meijer, and Grimmelikhuijsen, 2017.

An OGD reform attempts to transform parts of a society so that an OGD ecosystem can beget and grow from it to realize certain benefits to satisfy perceived needs in this society, such as economic growth or increased democratic accountability (Mars, Bronstein, and Lusch, 2012 Janssen, Charalabidis, and Zuiderwijk, 2012. Heimstädt,

\footnotetext{
${ }^{1}$ See Section 2.1 for more.
} 
Saunderson, and Heath, 2014). An ecosystem is a system that coalesce from actors and their interactions for a higher purpose as they exchange resources and information (Nardi, O'Day, and O'Day, 1999. Iansiti and Levien, 2004 Mars, Bronstein, and Lusch, 2012). The growth of an OGD ecosystem happens as providers, enrichers, and seekers join, interact, and work within the OGD ecosystem and contribute towards the realization of benefits. This joining can require actors to transform or evolve their conditions and work so that they can do the work required by the OGD ecosystem. Conditions can be formats of data, skills of people, and certain laws of the legal framework. I, based on my research, define work as the processes and activities actors conduct for certain purposes relating to their OGD reform or their OGD ecosystem based on certain conditions. The providers, enrichers, and seekers coalesce various flows where data are transformed into information, potentially, adding value to them (Davies, 2010: Lindman, Kinnari, and Rossi, 2016, Berends, Carrara, Engbers, and Vollers, 2017). At the same time, an OGD ecosystem can evolve as conditions are changed, introduced, managed, or removed by reformists (Nardi, O'Day, and O'Day, 1999. Crusoe, 2019b). For example, OGD portals and OGD centers are introduced to an OGD ecosystem to facilitate data transfers by helping providers make their data more discoverable to enrichers and seekers (Kalampokis, Tambouris, and Tarabanis, 2011a. Colpaert, Joye, Mechant, Mannens, and Walle, 2013). I see that the concept of ecosystem evolution is tightly related to the concept of reform as they both refer to the transformation of actors and their work for an OGD ecosystem but need further clarification.

When data provision and reuse happen recurrently even with no or few benefits, an OGD ecosystem functions and has acquired lifeness along with a degree of health. The concept of health has been used in previous OGD research but lacks conceptual development (e.g., Lee, 2014 Zuiderwijk, Janssen, and Davis, 2014: Heimstädt, Saunderson, and Heath, 2014). I introduce and develop an approach to understand the health of an OGD ecosystem in this thesis. I define health as an OGD ecosystem's ability to achieve its higher purpose while benefiting its actors without harming them and their society (see Section 5.3. The concept of health helps to differentiate between a well-functioning and a dysfunctional ecosystem (Rapport, Gaudet, Constanza, Epstein, and Levins, 2009). A well-functioning OGD ecosystem realizes certain benefits, while a dysfunctional OGD ecosystem can slowly degenerate and collapse as actors leave (Mars, Bronstein, and Lusch, 2012). Reformists and OGD actors can be obstructed or prevented in their work by conditions referred to as impediments, which, in turn, can obstruct or prevent their OGD reform or their OGD ecosystem. Impediments can, for example, be enrichers and seekers who lack the knowledge to use data from providers, data require substantial manual cleaning to make them machine-processable, and providers risk breaking laws if they provide data (Zuiderwijk, Janssen, Choenni, Meijer, and Alibaks, 2012: Barry and Bannister, 2014: Conradie and Choenni, 2014 Huang, Lai, and Zhou, 2017). An OGD reform can involve transforming impediments to conditions to enable the work of an OGD ecosystem, such as (possibly) removing or changing problematic laws or introducing training sessions to build knowledge for enrichers and seekers.

OGD actors believe a well-functioning OGD ecosystem can realize several benefits. Providers could gain increased transparency, higher public engagement, and opti- 
mization of administrative processes (Janssen, Charalabidis, and Zuiderwijk, 2012 Hartog, Mulder, Spée, Visser, and Gribnau, 2014 Kucera and Chlapek, 2014: Schrier, 2014). Enrichers gain access to free data that they can use to develop products, services, or processes, and to support their decision-making (Janssen, Charalabidis, and Zuiderwijk, 2012. Schrier, 2014: Safarov, Meijer, and Grimmelikhuijsen, 2017). Seekers could easier find public toilets, save time when commuting, and gain improved public services (Bichard and Knight, 2012: Janssen, Charalabidis, and Zuiderwijk, 2012. Carrara, Chan, Fischer, and Steenbergen, 2015). However, it also comes with risks, such as an increase in media's coverage of negative news about public organizations (which could make the public lose trust in the government) (Barry and Bannister, 2014) and enrichers can misunderstand data and violate the privacy of other actors (Zuiderwijk and Janssen, 2014b).

This compilation doctoral thesis is a continuation of my licentiate thesis. The licentiate thesis explored previous OGD research and OGD practice to draw lessons about why it is challenging to cultivate an OGD ecosystem by perceiving impediments from an ecosystem perspective (Crusoe, 2019b). Cultivation refers to activities that introduce, manage, remove, or transform conditions with the intent to change, encourage, or guide an OGD ecosystem towards a higher purpose (Crusoe, 2019b). I have continued with my research on OGD from the ecosystem perspective, focusing on ecosystem health and reform, encompassing cultivation and impediments. I believe this combination of concepts can help OGD researchers and OGD practitioners to (1) identify, maintain, and improve successful conditions, (2) identify, avoid, prevent, or mitigate impediments, (3) separate the transformations of an OGD reform from the everyday work of an OGD ecosystem. Together, the concepts can help OGD actors beget, sustain, and improve healthy OGD ecosystems and ameliorate dysfunctional OGD ecosystems. It creates a path towards successfully realizing benefits and betterment, which is a step away from apathy along with risks and impediments as barriers. My compilation doctoral thesis has an introductory part that aims to synthesize a conceptual framework based on five included articles and previous research.

In the successive sections, I present knowledge gaps and needs that I have identified in previous OGD research, then the research questions of my thesis, audience and expected contribution, delimitations, and the thesis outline.

\subsection{The Knowledge Gaps}

My doctoral thesis embarks to fill the three knowledge gaps presented below. The first knowledge gap is concerned with the interplay between an OGD reform and an OGD ecosystem. Previous OGD research has studied the interaction between an OGD ecosystem and its infrastructure (e.g., Davies, 2011: Harrison, Pardo, and Cook, 2012), various elements of an OGD reform and an OGD ecosystem (e.g., Lee, 2014), OGD actors with processes and interactions (e.g., Zuiderwijk, Janssen, and Davis, 2014. Attard, Orlandi, Scerri, and Auer, 2015 Lindman, Kinnari, and Rossi, 2016), and various elements and their flows within an environment (e.g., Dawes, Vidiasova, and Parkhimovich, 2016, Van Schalkwyk, Willmers, and McNaughton, 2016). However, previous OGD research has paid limited attention to the health of an OGD ecosystem 
(Oliveira, Lima, and Lóscio, 2019). Health tends to be treated as desirable, a goal, or a side note with little explanation (e.g., Zuiderwijk, Janssen, and Davis, 2014 Dawes, Vidiasova, and Parkhimovich, 2016. Martin, Turki, and Renault, 2017). Therefore, I introduce and develop an approach to understand OGD ecosystem health. On the other hand, previous OGD research contains several traces of OGD reforms, which are often included in their OGD ecosystem. It is a mix of transformations and processes. For example, Lee (2014) includes data audit and data access in an OGD ecosystem. Data audits are internal processes conducted by providers to identify and assess datasets to publish or not. Data access refers to the provision of data to enrichers and seekers by providers, such as through bulk or API (Lee, 2014). However, I see that once all relevant datasets have been assessed, the need for the data audits should be limited, while the need for the data access should have grown and continued as part of the OGD ecosystem (assuming enrichers and seekers continue to acquire the data). Similarly, Zuiderwijk, Janssen, and Davis (2014) include publishing datasets as part of their data flow, Dawes, Vidiasova, and Parkhimovich (2016) include advocacy and interactions in their OGD ecosystem, and Jetzek (2016) perceives an OGD ecosystem from a process perspective of strategy and planning, implementation of infrastructure, use and transformation of data, and impact. My interpretation is that previous OGD research is stuck between the partial transformations of a society for an OGD ecosystem and the OGD ecosystem itself. On the other hand, Davies (2010) has presented a sketch of a relationship between reforms and democratic engagement but has understood the reforms to be driven by engagement and OGD rather than the reverse. Based on the above, I see that the problem is that the temporary transformations of an OGD reform are conflated with the permanent processes of an OGD ecosystem that are supposed to realize benefits and need maintenance to be sustained. I introduce and develop the concept of OGD reform to help separate the temporary transformations for an OGD ecosystem from the permanent processes of an OGD ecosystem. I see that their present composite situation can hide potential interplay that can influence how OGD is practiced while limiting researchers' theoretical ability to understand the evolution and health of an OGD ecosystem. I also believe this situation encourages OGD researchers to approach an OGD ecosystem as if it is preexisting rather than growing, evolving, and reforming where the ecosystem can lose and gain elements as it matures. As such, there is a need to disentangle the interplay of an OGD reform and an OGD ecosystem.

The disentanglement of an OGD reform and an OGD ecosystem requires further knowledge about providers and enrichers, as their participation and work constitute their OGD reform and their OGD ecosystem. As such, the second knowledge gap is concerned with understanding the work of providers and enrichers. An OGD ecosystem grows from the actions and interactions of OGD actors based on certain conditions, such as capabilities of data storage systems and API of IT-systems (Zuiderwijk, Janssen, and Davis, 2014). An OGD reform acts to cultivate or transforms conditions to grow and evolve its OGD ecosystem. If the conditions are in the wrong state, OGD actors can experience impediments and barriers that obstruct or prevent their work. For example, data that are not collected or fragmented over several providers can impede enrichers and seekers when they try to find the data (Zuiderwijk, Janssen, Choenni, Meijer, and Alibaks, 2012). However, OGD researchers and OGD practitioners have developed various understandings about the work of providers (e.g., 
Carrara, Oudkerk, Van Steenbergen, and Tinholt, 2018, ÖppnaData.SE, 2018: Zuiderwijk, Janssen, Choenni, and Meijer, 2014: Kucera, Chlapek, Klímek, and Necaskỳ, 2015), but are dim on the side of enrichers. The descriptions of providers are fragmented and uneven in content and scope. For example, activities can be described summarily (e.g., Naturvårdsverket, 2018) or roles are not explained (Folmer et al., 2011 e.g., ), while some focus on the publishing of data (e.g., Hyland and Wood, 2011), others centre on the discovery of data (e.g., ÖppnaData.SE, 2018). On the other hand, the work of enrichers has received less attention by researchers and has been understood as, for example, data to an output (e.g., Davies, 2010), a series of activities with resources (e.g., Zuiderwijk, Janssen, Poulis, and Kaa, 2015), and business models for enrichers who develop products and services for seekers (e.g., Janssen and Zuiderwijk, 2014). However, the descriptions of the enrichers' work are often general and abstract and do not take into account the variety of forms data can be used, such as, to visualize, combine, clean, and re-provide data, and use data as part of a service (Davies, 2010). Therefore, there is a need for more knowledge about the work of providers and enrichers to understand an OGD reform and an OGD ecosystem.

Providers and enrichers are assumed to work for seekers, as such the third knowledge gap is concerned with how this work is done. Previous OGD research tends to focus on providers and enrichers, while seekers are in the background or a type of enricher (e.g., Zuiderwijk, Janssen, and Davis, 2014 Dawes, Vidiasova, and Parkhimovich, 2016. Lindman, Kinnari, and Rossi, 2016 Mokobombang, Gutierrez, and Petrova, 2020). The expectations of providers and enrichers are many and welldescribed (e.g., Berners-Lee, 2015; Lindman, Kinnari, and Rossi, 2016. Berends, Carrara, Engbers, and Vollers, 2017; Mokobombang, Gutierrez, and Petrova, 2020), while previous OGD research seems to assume seekers to be easy, want OGD, or ask their participation. For example, Attard, Orlandi, and Auer (2017) explain that the data flow ends with the enricher and Kucera and Chlapek (2014) state that OGD could increase transparency because seekers get better availability and accessibility to data about the performance of the public sector. However, seekers direct use of OGD appears to be a myth (Davies, 2010: Mayer-Schönberger and Zappia, 2011: Hunnius and Krieger, 2014 Hellberg and Hedström, 2015). Weerakkody, Irani, Kapoor, Sivarajah, and Dwivedi (2017) have noted that the rawness of data can make seekers unable to use OGD for any meaningful purpose relating to their life events or decisions. As such, enrichers play a vital role in assisting seekers in interpreting and acting on data shared by providers (Hunnius and Krieger, 2014). In sum, providers share raw data, enrichers add value to the raw data by developing products and services, and seekers realize the value as something real by using the raw data, products, or services. I see that previous OGD research needs to pay more attention to how providers and enrichers can work for seekers, as the value-adding by enrichers can be expected to match with the needs of seekers, and the data from providers need to match with both. However, in previous OGD research, it is unclear how providers and enrichers can consider seekers to grow a healthy OGD ecosystem.

Finally, the answer to the above three knowledge gaps can be further enriched by drawing on knowledge from previous research about public utilities (e.g., water network and the electric grid (Ascher, Marech, and Alexander, 2005)) and information systems. Public utilities have concepts for the creation and existence of vast and com- 
plex systems similar to OGD ecosystems. Previous OGD research contains three major issues related to synthesizing an ecosystem perspective that needs to be solved to disentangle an OGD reform from its OGD ecosystem. The three issues are: (1) an OGD ecosystem is often treated as one cohesive unit (e.g., Folmer et al., 2011; Lee, 2014. Oliveira and Lóscio, 2018) when it consists of several smaller ecosystems (Harrison, Pardo, and Cook, 2012: Ubaldi, 2013); (2) the extensive infrastructure that is the foundation for an OGD ecosystem is often abated and not fully integrated into an OGD ecosystem perspective (e.g., Van Schalkwyk, Willmers, and McNaughton, 2016. Dawes, Vidiasova, and Parkhimovich, 2016; Crusoe, 2019b); and (3) the legal system tends not to be incorporated into an OGD ecosystem perspective (e.g., Attard, Orlandi, and Auer, 2016 Abella, Urbina-Criado, and De-Pablos-Heredero, 2019: Crusoe, 2019b), when it can enable and limit an OGD ecosystem by laws, regulations, and licenses (De Rosnay and Janssen, 2014). On the other hand, information systems can provide insights into how providers and enrichers can consider seekers, but also concepts for the society of an OGD reform and an OGD ecosystem. Two relevant concepts supplied by the discipline are information seekers and information society. Information seekers are people who have information needs they seek to satisfy with information (or possibly data), while an information society is a society that extensively produces and uses information (see section 2.5). My ambition is to enrich OGD research by providing additional concepts and explanations for phenomena within my doctoral research. It is common to draw knowledge from other disciplines within previous OGD research. For example, Harrison, Pardo, and Cook (2012) borrow from business, open innovation, information ecologies, and science data, Heimstädt, Saunderson, and Heath (2014) draw from open government, business, and digital, and Zuiderwijk, Janssen, and Davis (2014) borrow from business, digital, information, innovation, and software.

\subsection{Purpose and Research Questions}

The purpose of this doctoral thesis is to disentangle the interplay between an OGD reform and an OGD ecosystem with a focus on evolution and health. Interplay is the actions between two or more things or the effects they have on each other (Interplay. 2021). Evolution is a transformative process of an OGD ecosystem similar to the transformations of an OGD reform. It is, as such, an implicit strand of my research that helps to understand the interplay between an OGD reform and an OGD ecosystem, but also indicates why they can be easy to conflate. Health is the ability of an OGD ecosystem to realize benefits and avoid determinants. Good health is the desirable goal of an OGD reform; as such, it transforms parts of a society to beget, grow, and cultivate an OGD ecosystem towards good health. It seeks to affect the health of an OGD ecosystem. I have generated my main research question based on the three mentioned knowledge gaps and my research purpose. The main research question is divided into three sub-questions. My doctoral research embarks on answering the following research questions:

Main Research Question: How can the interplay between an OGD reform and an OGD ecosystem affect the health of an OGD ecosystem? 
The main research question requires further knowledge to understand the work of providers and enrichers since it constitutes an OGD reform and an OGD ecosystem. Work refers to processes and activities that are based on certain conditions for some purpose. Thus, the first research sub-question is:

(1) What is the work of providers and enrichers for an OGD reform and an OGD ecosystem based on previous OGD research and OGD practice?

The main research question also requires further knowledge about the interactions between providers and enrichers to understand their OGD ecosystem and its health. Thus, the second research sub-question is:

(2) How has the work of providers and enrichers affected the health of the Swedish OGD ecosystem?

Finally, I study a complex country-wide phenomenon within a leeway of resources and time; as such, I seek knowledge from previous research to supplement my findings with an ambition to enrich OGD research. I explain these concepts in Chapter 2 Thus, the third research sub-question is:

(3) How can the concepts of information needs and information society from previous information system research and holistic perspectives from public utility research enrich the OGD ecosystem perspective?

Figure 1.1 presents the above knowledge gaps connected to knowledge need and research questions of my doctoral thesis. The figure can be summarized as follows. Previous OGD research conflates an OGD reform into their understanding of an OGD ecosystem, limiting its theoretical ability to understand the evolution and health of the OGD ecosystem. This conflation needs to be disentangled so that it is possible to understand how the interplay between an OGD reform and an OGD ecosystem can affect the OGD ecosystem's health. This disentanglement requires exploring providers' and enrichers' work, as knowledge about the actors is fragmented and uneven or abstract and limited. This exploration needs to happen on an actor level and an ecosystem level to understand the parts and the whole of an OGD reform and an OGD ecosystem. This research is enriched with concepts from previous information system research and perspectives from previous public utility research. 


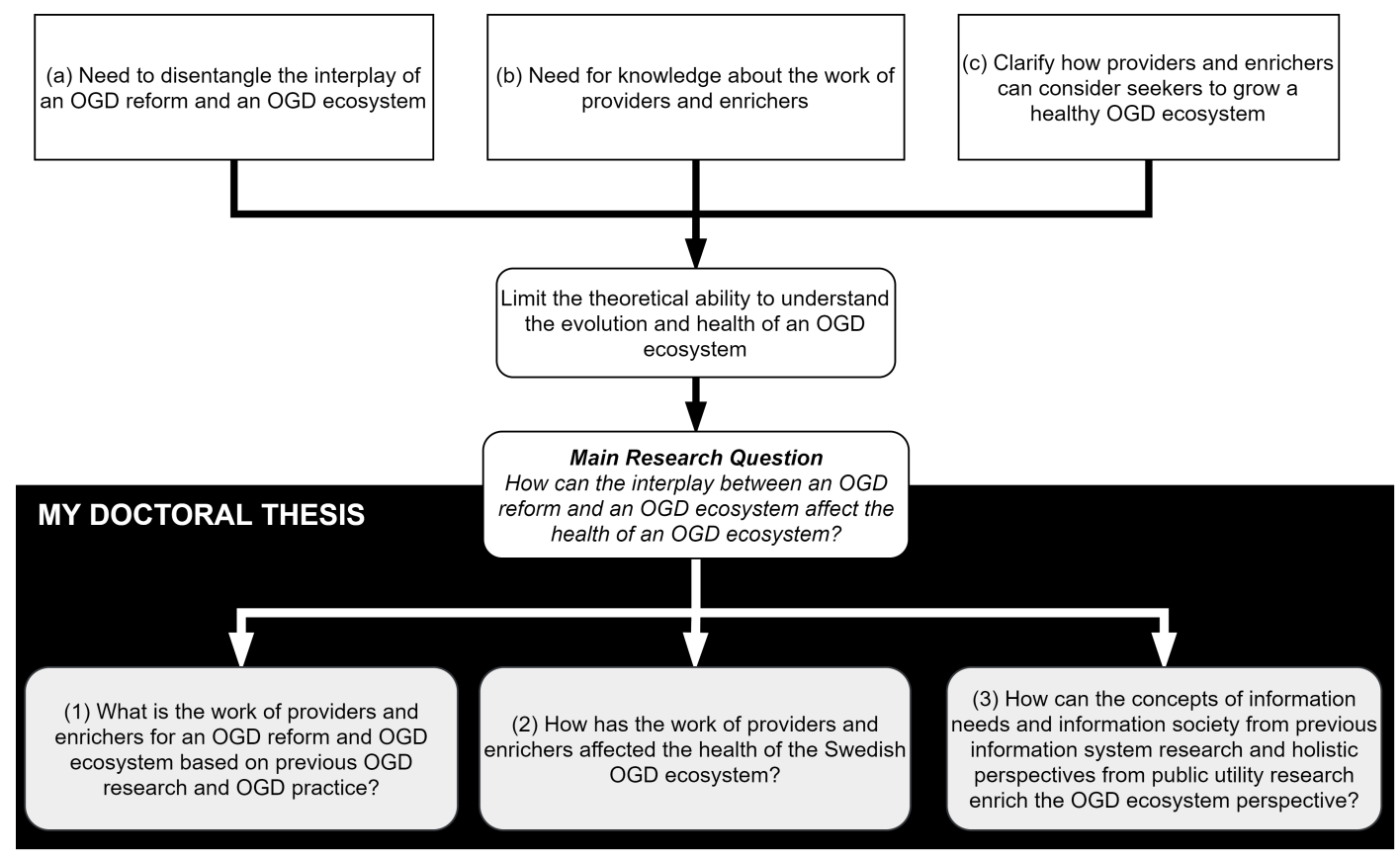

Figure 1.1: Overview of knowledge gaps, knowledge needs, and research questions.

\subsection{Expected Contribution and Audience}

My research is use-inspired basic research (Stokes, 2011), which means it is directed towards OGD researchers and OGD practitioners (the audience). It is inspired by design science research where the contributions are artifacts for others to reuse (see Chapter 3 and Chapter 4. My research is a step towards creating a theory of design and action ("how to do" something) (Gregor, 2002: Gregor, 2006) for OGD ecosystems. The expected contribution is a conceptual framework that can help the audience understand the interplay between an OGD reform and an OGD ecosystem focusing on evolution and health. The contribution also consists of five articles, included in my thesis, that are expected to help the audience understand (1) the work of providers, (2) the work of enrichers, (3) the health of an OGD ecosystem, (4) lessons learned about public utilities usable for an OGD ecosystem perspective, and (5) considerations for the work of providers and enrichers. The implications of the five articles are detailed in each article.

OGD researchers can use the conceptual framework to study OGD ecosystems as something alive and analyze how implications and recommendations from their research could impact the OGD ecosystems. OGD practitioners can use it to understand their OGD ecosystem and help them cultivate it. It can help them reflect on the in- 
terplay between their OGD reform and their OGD ecosystem, which can help them avoid pitfalls and work towards realizing their benefits.

\subsection{Delimitations}

My doctoral thesis has delimitations concerning its empirical material and theory. Empirically, my research explores the work of several OGD actors rather than a deeper exploration of a few cases. My focus has been on understanding an OGD ecosystem rather than, for example, internal use of OGD by providers and enrichers. I have studied a varied mix of OGD actors to generalize how other OGD actors within an OGD reform and an OGD ecosystem could work. My main focus has been on the work of providers and enrichers with some considerations to seekers and governments, but they have not been the focus of my research. Similarly, my focus has been on the OGD reform and OGD ecosystem with recognition to their society and related OGD political movement. The society has not been a focus of my empirical explorations. Instead, I have used concepts from previous research to understand it as a foundation for and target of transformation. I have interacted and studied parts of the OGD political movement but have not followed its development in relation to its OGD reform and its OGD ecosystem. There are several movements related to OGD, such as public sector information, mydata, and quantified self, that I know about but have not studied in my research.

IT-systems are important foundations for an OGD ecosystem as infrastructure (Davies, 2011: Van Schalkwyk, Willmers, and McNaughton, 2016). I define IT-systems as artifacts and systems made to work with data or information. They can also be known as information solutions or IT-artifacts. I understand that they can be routers, analytical reports, Excel 2016, books, and language (Ohlman, 2002 Day, 2002). I revisit this definition in Section 2.1. I have studied IT-systems as something with conditions and in their natural environments. They have been important for my respondents and OGD, similar to many other phenomena, such as licenses and data. I have not studied the development, implementation, and requirements of IT-systems for OGD. Rather, they are transformable for the OGD reform and parts of the OGD ecosystem. My focus has been on processes, activities, and actions (work) with conditions for the purpose of the OGD reform and the OGD ecosystem. My research is, as such, in line with process theory rather than variance theory (Maxwell, 2012b). It has been exploratory and open, which means practitioners have guided my attention towards work and conditions interesting for their OGD reform and their OGD ecosystem.

Theoretically, I have decided not to use a lifecycle perspective (e.g, Attard, Orlandi, Scerri, and Auer, 2015: Möller, 2013), actor-network perspective (e.g, Callon, 1999. Higman and Pinfield, 2015), or gatekeeper perspective (e.g., Shoemaker and Vos, 2009. Vos and Heinderyckx, 2015). I approach OGD from a reform-ecosystem perspective rather than an individualistic perspective. People are important for OGD and similar to IT-systems, but I have approached people as OGD actors or actors with conditions that need to be transformed for the purpose of OGD. I have also decided not to use inter-organizational (e.g., resource dependence theory and transaction cost 
theory (Williamson, 1991: Pfeffer and Salancik, 2003)) or role perspectives, as I use the ecosystem perspective. I have not focused my research on the legal system and its reform for OGD and the economic systems surrounding OGD, even if they are important for an OGD reform and an OGD ecosystem. They are partly included in my research because of my exploratory and open approach towards the experiences of practitioners.

\subsection{Thesis Outline}

This doctoral thesis is a compilation thesis encompassing five articles. The thesis is divided into seven chapters. The chapters are as follows. The first chapter was the introduction that you have just read.

Chapter 2 presents previous research divided into sections about information systems, open government data, reforms, an ecosystem perspective, and a data and information society. First, I explain how the discipline of information systems has influenced my perception of OGD and position my research within the discipline. Second, I present previous OGD research about OGD actors and their OGD ecosystem by first following their historical developments to then detail them. Third, I explain the concept of reform, the participants, features, stages of a reform, and general problems associated with an OGD reform. Fourth, I detail an ecosystem perspective based on previous research from ecology and oceanography to focus on an organizational ecosystem perspective. I also explain the concepts of evolution and health. Fifth, I present the society of an OGD reform and an OGD ecosystem. I consider this society to consists of a public sector, a data sector, an information sector, and a civic sphere. This chapter provides background and concepts that act as a base for Chapter 5 .

Chapter 3 presents my paradigmatic worldview that has influenced my research. I describe my assumptions about ontology, anthropology, sociology, and artifactology with epistemology, methodology, and axiology. I end the chapter with a summary of how my assumptions have influenced my research.

Chapter 4 describes my doctoral research. I start the chapter with an overview of my doctoral research process, then connect my research questions with my articles, present the methods of my five articles with descriptions, advantages, and disadvantages, and describe the synthesization of the RE-ECO framework. I end the chapter by describing the limitations of my doctoral research.

Chapter 5 gives the RE-ECO framework, which is a contribution of my doctoral research based on my research and empirical material as well as previous research. This framework describes the interplay between an OGD reform and an OGD ecosystem focusing on how it can affect the health of the OGD ecosystem.

Chapter 6 discusses my disentanglement of an OGD reform and an OGD ecosystem, tensions that OGD actors can experience, cycles and flows of an OGD ecosystem, and the interplay and health. The chapter ends with a summary of my discussion. 
Chapter 7 gives the conclusions and implications of my doctoral research. I present the conclusions of my doctoral thesis's main research question, as its five included articles have given conclusions to my doctoral thesis's sub-research questions. I reflect on my doctoral research process, thesis contribution, and research quality. I end the chapter with future research.

Lastly, Appendix A presents a list of the five included articles of my doctoral thesis and a list of additional articles produced through my doctoral research. Following the two lists are the five included articles. 



\section{Previous Research}

This chapter consists of six sections based on my conceptualization of various concepts in previous research to present my understanding of OGD, ecosystems, and reforms. The first section presents how the discipline of information systems has influenced my perception of OGD and positions my doctoral thesis within the discipline. The second section presents previous OGD research about OGD ecosystems, providers, enrichers, and seekers. It gives background to my research and further motivates it. The third section explains the concept of reform, introducing actors who can participate in a reform, features and stages of a reform, and general problems associated with an OGD reform. This section is mostly based on the work of Caiden (2017), which is motivated in Section 2.3 The fourth section details an ecosystem perspective based on previous research from ecology and oceanography. It then focuses on an organizational ecosystem perspective to explain the concepts of evolution and health, drawing on previous research. The fifth section presents the society of an OGD reform and an OGD ecosystem. I consider this society to encompass a public sector, a data sector, an information sector, and a civic sphere. I include this section since an OGD reform transforms parts of a society to beget and grow an OGD ecosystem for a higher purpose. The sixth section provides a summary of the chapter.

\subsection{Information Systems}

My background is in the information system (I $\mathrm{I}^{1}$ discipline from master's level and beyond, coming from a bachelor's in programming. As such, I study OGD from an IS perspective. IS research has through history developed several perspectives to understand information systems, such as IT-systems in a context, an open system that works with data and information, three related practices, and social units, IT-artefacts, their relations, and IS development (Goldkuhl, 2008. Sidorova, Evan-

\footnotetext{
${ }^{1}$ In this section, I use the abbreviation IS for the general and abstract category of information systems. I use the full form of IS when I write about the concrete phenomenon.
} 
gelopoulos, Valacich, and Ramakrishnan, 2008: Nolan and Wetherbe, 1980: Goldkuhl, 2008. Sidorova, Evangelopoulos, Valacich, and Ramakrishnan, 2008). In this thesis, I study how humans' work with data and information in social units (e.g., individuals, groups, families, communities, societies, and nations). An OGD reform and an OGD ecosystem involve the use and development of computers in social units but extend beyond computers to include the organization of IS and IT as other things (e.g., speeches and documents). Information systems are the foundation of an OGD ecosystem. If they were to be removed, data and information could not be worked. As such, I have a broad understanding of IS similar to Alter (2003b), which is different from a computer-based perspective like that of Benbasat and Zmud (2003). My understanding of IS has been shaped by the IS discipline's history. In this section, I present a summary of the IS discipline's history, some approaches of previous IS research to understand information systems, information technology (IT) from an IS perspective, and actors from an IS perspective. I end this section by positioning my doctoral thesis within the IS discipline.

\section{Short History of the Information System Discipline}

The birth of the IS discipline in the 1950s came with the first business computer, LEO (Davis, 2006: Hirschheim and Klein, 2011: Hirschheim and Klein, 2012). It gave rise to a focus on humans' use of IT as computers in organizations, which birthed a research demand for knowledge about this phenomenon. Nevertheless, computer scientists were unwilling to use their knowledge to solve problems in organizations. The technical perspective of computer science conflicted with the social nature of organizations (Adam and Fitzgerald, 2000). In the 1960s and onwards, information systems were also known as management information systems, which was the American stream of IS research (Sipior, 1996. Davis, 2006. Hirschheim and Klein, 2011), but a similar business focus also existed in Sweden (e.g., Langefors, 1968). I have observed a similar business focus within previous OGD research (see ??).

The IS discipline has gone through some developments in its approaches to understanding information systems (Hirschheim and Klein, 2011). At the early stages, information systems were mainly treated as a tool to automate clerical work, focusing on the automation of tasks and cost reductions (Hirschheim and Klein, 2011). For example, LEO was first applied in the valuation of the output of J. Lyons \& Co. Simple calculations were used on big data (Land, 2014). In the next stage, information systems were used as a support tool to facilitate management's decision-making, as organizations realized that information systems could add value beyond operations to management. Organizations believed that information systems were a competitive weapon that could increase their competitiveness, improve their productivity, and enhance their performance (Hirschheim and Klein, 2011). Today, information systems are viewed as strategic, and executives emphasize the importance of aligning their business strategy with their IS strategy (Hirschheim and Klein, 2011). The IS discipline has also grown to include the field of e-government and digital government (see Section 2.1.

IT (as computers) were developed by computer science researchers and experts in technical contexts but were then studied by heterogeneous groups of researchers and 
experts in new contexts of organizations. As the understanding of information systems grew in IS research and IS practice, their approaches shifted, and they identified new applications for IT. I understand that the period of the 1950s contained the birth of the IS discipline. It also came with eureka events where non-technical researchers and practitioners realized a novel way for IT to work with data and information. A way to work that was impossible or difficult to do with older methods, such as documents and manual calculations done by humans. It is also in the above history, we see a shared interest between the IS discipline and the OGD field, where they focus on data-processing and the use of IT. The OGD field also reuses old technologies of computers in the social innovation of an OGD ecosystem. The OGD field also follows in the same trend of digitalization as the IS discipline, where analog information systems are made digital. In addition, the e-government field of the IS discipline has developed into the digital government field, which includes OGD (see Section 2.1.

\section{Approaches to Understanding Information Systems}

IS researchers have historically treated IS and IT as strongly interdependent (e.g., Sidorova, Evangelopoulos, Valacich, and Ramakrishnan, 2008. Hirschheim and Klein, 2012. Gannon, 2013), but sometimes they are almost synonymous (e.g., Goldkuhl, 2008 Sidorova, Evangelopoulos, Valacich, and Ramakrishnan, 2008) or even the same (e.g., Froese, 1990). IS researchers have developed many perspectives to help practitioners and researchers manage the capabilities of IT in the context of organizations. For example, datalogical and infological systems, reporting and control systems, formal specified technical systems, inquiry systems, socio-technical systems, and human activity systems (Iivari and Lyytinen, 1999. Hirschheim and Klein, 2011). This scope has grown to include many areas (e.g., coordination and planning, healthcare, individuals' perspectives, and organizational approaches (Mason and Mitroff, 1973. Lucas Jr, 1973: Kunz and Rittel, 1970. Wennberg and Gittelsohn, 1973)).

"Because of [IS discipline's] roots in multiple disciplines, it is hardly surprising that the

[discipline] of IS is broad and embodies many themes and areas. Nor is it surprising that there is considerable disagreement about what the [discipline] actually includes and does not include, and what its core features are." (Hirschheim and Klein,2011. p. 16).

Benbasat and Weber (1996) argue that the IS discipline has diversity in addressed problems, theoretical foundations, reference disciplines, and research methods. My doctoral thesis follows this diversity through a broad multidisciplinary approach to my research of OGD. I draw on knowledge from, for example, information science and public utilities.

IS researchers' views of IS have changed and grown where information systems have been approached as if they often were novel. IS researchers have historically treated information systems as inside organizations (e.g., Checkland and Holwell, 1997, Alter, 2003a) and sometimes only existing for a small group of actors (managers) (e.g., Leavitt and Whisler, 1958. Dickson, 1968). For example, Checkland and Holwell (1997) explain that people organize information systems to serve, help, or support them in organizations. Nolan and Wetherbe (1980) perceive an information system 
to be an open system inside an organization. This system transforms organizational resources and data into information and requests information. Goldkuhl (2008) perceives an information system from a holistic view of IT as three related practices. A practice is a meaningful wholeness organized by humans, actions, and artifacts. IS practices are often embedded in organizations (Goldkuhl, 2008), which indicates that there are other contexts for information systems than the organization. However, while organizations have been in focus, individuals, markets, and groups have garnered attention (Sidorova, Evangelopoulos, Valacich, and Ramakrishnan, 2008). The core of IS can be understood to include social units (groups, individuals, markets, and organizations), IT-artefacts, and the development of IS (Sidorova, Evangelopoulos, Valacich, and Ramakrishnan, 2008). Sidorova, Evangelopoulos, Valacich, and Ramakrishnan (2008) explain that "The Information Systems academic discipline focuses on how IT-systems are developed and how individuals, groups, organizations, and markets interact with IT." (Sidorova, Evangelopoulos, Valacich, and Ramakrishnan, 2008, p.475). I agree that these elements are important for an OGD reform, an OGD ecosystem, and an information system. However, I see that depending on the definition of IT. It is possible to end up in a situation where an information system is treated by IS researchers as if it and information are a novel innovation. I do not want to extend this problem to my research, as I believe it would lead to difficulties in including and considering alternatives to computers as IT.

I see that IS researchers have historically studied the (possible) use and development of IT by actors as individuals or in collectives. Their general approaches have either focused on computers (IT for IS) or the social unit that uses IT as computers (IS use of IT). The approaches focus on the introduction of IT (as computers) to social units as if IS, IT, and information were novel innovations. For example, Froese (1990) perceives an IT as IS that is replacing libraries, and Downer, Teagle, and Whittle (1979) design a computerized IS to aid planning and evaluating dental services. These approaches are computer dominant and risk to exclude ideas such as a hybrid information system that could be a mix of traditional information solutions (e.g., documents) and computers. It can also overlook the possibility that the exclusion of computers could make an information system better or that a non-computer-based information system is better than a computer-based information system in certain situations. It is known that modern businesses store and use information in mixes of documents, computers, and people (Cortada, 2011). For example, OGD can be transformed into written reports, blogs, and info-graphics (Davies, 2010). As such, I argue that an OGD reform and an OGD ecosystem need to be understood from a diverse IS perspective, rather than a computer-based IS perspective, even if the relationship between providers and enrichers is founded on computer-based infrastructure.

\section{Information Technology of Information System}

IT (as computers) have been argued to be the core subject matter of IS research (Orlikowski and Iacono, 2001), which led to a discussion surrounding the identity of the IS discipline. One response was to use IT-reliant work systems (IS use of IT) as the core subject matter (Alter, 2003a), while another was the IT-artifact and its nomological net (IT for IS) (Benbasat and Zmud, 2003). However, the term IT had over time grown problematic with many different definitions and come to include more than 
information technology (Alter, 2003b). For example, Benbasat and Zmud (2003) assume that IT consists of hardware and software (computers), Checkland and Holwell (1997) define IT, at the broadest, as a collection of both practices, techniques, and devices concerned with collecting, storing, processing, and distributing data or information, while Leavitt and Whisler (1958) define IT as a new technology rotted in its contextual use (e.g., processing, support, and stimulate higher-thinking). At the same time, in the 1990s, IS researchers tended to give central theoretical significance to the context, the discrete processing capabilities of the artifact, or dependent variables. However, IT tended to disappear from view, be taken for granted, or be presumed to be unproblematic once built and installed (Orlikowski and Iacono, 2001). Orlikowski and Iacono (2001) argue that IS researchers should theorize the IT-artifact (which partly led to the identity crisis of the IS discipline), but ten years later, the absence of IT in IS research had increased (Akhlaghpour, Wu, Lapointe, and Pinsonneault, 2013). Similarly, despite repeated calls by IS researchers to engage with information as a concept, the engagement on a theoretical and conceptual level has been limited (Boell, 2017). Petter, Carter, Randolph, and Lee (2018) recommend that IS researchers define information in their research and consider how their definition of information might impact their research in explicit and implicit ways. Data and information can be the same or different phenomena within IS (McKinney Jr and Yoos, 2010: Boell, 2017. Emamjome, Gable, Bandara, and Gable, 2018). Consequently, IS researchers are studying social units that either develop software or somehow use computers to work with data or information but have a deep-rooted history of IT (computers) as an important innovation. It is also difficult to differentiate between IT and IS within the discipline, as their conceptual scope fluxes and are sometimes synonymous. My interest in an OGD reform and an OGD ecosystem touch on the use and development of computers in social units, but it reaches far beyond these to include the organization of information systems and IT as something else than computers. As a result, I believe my OGD research could indirectly help to broaden the IS discipline.

\section{Actors from the Perspective of Information Systems}

The information systems of an OGD reform and an OGD ecosystem are organized by actors and their work. Actors have a remarkable ability that makes information systems possible. They can shape events in each other's minds with delicate precision by simply making noises with their mouths. They can reliably cause precise new combinations of ideas to arise in each other's minds. This ability is also known as language, which is a biological adaptation to communicate information (Pinker, 2003b). I believe an OGD ecosystem is based on several (data) languages that allow OGD actors to share and use data. For example, it is possible for providers and enrichers to share words for measuring and understanding temperatures and winds (e.g., Celsius and wind speed).

I understand that actors possess two languages: a conceptual language and a shared language. The conceptual language is internal to them, while shared languages are used by groups of actors to help them understand each other (Pinker, 2007). Actors can, based on their conceptual language, encode experienced phenomena as information in their mind (based on Gleick, 2011). They can then encode the internal information into a shared language so that other actors can understand them. I un- 
derstand that an OGD ecosystem uses shared languages to ensure data collected by one actor is usable by other actors at different locations.

Actors' shared languages and encoding processes are based on a learned, complex system of concepts and behaviors (e.g., Swedish or mathematical formulas). Here, concepts are units of information (hidden, internal representations of knowledge) that influence actors' behaviors (Dawkins, 2016). They spread from actor to actor, interacting, evolving and mixing in the process, and act like the software or the internal programming of their minds (Brodie, 2009). Concepts can form complexes where they reinforce each other and work together, but they can also compete and conflict with each other (Brodie, 2009: Dawkins, 2016). An OGD reform and an OGD ecosystem use various conceptual complexes that spread from actor to actor, where some encourage transformations while others encourage the creation of data or solutions. In this situation, I have noted an assumption within OGD; an OGD ecosystem rests on the dual-idea that enrichers can (1) share enough conceptual complexes with providers to use their data and (2) possess conceptual complexes that allow them to add value to the data (e.g., draw new conclusions or identify new patterns). In my thesis, conceptual complexes are a type of condition and can be impediments, such as lack of awareness, skills, capabilities, and knowledge of enrichers and seekers (Huang, Lai, and Zhou, 2017).

\section{Public Reforms, OGD Reforms, and E-Government}

I understand that an OGD reform is one type of reform amongst several societal and public reforms. For example, an OGD reform and a public sector information (PSI) reform are similar in their quest for transparency but differ as an OGD reform seeks data, while a PSI reform seeks documents (Ubaldi, 2013). An OGD reform is also related to an open data (OD) reform and an open government (OG) reform. I perceive an OGD reform to be a common variation of an OD reform. Other variations include open citizen data and open business data. An OD reform aspires to make data open (unrestricted, free) to anyone, which means no restrictions from, for example, copyright and patents (Jaakkola, Mäkinen, and Eteläaho, 2014). It can follow the same principles as an OGD reform. The difference is that an OD reform strives for everyone to share their data, while an OGD reform pursues to make data from public organizations available to anyone. On the other hand, an OGD reform and an OG reform pursue open (unrestricted, free) access to information from public organizations (Harrison, Pardo, and Cook, 2012, Wirtz and Birkmeyer, 2015). An OG reform can be understood as a technological and institutional strategy. This strategy aims to transform governmental information from a citizen perspective. This reform believes that citizens could collaborate, interact, protect, or reuse information from governments. It strives to allow citizens to scrutinize public decisions and actions, which should empower them, but also allow them to propose alternatives (Sandoval-Almazan and Gil-Garcia, 2016). The transparency and accountability sought by an OG reform are something an OGD reform could deliver, but an OGD reform could provide more, such as cost savings and economic growth (Crusoe, 2019b).

An OGD reform is not the only type of reform concerned with IT in public organizations. The rise of computers as IT in the public sector has emerged to the field of 
e-government, which is studied by IS researchers (Grönlund and Horan, 2005). Egovernment is a tool that can be used to reform public organizations (Heeks, 1998 . Al-Shbail and Aman, 2018), but also a way to perpetuate governments as they are (Finger, 2009). Broadly, e-government is the use of ICT in and by public organizations since the introduction of the Internet in the 1990s (Bannister and Connolly, 2012). E-government intersects with the developing OGD field (Attard, Orlandi, Scerri, and Auer, 2015). Many academic e-government outlets have shown an interest in OGD (e.g., Government Information Quarterly and Information Polity), where they tend to focus on computer-based reforms of the public sector. This doctoral thesis is, as such, part of the e-government field similar to my licentiate thesis (Crusoe, $2019 \mathrm{~b}$. As a result, I have, firstly, directed the publication of my articles towards egovernment outlets, such as the Transforming Government: People, Process and Policy and EGOV-CeDEM-ePart. I have, secondly, participated in Scandinavian workshops on E-Government to discuss ideas with e-government researchers. In addition, the previous OGD research I cite is often related to or a part of the e-government field. At the same time, e-government has also developed into digital government where OGD is included as one part (Bounabat,2017). In this way, I understand that the OGD field has become a subfield of the digital government field of the IS discipline. My research is part of this development.

\subsection{Open Government Data}

OGD is data shared by providers for anyone to reuse (e.g., Tauberer and Lessig, 2007 Open Data Charter, 2015. Open Data Handbook, 2015). Data, in the simplest form, are facts (e.g., names and numbers) (Cortada, 2011). Actors encode details of a phenomenon as data where the data act like a substitute to the real phenomenon. Data are reduced to the bare minimum in comparison to the redundancy of information. Hey (2004) explains that data are treated like resources (e.g., mine and extract data), manipulatable, isolated, tiny objects (e.g., big and small data), and substances when occurring on mass (e.g., data stream or drowning in data) (Hey, 2004). Data are inputted into various reasoning frameworks to understand and explain the world around people (Kitchin, 2014). This input can become aggregated or derived data or information. Information can be distilled or drawn from data (Hey, 2004), while data could be created from information (Saldana, 2015). Information contains more redundancy than data to help the reader understand it, but also draw directed conclusions (Gleick, 2011). Information is a manipulatable object with attributes and content (e.g., sensitive information) and can be perceived as a vast resource or liquid (e.g., information flow) (Hey, 2004). It can inform and educate people. It aims to evoke concepts or shape events in the recipient's mind (Pinker, 2003b). Information is also under different requirements than data, such as its ability to inform and be useful in a given context for a specific person (Wilson, 1981).

The following sections present previous research about OGD ecosystems, providers, enrichers, and seekers with their elements and features. Elements are phenomena believed to be relevant for an ecosystem (Pickett and Cadenasso, 2002), while I define features as characteristics believed to be relevant for an ecosystem. 


\section{OGD Ecosystems}

OGD researchers and OGD practitioners have used several approaches to understand and depict OGD as a larger socio-technical system. For example, ecosystems (e.g., Immonen, Palviainen, and Ovaska, 2014; Dawes, Vidiasova, and Parkhimovich, 2016), lifecycles (e.g., Zuiderwijk, Janssen, Choenni, Meijer, and Alibaks, 2012. Attard, Orlandi, Scerri, and Auer, 2015), value networks (e.g., Attard, Orlandi, and Auer, 2016. Lindman, Kinnari, and Rossi, 2016), marketplaces (e.g., Zuiderwijk, Loukis, Alexopoulos, Janssen, and Jeffery, 2014), and value chains (e.g., Berends, Carrara, Engbers, and Vollers, 2017). In this section, I use "OGD ecosystem," as an umbrella term for the various approaches. I first present historical knowledge developments surrounding OGD ecosystems and then their perceived elements and features. The ecosystem perspective is further explained in Section 2.4

\section{Historical Knowledge Developments}

The concept of the OGD ecosystem has, between 2011 to 2021, received several developments by OGD researchers. I group the developments into periods of two years below. The list is not a complete account, as it focuses on developments I believe can contribute to my research. I start each paragraph with a topic sentence to present the direction I believe the research has developed in the period and end with a summary of the developments within the period.

Between 2011 and 2012, OGD research outlines the relationships, elements, and consistencies of an OGD ecosystem. Pollock (2011) depicts an OGD ecosystem as consisting of data cycles. Public organizations form a data pool where enrichers can get data for their solutions but can also contribute data to it. The solutions can be used by seekers who can also contribute by flagging errors or submitting corrections through feedback. Ding et al. (2011) describe an OGD ecosystem as production, consumption, and community around a linked data cloud, which is similar to the previously mentioned data pool logic. Kalampokis, Tambouris, and Tarabanis (2011a) depict an OGD ecosystem to vary in its structure based on an organizational approach (direct or indirect data provision) and a technological approach (linked or linking data) of the actors. The central actor can be an OGD portal holding metadata or a data center holding data. Davies (2011) presents an OGD ecosystem as a base infrastructure of solutions (provider) that is used by an ecosystem of solutions (enrichers). Harrison, Pardo, and Cook (2012) understand an OGD ecosystem as an ecosystem of interactions and dependencies between actors, infrastructure, and solutions. Thus, this period outlines the fundamental elements of an OGD ecosystem: data provision and its contribution to a data pool, data consumption and its developed solutions, an OGD community, OGD portals or OGD centers, and infrastructure. However, I find in this period a blurring between knowledge describing an OGD ecosystem and knowledge for an OGD ecosystem. For example, Ding et al. (2011) present an OGD portal developed by a research institute while they advocate OGD actors should use it, Pollock (2011) describes the future of an OGD ecosystem, and Davies (2011) draws on case studies in the United Kingdom. I have noted in my research that previous OGD research can attempt to be part of an OGD reform. The attempts' commonness and success are unclear. 
Between 2013 and 2014, OGD research continues to sketch an OGD ecosystem. Ubaldi (2013) perceives an OGD ecosystem as an ecosystem around a value chain. The value chain consists of (1) generating, collecting, checking, and cleaning data, (2) aggregating, combining, analyzing, modeling, and processing data, (3) distributing, delivering, and using software applications. It flows from data to information, knowledge, and then services. Jaakkola, Mäkinen, and Eteläaho (2014) understand an OGD ecosystem as a system of interconnecting and interacting elements based on an empirical report. There are three elements (government, business, and citizens) with data and service flows. Each element supplies data to itself. Lee (2014) describes the elements of an OGD ecosystem, mixing both the local and national (e.g., data audit within organizations and licensing between OGD actors). Heimstädt, Saunderson, and Heath (2014) perceive an OGD ecosystem as a business ecosystem constituted from providers and enrichers. Providers are the central actors who take initiatives within networked systems organized to achieve a higher purpose. Zuiderwijk, Janssen, and Davis (2014) depict an OGD ecosystem as the interactions between providers and enrichers based on infrastructure where tools, services, and actions are detailed. As a result, this period describes a value chain and flows within an OGD ecosystem, a networked system as an arena for providers, and local versus national elements. It is also within this period conditions and elements are clearly connected for an OGD ecosystem. In addition, I observe a continued development of the blurring line above, as Lee (2014) and Zuiderwijk, Janssen, and Davis (2014) suggest essential elements for an OGD ecosystem. Their essential elements could be embarrassed by other OGD researchers or OGD practitioners to fuel their OGD reform. From this period and forward, this type of knowledge contribution is common as OGD researchers present descriptive knowledge that could be used to transform parts of other societies.

Between 2016 and 2017, OGD research develops the concept of an OGD ecosystem. Dawes, Vidiasova, and Parkhimovich (2016) describe an OGD ecosystem as an ecosystem with several cycles around a core cycle of data provision, data use, and feedback. Lindman, Kinnari, and Rossi (2016) detail an OGD ecosystem as an ecosystem constituted by a value network made from a value-chain supported by service providers. The value chain starts with providers, then enrichers, and ends with seekers. Van Schalkwyk, Willmers, and McNaughton (2016) consider an OGD ecosystem as supply, demand, use, and the roles of providers, enrichers, and seekers. Jetzek (2016) presents an OGD ecosystem from a process perspective of strategy and planning, implementation of data infrastructure, use and transformation of data, and impact. The ecosystem is within a social, economic, and political context that contains IT infrastructure, regulatory infrastructure, and business environment. The author divides an OGD ecosystem into closed data, open data, private sector, public sector, and other. Kitsios, Papachristos, and Kamariotou (2017) perceive an OGD ecosystem to encompass data providers, service providers, infrastructure providers, new startup intermediaries, application developers, and application users. Martin, Turki, and Renault (2017) introduce the idea of a stimulator function to an OGD ecosystem. The stimulator function focuses on leadership, coordination, and cultivation of an OGD ecosystem. The stimulator role thinks about and influences an OGD ecosystem. I understand it to be similar to the role of a cultivator. The authors believe a stimulator can set goals for their OGD ecosystem and decide its production, form, and function. 
Therefore, this period continues with conceptual developments of an OGD ecosystem by including and refining cycles, feedback, a value network made from a value chain, and the idea of supply and demand. I find the process perspective of Jetzek (2016) interesting, as it recognizes an OGD ecosystem as something that is made and influenced by certain actors, which highlights the relationship between an OGD reform and an OGD ecosystem. In addition, the concept of enricher receives increased attention, and it becomes more common to divide it into multiple roles. At the same time, seekers, service providers, and stimulators are three roles more recognized as part of an OGD ecosystem.

Between 2018 and 2019, OGD research continues to define and capture an OGD ecosystem as knowledge. Charalabidis et al. (2018) present an OGD ecosystem as a lifecycle where providers release data and enrichers reuse them. Providers can also work with the data. Providers and enrichers work with feedback and can collaborate. Oliveira and Lóscio (2018) describe an OGD ecosystem to contain resources, roles, actors, relationships, elements, and features within a context. Gray, Gerlitz, and Bounegru (2018) understand an OGD ecosystem as a data infrastructure of distributed accomplishments, constituted by an evolving set of relations between people and solutions. In my licentiate thesis (Crusoe, 2019b), I depict an OGD ecosystem as providers, OGD portals, enrichers, seekers, and cultivators. It encompasses publishing, discovering, exchanging, transforming, and adapting elements within a social environment based on infrastructure. Cultivators are actors who cultivate or implement conditions in an OGD ecosystem (Bloom and Dees, 2008: Pollock, 2011: Harrison, Pardo, and Cook, 2012, Lee, 2014). While reformists act to change specific local conditions for an OGD ecosystem, cultivators act to change specific conditions for an OGD reform and conditions that can impact multiple actors within the OGD ecosystem (see Section 2.3). Jetzek, Avital, and Bjorn-Andersen (2019) understand an OGD ecosystem to have enablers (digital governance, openness of data, digital infrastructure), appropriation and utilization (shared digital content and digital products and services), and impact (corporate accountability, sustainable value, and voice and accountability). As a result, this period continues to develop previous OGD concepts to better define an OGD ecosystem. Several elements have been discovered in previous periods. It seems OGD researchers of this period are experimenting with what elements to include and exclude from an OGD ecosystem. In addition, I introduce the cultivator role to OGD research, which is similar to the stimulator role of Martin, Turki, and Renault (2017).

Between 2020 and 2021, OGD research synthesizes and details an OGD ecosystem. Mokobombang, Gutierrez, and Petrova (2020) depict an OGD ecosystem as a data process of providers, enrichers (infomediaries), seekers, and cultivators (intermediaries; e.g., Open Knowledge Foundation). The authors identify a total of 18 roles within an OGD ecosystem. Shah, Peristeras, and Magnisalis (2020) describe an OGD ecosystem as socio-technical networks with data functions and data value creation. The involved actors are providers, enrichers, support service providers, and seekers. Gelhaar, Groß, and Otto (2021) classify OGD ecosystems by domain, purpose, organization, infrastructure, openness, interdependence, and control. Therefore, this period is marked with recognition of variations and multiplicity. The idea of one 
OGD ecosystem is starting to unravel, and several roles are recognized. However, providers of OGD are still approached as a monolithic role.

In conclusion, I understand that the period between 2011 and 2021 has focused on developing the concept of an OGD ecosystem. OGD researchers have twisted, turned, added, merged, and removed various elements and relationships and tried various metaphors and conceptualizations. These behaviors highlight the complexities and vast size of an OGD ecosystem. I observe that it is possible to identify traces of an OGD reform. For example, the structuring effect of OGD portals and OGD centers (Kalampokis, Tambouris, and Tarabanis, 2011a), the networked arena of providers (Heimstädt, Saunderson, and Heath, 2014), the process perspective on OGD ecosystems (Jetzek, 2016), and stimulator and cultivator roles (Martin, Turki, and Renault, 2017. Crusoe, 2019b: Mokobombang, Gutierrez, and Petrova, 2020). I find that the arena and new roles indicate an OGD reform as something different from an OGD ecosystem. Harrison, Pardo, and Cook (2012) describe it as social infrastructure, which I return to below. Moreover, the concept of enricher has in previous OGD research received increasing attention and been broken into multiple variations. Other roles have received lighter attention and seen an increase in quantity rather than variation. Consequently, the present (knowledge) core of an OGD ecosystem can be understood to be enrichers while other actors are the borders of the OGD ecosystem.

\section{Elements}

In OGD ecosystems, providers, enrichers, and seekers are supported by service providers and guided by cultivators. In my research, cultivators are actors who cultivate (Crusoe, 2019b) and have increased in prevalence through my OGD research. I explain cultivators further in Section 2.3 as part of an OGD reform. The OGD actors' work can be understood as various elements. I have sorted elements from previous OGD research into the following element groups: data pool, effect, cultivate, governance, societal, and infrastructural elements.

Data pool elements refer to the release and use of data on the Internet (Ding et al., 2011: Pollock, 2011: Zuiderwijk, Janssen, and Davis, 2014. Dawes, Vidiasova, and Parkhimovich, 2016). Providers share the data through the data pool (Dawes, Vidiasova, and Parkhimovich, 2016). Enrichers and seekers can search, find, evaluate, and view data and related licenses (Zuiderwijk, Janssen, and Davis, 2014). Enrichers can go one step further and clean, analyze, enrich, combine, link, and visualize the data (Zuiderwijk, Janssen, and Davis, 2014). The seekers, enrichers, and providers can discuss the data and share feedback (Zuiderwijk, Janssen, and Davis, 2014: Dawes, Vidiasova, and Parkhimovich, 2016). A core condition is metadata that is attached to the shared data to explain them (Zuiderwijk, Janssen, and Davis, 2014). It describes the data and can explain how they were produced and the conditions for their use (Ubaldi, 2013).

Effect elements are the benefits or possible benefits realized by an OGD ecosystem (Ubaldi, 2013. Dawes, Vidiasova, and Parkhimovich, 2016). However, while I have found many possible benefits and some examples, I have been unable to find a conceptualization of the how-to between enrichers' solutions and their effects. 
Cultivation elements are activities that introduce, manage, remove, or transform conditions with the intent to change, encourage, or guide the OGD actors of an OGD ecosystem towards a higher purpose. The conditions can, for example, be events, expertise, ideas, and artifacts (Crusoe, 2019b). They can include fostering demand, revealing user paths, and increasing motivations for publishing OGD or using OGD (Harrison, Pardo, and Cook, 2012 Ubaldi, 2013 Zuiderwijk, Janssen, and Davis, 2014. Dawes, Vidiasova, and Parkhimovich, 2016). The higher purpose is often various effect elements or principled ideas (e.g., the right to data). I understand these elements to be part of an OGD reform (see Section 2.3).

Governance elements covers, for example, coordination, directives, financing, and legal and regulatory frameworks, policies, quality management, standards, and strategies (Ubaldi, 2013: Harrison, Pardo, and Cook, 2012: Zuiderwijk and Janssen, 2013. Zuiderwijk, Janssen, and Davis, 2014 Dawes, Vidiasova, and Parkhimovich, 2016. Van Schalkwyk, Willmers, and McNaughton, 2016: Shah, Peristeras, and Magnisalis, 2020). According to Gelhaar, Groß, and Otto (2021), governance has two dimensions: interdependence and control. The interdependence between OGD actors can range from tight to loose, and an OGD ecosystem's control can be central or decentral. Ubaldi (2013) emphasizes the balance between autonomy and control of OGD actors. Specifically, Jetzek, Avital, and Bjorn-Andersen (2019) define digital governance to include work structures, organizational behavior, governance, and the regulatory environment, which can influence how actors generate value through OGD. Two core conditions are OGD policies and open licenses (Lee, 2014). Charalabidis et al. (2018) explain that an OGD policy is a purposive course of action followed by OGD actors to deal with OGD-related issues. It encompasses processes, activities, and decisions to tackle these issues. Ubaldi (2013) explains that a legal and regulatory framework is essential to enable OGD but can also pose challenges. Zuiderwijk, Janssen, and Davis (2014) point out that licenses are important for OGD ecosystems. They describe legal conditions under which the data are provided and constrain their reuse. They help to guarantee the rights of the enrichers and seekers and are a cornerstone of an OGD ecosystem (e.g., Open Knowledge, 2015).

Societal elements refer to parts of a society that are conditions of or constrain an OGD reform and an OGD ecosystem. They include institutions, global and national influences, competing demand for the attention of the government, communities, business models, political regime, and government structure (Harrison, Pardo, and Cook, 2012: Dawes, Vidiasova, and Parkhimovich, 2016: Jetzek, 2016. Van Schalkwyk, Willmers, and McNaughton, 2016; Charalabidis et al., 2018). One core element is what Jetzek (2016) calls the business environment, which refers to the availability of skills, capital, business models to work with OGD for enrichers.

An OGD ecosystem is based on extensive infrastructure, which is its backbone (Jetzek, Avital, and Bjørn-Andersen, 2013: Jetzek, 2016. Jetzek, Avital, and BjornAndersen, 2019. Shah, Peristeras, and Magnisalis, 2020). The infrastructure can be centralized or distributed (Gelhaar, Groß, and Otto, 2021), but needs to be coordinated and stable for providers and enrichers to enable an OGD ecosystem (Davies, 2011). The infrastructure should allow searching, finding, analyzing, visualizing, and interacting with data (Charalabidis et al., 2018). I further divide infrastructural ele- 
ments into three categories: common, coupling, and private. Common infrastructure is ICT that enables OGD where Internet is a key element (Harrison, Pardo, and Cook, 2012. Ubaldi, 2013. Van Schalkwyk, Willmers, and McNaughton, 2016). Coupling infrastructure is built on the common infrastructure to couple providers, enrichers, and seekers. It can be OGD portals, standards, and access points to data (Ubaldi, 2013). Private infrastructure refers to the IT and general technologies owned and used by providers, enrichers, and seekers to work with data and information. External actors have no or limited access to it. In addition, social infrastructure partly based on the common infrastructure allows the actors to share ideas (Harrison, Pardo, and Cook, 2012). It could be hackathons, forums, or other events. However, this type of infrastructure could be considered as infrastructural elements as well as cultivation elements or societal elements.

\section{Features}

I have sorted an OGD ecosystem's features from previous OGD research into the following feature groups: ecosystem, structural, data pool, and emerging features.

An OGD ecosystem has at least four ecosystem features. They refer to the overarching behavior or complexity of an OGD ecosystem. First, an OGD ecosystem is multitudinous. For example, Ubaldi (2013) explains that it consists of ecosystems of providers, enrichers, and seekers. Previous OGD research has referred to an OGD ecosystem as multi-system, multi-layer, multi-context, and multi-dimension (e.g., Harrison, Pardo, and Cook, 2012 Zuiderwijk, Janssen, and Davis, 2014 Mokobombang, Gutierrez, and Petrova, 2020). Second, an OGD ecosystem is organized for a higher purpose (Mars, Bronstein, and Lusch, 2012), which could be innovation, interaction, or transaction (Gelhaar, Groß, and Otto, 2021). Third, an OGD ecosystem evolves, adapts, and grows (Harrison, Pardo, and Cook, 2012). It is believed to be self-organized and self-regulated (Oliveira and Lóscio, 2018). For example, demand for data can encourage supply for data (Heimstädt, Saunderson, and Heath, 2014). It has a degree of lifeness. Fourth, its health is believed to be dependent on variation and balance found in movement (Harrison, Pardo, and Cook, 2012. Nardi, O'Day, and O'Day, 1999), but also the sustainability of data provision and data use (Heimstädt, Saunderson, and Heath, 2014). However, previous OGD research about the health of an OGD ecosystem is limited as noted by Oliveira, Lima, and Lóscio (2019).

An OGD ecosystem has at least three structural features. First, an OGD ecosystem has keystone actors that are important for it to function properly (data is provided and used to realize benefits) (Harrison, Pardo, and Cook, 2012; Nardi, O'Day, and O'Day, 1999). The keystone actors can experience locality where they have specialized knowledge and skills not accessible to external actors (Harrison, Pardo, and Cook, 2012, Nardi, O'Day, and O'Day, 1999). Second, providers and enrichers develop dependencies over time and form a circular flow of resources (Heimstädt, Saunderson, and Heath, 2014). Third, the interactions between providers, enrichers, and seekers based on the infrastructure make a structure emerge. This structure is believed to be similar to a network (Oliveira and Lóscio, 2018). The coupling infrastructure can have a strong influence on this structure. For example, a data center can encourage indirect interaction between providers and enrichers, while a data portal 
can encourage direct interaction between them (Kalampokis, Tambouris, and Tarabanis, 2011a). This structure could be keystone-centric, platform-centric, marketplacebased, and decentralized (Gelhaar, Groß, and Otto, 2021).

The data pool elements have at least two data pool features. First, following Jetzek (2016), the data of the data pool need to be available, affordable, reusable, usable, interoperable, discoverable, and accessible. Ubaldi (2013) also stresses data quality, availability, accessibility, reusability, and redistributability. Quality of data is known to be linked to its usability (Zuiderwijk, Janssen, Choenni, Meijer, and Alibaks, 2012). One core feature of the data pool is interoperability (Charalabidis et al.,2018), which refers to the ability to mix or make exchanges between parts. An OGD ecosystem requires technical (IT-systems can connect), syntactic (structured data are exchanged), semantic (data are interpreted in the same way), and pragmatic (actors trust each other enough to connect) interoperability (Janssen, Estevez, and Janowski, 2014). It also requires open formats (Berners-Lee, 2015. Open Data Charter, 2015). This feature can be summarized as data utility (Van Schalkwyk, Willmers, and McNaughton, 2016). Second, the data and the data pool need to be secure and protected in the sense that they do not harm actors and their society (Lee, 2014 Shah, Peristeras, and Magnisalis, 2020). The data also have ownership that needs to be considered by OGD actors (Ubaldi, 2013). Privacy, and in extension security, is important to safeguard to ensure the safety of public organizations and citizens (Ubaldi, 2013).

The society and data pool have at least two emerging features. First, high-value, high-impact data should be released into the data pool (Ubaldi,2013), such as address and map data (Lee, 2014). These data are considered to have high potential value for OGD actors and an OGD ecosystem (Carrara, Oudkerk, Van Steenbergen, and Tinholt, 2018). Second, the society should have data infrastructure literacy, which includes reading and working with data and the ability to account for, respond to, and intervene around an OGD ecosystem in the creation, extraction, and analysis of data (Gray, Gerlitz, and Bounegru, 2018).

\section{Providers}

In previous OGD research, a public organization that shares OGD has been known as a supplier, a producer, a publisher, or a provider (e.g., Kalampokis, Tambouris, and Tarabanis, 2011a: Heimstädt, Saunderson, and Heath, 2014 Attard, Orlandi, Scerri, and Auer, 2015. Dawes, Vidiasova, and Parkhimovich, 2016). I agree with the label of provider, as it highlights the public organization's role to provide OGD as part of an OGD ecosystem. However, I disagree with (1) the label supplier since it brings with it a marketplace logic rather than ecosystem logic, (2) the label producer because it prioritizes production over provision, and (3) the label publisher, as it stresses a reform over an ecosystem and an editorial position that might not be sought for a public organization. Moreover, I sort elements of a provider into publishing elements and providing elements. It is possible to conflate the two elements (e.g., Folmer et al., 2011. Zuiderwijk, Janssen, and Davis, 2014: Attard, Orlandi, Scerri, and Auer, 2015). In addition, I include that a provider has begetter elements, private infrastructure elements, and coupling infrastructure elements. 
Publishing elements focus on the release of data, which is a transformation of a public organization and, as such, part of an OGD reform. They entail the implementation of a data stream or flow from inside the public organization outside for anyone to consume (Carrara, Oudkerk, Van Steenbergen, and Tinholt, 2018). Folmer et al. (2011) break the process down to identification, preparation, and publication. Hyland and Wood (2011) describe the process to publish linked OGD as identify, model, name, describe, convert, and publish. Janssen and Zuiderwijk (2012) mention data, decision to publish, and publish. Denis and Goëta (2014) present exploration, extraction, and rawifiction. Hunnius and Krieger (2014) explain that an OGD platform is developed, tested, and implemented. Lee (2014) gives data auditing, data selecting, cleaning, licensing, and publishing high-quality data. Serra (2014) gives the process as locating the data, selecting the data, and opening the data. Zuiderwijk, Janssen, and Davis (2014) detail the elements as creating or collecting, storing, checking, curating, cleaning, and publishing data. Kucera, Chlapek, Klímek, and Necaskỳ (2015) describe the process as developing a publication plan, preparing for a publication, realizing publishing, and archiving. Ayre and Craner (2017) advise public organizations to familiarize themselves with OGD and OGD portals, then familiarize themselves with data, evaluate what data to publish, review websites to identify more data to publish, help others find OGD, host a hackathon, and engage and encourage the public organization to transform into a platform. Charalabidis et al. (2018) describe the elements create or gather, pre-process, curate, store or obtain, and publish data. In sum, public organizations find data, reshape and extend their parent processes to an external coupling (access point), and then notify others about its open existence so that they may become enrichers and seekers by using their data.

The data stream or flow is constituted from providing elements and is part of an OGD ecosystem. Carrara, Oudkerk, Van Steenbergen, and Tinholt (2018) present them as collecting, extracting, transforming, publishing (sharing), maintaining, and monitoring. Folmer et al. (2011) give re-use, data management, and evaluation, but also build a community and advertize data. Janssen and Zuiderwijk (2012) have identified monitoring, maintaining, feedback management, and discussing. Lee (2014) gives data access, data discovery, engagement of enrichers, encouragement of economic reuse, and evaluation. Petrou, Meimaris, and Papastefanatos (2014) depict the flow for linked OGD as data is modeled and converted, then linked and stored, and, finally, released for reuse (Petrou and Papastefanatos, 2014). Zuiderwijk, Janssen, and Davis (2014) give satisfy data requests, discuss data, and analyze OGD portal use. In sum, the data stream consists of extracting, purifying, and sharing data. Attached are elements of maintenance, monitoring, and feedback.

In a metaphorical sense, the publishing elements represent the growth of roots for an OGD ecosystem where the roots are the data flows of the providing elements. Publishing elements are processes of becoming, while providing elements are processes of being. Sometimes when the data are collected only once or seldom, parts of the publishing and providing elements can be merged. For example, Zuiderwijk, Janssen, Choenni, and Meijer (2014) group elements by the roles of the contributor (researcher) and the coordinator. The contributor produces data, fills out a metadata template provided by the coordinator, registers their data collection, controls the storability of the data, saves and stores the data in a central location, and controls 
if the data can be published. The coordinator holds confirmations about storability, makes final checks, and uploads the data for publishing. Contributor and coordinator share feedback with each other. As such, an OGD reform and an OGD ecosystem can be difficult to see if not aware of them. This situation obscures the line between an OGD reform and an OGD ecosystem.

The original data come from begetter elements where they are possible used (Denis and Goëta, 2014). However, there is limited previous OGD research about types and variations in begetter elements. Conradie and Choenni (2014) explain that data storage, internal use of data, source of data, and suitability of data for release may be important for data release. Carrara, Oudkerk, Van Steenbergen, and Tinholt (2018) state that data can be published from existing publications, existing databases, source databases, source systems or packages, or consolidating from different sources. The authors stress that it is possible to publish data manually, but automation should be the standard. Based on Carrara, Oudkerk, Van Steenbergen, and Tinholt (2018), Conradie and Choenni (2014), and Zuiderwijk, Janssen, Choenni, and Meijer (2014), I can speculate that the lifespan of the begetter elements impacts the structure of the publishing and providing elements. I have found little OGD research that connects specific begetter elements with specific publishing elements and providing elements.

Private infrastructure refers to IT-systems, storage, inventories, archives, information structures, internal metadata, and processes that support the public organization's work with data and information. They are a source of impediments and barriers to the publishing and providing elements (e.g., Janssen, Charalabidis, and Zuiderwijk, 2012. Barry and Bannister, 2014. Zuiderwijk and Janssen, 2014a). Similarly, coupling infrastructure refers to, for example, standards, public metadata, and formats. I understand that the five-star provider scheme of Berners-Lee (2015) is a well-known example.

\section{Enrichers}

In previous OGD research, anyone who develops products or services on OGD has been known as an intermediary or an infomediary (Heimstädt, Saunderson, and Heath, 2014. Ubaldi, 2013. Janssen and Zuiderwijk, 2014). However, I disagree with the terms of intermediary and infomediary, as they stress a position between a provider and a seeker, activities of mediation, a messenger role, and accommodation of agreements between a provider and a seeker. Instead, I use the term enricher to emphasize its value-adding behavior within an OGD ecosystem (similar to Berends, Carrara, Engbers, and Vollers (2017)). Moreover, enrichers have been understood in three ways:

First, enrichers' role in a value chain. Lindman, Kinnari, and Rossi (2016) explain that enrichers can be extractors and transformers, analyzers, and user-experience providers. Carrara, Chan, Fischer, and Steenbergen (2015) state that they can be aggregators or developers. Van Schalkwyk, Willmers, and McNaughton (2016) describe an enricher as an intermediary between providers and seekers. Mokobombang, Gutierrez, and Petrova (2020) have identified data facilitator, application developer, service designer, data broker, data curator, translator or coordinator, value constel- 
lation designer, data developer, data management provider, infrastructure provider, data advocate, and value chain analyst.

Second, enrichers' work as series of activities. Janssen and Zuiderwijk (2012) describe that enrichers first search for data, then finds, process and visualize, use, and discuss them. Enrichers can discuss with and give recommendations to providers. Zuiderwijk, Janssen, and Davis (2014) detail the process as search, register or sign in, select language and translate metadata, search for license, view data, download data, clean, analyze, enrich, combine, and link data, share data, use tutorials to learn to use data, visualize data, discuss data, and rate the data. Charalabidis et al. (2018) describe the process as retrieving or acquiring, processing, using data, collaborating with data users, and giving feedback to the providers.

Third, enrichers' outputs as data, products, or services. Davies (2010) explains that enrichers can transform data into facts, information, interfaces, new data, and services. Janssen and Zuiderwijk (2014) explain that enrichers could develop singlepurpose apps, interactive apps, information aggregates, comparison models, data repositories, and service platforms. Johnson and Greene (2017) describe that enrichers can produce searchable databases, interactive maps, reporting services, find-aservice, reports, static maps, graphs, games, web pages, and articles.

In sum, I understand that the elements of enrichers are discovering and transforming data to develop solutions. However, the work of enrichers from needs to their solutions with variations is less known.

\section{Seekers}

In previous OGD research, anyone who uses OGD or products and services based on OGD has been known as a consumer, an end-user, and a user (Heimstädt, Saunderson, and Heath, 2014 Pollock, 2011. Zuiderwijk, Janssen, Choenni, Meijer, and Alibaks, 2012). I do not use the term consumer as I find that it brings a marketplace logic and passive perception of people. I disagree with the terms end-user and user since they are easy to mix (supported by reviewers) and are defined in relation to a solution rather than an OGD ecosystem. Elisabeth Gebka and I introduce the term seeker to OGD research. This term highlights actions, information needs, and behaviors in everyday life of people. It fits better with the active lives ascribed to providers and enrichers who can act and transform conditions. Moreover, sometimes seekers are grouped together with enrichers (e.g., Shah, Peristeras, and Magnisalis, 2020 Purwanto, Zuiderwijk, and Janssen, 2020) or noted, but excluded from an OGD ecosystem (e.g., Attard, Orlandi, and Auer, 2016). They can have the roles of data consumer, data prosumer, value constellation designer, data management provider, and data advocate (Mokobombang, Gutierrez, and Petrova, 2020). They use data and related services and products. They have been considered in previous OGD research about enrichers or as part of an OGD ecosystem (e.g., Ding et al., 2011 Lindman, Kinnari, and Rossi, 2016. Smith and Sandberg, 2018), but more research is needed from their point of view (Magalhaes, Roseira, and Manley, 2014). On the other hand, seekers' direct use of OGD appears to be a myth (Davies, 2010. Mayer-Schönberger and Zappia, 2011. Hunnius and Krieger, 2014. Hellberg and Hedström, 2015). There 
seems to be a tendency to assume them to be unproblematic, crave OGD, or demand their participation. For example, Kucera and Chlapek (2014) state that a possible benefit of OGD is increased transparency because of better availability and accessibility to data about the performance of the public sector (as if seekers are longing for more data transparency). At the same time, the existence of solutions and their functionalities are sometimes taken as proof of benefits or value (e.g., Kassen, 2013). Weerakkody, Irani, Kapoor, Sivarajah, and Dwivedi (2017) have noted that the rawness of data makes seekers unable to use OGD for any meaningful purpose relating to their life events or decisions. As such, enrichers play a vital role in assisting seekers in interpreting and acting on information drawn from data (Hunnius and Krieger, 2014). On the other hand, it could be possible that seekers participate in OGD as enrichers to satisfy their own information needs. For example, they download data to create a visualization that provides them with new and different understandings of the data (Attard, Orlandi, and Auer, 2016). Gurstein (2011) provides a list of conditions and elements that need to be in order for seekers to effectively use OGD: the Internet, computers and software, content and formatting, interpretation and sense-making, advocacy, and governance. However, Gurstein (2011) seems to understand seekers as a general population of enrichers who are supposed to use OGD directly. The features of seekers could be their need (Pereira, Macadar, Luciano, and Testa, 2017) or demand for information (Agrawal, Kettinger, and Zhang, 2014) but have not been specified in previous OGD research. Consequently, the role of seekers has received limited attention in previous OGD research, which is a problem for OGD research since seekers are the end-users in the OGD value chain. They are the actors who turn data and solutions into something valuable outside of an OGD ecosystem and give purpose to the activities of providers and enrichers. I revisit them more in the Section 2.5

\subsection{Reform}

An OGD ecosystem begets and grows from the transformations of an OGD reform, as actors become providers, enrichers, and seekers. An OGD reform contains many elements of transformation. For example, providers publishing data by implementing new data flows and enrichers transforming certain data to certain valuable information solutions (Davies, 2010: Carrara, Oudkerk, Van Steenbergen, and Tinholt, 2018). An OGD reform also transforms parts of a society as public organizations become providers and various actors become enrichers or seekers. Enrichers can provide new or improved services and products to seekers, and it is possible that innovations are made. An OGD reform is partly a social reform, but mainly a public administrative reform, as it seeks to change the public sector to make improvements in society.

In this section, I explain the origins of a reform, the role of public organizations, and then the spectrum to which a reform is a member. In the following subsections, I present actors who participate in a reform, features of a reform, the stages of a reform, and general problems associated with an OGD reform. In the section about stages, I position my research amongst approaches to understand an OGD reform. 
A society will always continue to change, as there is constant flux originating from (1) changing relationships with the environment, (2) new ideas and innovations, (3) powerful drives to progress by eradicating observable social ills, and (4) natural inclinations to compare and evaluate social activities (Caiden, 2017). The natural time of birth and death of generations and generational interactions also contribute to constant changes as values and ideas are forgotten, mutated, and reinvented (Brodie, 2009. Strauss and Howe, 2009. Durant and Durant, 2012. Dawkins, 2016). Public organizations can influence the fate of citizens outside their reach, prevent or assist societal reforms, affect the level of products and services available to a society, and are to some degree expected to perform the role of societal reformist by remedying social evils. Societal reforms go in hand with public administrative reforms, which form and impact each other (Caiden, 2017). Actors of an OGD reform seek to transform conditions and persuade other actors to join their OGD reform. Some actors are encouraged to continue and spread the OGD reform by accepting the role of a cultivator. For example, providers can be encouraged to continue spreading an OGD reform by engaging and cultivating enricher communities (e.g., Folmer et al., 2011. Davies, 2012. Carrara, Oudkerk, Van Steenbergen, and Tinholt, 2018.

Changes, reforms, and revolutions form a spectrum for the development of public organizations. All three leads to tension, are dependent on mobility, and can be premeditated, planned, expected, and uneven. Changes tend to be automatic, selfadjusting, autonomous, unforeseen, ceaseless, universal, anonymous, imperceptible, multi-causal, normal, and unavoidable while stressing consensus, conformity, and acceptance (Caiden, 2017). On the other hand, reforms tend to be purposive, willed, manipulated, artificial, avoidable, episodic, particularistic, identifiable while stressing conflict and difference and arising out of a crisis, threats to treasured values, loss of vitality, and inflexibility (Caiden, 2017). Revolutions can grow from oppressed reforms, but the concept is difficult to apply to public organizations. Thus, the critical line is between change and reform, not reform and revolution (Caiden, 2017). As seen in section 2.2. an OGD reform involves purposive, willed, artificial transformations, but it also involves resistance, avoidance, and fears by actors (e.g., Barry and Bannister, 2014. Wirtz, Piehler, Thomas, and Daiser, 2016. Huang, Lai, and Zhou, 2017). The crisis behind an OGD reform varies based on different OGD principles. For example, (1) Tauberer and Lessig (2007) believe OGD can resolve an incomplete democracy, elite restricted information supply, wasted information value, and dysfunctional, obscure governments; (2) Sunlight Foundation (2014)'s problem is that information and data are kept in walled gardens; and (3) Open Data Charter (2015) can be interpreted to be that we live in an obscure, divided, isolated, corrupt, lacking, bad world that needs to be changed and improved. Data are an underused resource locked inside governments that can help us (the humanity). On the other hand, an OGD reform tends to focus on the possible benefits and opportunities of an OGD ecosystem over a crisis (e.g., Carrara, Chan, Fischer, and Steenbergen, 2015: Jetzek, Avital, and BjornAndersen, 2019. Huyer, Van Knippenberg, Arriëns, and Blank, 2020). I understand this focus assumes a need to satisfy a lack of something else. This varied situation contributes to the perception of an omnipresent ghost looming within an OGD reform. 


\section{Actors who Reform}

Actors who seek to transform a public organization do not need to be part of it. For example, the Open Data Institute and Open Knowledge Foundation are two such actors. According to Caiden (2017), actors receptive to reforms fall into three general categories: (1) societal changers (accept inevitable changes and administer changes through established frameworks, but resist innovations that lack support or threaten the framework or their position), (2) societal revolutionaries (seek to become the new institutional elite to impose their ideas of change on the remainder of society and quickly change the established framework with little concern to compromise), and (3) societal reformists (work within the established framework while aiming to replace it eventually - they seek to educate, persuade, and pressurize others to their way of thinking). Reformists are persistent (when they fail, they try again) and are reluctant to leave the field to conservatives. Each of the general categories relates to either changes, reforms, and revolutions described above (Caiden, 2017). This doctoral thesis focuses on societal reformists and little on societal changers but leaves societal revolutionaries for future OGD research.

At the same time, I divide societal reformists into two broad groups within an OGD reform. First, reformists who transform local conditions directly so that they may do work for the purpose of their OGD ecosystem. For example, OGD managers can lead the implementation of new data flows (Carrara, Oudkerk, Van Steenbergen, and Tinholt, 2018). Second, cultivators who cultivate conditions to change, encourage, or guide their OGD ecosystem towards a higher purpose (Crusoe, 2019b). This cultivation can involve changing communal attitudes, which makes good communication essential. The existing knowledge and opinions of actors need to be altered to recognize, accept, assimilate, and integrate innovations (Caiden, 2017). Cultivators use the tools of propaganda to change the attitudes and existing knowledge of actors, which are efforts to persuade the actors to the idea of OGD (Bernays, 2005). For example, OGD principles (e.g., Tauberer and Lessig, 2007; Open Data Charter, 2015) need to be spread and adopted by public organizations, which can help to transform them into providers.

\section{Features of a Reform}

According to Caiden (2017), a public administration reform has three features, and I argue that they can be seen in the OGD principles of an OGD reform. First, a reform has a moral purpose grounded in some moral values, and the objectives of a reform can be to improve the status quo by removing alleged defects, ending evil or wrong ways, and curing faults. A reform is subjective and evaluative and, hopefully, based on probability rather than demonstration. Reformists' moral conscience does not permit them to stand idly when their moral imperatives are compromised. They must act or react to challenge with a crusading zeal, but they may be wrong, as their diagnosis is mistaken, their morals unacceptable, their reasoning faulty, or their calculations of probability grossly misleading. At the same time, they might project selfish ambitions as the general good, and their crusading zeal may blind them to goodness found elsewhere and to the worse abuse they leave in their wake. Until they clarify their intentions and prove their worth, they remain suspect (Caiden, 
2017). The moral purpose of OGD is to realize benefits of political, social, economic, operational, and technical nature (Janssen, Charalabidis, and Zuiderwijk, 2012) and cure restricted access to data, which wastes potential value and obscures the government (e.g., Tauberer and Lessig, 2007: Sunlight Foundation, 2014 Open Data Charter, 2015).

Second, a reform involves artificial transformation, as it is a calculated contravention of the principle of the dangerous precedent and is innovating. A reform is a more radical process than small changes and carries a higher risk and uncertainty with equally higher stakes. "It is a form of creative destruction in that an old order is broken down to pave the way for a new order" (Caiden, 2017, p. 66). For example, the rawification of data by providers contains the removal of private information from data to make them anonymous and usable for anyone (Denis and Goëta, 2014). This rawification needs to be created by someone and then implemented in the organization.

Third, administrative resistance distinguishes a reform from a change, which means a reform needs to be backed by power either through existing channels or by the usurpation of authority. A reform is a political process. Reformists are a type of politician with a mission and can support a reform to challenge authority and complacency and as an opportunity for self-advancement. They may be prepared to compromise on makeshift agreements that incorporate some of their proposals. Reform movements are open to internal dissension between rival factions at both extremes (Caiden, 2017). An OGD reform is championed by an OGD movement (Ubaldi, 2013), can experience resistance (Huang, Lai, and Zhou, 2017), and contains, for example, several rival OGD principles (e.g., Tauberer and Lessig, 2007; Sunlight Foundation, 2014. Open Data Charter, 2015).

The three above features are for an OGD reform visible in its OGD principles.

OGD Principles. I understand that OGD principles are the tenants of an OGD reform where several have sprouted over the years. An early seed is said to have been germinated around 2005 by the Open Knowledge Foundation through their Open Knowledge Definition 1.0 (Open Knowledge, 2005: Tauberer and Lessig, 2007). These early principles focused on knowledge, which was defined as content (e.g., music, films, and books), data (e.g., scientific, historical, and geographical), and government and other administrative information (Open Knowledge, 2005). Since 2005, eight OGD principles have blossomed (Tauberer and Lessig, 2007, Open Knowledge, 2015. Open Data Charter, 2015: European Data Portal, 2020. Open Data Handbook, 2015. Scott, 2020. Tauberer, 2014. Sunlight Foundation, 2014). I argue that these OGD principles are the core tenets of an OGD reform and an OGD ecosystem because they define OGD by giving it criteria and rules for the OGD actors to follow as a basis for an OGD ecosystem. At the same time, they express a moral purpose, as they encourage certain behaviors and reject others for a higher purpose (often in the form of what should be done). For example, the OGD principles of Tauberer and Lessig (2007) are believed to resolve an incomplete democracy, elite restricted information supply, wasted information value, and dysfunctional, obscure governments. Their OGD principles are: complete, primary, timely, accessible, machine-processable, nondiscriminatory, non-proprietary, license-free, online and free, permanent, trusted, a 
presumption of openness, documented, safe to open, and designed with public input. If actors follow their OGD principles, the authors believe the actors will experience increased civil discourse, improved public welfare, more efficient use of public resources, new insights by the public, and new business models (Tauberer and Lessig, 2007).

I have observed variations in OGD principles but also that they tend to share three focuses: (1) free access to data, (2) unrestricted use of said data, and (3) that the data needs to be usable. I understand that these three focuses set a rudimental standard for the artificial transformations of an OGD reform. If a public organization publishes data following the focuses, it provides OGD and has become a provider. Beyond these three focuses, the OGD principles tend to branch out and touch on other issues. Principles that touch on data provision (e.g., timely and online and free (Tauberer and Lessig, 2007)) and the data itself (e.g., non-proprietary formats or safe file formats (Tauberer, 2014)) are common but not universal amongst OGD principles. Some of the OGD principles touch on culture and the work itself, such as Tauberer and Lessig (2007)'s "the presumption of openness" and "designed with public input", Open Data Charter (2015)'s "open by default", or Tauberer (2014)'s "inter-agency coordination". Other OGD principles stress the importance of interoperability of the data (Open Knowledge, 2015: Open Data Charter, 2015: Open Data Handbook, 2015. Tauberer, 2014). Few OGD principles directly stress benefits, such as for "improved governance and citizens engagement" and "for inclusive development and innovation" of Open Data Charter (2015). Consequently, I believe it is possible that OGD actors can accept an actor as part of an OGD ecosystem but disagree about if their work is properly based on the OGD principles they follow. At the same time, it is possible that actors resist the OGD principles and their OGD reform. For example, Barry and Bannister (2014) explain some public officials can be afraid that the openness brought by OGD principles could lead to an increase in media's coverage of negative news, which could harm the public's trust in public organizations; and Janssen, Charalabidis, and Zuiderwijk (2012) explain that public organizations might not want to publish data as they perceive their data to have to low quality or their income is based on selling the data.

\section{Stages of Reform}

I understand that the stages of an OGD reform could be understood as ecosystem cultivation, a maturity model, and a process. Ecosystem cultivation involves activities to change, encourage, or guide an OGD ecosystem toward a higher purpose (Crusoe, 2019b). Bloom and Dees (2008) explain cultivation can be changing one or more environmental conditions or introducing an innovation that spreads well enough to establish new and stable behaviors. On the other hand, Martin, Turki, and Renault (2017) explain that the stages of cultivation are: knowing an OGD ecosystem, developing a strategic vision, positioning within the OGD ecosystem, and orchestrating processes serving the strategic vision. While the approaches of Bloom and Dees (2008) and Martin, Turki, and Renault (2017) can explain actors who act to transform an existing OGD ecosystem, I do not see how they can explain how an OGD ecosystem can beget from its society. Thus, my doctoral thesis has included the concept of cultivation to be part of an OGD reform. 
An OGD reform can be understood as an e-government or an OGD maturity model. Fath-Allah, Cheikhi, Al-Qutaish, and Idri (2014) present and compare 25 egovernment maturity models, varying between 3 to 5 stages. Two of their models focus on open government, which relates to OGD (see Section 2.1. The first model is presented by Baum and Di Maio (2000) as the stages of web presence, interaction, transaction, and transformation. The second model is given by Lee and Kwak (2012), following the five stages of (1) initial conditions, (2) data transparency, (3) open participation, (4) open collaboration, and (5) ubiquitous engagement. On the other hand, Kalampokis, Tambouris, and Tarabanis (2011b) propose a stage model for OGD with the stages of (1) aggregation of government data, (2) integration of government data, (3) integration of government data with other formal data, and (4) integration of government data with other formal and social data. I believe similar to Baum and Di Maio (2000), Lee and Kwak (2012), and Kalampokis, Tambouris, and Tarabanis (2011b) that an OGD reform follows certain stages. However, I find that maturity models are too similar to solutions to problems that originate from the OGD idea itself (see Section 2.3. Consequently, I understand them to be a possible part of an OGD reform than describing it.

An OGD reform can be understood as a process of innovation diffusion or administrative reform. Rogers (2003) explains innovation diffusion is the process where an innovation is communicated through certain channels amongst actors of a social ecosystem. He defines an innovation as an idea, a practice, or an object perceived as new by an actor. His theory focuses on technological innovations, different types of adopters, diffusion networks, and change agents. It is, to my understanding, based on an innovation-decision process that follows the stages of knowledge, persuasion, decision, implementation, and confirmation. On the other hand, Caiden (2017) explains that a public administration reform is continuous activities that happen in varied circumstances. It follows the stages of awareness of need, formulation of goals and objectives, implementation of reforms, and evaluation of the reformed. I agree that the stages presented by Rogers (2003) and Caiden (2017) are applicable to an OGD reform. However, Rogers follows a specific innovation rooted in the behaviors of actors, while Caiden follows the transformation of an ecosystem based on a societal need or problem driven by actors. A public administration reform could contain several cycles of Roger's diffusion of innovation, as various innovations are invented, tested, evaluated, and discarded in attempts to solve societal needs or problems. Therefore, my doctoral thesis follows Caiden's four general stages to understand an OGD reform as a public administrative reform.

Four General Stages of an OGD Reform. According to Caiden (2017), an OGD reform should follow four general stages: (1) awareness of need, (2) formulation of goals and objectives, (3) implementation of reforms, and (4) evaluation. Figure 2.1 presents an overview of these general stages.

In the first stage of a reform, an awareness of a need for a reform needs to be identified by people who cannot agree that the administration or certain of its features should be improved. People might live with an ill administration because changing it would mean sacrificing other things (e.g., unity). Insiders of a public administration might fail to disclose problems and see them as they are too committed to the 


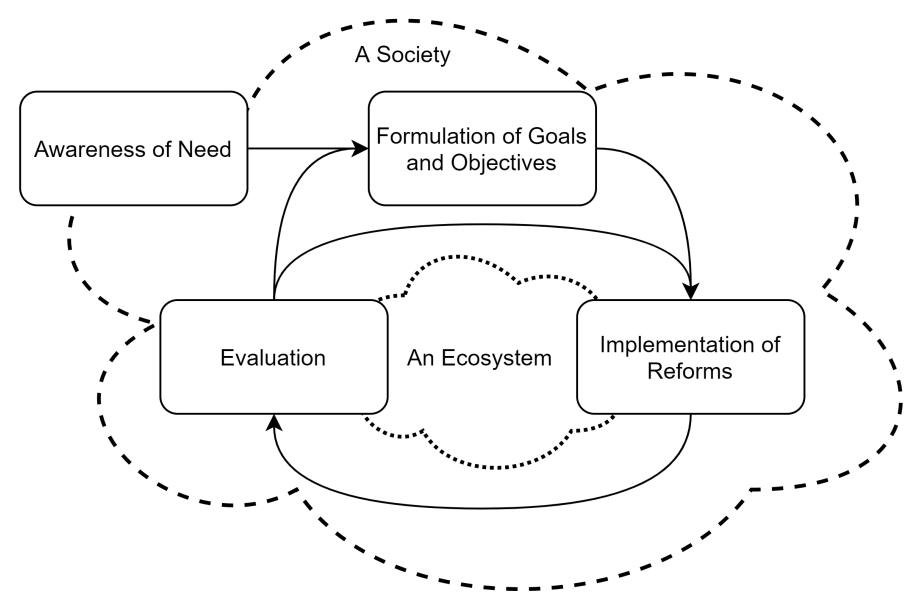

Figure 2.1: An overview of the general stages of an OGD reform.

system. Feedback, new knowledge, and outsiders can help identify ills in the administration. People tend to borrow ideas, institutions, and techniques that have been proven elsewhere. The need for a reform can grow from political (e.g., war and electoral victory), economic (e.g., poverty and bankruptcy), social (e.g., redistribution of power and literacy), demographic (e.g., population pressures and urbanization), and cultural (e.g., modernization and crime) reasons. Once a complaint is raised by a reformist, it is difficult to tell to what extent it is shared by others. It might be isolated or common. The reformist may see mistakes, faults, or corruption where others do not (either because the reformist is more perceptive or has more access, information, education, or contact than others). On the other hand, it is possible that he or she imagines mistakes, faults, or corruption, as the reformist only sees a small part of the administration and not the full circumstances. At the same time, the reformist can be an insider or outsider who is part of society or external to it (Caiden, 2017).

In the second stage of a reform, reformists agree on the need for improvement, but not on the best method for achieving their main objective. It is easier to draft proposals and plans than it is to execute them. The wider the range of reform sources, the more likely it is that proposals do not coincide. The initial steps of this stage are judged more critically than later stages. Complex radical reforms need more time and instruction to implement than simple incremental reforms. The greatest reformists combine innovation and administrative-political skills. Reformists can originate or imitate. Imitation is an easier process since the reformists only have to find out what others have done when confronted with similar situations. On the other hand, inventions involve originality. A mix of imitations and inventions helps to form the basis for a reform proposal, which is backed and supported by reformists (advocates). Some reformists reflect on the nature of the maladministration to formulate 
specific proposals for improvements. They share a conviction that perceived wrongs should be righted and remain disconnected from some aspects of their environment until their remedies are implemented. A reform to them is an article of faith, which requires unique personality traits of the reformist that are rare amongst people (e.g., ability to transcend group-thinking and a strong sense of compassion). Reforms are likelier to be accepted for three reasons: (1) if they are tailored to local circumstances, implemented through existing institutions and invite local participation, (2) if existing institutions and practices are not condemned out of hand (attention is given more to enthusiastically praise the virtues of the reform than the defects of the unreformed), and (3) if they are based on critical factors other than those defined through measurement. The reformists' overall strategy is to win over vested interests, opponents, and neutrals. As such, they may have to disguise their real aims and purposes of their reform behind vague general catchwords, such as livery, peace, justice, and prosperity (Caiden, 2017).

In the third stage of a reform, the reform is implemented, and there is no way or means to guarantee the potential reformist that the reform will work and that he will have the skills for the job. Once started, the reformist cannot restart a reform if it would fail, which can discredit the reform. The techniques used to implement the reform vary based on the objectives of the reform, the people involved, and the local circumstances. A reform can happen through political revolution, remedy organizational rigidity, legislation, and changes in attitude (Caiden, 2017).

In the fourth stage of a reform, no matter the cost of the implementations and dislocations, the result must be some kind of permanent transformation for the better (in terms of the reformists' objectives). The result needs to be evaluated to ensure it has caused a transformation. If the implementation cannot measure up to its criteria, it can be considered a failure. However, it is difficult to evaluate reforms, as (1) they are not an end in themselves, (2) their success is ambiguous, (3) it is difficult to attribute success to their reformists, (4) it is impossible to determine the true intentions of actors, (5) they are limited by time constraints, (6) they tend to ignore failed retrials, (7) there is a separation of morals and research, (8) reformists' charisma cannot be measured, (9) reforms' goals are unclear, and (10) the reformists seldom know about better alternatives (Caiden, 2017).

\section{General Problems Associated with an OGD Reform}

The implementation of an OGD reform has not come without problems (e.g., Zuiderwijk, Janssen, Choenni, Meijer, and Alibaks, 2012. Beno, Figl, Umbrich, and Polleres, 2017. Huang, Lai, and Zhou, 2017). My research divides these problems into four general groups: (1) problems solved by the reform, (2) problems of the reform, (3) problems in the reform, and (4) problems from the reform.

The first group is "problems solved by the reform". These problems are sometimes mentioned with the OGD principles, such as data are untapped resources that could help to overcome dysfunctional democracies (Open Data Handbook, 2015). They are part of the moral purpose of the reform (Caiden, 2017) and often framed as and hidden with potential benefits or possibilities. For example, publishers can increase 
their transparency, which assumes there is low transparency. This doctoral thesis recognizes this group of problems but does not explore them, as it is the focus of the OGD actors to overcome them with their OGD ecosystem.

The second group is "problems of the reform". These problems originate from the OGD idea itself and form a domino chain of problems and solutions. For example, if actors are supposed to access data anywhere at anytime, how can that be solved? The answer is automatically over the Internet (Berners-Lee, 2015. Carrara, Oudkerk, Van Steenbergen, and Tinholt, 2018). These solutions can also lead to new problems. For example, how will actors find the data on the Internet? The response is OGD portals, which leads to questions about their features and functions (Colpaert, Joye, Mechant, Mannens, and Walle, 2013). In turn, how will actors discover and understand the data? The answer is metadata (Carrara, Oudkerk, Van Steenbergen, and Tinholt, 2018). This relationship of problem-solution-problem follows in the idea of reforms (Caiden, 2017) and continues for a while. This doctoral thesis focuses on the solutions (conditions or elements) to this group of problems rather than the problems themselves. The problems are for OGD actors to solve.

The third group of problems is experienced by OGD actors when they encounter barriers and impediments that obstruct or prevent their work. It is "problems in the reform". For example, publishing data can lead to loss of income for providers (Barry and Bannister, 2014) or enrichers might be unable to discover data they need (Zuiderwijk, Janssen, Choenni, Meijer, and Alibaks, 2012). These kinds of problems can originate as a solution in one part of an OGD ecosystem and be an impediment in another (Zuiderwijk and Janssen, 2014a). They can also give rise to other problems at other locations (Huang, Lai, and Zhou, 2017) and vary in severity for different actors (Beno, Figl, Umbrich, and Polleres, 2017). Barry and Bannister (2014) group them into economic, technical, cultural, legal, administrative, and risk-related problems for providers. Zuiderwijk, Janssen, Choenni, Meijer, and Alibaks (2012) group them into availability and access, findability, usability, understandability, quality, linking and combining data, comparability and compatibility, and metadata for enrichers and seekers. This group of problems can also be reformulated as risks towards OGD, such as technology (e.g., outdated data collection methods and IT-vulnerabilities), management (e.g., insufficient investment in skills and funding), and environment (e.g., lack of governance experts and immature OGD knowledge) risks (Wang, Zhao, Zhao, and $\mathrm{Chu}, 2019$ ). OGD is also open to risks from post-truth thinking, which can lead to the withdrawal of datasets, dilution of data with bias, tweaks of data to make "corrections", reduce spending to reduce the volume of high-quality data, obscure or obfuscate the location of data access, and not adding or updating data (Colborne and Smit, 2020). Impediments can be a problem in an OGD reform and an OGD ecosystem. Therefore, impediments are relevant for this doctoral thesis. I understand them as a form of misaligned conditions, which OGD actors can seek to avoid, remove, mitigate, or overcome.

The fourth group of problems is experienced from an OGD ecosystem, such as heterogeneity of data makes public access difficult (Attard, Orlandi, Scerri, and Auer, 2015. It is "problems from the reform", as an OGD reform begets and grows an OGD ecosystem. It is also framed and understood as risk. For example, media can 
run more negative stories about providers (Barry and Bannister, 2014) and enrichers can misinterpret data and misuse data (Zuiderwijk and Janssen, 2014b). There are also risks to the security of infrastructure and increase requests of data (Kucera and Chlapek, 2014). Wang, Zhao, Zhao, and Chu (2019) divide risks from OGD into data risks and utilization risks. Data risks refer to the uncertainty surrounding data release (e.g., harm or violations of privacy) and relate to legitimacy (e.g., breaks laws or regulations), quality (e.g., possible distortions, errors, and format chaos), and value (e.g., trivial value or no clear enrichers or seekers) of released data. Data of poor quality could bring inestimable losses to enrichers or damage the credibility of governments. Utilization risks come from misuse, malicious, or improper use or insufficient use of released data. Consequences can include erroneous decision-making, invasion of privacy, or insufficient exploitation of data (Wang, Zhao, Zhao, and Chu, 2019). This group of problems is related to the health of an OGD ecosystem. An OGD ecosystem that would realize a negative purpose (e.g., harm or chaos in a society) cannot be considered fully healthy. I use the term "fully," since an OGD ecosystem consists of multiple data flows. Some of these flows could realize benefits, while others could realize detriments.

\subsection{An Ecosystem Perspective}

In this doctoral thesis, I understand OGD as a system of interdependent, interacting actors and artifacts from an ecosystem perspective. Tansley introduced this perspective for ecology in 1935 (Tansley, 1935: Real and Brown, 2012 Pickett and Cadenasso, 2002), which henceforth experienced rich conceptual developments. It has, for example, been applied in the fields of innovation, education, and health care (Mars, Bronstein, and Lusch, 2012). However, the extensive use of the perspective has led to questions if it is becoming or already is a zombie category (a concept that is actively used with dead or ambiguous content) (Hyrynsalmi and Hyrynsalmi, 2019). An ecosystem perspective is defined in relation to the studied phenomenon and is a type of holistic, system thinking (Jax, 2002. Jax, 2006. Jax, 2007). It includes assumptions and perceptions about the nature, history, and value of reality (Goldkuhl, 1998). It helps its users to focus their perception on interesting elements, interactions, and conditions in an environment (Jax, 2007). Something similar to a perspective is a metaphor that is an approach to see and think about organizations (Morgan, 1997). In common, I understand that they can help highlight what is important for a phenomenon and foster people's understanding of it.

The ecosystem perspective sees nature on a certain level, while objects are phenomena realized in space and time. This type of perspective is a level of observation (e.g., pathways of matter and energy) or focuses on larger unspecific chunks of nature (Jax, 2007). Jax (2006) and Jax (2007) explain that the term ecosystem can be used dually for objects in an empirical context and either in a metaphorical sense or for describing a particular perspective. On the other hand, Pickett and Cadenasso (2002) merge a perspective and its object by viewing an ecosystem as a model. This approach is inclusive to both living and nonliving elements (e.g., animals and rocks) and related processes but has to balance between conceptual quantity and quality (Weathers, Strayer, and Likens, 2012). The concept of ecosystem is transferred from ecology 
to OGD through several other disciplines. For example, previous OGD research has studied large, unspecific elements (e.g., Dawes, Vidiasova, and Parkhimovich, 2016, and sometimes other ideas have been transferred (e.g., keystone species and a balance found in motion explained by Nardi, O'Day, and O'Day (1999) to Harrison, Pardo, and Cook (2012)), which gives the concept the status of a perspective (Jax, 2007). Previous OGD research has also borrowed from research about business, innovation, information, science data, open government, digital, and software ecosystems (e.g., Harrison, Pardo, and Cook, 2012. Heimstädt, Saunderson, and Heath, 2014 Zuiderwijk, Janssen, and Davis, 2014). However, to identify, map, and determine the health of an OGD ecosystem and answer other how-questions, it needs to be conceptualized as an object (Jax, 2007). Thus, I understand an OGD ecosystem as something realized in time and space.

An ecosystem perspective is captured in a model that may be verbal, graphical, diagrammatic, physical, or quantitative (Pickett and Cadenasso, 2002). The model is a general representation of an ecosystem and shows elements, conditions, and interactions believed to be important for some purpose. An ecosystem perspective helps guide the observer's perception towards interesting elements based on some purpose among a collection of objects and their interactions in an environment. One consequence is that several ecosystems can overlap (Jax, 2007) and another is that the ecosystem as a model has a purpose, while the ecosystem as an object has a function. The perspective also includes descriptions of constraints and other factual information (Pickett and Cadenasso, 2002: Jax, 2007), which give an understanding of the behaviors of the ecosystem. An ecosystem perspective is constructed by a researcher based on the perceived strength (e.g., more numerous and intense than other types) of the interactions between elements (Jax, 2006). However, proximity should not be mistaken for interaction (Jax, 2006). An element should be described with a descriptive definition (to allow the attribution of it to an object) and factual information (to explain expected features of the object) (Jax, 2007). Elements interact with each other, which can take different forms depending on the type of model being built (Pickett and Cadenasso, 2002). Thus, I construct a model of an OGD reform and an OGD ecosystem based on elements in time and space. I have selected elements I believe are important for the purpose of the model and the function of an OGD reform and an OGD ecosystem.

An ecosystem has a border and can be divided into different areas. The border is drawn by a researcher, who also needs to consider loadings (inputs) and exports (outputs) that can cross it. It can act as a barrier, serve as a distinctive habitat area, or be areas of dynamic interaction between patches (Weathers, Strayer, and Likens, 2012). The ecosystem can also be divided into different areas (also known as zones). For example, an ocean ecosystem can be divided into the pelagic zone (water) and benthic zone (seafloor) based on its environment; or photic zone (sufficient light for photosynthesis), twilight zone (limited light), and aphotic zone (no light) based on its depth (Sverdrup and Kudela, 2013). The division of zones is based on properties of the environment that influences the inhabitants of the ecosystem at certain locations (Sverdrup and Kudela, 2013). It can also be divided into -clines (e.g., thermocline and halocline), which are vertical layers within the water, or -spheres (e.g., thermosphere and stratosphere) that are vertical layers in the atmosphere. In the layers, important 
properties changes, such as temperature or pressures (Sverdrup and Kudela, 2013). It can also be divided into patches based on the concentration of elements at certain locations, such as a grove beside a farm (Weathers, Strayer, and Likens, 2012). I understand that an essential activity of the ecosystem perspective (to manage complexity) is, as such, drawing borders while grouping elements within an ecosystem to study interactions between groups and ecosystems. This grouping can be based on different properties or concentrations.

From the ecological perspective, an ecosystem is an interacting system of all living creatures and nonliving objects in a specified environment (Weathers, Strayer, and Likens, 2012). It has a structure and a function. Structure refers to key organisms and materials. Materials can accumulate or be drained from pools. Function refers to the need for an ecosystem to consume energy and transform materials. Organisms need the energy to survive, but the energy can also flow through nonliving processes. Some creatures within an ecosystem can transform energy and material from living and nonliving sources to products. Other creatures can then consume these products to extract some of their energy and material. The energy is needed to build and maintain the structures against entropy, as such energy flows are important for an ecosystem (Weathers, Strayer, and Likens, 2012). As a result, I believe OGD actors need to consume, transform, and accumulate energy and materials. The energy is likely a crucial transformational fuel to an OGD reform and helps maintain an OGD ecosystem.

An ecosystem contains element cycles, which are the transportation and transformation of living and nonliving elements (often essential for life). The cycles can stretch between ecosystems, which means elements can be produced in one ecosystem and then consumed in another or just passing through. They are required by life and link the living and nonliving elements of an ecosystem. Element cycles can be understood as actions of moving, sticking, or changing materials. The properties of the material are important for a cycle. Materials can move within or between ecosystems. Materials can stick temporarily somewhere within an ecosystem. Materials can be changed from one state to another (Weathers, Strayer, and Likens, 2012). As such, I believe that data provision, as well as data use, can be understood as element cycles that load and export materials and energy to an OGD reform and an OGD ecosystem.

\section{An Organizational Ecosystem}

In my doctoral research, I specifically use the concept of an organizational ecosystem, unlike the concept of an ecological ecosystem (see Mars, Bronstein, and Lusch, 2012). An organizational ecosystem describes organizational structures, networks, and systems (Mars, Bronstein, and Lusch, 2012). The perspective sees a large complex social ecosystem by studying the coalescence made from actors, practices, values, technologies, and interactions. Technology supports actions for the ecosystem (Nardi, O'Day, and O'Day, 1999). The ecosystem can emerge and develop from spontaneous actions and planning, depending on certain conditions that can differ between ecosystems. Actors of the ecosystem come together to realize a higher purpose and share a logic or worldview (e.g., about using their products) that sometimes can be competing. They 
interact to exchange information and resources while pursuing their objectives and agendas (Mars, Bronstein, and Lusch, 2012).

Actors coalesce as their ecosystem through interdependence and interactions, as they gain function and purpose based on each other (Nardi, O'Day, and O'Day, 1999. Harrison, Pardo, and Cook, 2012: Heimstädt, Saunderson, and Heath, 2014). The structure of their ecosystem forms from the relationships, connections, and interactions of the actors (Iansiti and Levien, 2004). The actors have roles related to the collective properties of their ecosystems, which guides the formation (Iansiti and Levien, 2004). They can leverage resources and information from each other, meaning they can avoid producing them, which allows them to save energy and free them to focus on other things, specialize, and do things they otherwise would not be able to do (Iansiti and Levien, 2004). They need each other to realize the higher purpose of their ecosystem (Nardi, O'Day, and O'Day, 1999), but from the perspective of every actor, everyone does not perform optimally (Mars, Bronstein, and Lusch, 2012).

Evolution. The coalescence of an organizational ecosystem gradually occurs as it emerges from various contexts (Heimstädt, Saunderson, and Heath,2014). Actors are continually adapting and evolving to the changes of other actors without reaching a perfect state (Nardi, O'Day, and O'Day, 1999). They also evolve and adapt to survive (Iansiti and Levien, 2004). Evolution can happen through the introduction and spread of activities, ideas, knowledge, and artifacts in the ecosystem (Nardi, O'Day, and O'Day, 1999). At all levels, actors can co-evolve mutual dependencies that work to their benefit (Iansiti and Levien, 2004). Changes in the ecosystem can be gradual and subtle or fast and dramatic. They can be driven by external forces and internal events (Weathers, Strayer, and Likens, 2012). At the same time, actors can evaluate, plan, design, and purposefully change their ecosystem (Mars, Bronstein, and Lusch, 2012). Actors can also manipulate their environment (Iansiti and Levien, 2004). I see that evolution is (nearly) synonymous with the concepts of reform and change (see section 2.3.

An organizational ecosystem is assumed to evolve towards a higher purpose. If it deviates, actors can pressure or influence the ecosystem towards the higher purpose (Mars, Bronstein, and Lusch, 2012). In biological research, evolution has been conceptualized as an adaptive landscape. The peaks and valleys of this landscape represent degrees of adaptation to an environment for survival and procreation. Peaks mean good adaptation, while valleys mean poor. A well-adapted actor is healthy, well-fed, and can devote more time and energy to other tasks than survival. A poorly adapted actor must spend more time surviving and is generally less healthy, and has little time and energy for other tasks than surviving. On the adaptive landscape, actors are spread out based on their combination of conditions. They seek to climb their closest peak by transforming their conditions, but can also get stuck on a small peak as it is surrounded by valleys, unable to continue as the peak is too steep, and even slide down (McGhee, 2006). I see that, in an organizational ecosystem, a peak would be an actor fulfilling its role for a higher purpose and benefit from its participation. A valley would either be an inability to contribute to the higher purpose or harmful or profligate participation. The inclination of peaks and valleys is the effort and resources needed to move towards better health, which can be influenced by impediments. 
The adaptive landscape is covered in various peaks and valleys. An actor can find itself on one peak but want to be on another peak. It could then (possibly) try to jump between them. Alternatively, it could wait and see if the landscape changes and then move. If a peak suddenly collapses, it can kill all of its actors. If it then later rises back, convergent evolution can happen as various actors start to move towards the reborn peak (McGhee, 2006). I understand that from the reform perspective, actors attempt to stay on peaks even if changes attempt to bring them away. A reform could be a jump from one peak to another or a new formulation of the adaptive landscape. This formulation could be a change in what is considered the higher purpose or the specific work of an actor and, in turn, what is considered a high degree of adaptation.

Health. The concept of ecosystem health helps to differentiate between a wellfunctioning and dysfunctional ecosystem (Rapport, Gaudet, Constanza, Epstein, and Levins, 2009). It is a value-driven and mission-oriented concept (Rapport, Gaudet, Constanza, Epstein, and Levins, 2009). I understand that the drive and orientation align health with the idea of a higher purpose for an organizational ecosystem. Health can be assessed by studying different indicators, rebound capacity, risks, and threats. The assessment is based on the idea of probable causes for dysfunction and problems. Actors can prevent illness in their ecosystem and rehabilitate it with interventions (Rapport, 1995). The health of an ecosystem is diagnosed by dividing it into domains, where each domain covers a group of actors who engage in similar activities. Healthy domains mean a well-functioning (healthy) ecosystem (Iansiti and Levien, 2004). Even if the domains and ecosystem are healthy, not all actors have optimal performance (Mars, Bronstein, and Lusch, 2012). The diagnosis is done by studying different health dimensions, such as productivity and niche creation (Iansiti and Levien, 2004 Manikas and Hansen, 2013) or basic functions and adaptation (Shi, Rong, and Shi, 2018). As a result, I understand that the concept of health domains maps to how elements have been divided and grouped and where the border of an OGD ecosystem has been drawn.

The health of an ecosystem is dependent on the interactions of actors and external conditions (Iansiti and Levien, 2004: Mars, Bronstein, and Lusch, 2012). Actors are to some degree dependent on each other for the simple reason that they are adapted to each other's presence. Essential inputs to the survival and health of each actor are provided by other actors of their organizational ecosystem (Iansiti and Levien, 2004). The removal or displacement of actors can result in the loss of important inputs, which impacts the health of the ecosystem, as such its ability to realize the higher purpose (Iansiti and Levien, 2004). An ecosystem can experience slow and almost invisible degeneration and collapse under different conditions that would work for other similar ecosystems. Its emergence and ability to prosper depend on certain conditions, which can differ between ecosystems (Mars, Bronstein, and Lusch, 2012). Iansiti and Levien (2004) explain that actors within an ecosystem share their fate and, as such, the fate of their ecosystem. If their ecosystem is healthy, actors thrive, and new opportunities are created. If it is unhealthy, they suffer. Damage to key interactions or poisoning of elements can harm the ecosystem and its actors. Localized disruptions can result in widespread and cascading consequences throughout the ecosystem (Iansiti and Levien, 2004). 
Ecosystem health has been applied to business and software ecosystems (e.g., Iansiti and Levien, 2004 den Hartigh, Tol, and Visscher, 2006. Manikas and Hansen, 2013) and previous OGD research has drawn knowledge from these disciplines to understand an OGD ecosystem but only made limited progression towards understanding the health of an OGD ecosystem. For example, Lee (2014) indicates that user engagement could encourage good health, Zuiderwijk, Janssen, and Davis (2014) suggest that various elements affect health, and Heimstädt, Saunderson, and Heath (2014) explain that the interdependence between providers and enrichers affects health. According to Oliveira, Lima, and Lóscio (2019), few OGD studies have researched the health of an OGD ecosystem. In this doctoral thesis, I develop the concept of health together with the concepts of ecosystem and reform. I believe the combined use of these three concepts can help OGD researchers and OGD practitioners in three ways. They can help them: (1) identify, maintain, and improve successful conditions, (2) identify, avoid creating, prevent, or mitigate impediments, and (3) separate between transformations of an OGD reform from the everyday processes of an OGD ecosystem. This separation allows actors to understand the difference between temporary and continual work. It can also support them in identifying and developing their division of labor. Together, the concepts can help OGD actors understand how a healthy OGD ecosystem is begotten and sustained by an OGD reform and how they could ameliorate a dysfunctional OGD ecosystem using an OGD reform. It can help create a path towards successfully realizing benefits, better their OGD ecosystem, and ameliorate dysfunction. I believe this path is a step away from apathy along with risks and impediments as barriers (e.g., Barry and Bannister, 2014; Beno, Figl, Umbrich, and Polleres, 2017; Zuiderwijk and Janssen, 2014a). In sum, it could be a shift from problems to solutions.

\subsection{Data and Information Society}

An OGD reform transforms some conditions of a society, which begets and grows an OGD ecosystem. An OGD reform can, for example, transform public organizations into providers, introduce and change laws, and create or improve solutions. It can also be restrained and impeded by its society. For example, a country's legal and regulatory framework can enable and impede an OGD ecosystem (Ubaldi, 2013: Barry and Bannister, 2014). As such, an OGD reform and an OGD ecosystem are parts of a society, but the concept of a society is still vague and undefined. This section presents concepts to understand the parts of a society that are transformed by an OGD reform. Some OGD researchers have mentioned this society to be an information society (e.g., Hyland and Wood, 2011; Jaakkola, Mäkinen, and Eteläaho, 2014: Jaakkola, Mäkinen, Henno, and Mäkelä, 2014: Rohunen, Markkula, Heikkila, and Heikkila, 2014: Attard, Orlandi, and Auer, 2016) and fewer researchers have mentioned this society to be a data society (e.g., Halonen, 2012: Angelopoulos and Pollalis, 2020). Other OGD researchers have mentioned this society to be a data-driven society (e.g., Jetzek, Avital, and Bjorn-Andersen, 2019. Kassen, 2019). I argue that further conceptual developments are needed since the concepts are often mentioned as a framing device or sidenote. I use a combination of these concepts to understand the society that is the home to an OGD reform and an OGD ecosystem. I envelop the concept of a data-driven society with the concept of a data society, as I understand them as synonyms. In this 
section, I present my understanding of an information society, a public sector, and a civic sphere. I understand an information society as a data-information society since the work of data and information can be hard to separate. A point I further develop in the next section.

\section{(Data-)Information Society}

The concept of an information society is muddy since all groups (and, in extension, societies) develop their collective character through shared activities that depend on collaboration and communication, as such the use of information (Buckland, 2017). Day (2002) explains that all human activities (except the simplest and most primitive) require cooperation, which is not possible without language. The origin of language is hidden in the remote past and most likely dates back to a million years ago, around the time the earliest tool-making and cooperation emerged from humans. Ohlman (2002) adds that information systems in the past were organized by, for example, actors shouting to signal the finding of prey or warn of danger and were later supplemented with the beating of sticks on hollow logs (drums) and the blowing of hollowed shells (trumpets). Innis (2007) explains that communication of information has been vital in the organization and administration of empires (e.g., Egypt and Roman Empire). Day (2002) adds that they had complex writing systems that developed over time to convey messages and keep records. Innis (2007) includes writing also allows actors to overcome problems originating from space and time (e.g., texts can be stored and transported for later use or analysis). For example, the development of Rome from a small city-state into an empire (that covered most of the known world) bought with it the necessity for reliable and speedy communication with the governors of distant provinces. The cursus publicus (information system) was organized to meet this need. It was the most highly developed postal system of the ancient world (Brix, 2017) and has served to be a role model for postal services in Europe (Cursus Publicus 2020). Consequently, I agree that most societies in human history could be argued to be information societies.

Specifically, an information society refers to a society where the population use information at a broader scale (Buckland, 2017). The growing importance of information comes from the developing division of labor. Actors are growing interdependent as they develop specialized skills and greater efficiency from economies of scale, which requires coordination, communication, and documentation that, in turn, lead to a higher dependence on information and secondhand knowledge (Buckland, 2017). This situation is not neutral or simple, as actors can seek to advance their agenda by using the information in different forms (propaganda) to shape other actors' believes and behaviors (Bernays, 2005: Buckland, 2017). I believe an OGD reform is a good example of this complexity where cultivators and reformists attempt to persuade actors to join their OGD reform or their OGD ecosystem. Other examples include textbooks in schools that guide learning, sacred texts in religions to inspire particular beliefs, arguments from politicians to persuade others to vote for them (Buckland, 2017). Peoples' relationship to documents is based on trust, which grows problematic as indirect communication increases (Buckland, 2017). I understand that the existence of an information society means that OGD is more than just sharing and using data, as information is an integral part of a society. Its information sector can contain al- 
ternatives (Shoemaker and Vos, 2009: Nicholas and Herman, 2010), which I see OGD solutions can compete with these alternatives. For example, I can see that within a country, its journalistic ecosystem can compete with its OGD ecosystem over the creation of transparency for its public sector. On the other hand, it is also possible that the OGD ecosystem feeds the journalistic ecosystem with data and information.

According to Moore (1997), an information society has three main characteristics: (1) information is used as an economic resource (actors can use the information to increase efficiency, stimulate innovation, increase effectiveness, and for better competitive positions), (2) the public uses information to a greater extent (people use information more intensively in their activities as consumers and information systems are developed to extend public access to educational and cultural provisions), and (3) an information sector is developing (Moore, 1997). I understand that the ability to make data into information means that an OGD ecosystem could contribute to the growth of an information sector and, in turn, an information society.

The idea of sharing the data behind the information is on the rise (Buckland, 2017), which is a core tenant of an OGD reform and an OGD ecosystem. I believe that the three information society characteristics of Moore (1997) can be adapted for a data society because data and information can be worked by information systems (Alter, 2003b). I define the three characteristics of a data society: (1) data are used as economic resources, (2) the public uses data to a greater extent, and (3) a data sector is developing. I understand that people, to a greater extent, are connected and share data. They or artifacts also move, store, manipulate, use, and act on data to a greater degree (Lee and Cook, 2020). Similar to an information society, a data society is not something new. De Saulles (2020) explains that the usage of data by businesses dates back to early civilization. The modern data sector started to take shape in the eighteenth century, for example, with stock exchanges. The sector proliferated through the $2000^{\text {th }}$ century, as IT developed and data were increasingly seen as core resources, rather than by-products of other activities. Today, there are business models for datadriven revenue (De Saulles, 2020) and data are used in, for example, public rankings of universities, predicting and fighting crime, and online advertizement ( $\mathrm{O}^{\prime} \mathrm{Neil}$, 2016). The phenomenon can be called datafication, which is the reduction of things into facts that are then analyzed or used to (fabricate) predictions (Hong, 2020). People are reduced to facts and might need to adapt their lives to technology that can monitor them. They can be encouraged to behave in ways that are more compatible with the technology around them (and, in turn, the institutions behind the technology) (Hong, 2020). Pentland (2013) argues that social research needs to go deeper and analyze behaviors of people where big data is the tool for this purpose. On the other hand, Pentland (2013) argues that to achieve a data society, the data needed for public goods are open while the public is protected and personal data are treated like assets with individual ownership rights. Thus, I understand the society of an OGD reform and an OGD ecosystem as both (potentially) becoming and being a data society and information society. I name this combination the data-information society.

From the perspective of OGD, I understand a data-information society to contain a public sector, an information sector, a data sector, and a civic sphere, which are based on information systems (see Figure 2.2. A sector is a part of a society that can be 
separated from other parts because of its own special character (Sector 2021), such as a specific type of work. A sphere is an area of activity (Sphere 2021). The public sector refers to public organizations that provide public goods (De Vries, 2016). The information sector has the function to satisfy the general demand for information (Moore, 1997), while the data sector, building on Moore (1997), has the function to satisfy the general demand for data. The civic sphere refers to the seekers in everyday life who are possible beneficiaries of the sectors. Information systems are systems organized by actors to work with data and information for some purpose (see Section 2.1. They permeate the sectors and the sphere and can deliver data or information between them. However, I understand that the dualistic nature of IS as data and information work means that the data and information sectors can be difficult or impossible to separate. As such, I understand them as the data-information sector. They are two sectors with potential confluences and separations. An OGD reform seeks to transform conditions of the public sector to release free and open data for anyone in the data sector, which can then be enriched into information in the information sector by enrichers and later used by seekers in the civic sphere as data, products, or services. This transformation also changes a society towards the idea of a data-information society. An OGD reform seeks to create or develop a data-information sector, which makes or develops its data-information society.

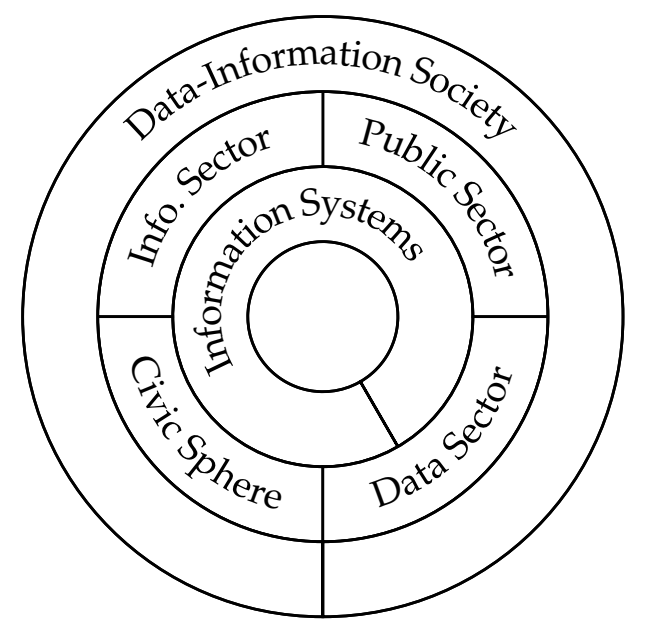

Figure 2.2: A data-information society with its sectors and sphere.

\section{Public Sector}

The public sector refers to public organizations that are owned or controlled by the government (De Vries, 2016). It is the home of the public organizations that can be transformed into providers of data (Ubaldi, 2013. Harrison, Pardo, and Cook, 2012). The governmental components of an OGD ecosystem are hierarchical organizations of departments, bureaus, and offices that interact between and within levels (Harrison, Pardo, and Cook, 2012). A government also has a regime (e.g., theocracy, monar- 
chy, democracy, or military junta) that needs these governmental components to provide public goods through policies and programs and ensures that people contribute to that provision through taxes or participatory contributions (De Vries, 2016). This administrative apparatus (including the people who work in it and the work they do) constitutes the public administration and is a large part of the public sector, which is the major employer and largest sector in all states (De Vries, 2016). The public sector plays a key role in a data-information society, as governments are major collectors and compilers of information. They hold, use, and (in some cases) publish large amounts of information (Moore, 1997). It often monopolizes certain functions (e.g., right to use violence, levy taxes, and discipline individuals) (De Vries, 2016). Heimstädt, Saunderson, and Heath (2014) explain that data are often acquired within natural monopolies of public organizations (due to high fixed costs, low variable costs, and a small number of potential customers), meaning an OGD ecosystem is based on a degree of governmental monopoly. At the same time, a government is the totality of political and administrative organizations and institutions within a country. It is authorized to allocate collectively binding values and services (De Vries, 2016). It is these values and services an OGD reform seeks changing to include, for example, the OGD principle of "open by default" and the provision of OGD (Open Data Charter, 2015). A government plays a key role in developing, deciding upon, executing, and enforcing public policies and steers the socio-economic development of its nation (De Vries, 2016). Lee (2014) argues that public organizations require leadership support, policy support, and financial support from their regime to go through an OGD reform. The public administration is the organization that puts politics into practice, implements laws, and organizes and manages the public sector (De Vries, 2016). Therefore, I understand the public sector to be a major sector of an OGD reform and an OGD ecosystem. However, a central question is how to organize public organizations to the interest of their public administrators to serve their superior and their community (Wilson, 1886: De Vries, 2016). This purpose is captured in the term "public administation" which means "serving the public good" (De Vries, 2016). I see the possibility that an OGD reform seeks to open the data of the public administration and regime, as a new public good.

\section{Public Goods}

According to De Vries (2016), the provision of public goods to resolve collective problems forms the basic legitimacy of any modern-day government. Public goods are supposed to benefit citizens who are also expected to contribute. For example, a public good could be a dam to prevent flooding, an army to defend against attacks from roaming tribes, or police to uphold the law (De Vries, 2016). Public goods also include public utilities. A public utility is a large group of public service organizations, a group that produces and manages various products and services vital to modern life (McNabb, 2016). A public utility can, for example, be water supply and power supply (Buchanan, 1990). A public utility is based on an extensive infrastructure that helps actors to create products or services at one location and distribute them to several consumers (Geddes, 1998: McNabb, 2016). A government's involvement in a public utility can vary, as the government can work within, oversee, or regulate the public utility (McNabb, 2016). Similar to an OGD ecosystem, a public utility is not allowed 
to discriminate against its customers (McNabb, 2016). A public good can become a private good through the process of privatization. However, when a problem cannot be solved or is not handled by individuals or groups, when many individuals have an interest in the resolution of the problem, and when the government is expected to find an efficient and effective solution, the pressure for public goods can increase (De Vries, 2016).

According to De Vries (2016), public goods are non-excludable (cannot feasibly be withheld from individuals in a group if there are others in the group who are able to consume or use them), non-rivalrous (many people can consume or use public goods without diminishing their value or exhausting their supply), and require a collective contribution (citizens are supposed to contribute to the creation and maintenance of public goods even if it does not benefit them individually) (De Vries, 2016). I understand that OGD is non-rivalrous as data can be copied and recopied again for distribution and use. It is also a collective contribution as citizens would pay taxes to their government for public organizations to share data with them. Data acquisition and maintenance cost money (Boulton, Rawlins, Vallance, and Walport, 2011. Lee, 2014. Hossain, Dwivedi, and Rana, 2016). On the other hand, I see that OGD might be excludable to certain actors. Tauberer and Lessig (2007) explain that one purpose of OGD is to open the information supply beyond a restricted elite. Sunlight Foundation (2014) perceives this restricted supply as walled gardens that need to be opened for anyone. Therefore, the existence of an OGD reform implies data excluded from the public. However, OGD, through its use of data available for free without restrictions, also makes data once opened non-excludable by principle. While OGD is going to be available for anyone, not every citizen has the resources and skills to use this data (Gurstein, 2011). On the other hand, public goods have tendencies of overproduction where tax money is invested in solutions that only benefit a small portion of the population (De Vries, 2016). As such, I understand that an OGD reform could attempt to make data a new public good.

Public goods can be evaluated following other criteria than economic values, such as human rights. This approach can be understood as value-governance (De Vries, 2016). An OGD reform and an OGD ecosystem are believed to lead to political, social, economic, operational, and technical benefits (Janssen, Charalabidis, and Zuiderwijk, 2012. Hartog, Mulder, Spée, Visser, and Gribnau, 2014: Kucera and Chlapek, 2014 Schrier, 2014). However, Zuiderwijk, Shinde, and Janssen (2019) found that the social benefits of OGD might be no or few, as OGD programs mainly deliver operational and technical benefits then secondly economic benefits, and lastly societal benefits. It has been recognized that it is difficult to harness the economic and social benefits that support innovations (Jamieson, Wilson, and Martin, 2019). On paper, OGD at least seems to have the goal to use a mixed value-governance, but it is also possible that OGD actors do not yet know the possible benefits of OGD. For example, Carrara, Chan, Fischer, and Steenbergen (2015) estimate that OGD could create 25.000 new jobs, save 2.549 hours for drivers wasted in finding parking spots, and reduce energy consumption by $16 \%$, which could be used elsewhere. On the other hand, Safarov, Meijer, and Grimmelikhuijsen (2017) found that most of the effects of OGD were not empirically tested but more proclaimed in previous OGD research. OGD could benefit businesses over citizens, as free data are made available to businesses 
that they can profit from, and the opening of data can weaken the market position of other providers of such data. At the same time, the public sector leaves the market (Kitchin, 2014). Thus, it is not straightforward to say that OGD is a public good. Instead, it is something it might become. I believe it could possibly become a public utility, as they share several structural similarities, such as being based on extensive infrastructure, focus on a resource for the public, and governmental involvement.

\section{Data-Information Sector}

The combined data-information sectors have the function to satisfy the general demand for data and information in a society (see Figure 2.2). Part of these sectors is the business environment, which refers to the availability of skills, capital, and business models to (potentially) can work with OGD (Jetzek, 2016). The sectors are as old as societies themselves and have driven and been driven by their developments (Day, 2002: Ohlman, 2002. Innis, 2007). For example, the invention of the printing press made it cheaper to mass-produce texts and reduced the potential for errors (Day, 2002), while the invention and introduction of trains and steam-driven ships increased the mail delivery capacity of the Royal Mail in the United Kingdom (Starmans, 2015. Royal Mail Group, 2020). The invention of counting and writing extended the memory of actors (Ohlman, 2002). Writing also enormously enhanced actors' capacity for abstract thinking (Innis, 2007). The first counting was likely done with the fingers of actors and with piles of small, natural objects (Ohlman, 2002). The first mechanical calculation aid was the abacus (at least 450BC) that enabled actors to add and subtract quantities using beads as counters (Ohlman, 2002). On the other hand, writing allowed actors to no longer depend on oral history (Ohlman, 2002). Writing evolved by simplifying pictures and then conventionalizing them until they did not look like their original pictures, then the signs were made to stand for linguistic components (first words, then syllables, and, finally, individual sounds or groups of sounds) (Day, 2002). The forms of signs were dependent to some extent on the materials used as a medium for the text (Day, 2002). The advantage of writing is that it exceeds speech or gestures to counteract the effects of time and space (Buckland, 2017), but requires the actors to learn to read and write.

The data sector is in a state of being ancient and nascent. It can be understood as (1) data interfaces that help people to connect and share data, (2) data circulations where data are moved and stored, and (3) data processing where data are manipulated, used, and acted on (Lee and Cook, 2020). Data are also collected, acquired, gathered, or created (Checkland and Holwell, 1997). De Saulles (2020) explains that the origin of business data dates back to early civilizations as business transactions, financial accounts, credit, and loans. The growing middle class in many industrialized economies extended the idea of credit to citizens, which required data gathering and processing on an unprecedented scale. This growth continued through the $2000^{\text {th }}$ century up to the present day and now forms a cornerstone of the financial data sector (De Saulles, 2020).

In the $19^{\text {th }}$ and $20^{\text {th }}$ centuries, great leaps were made for IT to extend human sensorymotor capabilities: sight, hearing, memory, speech, and manipulative skills (e.g., computing and writing) (Ohlman, 2002). Some inventions include mechanical cal- 
culators, pocket watches, telegraphs, telephones, television, micro-computers, radar, floppy disks, the radio, and the programming language Ada (Ohlman, 2002). One of the prominent inventions was the computer. While it could work with documents, "the situation of using a computing machine for this job [of information work] is like using a bulldozer to crack peanuts" (Mooers, 1959. p. 82). It was invented for calculations and lacked an easy, effective capability to process and work with texts (Gleick, 2011). I understand that experts and researchers have since then invented ways for computers to manage texts by, for example, treating them as numbers (e.g., ASCII and UTF-8) while displaying them as letters and the use of word processors (e.g., Microsoft Word or OpenOffice Writer).

In the $2000^{\text {th }}$ century, businesses grew more reliant on data gathering and processing and tools and techniques to help them in their data work. The access to data (specifically, the financial markets) could prove a competitive advantage for businesses that were able to see prices or significant news before their competitors. News reporting services and stock market data feeds emerged to satisfy this demand for data, which contributed to the business data sector starting to take shape (De Saulles, 2020). Today, smartphone applications can collect data (e.g., age, gender, and location) and share them with Google and third parties (De Saulles, 2020). This phenomenon is part of datafication where people and things are reduced to facts that are analyzed or used for predictions (Hong, 2020). On the other hand, Buckland (2017) explains that researchers have previously shared their work as information, but recent technological developments have enabled them to share their underlying data. The author notes that while there is a specialized infrastructure for information sharing, nothing similar is in place for data. If you asked a researcher to share its data of a project finished five or 10 years ago, it would generate more embarrassment and frustration than success (Buckland, 2017). I understand that an OGD reform seeks to share the data behind the information, which could be the data behind the research of the public sector. It is possible that the OGD reform puts a wedge in the data-information sectors between information providers and data providers to contribute to the size of the data sector. It could also bud of a data provider from an existing information provider. For example, the Swedish weather agency provides OGD about the weather and an informative website about the weather. As a result, I see that OGD actors can participate in both the data sector and the information sector, and the line between these sectors is paper-thin and possibly even a confluence.

The information sector has the function to satisfy the general demand for information facilities and services in a society and is significantly concerned with technological infrastructures, such as telecommunication networks and computers (Moore, 1997). It can be understood as (1) information creation, (2) information delivery, and (3) information processing (Moore, 1997). Broadly, this sector consists of actors (from both the public and private sectors) that work with information and intellectual property, such as actors who provide facilities to deliver information to information seekers and actors who develop the IT that enable the work with information (Moore, 1997). The information value chain is suggested to be creating, developing, packaging, distributing, and accessing information (Moore, 1997). In the traditional view, actors in the information sector collect and reason data to information inside one organization 
(Tananbaum, 2008). I see that it is also possible that the actors acquire the data from other actors, but this type of acquisition is limited to a few authorized actors.

I understand that from the perspective of OGD, the data-information sector contains the following parts: (1) creation of data and information, (2) distribution of data and information, (3) processing of data and information, (4) development of data and information technologies and infrastructure, and (5) encoding of data and information. Encoding refers to work related to the standards that surround the reduction of phenomena to data or information. For example, temperatures can be encoded as Celsius or Fahrenheit. I base it on the data, capta, information, and knowledge chain of Checkland and Holwell (1997), the datafication of Hong (2020), and the work of Gleick (2011).

\section{Civic Sphere}

In a data-information society, a civic sphere refers to the everyday life of seekers where their needs for data and information arise. An objective of the datainformation sector is to satisfy these needs by providing data, products, and services. The civic sphere is, as such, one location where possible benefits are realized by an OGD ecosystem (Ubaldi, 2013: Dawes, Vidiasova, and Parkhimovich, 2016). This doctoral thesis is interested in instances where seekers are using data or information that originate in an OGD ecosystem. Seekers can use the information to help them work effectively, solve a problem satisfactorily, or pursue a hobby (Nicholas and Herman, 2010). They can use the information to (1) find facts (answer specific questions), (2) stay aware (keep up-to-date on a topic), (3) research (investigate a field in-depth), (4) brief themselves (obtain a background understanding of a topic or issue), (5) stimulate thoughts (procure ideas or stimuli), and (6) recreation (surf interesting tidbits for fun) (Nicholas and Herman, 2010). It is possible that seekers extract facts from OGD and share them with friends (Davies, 2010). The value of information does not decrease as it is consumed. Instead, the value may increase as one piece of information is added to another. While it is cheap to copy information, it is usually costly to create it (e.g., compile a new encyclopedia costs a lot while copying it between digital storage is cheap) (Moore, 1997). I see that these properties of information apply to data based on Hey (2004) and the dualistic nature of information systems.

The information-seeking process of seekers follows these stages: needing (the first hint that information might be interesting), starting (to work on the need for information), working (on the need), deciding (on the value of any results from the work), and closing (the work) (Westbrook, 1993). Any of these stages can be the final stage, skipped (except needing), iterated between, and start a new effort to seek information (Westbrook, 1993). The use of OGD solutions to satisfy information needs is more complex than enrichers developing and selling solutions to seekers. Seekers require a need for them, then need to find and use them. Consequently, I understand that the data from providers and products and services of enrichers need to be integrated into the processes of seekers.

Information needs can be understood as a hologram that seekers walk around and through and may have difficulty putting into words and be experienced as an 
anomaly (Westbrook, 1993). Seekers can experience these types of needs when they encounter a gap in their knowledge (Belkin and Vickery, 1985), which can come from them attempting to satisfy a primary need (Wilson, 1981). This event can be accompanied by a feeling of uncertainty and apprehension (Kuhlthau, 1991). On the other hand, seekers might not be aware of their need (dormant or unrecognized need) or be aware but not work to satisfy it (unexpressed need) (Erdelez, 1999. Nicholas and Herman, 2010). If seekers recognize they have a need, they might need to do some initial gathering of information to make a general, internal expression of the need (Westbrook, 1993). They might discuss the topic with peers or relate it to previous experiences and knowledge (Kuhlthau, 1991). If the seekers' situations are unclear, confusing, or difficult to understand, they may be unable to formulate questions that can help them identify information for their need (Daft and Lengel, 1986). As seekers search for information to clarify their need, new pieces of information can cause their frame of reference to change (Westbrook, 1993), which, in turn, can change their understanding of their information need. Thus, I understand that providers and enrichers might need to help seekers express their needs and understand that their solutions can satisfy them. They might also need to take an active role and spread propaganda to satisfy dormant, unrecognized, or unexpressed needs.

The seekers start their search for information when their need is conceptualized, and they have determined the means of meeting the need. This stage can be anything from an internal thought process to causal discussions with peers to the approach of an expert (Westbrook, 1993). Seekers need to identify and select a general topic to be investigated and the approach to be used (Kuhlthau, 1991). This stage can be accompanied by a feeling of optimism after the selection of approach, and there is a readiness to begin the search (Kuhlthau, 1991). Some seekers might conduct preliminary searches and skim and scan for an overview of alternative topics (Kuhlthau, 1991). Delayed or postponed selection can give rise to feelings of anxiety (Kuhlthau, 1991). As such, I see that providers and enrichers need to make their solutions discoverable to seekers.

With a conceptualized need and action plan, the seekers set out to find information that can help them (Westbrook, 1993). However, this stage is the most complex, as every possible action and result may alter their perceptions and ideas, end the work, spark a new or related need, meet the need, or any combination of them (Westbrook, 1993). Seekers tend to feel confused, uncertain, and doubtful (Kuhlthau, 1991). The work can include chaining (follow references), browsing (semi-directed searching in an area of potential interest), differentiating (use source differences as filters), monitoring (follow certain sources), and extracting information (systematically working through a source to locate information) (Ellis, Cox, and Hall, 1993). If seekers cannot express their need, interactions with information systems can be awkward (Kuhlthau, 1991). On the other hand, seekers might encounter information when they look for information related to one topic but find information relating to another. It can also occur when they bump into information while carrying out a routine activity (Erdelez, 1999). When seekers are working to find information, they might encounter information that (1) can help them satisfy another information need in the present, (2) could have helped them or other seekers in the past, and (3) discover information that helped them satisfy a future information need (Erdelez, 1999). Seekers can jump 
between past, current, and future information needs and information-seeking processes, which can lead to cross-pollination. These behaviors can make seekers seem to behave irrational, change focus, and not follow search directions provided by experts (Erdelez, 1999). As a result, other seekers, experiences, and situations are all sources of information and knowledge, which means information can be found in unexpected ways and places (Erdelez, 1999). Seekers experience a turning point in their work to find information when their understanding starts to increase, and feelings of uncertainty demist and confidence increases (Kuhlthau, 1991). This formulation of knowledge leads to a focus on collecting information, and the work flows more effectively and efficiently with increased feelings of confidence and lowered uncertainty and deepening interest in the project (Kuhlthau, 1991). Therefore, I understand that providers and enrichers can expect seekers to be a bit chaotic and irrational when they work to satisfy their information needs. The OGD actors can work to make the interactions between seekers and information systems less awkward.

Close to the end of the information-seeking process, seekers have to decide to stop their search for information. They might think it is not worth the effort or have found what they wanted (Westbrook, 1993). At this stage, the seekers might evaluate documents (Ingwersen, 1982) or check the accuracy of acquired information (Ellis, Cox, and Hall, 1993). Seekers can feel relief that they found the information or disappointed if they did not (Kuhlthau, 1991). As such, I see that providers and enrichers can help seekers understand the quality of their solutions to ensure that they are not misunderstood.

Finally, seekers can close their information-seeking process and wrap up their experience (Westbrook, 1993), such as including references in a research paper or tell someone they found what they were looking for (Kuhlthau, 1991: Westbrook, 1993). Thus, I believe providers and enrichers can expect seekers to reference their solutions to others and use their data and information beyond their OGD ecosystem.

Beyond seekers and their information use, they might want or demand information they believe can satisfy their need (Nicholas and Herman, 2010). The want of seekers is what information they would like to have. In a perfect world, this want would be the same as their information need. Nevertheless, seekers might lack time, resources, motivation, knowledge, and many other things to understand their own need. They can be tempted to obtain information that they do not need (Nicholas and Herman, 2010). Information wants are similar to the dream scenario and are often based a bit on wishful thinking. A want for information can lead to a demand for information, which is a request for an item of information that is believed to be wanted (Nicholas and Herman, 2010). Demands for information come when actors are working towards satisfying their information need. Mismatches between their knowledge and reality might cause them to demand information they do not need (Nicholas and Herman, 2010). Consequently, I argue that providing information to meet the wants and demands of seekers can lead to tons of information not used. This insight is important to OGD as it is often painted as a supply-and-demand or problem-solution driven (e.g., Dawes, Vidiasova, and Parkhimovich, 2016. Van Schalkwyk, Willmers, and McNaughton, 2016. Turki, Martin, and Renault, 2017 Susha, Grönlund, and Janssen, 
2015. I believe an OGD reform and an OGD ecosystem should be data or information need-driven.

\subsection{A Summary of the Previous Research Section}

This chapter has presented previous research about information systems, open government data, reforms, an ecosystem perspective, and a data-information society.

I understand an information system to refer to actors and artifacts working with data and information. The artifacts are referred to as IT and can, for example, be computers, written reports, and spoken words. Data are austere facts that act like substitutes to real phenomena, which can be inputted into various reasoning frameworks to understand and explain the world around the actors. Information is redundant and can inform and educate actors. It aims to evoke concepts or shape events in the recipient's mind. I position my research within the IS discipline as part of the OGD subfield of the e-government and digital government field (see Section 2.1).

OGD researchers have made several developments to the concepts of an OGD ecosystem between 2011 and 2021. They twisted, turned, added, merged, and removed various concepts and relations while trying various conceptualizations and metaphors. I observe traces of an OGD reform in their research concerning structure, systems, processes, and roles. At the same time, providers, enrichers, and seekers have received uneven attention with a focus on providers, then enrichers, and less on seekers. Providers find data, reshape and extend the datas' parent processes to external access points, and then notify enrichers and seekers about the datas' open existence so that they may use their data. The data flow out as a data stream consisting of extracting, purifying, and sharing the data. Providers can maintain and monitor their data steams and receive feedback from enrichers and seekers. Less is known about how their data are created. Enrichers can discover and transform data into data, products, and services for seekers. Less is known about enrichers' work and its variations. Seekers turn data, products, and services into something valuable outside of an OGD ecosystem by satisfying their needs with them. However, seekers have received limited attention from previous OGD research (see Section 2.2.

An OGD reform transforms parts of a society to beget and coalesce an OGD ecosystem. An OGD reform has the moral purpose of realizing certain benefits, involves artificial transformations of conditions, and can experience resistance from actors. I understand the OGD principles to be tenants of an OGD reform who in common state: (1) free access to data, (2) unrestricted use of the data, and (3) the data need to be usable. The OGD actors of an OGD reform are cultivators who change conditions and recruit others, reformists change local conditions, changers are transformed or become part of the OGD ecosystem's work, and helpers who support and help the other actors. An OGD reform should follow four general stages: (1) awareness of the need for an OGD reform, (2) formulation of goals and objectives of an OGD reform to realize certain benefits, (3) implementation of a reform as the partial transformations of a society, and (4) evaluation of an OGD ecosystem. An OGD reform also encounters four general problems: (1) problems solved by an OGD reform, (2) problems of 
an OGD reform, (3) problems in an OGD reform, and (4) problems from an OGD reform (see Section 2.3).

I understand an OGD ecosystem as an organizational ecosystem of networks, systems, and OGD actors who work towards a higher purpose. The OGD ecosystem consists of various areas that have different characteristics and properties. I believe OGD actors need to consume, transform, and accumulate energy and resources. Energy can fuel the transformations of an OGD reform and help to maintain an OGD ecosystem. Resources move in cycles, while energy moves in flows, which can start, end, or pass through an OGD ecosystem. They can be loaded (inputted) and exported (outputted) over the borders of an OGD ecosystem. The borders can be habitat zones for various actors. The OGD actors are dependent on others to do their work, and they evolve in relation to each other, and their health is also dependent on them. The evolution of the actors can be understood through a landscape metaphor. Health as a concept helps to differentiate between a well-functioning and dysfunctional ecosystem. It highlights that OGD actors share their fate with their OGD ecosystem (see Section 2.4.

I understand a data-information society to be and becoming through an OGD reform and an OGD ecosystem. It encompasses a public sector, a data-information sector, and a civic sphere, which are based on information systems. In a data-information society: (1) data and information are used as economic resources, (2) it is possible to identify greater use of data and information amongst citizens, and (3) the development of a data-information sector. An OGD ecosystem can contribute to these three characteristics, but there may be alternative or competing ecosystems to an OGD ecosystem. The public sector refers to public organizations that can provide public goods to citizens. OGD could become a public good. The data-information sector has the function of satisfying the general demand for data and information in a society. The civic sphere refers to the everyday life of seekers where their needs for data and information arise (see Section 2.5).

In the next chapter, I present my paradigmatic worldview and how it has influenced my research. I present some common formal worldviews (e.g., positivism and critical realism) and discuss my paradigmatic worldview following six elements. 


\section{CHAPTER}

\section{Paradigmatic Worldview}

This chapter uses the paradigmatic worldview of my licentiate thesis as a point of departure (Crusoe, 2019b). It starts by introducing some common formal paradigmatic worldviews to present six elements of a paradigmatic worldview and how I understand their relationships. I then discuss each element and end the chapter with a summary of how my worldview has influenced my doctoral research. I use worldview and paradigm synonymously (cf. Creswell and Creswell, 2017) to refer to the worldview of a researcher. I call this worldview a paradigmatic worldview (Crusoe, $2019 \mathrm{~b}$ ) and it is a philosophy concerning nature and research (Creswell and Creswell, 2017). It consists of a belief system concerning the nature and development of knowledge (Saunders and Lewis, 2012) while providing ideas and assumptions that establish and influence the perception, thoughts, knowledge, and actions of a researcher (Funk, 2001).

\subsection{Paradigmatic Worldviews and Elements}

A common approach amongst researchers is to join a formal paradigmatic worldview. Today, five formal paradigms are (1) critical realism, (2) interpretivism, (3) pragmatism, (4) positivism, and (5) transformatism (Guba, Lincoln, et al., 1994; Saunders and Lewis, 2012: Bhaskar, 2013). First, critical realists (of critical realism) attempt to understand reality as basic structures and mechanisms, which can shape perceivable events, using a mix of qualitative and quantitative methods (Saunders and Lewis, 2012. Bhaskar, 2013). Second, interpretivists (of interpretivism) explain knowledge to be socially constructed within a social context, which they study through qualitative methods (Berger and Luckmann, 1966: Orlikowski and Baroudi, 1991; Fitzgerald and Howcroft, 1998. Saunders and Lewis, 2012. Myers, 2013. Creswell and Creswell, 2017). Third, pragmatists (of pragmatism) utilize research objectives with a set goal in mind. It allows them to select amongst several basic beliefs and assumptions. The selections enable the mixing of methods to generate knowledge that works rather than being true (Saunders and Lewis, 2012. Creswell and Creswell, 2017). Fourth, positivists (of positivism) believe that law-like generalizations can describe objec- 
tive reality through systematic quantitative methods (Orlikowski and Baroudi, 1991 . Fitzgerald and Howcroft, 1998; Saunders and Lewis, 2012: Myers, 2013. Creswell and Creswell, 2017). Transformatists (of transformatism) form loose groups of similar paradigms (e.g., postmodernism and post-structuralism) who stress language, power, and conflicts and seek to transform society following their ideology (Orlikowski and Baroudi, 1991: Guba, Lincoln, et al., 1994: Saunders and Lewis, 2012: Myers, 2013. Creswell and Creswell, 2017).

A researcher's paradigmatic worldview can be split into at least six elements (based on Guba, Lincoln, et al. (1994), Funk (2001), and Fleck (2012)). I use the same six elements of my licentiate thesis (Crusoe, 2019b), except that I group three of the elements into one element, as they are human-made phenomena. I use the following six elements:

- Ontology refers to assumptions concerning reality's nature and form (Guba, Lincoln, et al., 1994. Adam and Fitzgerald, 2000. Funk, 2001 Saunders and Lewis, 2012: Crusoe, 2019b). Liston (2016) explains that anti-realists and realists have adverse assumptions concerning ontology.

- Anthropology encompasses assumptions concerning humans' nature and purpose (Funk, 2001: Crusoe, 2019b). It is not the same anthropology as that of research, discipline, and field.

- Sociology refers to assumptions concerning society's development, nature, form, and function (Crusoe, 2019b). It connects to the elements of anthropology and artifactology, as they constitute social systems and social units. For example, research is a human enterprise, as researchers communicate using a special language and discuss and share their work through conferences and journals. The element is not the same as the sociology of research, discipline, and field.

- Artifactology encompasses assumptions concerning artifacts designed and made by humans; the what and how for the purpose, existence, use, development, and maintenance of artifacts.

- Epistemology refers to assumptions concerning definitions, methods, origins, and relations of knowledge (Guba, Lincoln, et al., 1994; Fitzgerald and Howcroft, 1998; Funk, 2001: Saunders and Lewis, 2012; Myers, 2013. Crusoe, 2019b).

- Methodology constitutes assumptions concerning methods and practices to construct knowledge from the elements of ontology, anthropology, artifactology, and sociology (Guba, Lincoln, et al., 1994: Fitzgerald and Howcroft, 1998. Crusoe, 2019b).

- Axiology encompasses assumptions including a researcher's ethics, morals, and values (Fitzgerald and Howcroft, 1998; Saunders and Lewis, 2012. Myers, 2013: Crusoe, 2019b).

I recognize that depending on a researcher's paradigm, the meaning and relationships of the elements can differ. I understand reality to encompass all things where 
humans emerge from other things and processes. These actors (humans) can form artifacts out of reality and themselves. Humans, together with artifacts, organize as social units or systems. Societies emerge from the interactions between social units and systems. Humans, artifacts, and social units and systems happen all at once and constrain and influence each other.

In the ensuing sections, I discuss my assumptions and their influences on my research for each of the six elements. The discussion follows the above list. The discussion starts broad by presenting the views of critical realism, interpretivism, pragmatism, positivism, and transformatism, but concentrates as it progresses through the elements and I position myself. This chapter ends with a summary of the influences of my assumptions on my research.

\subsection{My View on Reality}

The ontological element of a paradigmatic worldview is the assumptions concerning realty's nature and form (Funk, 2001: Saunders and Lewis, 2012: Crusoe, 2019b). Two sides of ontology are (1) to understand ontology to be equal to the researchers' perceptions (e.g., Guba, Lincoln, et al., 1994) and (2) to believe reality does not exist (Liston, 2016). The worldviews of previous research have approached reality differently. Critical realists believe reality to be made of events, experiences, mechanisms, and structures, emerging as different strata (Bhaskar, 2013). Interpretivists understand that humans construct reality as a social product within a social context, which can only be interpreted by researchers (Orlikowski and Baroudi, 1991). Pragmatists believe in a reality of human action and change. They see things and events as independent of observers but also emphasize reason and thought as originators of elements in the external world (Goldkuhl, 2012). Positivists see reality to be an independent physical, social world from humans, which can be discovered by researchers (Orlikowski and Baroudi, 1991; Creswell and Creswell, 2017). Transformatists believe in a social reality as created and re-created at the hands of humans. It has properties that are objective, which can dominate the experiences of humans (Orlikowski and Baroudi, 1991).

My ontological element is closest to the critical realist and the pragmatic paradigms. I believe in the social construction of knowledge similar to interpretivists. I see people as part of reality where they experience phenomena and their changes but can also act to change them. People are spread over space and time where only real things are shared between them (e.g., tools, written letters, and spoken words). People use their own contextual language to describe what they see, but their knowledge is not equal to that of reality. Thus, there can be discrepancies between them. Their bodies, actions, and interactions are ontological, while their thoughts, minds, and knowledge are epistemological, where the interstice and confluence are their biological bodies, making the epistemological a part of the ontological. At the same time, an OGD reform and an OGD ecosystem cover a vast geographical area. Therefore, I have interviewed people from various locations in Sweden but also explored international contexts. I understand that reality includes several elemental cycles and energy flows (Weathers, Strayer, and Likens, 2012) where some are made and maintained by hu- 
man actions while governed and guided by social constructs. A consequence is that my research at its ontological tip is a question of what humans in groups can become, where the OGD practitioners and I are explorers of this process.

\subsection{My View on Humans}

Anthropology encompasses assumptions concerning humans' nature and purpose (Funk, 2001: Crusoe, 2019b). The formal paradigms have various assumptions about humans. Critical realists believe that humans are open systems that have the ability to adapt and change and can communicate and be creative and resistant (Gorski, 2013). Interpretivists understand humans as subjective sense-makers who interpret the world around them and participate in social systems (Orlikowski and Baroudi, 1991. Saunders and Lewis, 2012: Myers, 2013). Pragmatists build on the interpretivists and believe humans are creatures of action, problem-solvers, and practitioners (Goldkuhl, 2012). Positivists understand the actions of humans to be partly rational filled with intentions (Orlikowski and Baroudi, 1991). Transformatists understand humans to have politics, history, and limitations. Humans, as such, have potential that can be released or realized (Orlikowski and Baroudi, 1991) Myers, 2013).

I approach human biology as a critical realist, human socialization as an interpretivist, and their overlap as a pragmatist. The worldview of the positivists has been criticized for not considering the history of humans and implying that humans do not actively construct their social reality (Orlikowski and Baroudi, 1991). The paradigms of interpretivists and transformatists suggest that an invisible discourse steers humans, while the reality is equal to their language (Gorski, 2013). The paradigms understand humans to be sites of socialization and not being biological (Archer, Bhaskar, Collier, Lawson, and Norrie, 2013); as products to be shaped based on political whims of researchers (Lewis, 1978: Lewis, 2001). Positivists, interpretivists, and transformatists neglect important elements of humanity. Critical realists focus on the basic structures and mechanisms that can shape perceivable events and experiences (Saunders and Lewis, 2012). These researchers accept the plurality of human experiences while they defend an independent reality (Mingers, Mutch, and Willcocks, 2013). They understand that humans exceed their biology and are different from their socialization (Archer, Bhaskar, Collier, Lawson, and Norrie, 2013).

I understand that humans as biological creatures exist in and experience the present. Humans can imagine a possible future and then act to change the present towards the possible (Peterson, 1999). They can think about problems and situations but also act automatically and quickly with little or no effort and no sense of voluntary control (and verification) (Kahneman, 2011). Their biology provides them with intuitive understanding $4^{1}$ of biology, economics, engineering, ethics, information, knowledge, language, logic, numbers, physics, probability, psychology, and space (Pinker, 2003a. Haidt, 2012). Their intuitions are less than perfect and can lead to discrepancies between reality and knowledge (Peterson, 1999). The intuitions contain flaws but have evolved to help humans perceive and survive their reality (Pinker, 2003a). For exam-

\footnotetext{
${ }^{1}$ Here, intuitive referees to systems organized in advance of experiences.
} 
ple, emotions might appear irrational but are interwoven with our reasoning (Damasio, 1994. Haidt, 2012). I understand that perceived flaws cannot easily be ignored or resolved because they can fulfill essential functions for humans and their social lives (Pinker, 2003a Haidt, 2012).

I understand that humans are also socialized. They learn languages, traditions, rituals, and norms. Humans investigate the world in which they live and work in hopes of understanding it (Creswell and Creswell, 2017). They educate and socialize themselves based on various disciplines of specialized knowledge that come to shape their understating of reality (Berger and Luckmann, 1966). Humans can collaborate to construct knowledge concerning ontology, anthropology, sociology, and artifactology (Berger and Luckmann, 1966. Peterson, 1999). This knowledge is part of their history and social context. It can only be accessed by using social constructs from this context (Berger and Luckmann, 1966; Fitzgerald and Howcroft, 1998, Orlikowski and Baroudi, 1991: Myers, 2013).

I am a critical realist for the biological parts of humans, while for the social parts of humans, I am an interpretivist. I am a pragmatist to cover the overlap between biology and socialization, as pragmatists focus on action and change. My anthropological assumptions have influenced my research with increased use of data verification and studies of various other disciplines beyond OGD. The institutions and dual-mind systems (thinking and automatically acting) of humans have also influenced the analysis of empirical material, as I have had to connect (imprecise) words with real things and identify things interviewees have done but not said.

\subsection{My View on Social Systems}

I define sociology as the assumptions concerning society's development, nature, form, and function (Crusoe, 2019b). It is an element that I see in and around my research, such as I have written popular science articles and a licentiate thesis. I view sociology through an ecosystem perspective (see Section 2.4, a reform perspective (see Section 2.3, and a society perspective (see Section 2.5. I study the interactions of humans, artifacts, and reality on a certain level and their ability to coalesce social systems. I understand that humans and artifacts are phenomena realized in space and time and made from matter (reality). Social systems happen all at once, and behaviors can arise from the interactions between humans and artifacts; rather than the things themselves (Meadows, 2008). They are systems of action and change (Goldkuhl, 2012). The ecosystem perspective is a level of observation or focuses on a larger unspecific chunk of humans and artifacts (cf. Jax, 2007). The concept of an ecosystem can be used dually for humans and artifacts in an empirical context and either as a metaphor or for describing particular perspectives (Jax, 2006. Jax, 2007). Similar behavior is shown by humans towards organizations as they talk about them as if they were entities (Checkland and Holwell, 1997), while not in fact being so. The reform perspective is an approach to understanding how social systems change, transform, beget, or dissolve (Caiden, 2017). I understand that it reveals questions of where humans want a social system to be, its ability to realize a higher purpose, and remedied social ills. The society perspective is an approach to understand a large collection 
of interdependent social systems within a territory. These systems have their own higher purpose and function while exchanging data, information, and resources. I believe they can consolidate around symbiosism ${ }^{2}$, a worldview, or a governmental system to coalesce a society. The reform perspective understands how a smaller selection of these social systems are transformed to beget and grow a new social system, which can remedy problems in existing social systems or environments or improve society. I understand this new social system from an ecosystem perspective. On the other hand, social systems are part of reality and coalesce from objects (e.g., stones and wood), humans, actions, and artifacts (e.g., language and norms). A consequence is that the subjective knowledge of humans can give rise to a (real) social system that can then be depicted in models and then organized somewhere else. However, it is possible that there are discrepancies between humans' knowledge and their social system. Humans can (1) believe their social system works in one way, but, in fact, it works in another way, (2) believe certain phenomena is part of their system, while not being so, (2) lack words to describe and explain what they see within their system, and (3) act and change without knowing or perceiving, as such they might only give fragmented descriptions of their social system. Therefore, my sociological assumptions have made me involve various participants and studied several documents to triangulate an OGD reform and an OGD ecosystem. I have worked to understand their ontology and their sociology as something that is becoming and existing.

\subsection{My View on Artifacts}

In the above sections, I have positioned myself amongst formal research paradigms as close to critical realism, interpretivism, and pragmatism. In this section, I discuss artifactology as epistemology, methodology, and axiology. Artifactology is assumptions about artifacts designed and made by humans. Their purpose, existence, use, development, and maintenance. The element is not defined by this text. Instead, I have come to understand it from my studies of interpretivism, pragmatism, and design science research (DSR). DSR is a research methodology where the output is an artifact. It aims to contribute to the knowledge base and be useful in its environment (Dresch, Lacerda, and Antunes, 2015), like use-inspired basic research (Stokes, 2011). The developed artifacts should achieve a goal or solve a problem. They can be constructs, models, methods, or instantiations (March and Smith, 1995). I have followed interpretivism, pragmatism, and DSR for my epistemology, methodology, and axiology. In this section, I present my assumptions about each in the order previously presented.

\section{My View on Knowledge}

Assumptions concerning definitions, methods, origins, and relations of knowledge are part of epistemology (Guba, Lincoln, et al., 1994: Fitzgerald and Howcroft, 1998 . Funk, 2001. Saunders and Lewis, 2012: Myers, 2013: Crusoe, 2019b). In general, the epistemological element focuses on methods to construct knowledge of high quality

\footnotetext{
${ }^{2}$ The social systems benefit each other to such a degree that their connections tighten while loosening for other social systems.
} 
and validity (Guba, Lincoln, et al., 1994 Funk, 2001 Saunders and Lewis, 2012 Myers, 2013). As a result, the element connects to axiology and methodology. I agree with the concept of valid knowledge, but I find that it excludes humans as the interstice between knowledge and reality. Humans construct knowledge as an artifact using methods, their experiences, and previously constructed knowledge. The knowledge becomes a localized, social artifact and can only be understood within its social context. Its creation can also be a social event that transforms other elements (Hirschheim, 1985: Orlikowski and Baroudi, 1991: Fleck, 2012: Bhaskar, 2013). The phenomenon of knowledge is a coalescence of humans' experiences, intuitions, and thoughts following collective styles of thought that can constrain and direct humans' understanding of another phenomenon. Knowledge can, partly, be recorded as information in reality (e.g., body language, documents, and speeches) to help humans bypass the need to individually reinvent certain knowledge (Fleck, 2012). It helps them overcome problems from time and space (e.g., long-distance communication and degradation of human memory) (Gleick, 2011). There are different kinds of knowledge, such as oral, perceptual, self, semantic, scientific, and tacit (Bernecker and Pritchard, 2011). My research constructs scientific knowledge, which could be critical realist knowledge that describes mechanisms that shape an event, interpretivist knowledge presents contextual generalizations, and positivist knowledge gives law-like generalizations (Bhaskar, 2013. Myers, 2013). I interpret the humans' experiences and social systems to construct knowledge as analytical generalizations (expand and generalize theories) (Walsham, 1995. Yin, 2018).

In my research, I strive towards the creation of a common ground infrastructure for the transfer of knowledge between disciplines and practices. I believe in a form of unity of knowledge (consilience) (Wilson, 1999), but do not aim for a unification of knowledge with a focus on prediction similar to Wilson (1999) or the creation of research programs like Lakatos (Chalmers, 2013). I seek unity of knowledge for the design and action of human phenomena where knowledge is produced by use-inspired basic research that can help humans coalesce certain social systems. I understand knowledge to be constructed as interrelated "parts" that researchers can analyze, extract, and synthesize to create new knowledge (Becker, 2008. Maxwell, 2012b). Parts that I extract and recombine into new knowledge. I seek to develop understanding and am also inspired by considerations of use (Stokes, 2011). I see the information recorded in the literature as the authors' best attempt to capture and convey their knowledge and possible experiences of a phenomenon. I develop my worldview through the study and consumption of broad and specialized knowledge (Lin, 2019). My position is similar to the pluralist position of pragmatists but closest to the DSR approach. My research is use-inspired basic research (Stokes, 2011). Thus, it is common that I attempt to synthesize use-inspired frameworks based on empirical material and previous research. The RE-ECO framework is one such example.

\section{My View on Practice}

While epistemology is concerned with the knowledge artifacts, methodology constitutes assumptions about methods and practices to construct knowledge (Guba, Lincoln, et al., 1994 Fitzgerald and Howcroft, 1998. Crusoe, 2019b). Researchers interpret their experiences of artifacts, humans, reality, and social systems, which they encode 
as knowledge following a research process. Myers (2013) divides methods of research into two broad categories: quantitative and qualitative. The first category of quantitative methods tends to be related to positivism, as the methods are constructed to research natural, physical phenomena by measuring and recording them as statistics and numbers. The second category of qualitative methods tends to be related to interpretivists since the methods are constructed to research social phenomena with a specialization on documents, texts, and words (Myers, 2013). In my doctoral research, I research systems where humans using artifacts attempt to realize a higher purpose. As such, I understand it to be advantageous to use qualitative methods over quantitative methods.

The phenomena under study are independent of the knowledge recorded about them (Fleck, 2012: Mingers, Mutch, and Willcocks, 2013) and there are several approaches to learn about them. Critical realists advocate mixed-methods dependent on the studied phenomena (Fitzgerald and Howcroft, 1998: Mingers, Mutch, and Willcocks, 2013). Interpretivists' methods use a native view to access contexts and social phenomena through case studies and analysis of, for example, body languages, texts, and words (Orlikowski and Baroudi, 1991: Myers, 2013). Interpretivism is subjective and attempts to avoid imposing externally defined categories on phenomena, while critical realism allows different kinds of knowledge objects (Orlikowski and Baroudi, 1991. Fitzgerald and Howcroft, 1998: Mingers, Mutch, and Willcocks, 2013). The two paradigms permit the use of triangulation of phenomena (Myers, 2013). On the other hand, pragmatists focus on what works as solutions to problems and, similar to critical realists, allow for a plurality of methods. Researchers have a freedom of choice to fit their research to their needs and purpose and intended outcomes (Creswell and Creswell, 2017). DSR works to identify problems, define objectives, design and develop solutions, demonstrate and evaluate the solutions, and then communicate the solutions to others. The research process is iterative and can start at different steps of the process (Peffers, Tuunanen, Rothenberger, and Chatterjee, 2007), as such I understand DSR to be related to pragmatism (similar to Goldkuhl, 2012).

In my research, I use a mix of methods with an inclination towards qualitative, interpretivist methods to access, crystallize, and understand the studied social phenomena, as an OGD ecosystem exists as an open system. However, the focus of my epistemological element on frameworks means my research draws directly or indirectly on DSR. I do not see myself as an objective outsider studying OGD actors through a telescope. I see myself as part of the knowledge development where previous research has guided my data collection and supported my analysis of empirical material (Eisenhardt, 1989. Walsham, 1995). As I have developed my knowledge concerning OGD, I have started to understand the phenomenon clearer and better (Fleck, 2012). I attempt to record my knowledge as information with hopes that it can give rise to similar knowledge within others. I have communicated my research to academics and practitioners as research articles and popular science articles. I am a part of the OGD reform and the OGD ecosystem in Sweden, while they have influenced me. I reflect on my role as a researcher in Section 7.4 from an axiological perspective. 


\section{My View on Value and Ethics}

Axiology covers assumptions about ethics, morals, and values and is, in the broadest, the character of value and judgments about positives and negatives (Funk, 2001). The scope of this element in my doctoral research is value and ethical assumptions for research (Saunders and Lewis, 2012). As for my epistemological and methodological assumptions, I accept interpretivist and pragmatic values. For example, I believe human interactions and research using mixed methods can create valuable knowledge with utility. Moreover, rigor and relevance can be dichotomized (Fitzgerald and Howcroft, 1998: Myers, 2013). Rigor is often thought to be scientific and positivistic with an aim towards theoretical contributions, while relevance tends to be related to ideas of "consulting" and expeditious practical contributions. Nevertheless, I believe both are essential for my research. I use them together with the assumption that qualitative methods can contribute to theory and practice. I base my assumption that research is an original investigation where the studied phenomena are not transformed or consumed in the process. Instead, the results are knowledge and understanding of the studied phenomena (Myers, 2013). Therefore, I believe research can result in contributions relevant for theory and practice. My research is use-inspired basic research (Stokes, 2011).

The field of ethics concerns concepts of right and wrong, which it systematize and defend to recommend certain behaviors and actions (Fieser and Dowden, 2011). I divide my ethical activities into two areas: (1) reflection and (2) research.

First, Rachels and Rachels (2012) explain that it is important to reflect on ethics for various actors in social systems. Fieser and Dowden (2011) add that this reflection can be based on virtue ethics (good and bad habits of character), duty ethics (obligations and duties to others, as actions that must be done or not), and consequentialist ethics (good and bad consequences for yourself and other actors). I use this base to reflect on possible habits and obligations of OGD actors in relation to possible consequences, but also trade-offs between various solutions and actions (Sowell, 2019). Three examples of ethical reflection are (a) Gebka and me naming seekers to highlight their ability to act and their needs within their lives (see Section 2.2, (b) including problems experienced from an OGD ecosystem (see Section 2.3, and (c) the possible tension between public organizations' mission and expectations of an OGD reform (see Section7.1.

Second, research ethics is concerned with how I apply ethics when I plan, conduct, and report my research $(\mathrm{McNabb}, 2002$ : Myers, 2013). I follow and revisit the ethical principles of Myers (2013) and the codes of conduct from Guchteneire (2006) and Davison, Munro, and Straub (2004). I have revisited them as part of doctoral courses, writing on my doctoral thesis, and refreshing my memory. I follow the ethical principles and codes of conduct when I plan, conduct, and report my research. The use and weight of various ethical principles can vary based on the methodology used. For example, I have experienced that case studies can reveal private and sensitive information about participants, while design science methods can put participants through processes designed by colleagues and me. 
Generally, when I plan my research, I integrate some principles directly into method templates. For example, at the start of my interviews, I explain my interests, how the empirical material will be used, and the purpose of my research (Myers, 2013). I ensure to use research methods that have limited influence on my participants and reflect on potential trade-offs with releasing my knowledge to participants and society (Guchteneire, 2006). If I lack expertise about a certain methodology, I study it to the best of my capability or collaborate with researchers who possess expertise (Guchteneire, 2006). When I conduct my research, I follow the golden rule (treating others as you want to be treated) (Myers, 2013). I am honest about my knowledge and experiences and work to be clear about what is known in previous OGD research and not. I inform my participants about my research and invite them to participate in it, which means I avoid spying on their semi-private activities in forums and their lives (Myers, 2013). However, I have used recorded material publicly available on the Internet through streaming services (e.g., YouTube). I do not consider this private material. I also ask for preference when it comes to interview medium (e.g., phone, Skype, or face-to-face) and consent to record the interview. I also verify my analysis and findings with participants to avoid misunderstandings. When I report my research, I distribute the results to participants and researchers alike where participants are written as anonymous (Guchteneire, 2006). I do not fabricate or falsify empirical material, and to the best of my ability, I work to avoid plagiarism ${ }^{3}$ (Davison, Munro, and Straub, 2004). I iterate between my research and empirical material and previous research to ensure that they are consistent and ethically presented. I do my best to be clear about the origin of ideas and concepts (Davison, Munro, and Straub, 2004). For example, I recognize Elisabeth Gebka's contribution to my research about seekers.

\subsection{My Paradigmatic Worldview's Influence on my Research}

I have above presented my paradigmatic worldview and its influence on my doctoral research and discussed my role within my doctoral research. Table 3.1 gives a summary of how my assumptions have influenced my research.

Table 3.1: My paradigmatic worldview's influence on my research.

\begin{tabular}{lll}
\hline Element & Assumptions & Research Influence \\
\hline Ontology & Reality constitutes conditions, & I have interviewed people \\
& bodies, events, mechanisms, & from different locations and \\
structures, strata, change, pro- & backgrounds as well as stud- \\
& cesses, actions, and energy & ied human-created processes, \\
spread over time and space. & $\begin{array}{l}\text { conditions, and energy con- } \\
\text { sumption. }\end{array}$ \\
\hline
\end{tabular}

${ }^{3}$ I have submitted my doctoral thesis to Similarity Check, which is a software to check for plagiarism. It was provided by the library of Linköping University. 
Table 3.1

\begin{tabular}{|c|c|c|}
\hline Element & Assumptions & Research Influence \\
\hline Anthropology & $\begin{array}{l}\text { Humans exist in reality as bi- } \\
\text { ological and in societies as } \\
\text { socialized. They bridge the } \\
\text { gap between processes and ac- } \\
\text { tions. }\end{array}$ & $\begin{array}{l}\text { I used increased data verifi- } \\
\text { cation, studied several topics, } \\
\text { and reflected on meanings and } \\
\text { what is done but not said. }\end{array}$ \\
\hline Sociology & $\begin{array}{l}\text { Humans can coalesce a so- } \\
\text { cial system to achieve a higher } \\
\text { purpose, which they might not } \\
\text { fully understand. }\end{array}$ & $\begin{array}{l}\text { I have studied the transforma- } \\
\text { tion of social systems to coa- } \\
\text { lesce a new social system and } \\
\text { used increased triangulation. }\end{array}$ \\
\hline Epistemology & $\begin{array}{l}\text { Knowledge consists of com- } \\
\text { binable parts, which can be } \\
\text { uncoupled and synthesized } \\
\text { with empirical material to } \\
\text { make analytical generaliza- } \\
\text { tions. Knowledge exists with } \\
\text { some degree of consilience. }\end{array}$ & $\begin{array}{l}\text { I tend to synthesize frame- } \\
\text { works based on generalizable } \\
\text { patterns identified in previous } \\
\text { research and empirical mate- } \\
\text { rial. I draw on previous } \\
\text { research from various disci- } \\
\text { plines. }\end{array}$ \\
\hline Methodology & $\begin{array}{l}\text { Human experiences and their } \\
\text { social systems can be cap- } \\
\text { tured through interpretivist } \\
\text { methods as empirical mate- } \\
\text { rial. Other methods can sup- } \\
\text { plement these methods. }\end{array}$ & $\begin{array}{l}\text { I have interviewed and ob- } \\
\text { served humans perceived as } \\
\text { relevant to OGD, studied rele- } \\
\text { vant documents and websites, } \\
\text { and used a mix of methods, } \\
\text { with an inclination towards } \\
\text { qualitative methods. }\end{array}$ \\
\hline Axiology & $\begin{array}{l}\text { Use-inspired interpretivist, } \\
\text { pragmatic values where rigor } \\
\text { and relevance are keystones. } \\
\text { Reflective ethics covering } \\
\text { virtues, duties, and conse- } \\
\text { quences. }\end{array}$ & $\begin{array}{l}\text { I understand myself as part } \\
\text { of the Swedish OGD prac- } \\
\text { tice. Rigor motivated me to } \\
\text { be thorough in my research, } \\
\text { while relevance motivated me } \\
\text { to share my findings with } \\
\text { practice. I followed ethical } \\
\text { principles and codes of con- } \\
\text { duct when I planned, con- } \\
\text { ducted, and reported my re- } \\
\text { search. }\end{array}$ \\
\hline
\end{tabular}

In the next chapter, I present my doctoral research process. I give an overview of my doctoral research process, connect my research questions to my five included articles, present the methods of the included articles, describe the method for the synthesization of the RE-ECO framework, and present the limitations of my doctoral research. 



\section{CHAPTER}

\section{Doctoral Research Process}

This chapter presents an overview of my doctoral research, then connects my research questions with each of my five articles, summarizes the method for each of my articles and lists my other works, and describes the synthesization method for the reform-ecosystem (RE-ECO) framework, and, finally, gives the limitations of context and methods. The RE-ECO framework is the name for the conceptual framework synthesized in this doctoral thesis (see Chapter 5). My doctoral research started in 2016 and was concluded in 2021 with a licentiate thesis as a milestone in 2019. My research has mainly focused on Sweden but has been verified in Belgium. Belgium was selected as the country and Sweden are both parts of the European Union and have similar population size, Sweden has higher digital maturity than Belgium (DESI, 2019), Belgium has higher OGD maturity than Sweden (OECD, 2019b), and I had an established relationship with OGD researchers in Belgium. The differences in digital maturity and OGD maturity could lead to interesting insights and help identify essential conditions, elements, and interactions. My research is based on studies of OGD practitioners and previous research about OGD, information systems, and public utilities. My doctoral thesis encompasses five articles: (1) a comparison between a Swedish provider and a Belgian provider based on a provider framework, (2) an enricher process framework synthesized from empirical material and previous research, (3) a diagnosis of the Swedish OGD ecosystem, (4) a comparison between previous research about OGD ecosystems and public utilities, and (5) a tentative model capturing OGD from the perspective of seekers. My doctoral thesis presents the RE-ECO framework (see Chapter 5), which is synthesized from the included five articles, their empirical material, and previous research. The RE-ECO framework is a conceptual framework of the interplay between an OGD reform and an OGD ecosystem from the perspective of evolution and health. A conceptual framework is a set of concepts and ideas with their proposed relationships. It is a tentative or incomplete theory about a phenomenon (Maxwell, 2012a). The RE-ECO framework is a step towards creating a theory of design and action ("how to do" something) (Gregor, 2002: Gregor, 2006) for an OGD ecosystem. This type of theory could explain the general process of an OGD reform and the maturity process of an OGD ecosystem. It could help OGD actors 
partially transform their society to beget and grow an OGD ecosystem that realizes their higher purpose without harming others.

\subsection{Overview of my Doctoral Research Process}

My doctoral research is qualitative research (Myers, 2013) with elements of mixed methods (Creswell and Creswell, 2017), design science research (Peffers, Tuunanen, Rothenberger, and Chatterjee, 2007), and engaged scholarship (Ven et al., 2007). It is also use-inspired basic research that seeks to develop understanding while being inspired by considerations of use (Stokes, 2011). My licentiate thesis focused on Sweden and drew lessons about cultivation and its challenges. It germinated my doctoral research. As part of my licentiate, I conducted national explorations of OGD in Sweden from 2016 to 2017. The exploration involved a pilot study in 2016 and following the Swedish OGD community in 2017. I wrote two articles in 2017 and one article in 2018 (see Crusoe, 2019b). The article of 2018 has received continued development and is now part of my doctoral thesis. It develops a diagnostic framework to diagnose the OGD ecosystem of Sweden (Crusoe, 2021a ead. Article C) Moreover, I, together with Karin Ahlin, studied the work of enrichers in 2019 to synthesize an enricher process framework (Crusoe and Ahlin, 2019b, ead. Article B) Our research was germinated in 2018 as part of a research collaboration. An early version of our framework was presented and discussed at an e-government workshop and evaluated in Belgium by Anthony Simonofski, Antoine Clarinval, Elisabeth Gebka, and me (Crusoe, Simonofski, Clarinval, and Gebka, 2019). The enricher framework is published in Transforming Government: People, Process and Policy (TGPPP). We selected TGPPP, as it is international, inter- and multi-disciplinary, and focuses on how people, processes, and policy can transform governments, which fits with the reform perspective. Other OGD research has also been published in the journal. Ahlin and I continued to study the work of providers in 2020 to synthesize a provider work framework. We presented and discussed an early version of our framework at an e-government workshop. It was also presented to researchers in the Netherlands and discussed with an OGD professor. I then evaluated the framework in Belgium with Anthony Simonofski and Antoine Clarinval. This evaluation is included in my doctoral thesis (Crusoe, Simonofski, and Clarinval, 2020 ead. Article A] The evaluation was a comparison between a Swedish provider and a Belgian provider. In addition, the previous evaluation of the enricher framework in Belgium also germinated a research collaboration between Elisabeth Gebka, Karin Ahlin, and me. We developed a tentative model to understand OGD from the perspective of seekers' information needs (Crusoe, Gebka, and Ahlin, 2020b ead. Article E] At the end of 2019, I initiated a research project with Anneke Zuiderwijk and Ulf Melin. We compared previous research about OGD ecosystems and public utilities to draw lessons from a public utility perspective about OGD ecosystems (Crusoe, Zuiderwijk, and Melin, 2020 ead. Article D) The provider framework (Crusoe, Simonofski, and Clarinval, 2020 ead. Article A) the information needs model (Crusoe, Gebka, and Ahlin, 2020b ead. Article E] and the public utility comparison (Crusoe, Zuiderwijk, and Melin, 2020, ead. Article D) were presented and published at the EGOV-CeDEM-ePart conference. We decided to publish the articles at this conference because the conference fitted in relation to the progression of my doctoral thesis research, and important OGD researchers within digital or e- 
government would participate. Then, I commenced to write my doctoral thesis and synthesize the RE-ECO framework in the middle of 2020. My research has been an iterative process driven by curiosity, peer feedback, and learning. Thus, I know that the terminology used in the articles is not always a perfect fit with the terminology used in this doctoral thesis. At the same time, it is common that qualitative researchers collect a huge amount of empirical material from a study, which cannot be included in a single article or doctoral thesis (Myers, 2013). As such, I have been able to reuse some empirical material from Crusoe (2016) in Crusoe (2021a. ead. Article C] and some empirical material from both in Crusoe and Ahlin (2019b ead. Article B] I have also been able to reuse some empirical material from the five included articles in my doctoral thesis (see Section 4.4).

\subsection{Research Questions and Articles}

This section connects my research questions with my five articles. In my doctoral research, I seek to disentangle the interplay between an OGD reform and an OGD ecosystem from the perspective of evolution and health; as was seen in previous OGD research, they are mixed (see Section 2.2. I further specify my purpose by exploring how this interplay can affect the health of the OGD ecosystem. This focus is intentional, as was seen in Section 2.4 I assume that OGD actors evolve towards better health where an OGD reform enables them to participate and work in their OGD ecosystem (see Section 2.3. The concept of work refers to processes and activities these actors conduct for the purpose of their OGD reform or their OGD ecosystem. The term has intentionally been left open to allow for an inductive exploration of empirical material but also previous OGD research. It has grown more specific as OGD actors have explained their work to me, and previous OGD research has informed me. I divide the exploration of the interplay into two undertakings and one enrichment.

The first undertaking is to understand the work of providers and enrichers (where the crude question is "how do they reform themselves and then work within their OGD ecosystem based on the changed conditions?"). This undertaking generated the first sub-research question, which was answered by Article A and Article B The articles present a different view of the work of providers and enrichers. Article A presents a comparison of two providers based on a conceptual framework to describe their work. One provider is from Sweden, while the other is from Belgium. The framework divides the work of providers into six process groups (initiation, inventory, publish, sustain, withdrawal, and user engagement). Article B describes the variations of the enricher process from start to deployment, captured in a process framework. This framework has been developed in Sweden and evaluated in Belgium. I see that the two articles satisfactorily answer the first sub-research question.

The second undertaking is to understand the interactions of providers and enrichers and how their work can impact each other. Specifically, I wanted to know how their work could affect the health of their OGD ecosystem. This health is bound with the OGD actors, as they share its fate, which means that if they cannot provide or enrich data, something is (likely) unhealthy. I decided to focus on impediments, as they can obstruct or prevent the work of OGD actors. The second sub-research question 
explored this issue and was answered by Article $\mathrm{C}$ Article $\mathrm{Cgives}$ an introduction to ecosystem health and presents a diagnostic framework to diagnose the health of an OGD ecosystem. It can be used to diagnose faults (illness) based on OGD actors' work and experienced impediments (as indicators). The diagnosis is based on a blueprint, health dimensions, and general indicators of faults. The blueprint is a conglomeration of plans and designs that explains how to organize an OGD ecosystem. The used health dimensions are evolution, realization, resilience, and stability. The blueprint and health dimension give meaning to health as good or bad. The general indicators are harm, absence, deviation, isolation, and fail to realize. They help to identify how impediments can obstruct or prevent the purpose of an OGD ecosystem. I see that Article Canswers the second sub-research question, as faults can obstruct or prevent the process of coalescence for an OGD ecosystem. This situation means that OGD actors cannot properly interact or benefit from their interactions to coalesce as an OGD ecosystem. They are dispersed or unfit parts, which affects the health of their OGD ecosystem.

Finally, actors working with data and information are not something new, and other researchers have paid attention to this phenomenon (see Section 2.5). It gives me the opportunity to draw on knowledge from other disciplines to enrich my understanding of OGD and my findings. I am curious about the knowledge of information needs (from information systems) and holistic perspectives (from public utilities), as was explained in Section 1.1 I believe this knowledge can enrich OGD research. Therefore, it generated my third sub-research question. This question was answered by Article $\mathrm{E}$ and Article $\mathrm{D}$ Article $\mathrm{E}$ presents a model for how the data of providers are connected to the information needs of seekers through the solutions of enrichers. It presents important considerations about seekers that providers and enrichers should take into account in their work. Article D compares previous OGD ecosystem research with public utility research based on the dimensions of the system, the public, the infrastructure, the resource, and the governance. The two articles fill some of my curiosity, but $\mathrm{I}$ had to add extra previous research about information society in my doctoral thesis. I take this extra step to give an OGD reform and an OGD ecosystem an environment and a context to act within, as it else would place them in a semi-isolated bubble. It provides an OGD reform with preexisting conditions to transform while including a source of impediments. I believe this addition with the two articles has answered my third sub-research question.

Figure 4.1 presents my research questions connected with their responding articles. My doctoral thesis answers the main research question. The figure's white arrows represent the division of the main research question into sub-questions, while the black arrows connect articles as answers to the sub-questions.

\subsection{The Methods of my Five Included Articles and Other Works}

This section summarizes the methods of my five articles included in my doctoral thesis with an overview of their research process, their cases (if applicable), their research process, and their contribution to the RE-ECO framework. Each article is 


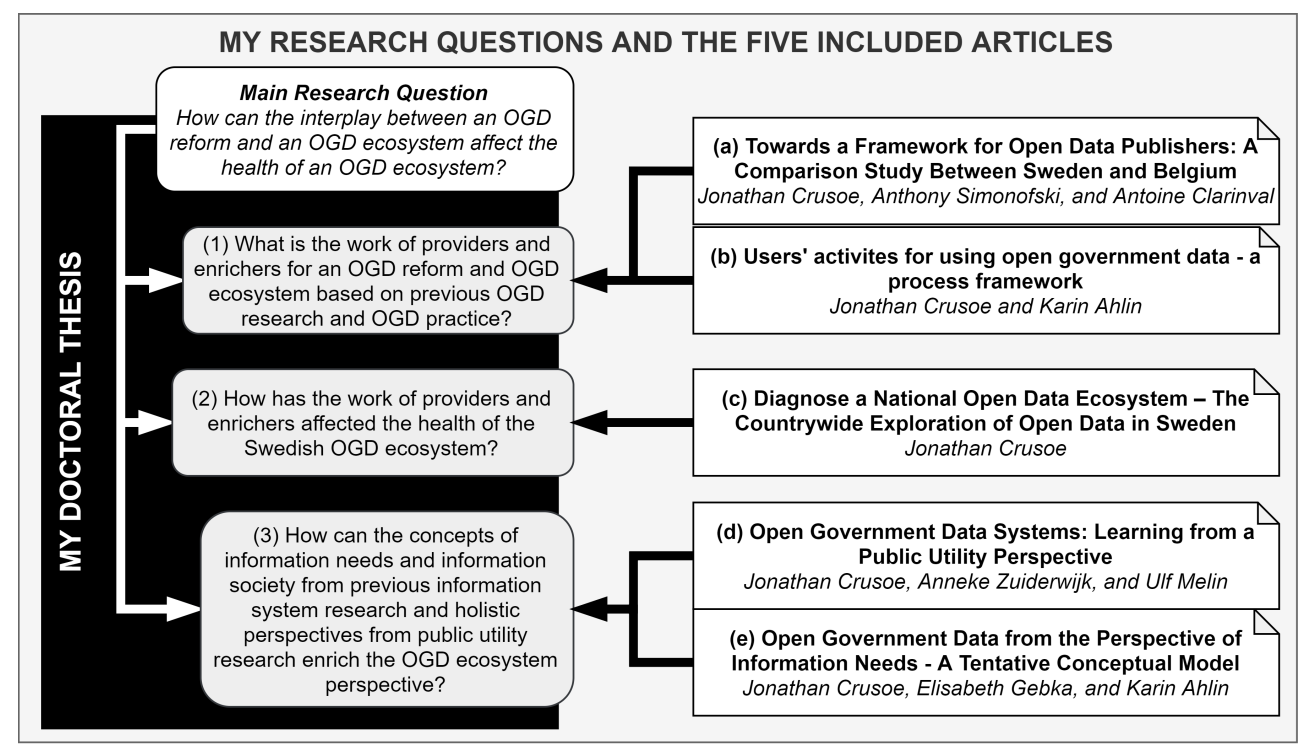

Figure 4.1: My research questions connected to the five included articles.

presented with its title and its participating authors with their research roles. When I present a methodology or method for the first time, I give them a short description and their advantages and disadvantages. Beyond the five included articles, I have presented and discussed seven articles at e-government workshops, presented and defended one thesis plan at an e-government colloquium, and participated in the following studies; Crusoe and Melin (2018a), Crusoe, Simonofski, Clarinval, and Gebka (2019), Berntzen, Johannessen, Andersen, and Crusoe (2019), Gebka, Crusoe, and Ahlin (2020a), and Gebka, Clarinval, Simonofski, and Crusoe (2019). My licentiate thesis encompasses three articles where Crusoe (2021a) is a continuation of one of these article, while the articles of Crusoe and Melin (2017) and Crusoe and Melin 2018a) are unique to my licentiate thesis. Chapter A presents a full list of my previous works.

\section{Article A-A Provider Comparison}

Title: “Towards a Framework for Open Data Publishers: A Comparison Study Between Sweden and Belgium"

Authors: Jonathan Crusoe (Data Collection, Analysis, Methodology, Theory), Anthony Simonofski (Data Collection, Analysis), and Antoine Clarinval (Data Collection, Analysis) 
Overview. This article presents the comparison between two providers (ead 1 publishers). The providers were studied using qualitative case studies. A case study is a methodology where a researcher studies a specific phenomenon in the present real-life to derive general conclusions (Myers, 2013). Its advantages are data collection triangulation, the ability to involve previous research in multiple ways and evaluate theories in real life, philosophical neutrality, face validity, and allow a researcher to come close to practice (Myers, 2013). Its disadvantages are that a researcher can experience access difficulties and can have little sway over the phenomenon, participants can be worried about laboriousness and consequences, it is difficult for beginners to identify essential aspects, it can be laborious, and seldom involve observations and fieldwork (Myers, 2013). Specifically, we used a two-case embedded case study, meaning we studied two cases in different contexts where the cases are divided into specific analytical units. It can be used to evaluate and verify theoretical frameworks (Yin, 2018). Its advantage is that it is considered more robust since the evidence is often considered more compelling. Its disadvantages are that it requires more resources and time, and uniformity amongst the cases (Yin, 2018). Moreover, the collection of empirical material happened through semi-structured interviews and document analysis, which was analyzed using coding based on a tentative framework developed in a previous study (Crusoe and Ahlin, 2020). The semi-structured interviews were supported with an interview guide. An interview guide helps a researcher stay focused on certain topics and ensures his questions are answered, while the semistructure allows him to generate new questions. The advantages of a semi-structured interview are that it can engage people in different contexts and roles to generate rich empirical material, while it starts with an expandable list of planned questions (Myers, 2013). Its disadvantages are that a researcher might focus on perceived elites or be blocked by gatekeepers, the interview is artificial and can go wrong, it can contain a lack of trust, time, and Hawthorne effect, and it can construct knowledge, and the communication can contain ambiguous language (Myers and Newman, 2007). Document analysis is the study of important documents and presentations. The method's advantages are its efficiency, availability, cost-effectiveness, detachment from the researcher, stability, exactness, and coverage (Bowen, 2009). Its disadvantages are the limited ability to find and retrieve the documents, the possibility that the documents lack details, and the authors can be biased (Bowen, 2009).

The Cases. The two cases are Namur (Belgium) and Linköping (Sweden). Namur is the regional capital of Wallonia with a population of 110,939 . Its main industry is service. The municipality had published 127 datasets on its OGD portal. Linköping is the regional capital of Östergötland with 161,499 inhabitants. It focuses on ICT and knowledge development, manufacturing, and cultivates a service sector. On its OGD portal, it has 18 datasets. The municipalities have one university each.

Research Process. We collected the empirical data through interviews and document studies. We analyzed it using process and initial coding, which has similar advantages and disadvantages to content analysis. Content analysis is befitting for the analysis of delicate, heterogeneous phenomena. The advantages of content anal-

\footnotetext{
${ }^{1}$ I use "ead." to mean "the same as."
} 
ysis are its ability to manage large volumes of empirical material and corroborating evidence (Elo and Kyngäs, 2008). Its disadvantages are its openness for redundant analysis and its need to use vague, broad questions (Elo and Kyngäs, 2008). We based the comparison on six process groups from a tentative framework using the guidelines from Rose and Mackenzie (1991). The advantages of comparison are its ability to identify patterns, draw lessons from differences, and give structure to comparing two heterogeneous phenomena in different contexts (as experienced). Its disadvantages are that similarities could only be superficial and misleading (Mars, Bronstein, and Lusch, 2012), requires clear, comparable concepts (Rose and Mackenzie, 1991), and broad or faulty category selection could result in a misleading comparison (as I have experienced).

Contribution to the RE-ECO Framework. This article contributes with a framework describing the OGD work of providers. It provides common areas of the organization but also highlights differences. It gives insight into OGD managers as agents of change, OGD units as cross-organizational, and the importance of orthodox methods. The need for balance between implementation and guidance with the internal spread of OGD needs consideration.

\section{Article B- An Enricher Process}

Title: "Users' activities for using open government data-a process framework" Authors: Jonathan Crusoe (Data Collection, Analysis, Methodology, Theory) and Karin Ahlin (Data Collection, Analysis, Critical Friend)

Overview. The second article presents an enricher (ead. users) process framework with activities and variations. The research used a qualitative research approach since we required a deeper understanding of enrichers' activities (Myers, 2013). The framework was synthesized from iterations between previous research and empirical material. It was developed using concept mapping. Concept mapping is an analytical method to develop tentative or incomplete theories by first defining concepts and then their relationships based on various sources (e.g., previous research and empirical material) (Maxwell, 2012a). The method's advantages are its ability to produce a framework that helps to justify and guide research, pull together and clarify implicit theories, identify holes and contradictions in theories, and the result is concrete and can be developed and evaluated (Maxwell,2012a). The method's disadvantages are its need for considerable reworking to get to a point where the framework can be useful, the result is always simplified and incomplete, and it is possible to lose the article-trail of your work (Maxwell,2012a). The advantages of concept mapping are its openness to experiences, empirical material, and previous research, while the possibility to evaluate them in practice, adaptability to other methods and methodologies, force the research to place concepts in relation to each other, which can reveal flaws or gaps in the thinking (as I have experienced). Its disadvantages are that it can require several iterations before it can be useful, and it is an incomplete and simplified depiction of reality (Maxwell, 2012a). At the same time, the study moved from inductive reasoning (exploratory where empirical material is used to build a 
theory) to deductive reasoning (confirmatory where a theory is evaluated) (Myers, 2013).

Research Process. The research process of this article followed three stages. In the first stage, we started by exploring enrichers' activities and impediments but shifted to activities and their variations over time. In this stage, we sketched, filled, and completed a tentative framework. It followed an abductive approach that iterated between exploration of previous research, framework development, data collection, and analysis. It leaned towards induction than deduction at this stage, which allowed the empirical material to be expressed. We started by selecting a foundational sketch based on a previous study of the enricher process. A literature review was used to find previous OGD research (Machi and McEvoy, 2016). One of the method's advantages is that it can narrow in on a specific topic within a wider pool of topics to identify relevant literature. The method can also limit the bias of the literature through comparisons and synthesization (Greenhalgh, 1997; Kitchenham, 2004). The disadvantages of this method are that it can substantially consume the time and energy of a researcher (Kitchenham, 2004), but it is also easy to get stuck when few articles have been published about a topic since it lacks adaptability (as I have experienced). Then, the sketched framework was filled out using previous OGD research and inductive analysis of empirical material from desktop research. The desktop research investigated open data portals, open data forums, and other interesting open data websites. The method's advantages are its low cost, collects much empirical material quickly, low impact on actors, and exploratory unfolding of understanding. Its disadvantages are its ability to generate large quantities of useless empirical material, only actors that are active in OGD and on the Internet are visible, and uneven data collection for different actors (comparison can be difficult to make). The advantages and disadvantages of content analysis have been explained above (Elo and Kyngäs, 2008). We then attempted to complete the framework with previous OGD research and empirical material. The empirical material collected through semi-structured interviews via Skype or e-mail and coded using inductive content analysis. Voice (Telephone and Skype) interviews can be used as another option to interviews where researcher and participant meet face-to-face (Novick, 2008). The advantages of voice interviews are that the technology allows for wider geographic availability and takes smaller space, the researcher gains safety and saves costs by avoiding traveling, and he can privately write notes, the participant can remain in his space and gives him increased anonymity and privacy, and the researcher and the participant can experience less social pressure (Novick, 2008). Its disadvantages are that the technology can restrain body language communication and that a participant can lack the technology or be out of range and be distracted by events in his surroundings (Novick, 2008). On the other hand, e-mail interviews use the Internet to asynchronously communicate between a researcher and a participant. The researcher divides his research questions into small batches that are sent to the participant who can answer when available over several days (McCoyd and Kerson, 2006). The advantages of this method are that the technology allows for broad communication to several participants over a long period, the responses are already transcribed into texts and can easily be analyzed, the geographical coverage allows for comparisons between responses, and the participant can experience less social pressure and take his time to answer (Mc- 
Coyd and Kerson, 2006). Its disadvantages are that the researcher cannot observe the body language of the participant, and the technology can hassle and break down (McCoyd and Kerson, 2006). The e-mail interviews have also been used in Article C "Diagnose a National Open Data Ecosystem - The Countrywide Exploration of Open Data in Sweden" In addition, I have experienced that it is difficult to guarantee the participant's identity, and the participant can stop answering the e-mails at any time. The inductive content analysis started with the researchers individually analyzing the empirical material to then analyze it together, which is one way to ensure the quality of the findings (Hsieh and Shannon, 2005: Bengtsson, 2016). In the second stage, we verified and reflected on the tentative framework in three parallel processes: (1) academical discussions and peer-reviewed at an e-government workshop (Crusoe and Ahlin, 2019a), (2) evaluated with 30 master students in Belgium (Crusoe, Simonofski, Clarinval, and Gebka, 2019), and (3) discussions and reflections. The advantages of these parallel processes with reflections are adaptability to the needs of the framework, multiple forms of verification, and identify avenues of development. Its disadvantages are that feedback and evaluation can conflict, time consumption for coordination, and cognitive tax (as experienced). In the third stage, we then evaluated and enhanced the framework. This stage involved refreshing, evaluating, and adding finishing touches to the framework. This stage was deductive in nature compared to the abductive nature of the first stage. The mix of approaches helped us to reduce the possible blindness of deduction (Maxwell, 2012a) and wildness of induction (as experienced). We first refreshed the framework and then created a template based on the framework. We filled the template with empirical material from new semi-structured interviews via Skype or phone. This approach is a form of deductive content analysis where the researchers start with a theory to validate or extent (Hsieh and Shannon, 2005). Its advantages are that it is more structured and works directly with previous research, can help focus research questions, guides towards interesting concepts and relationships, and gives a foundation for preliminary codes (Hsieh and Shannon, 2005). Its disadvantages are that it can come with a strong bias towards supportive evidence, probe questions can get interviewees to answer the "correct" way, and it can blind the researcher to contextual aspects (Hsieh and Shannon, 2005). In the end, the respondent validated the final framework (Mays and Pope, 2000).

Contribution to the RE-ECO Framework. This article contributes with a detailed description of the enricher process with variations. This contribution is a puzzle piece for the synthesis. It also stresses the importance of the need for enrichers to learn, but also problems of backtracking and forward-thinking.

\section{Article C-An OGD Ecosystem Diagnosis}

Title: “Diagnose a National Open Data Ecosystem - The Countrywide Exploration of Open Data in Sweden"

Author: Jonathan Crusoe

Overview. The third study presents a diagnostic framework synthesized from previous research, which was used to diagnose the national OGD ecosystem in Sweden. Impediments as indicators experienced by providers, enrichers, and cultivators 
were analyzed with their activities into an ecosystem model and then diagnosed to identify faults as illness. The study was performed as an exploratory case study and went through several iterations. This type of case study is like a qualitative case study but discovers the phenomenon within its present, real-life context (Myers, 2013). The study started with a literature review to synthesize the diagnostic framework and then to explore the national OGD ecosystem in Sweden. The synthesization used concept mapping with previous research about OGD and ecosystem health. The use of previous research can be helpful to guide the researcher's attention and enable him to express his findings (Fleck, 2012) but can also make the researcher blind, deform arguments to fit with prevalent narratives, and impede reflection (Maxwell, 2012a). The exploration of the national OGD ecosystem identified several potential interesting actors, documents, presentations, recorded presentations, and websites. Exploration happened through desk research, where the Internet was used to identify empirical sources. Almost every actor was asked to participate in an interview. The semi-structured interviews were analyzed for activities and impediments and resulted in an ecosystem model. A tentative diagnosis of faults was captured in a popular science article and sent to the participants for feedback and comments. Then, the empirical material was supplemented with codes from several important documents. Finally, the national OGD ecosystem was diagnosed using the diagnostic framework. This study used method and data triangulation and respondent validation to increase its validity (Mays and Pope, 2000) but also feedback from critical peers.

The Case. Sweden is a country with a population of 10 million governed by a parliamentary government. It is divided into 21 counties with 290 municipalities and is supported by 460 government agencies. In common, the Swedish government gives high autonomy to the public organizations. The country has a long-standing history with document transparency and a favorable digital maturity with several initiatives into OGD. In 2018, it launched almost 200 digitization initiatives (some about OGD) and was in the top three of DESI (the digital economy and social index) from 2015 to 2018. Its long-standing history with transparency started in 1766 when the government amended the constitution with the principle of public access to official records as part of the freedom of the press act. In 2018, few OGD portals and many providers, enrichers, and cultivators participated in the Swedish OGD ecosystem. On the national OGD portal, providers had registered a total of 1647 datasets. Nevertheless, even if Sweden has the conditions for an active OGD ecosystem, their OGD maturity is slow compared to the OGD maturity of other EU countries.

Research Process. This study started with a literature review followed by an exploration of Sweden and its OGD ecosystem to collect empirical material. The empirical material was analyzed, which could lead to iterations of previous research activities. I used a literature review method inspired by a hermeneutic literature review (Boell and Cecez-Kecmanovic, 2014). A hermeneutic literature review is a literature review method that integrates the analysis and interpretation of literature with the search for it. It focuses on a process of developing understanding through iterations (Boell and Cecez-Kecmanovic, 2014). I also used citation tracking and citation analysis to identify more literature (Boell and Cecez-Kecmanovic, 2014). The method's advantages are its ability to discover relevant literature (in odd places) not consid- 
ered at the start, adaptability to the learning process of the researcher, and reflective and cumulative knowledge acquisition over time. The method's disadvantages are its ability to consume time without a clear end in sight, shoot away into structures of irrelevant literature, and require long-term structured work (as experienced). It aimed for saturation in understanding (which was reached when relevant literature enabled the synthesization of the diagnostic framework and new literature added little). In addition, I used concept mapping to synthesize the diagnostic framework and interpreted previous OGD research from the perspectives of ecosystems, health, and faults to identify general indicators of faults. General indicators were later used to help me identify faults in the Swedish OGD ecosystem. In the end, previous research guided data collection and analysis (Eisenhardt, 1989 Walsham, 1995). It was used in the discussion and diagnosis but was not synthesized with empirical material into the ecosystem model. This approach allowed the empirical material to take a prominent role where previous research has given names and concepts to perceived phenomena. Moreover, the empirical material was inserted into a data ecosystem for analysis. The data ecosystem was a digital file ecosystem and Evernote. The primary data source was the interviews, while the secondary was documents, websites, and presentations. I conducted semi-structured interviews with providers, enrichers, and cultivators via face-to-face, voice, and e-mail. I transcribed and prepared the empirical material for analysis by recording a data memo per interview. I used the interview guide to probe the interviewees' experiences with a focus on activities and impediments in relation to OGD. When concluding the analysis, I included important documents to supplement the findings. They were national and local studies of the Swedish OGD ecosystem, OGD actors, and experienced impediments. Furthermore, I used concept mapping to construct the diagnostic framework, and I analyzed the data memos with inductive content analysis. Content analysis builds a model that conceptually describes a phenomenon where its inductive variation creates concepts based on the analyzed empirical material (Elo and Kyngäs, 2008). I validated the concepts with the interviewees and peer-reviewed by colleagues. Similarly, I recorded a tentative diagnosis as a popular science article. I sent this article to the interviewees for validation. I closed the research by analyzing important documents, which I included to supplement my findings. I included them at the end to allow the interviewees to express their experiences.

Contribution to the RE-ECO Framework. This article contributes with an approach to elucidate normative assumptions about an OGD ecosystem, map and model an OGD ecosystem, and diagnose them for problems. It gives an idea about how and why things can go well and wrong for OGD actors and their OGD ecosystem (e.g., the journey to the goal versus the goal itself). It highlights important dimensions (evolution, realization, resilience, and stability) and a needed to balance development and infrastructure. It opens for ameliorative action and research. Therefore, it helps to disentangle an OGD ecosystem and an OGD reform and how their interplay can affect the health of the OGD ecosystem. 


\section{Article D-An OGD and Public Utility Comparison}

Title: “Open Government Data Systems: Learning from a Public Utility Perspective" Authors: Jonathan Crusoe (Analysis, Methodology, Theory), Anneke Zuiderwijk (Guidance, Analysis, Critical Friend), and Ulf Melin (Guidance, Analysis)

Overview. This study presents lessons drawn from a comparison between the public utility literature and the OGD ecosystem literature. The lessons are drawn from how public utilities perceive and organize their vast and complex systems compared to OGD ecosystems. I used a hermeneutic literature review with snowballing (Boell and Cecez-Kecmanovic, 2014) to develop an understanding of public utilities and OGD.

Research Process. The study was divided into two phases. The first phase explored and mapped the public utility literature. The second explored the OGD ecosystem literature, created comparative categories, and compared public utilities and OGD ecosystems (Rose and Mackenzie, 1991). The advantages and disadvantages are similar to those mentioned above. However, this study was conceptual and was not evaluated in practice and needs further evaluation.

Contribution to the RE-ECO Framework. This article contributes by changing how an OGD ecosystem can be understood, adding things to consider when organizing them and a new role. An OGD ecosystem can be understood and depicted from a node-flow view where the OGD ecosystem is organized on a foundational data flow. This view is an original way to draw the blueprint from Article C When organizing an OGD ecosystem, combinability, interpretability, and boundless reusability need to be considered. An OGD ecosystem also needs governance organizations.

\section{Article E-An Information Need Perspective}

Title: “Open Government Data from the Perspective of Information Needs - A Tentative Conceptual Model"

Authors: Jonathan Crusoe (Analysis, Methodology, Theory), Elisabeth Gebka (Data Collection, Methodology, Theory), and Karin Ahlin (Guidance, Critical Friend)

Overview. This study developed a tentative framework from the perspective of information seekers on an OGD ecosystem. It was used to identify considerations for the providers and enrichers (ead. transformers) of the OGD ecosystem. It was developed using design science research methodology (DSR) (Peffers, Tuunanen, Rothenberger, and Chatterjee, 2007) based on previous research and empirical material. It is a methodology to develop an artifact that contributes to the knowledge base (rigor) and is useful in its environment (relevance) (Dresch, Lacerda, and Antunes, 2015). DSR's advantages are its structured process that includes problem identification, design, demonstration, and evaluation (Peffers, Tuunanen, Rothenberger, and Chatterjee, 2007), production of tangible results, and the freedom given to solve problems 
(as experienced). Its disadvantages are difficulty in transferring complex solutions, the process is resource-intensive, and the freedom to solve problems combined with previous research can be taxing to manage (as experienced).

Research Process. The research process was iterative and started with a reflection about a noted lack of OGD use to then contemplate the need for solutions based on OGD. This reflection promoted a traditional literature review (similar advantages and disadvantages to a systematic review). The next step was observations, structured interviews, and one in-depth interview to collect empirical material. It was not satisfactory, as such two workshops were organized (Gebka, Crusoe, and Ahlin, 2020a). This study has a twin study led by Gebka. Gebka has developed the data collection method, while I have analyzed and developed the tentative framework. The advantages of this workshop method are its ability to allow participants to engage and motivate each other, the rich production of pre-structured empirical material, and its structured approach to slowly express information needs (as experienced). Its disadvantages are that it is easy for participants to get distracted if not guided properly, it is time-consuming and difficult to find participants, and some participants can dominate their group (as experienced). The analysis of the empirical material was inspired by concept mapping (Maxwell, 2012a) and comparative analysis (Rose and Mackenzie, 1991). The tentative framework was reviewed and discussed at an e-government workshop for feedback.

Contribution to the RE-ECO Framework. This article contributes with a tentative framework describing the connection between information needs of information seekers, solutions of enrichers, and data sources of providers. It gives several considerations that need to be taken into account to make the work of providers and enrichers within an OGD ecosystem valuable for seekers. It enables me to understand the solutions of an OGD ecosystem as part of a society.

\subsection{Synthesizing the RE-ECO Framework}

My doctoral thesis aims to synthesize a conceptual framework based on empirical material and previous research, which is named the RE-ECO framework. This synthesis used many of the methods described with advantages and disadvantages above (see Section 4.3). The synthesis of the RE-ECO framework describes a national OGD ecosystem. I have studied and analyzed a small set of actors and their interactions to make generalizations about similar actors and their interactions within their OGD reform and their OGD ecosystem. This generalization is enabled thanks to the idea that OGD is based on certain principles and expectations (see Section 2.2 and Section 2.3. I experienced that the advantages of this synthesis are its use of previous research to guide and structure its steps and reduce empirical complexity. However, I experienced its disadvantages to be an internal conflict between varied recruitment of actors and the difficulty to observe a national ecosystem and needs for multi-level analysis (which can be time-consuming and cognitive taxing). The synthesis followed four steps: (1) I created a skeleton framework based on my research and related previous research, (2) I filled the skeleton framework with my previously collected em- 
pirical material, (3) I analyzed the filled framework and the empirical material to identify patterns of interplay, and (4) the RE-ECO framework was peer-reviewed by colleagues. For the first step, I started the synthesis of the RE-ECO framework by creating a skeleton framework. The skeleton framework was developed using concept mapping based on my five included articles and related previous research. I then conducted a literature review to supplement and develop the mapping from a metaphorical perspective. I searched for literature about oceanography, ecosystems, and reform. I divided the skeleton framework into four parts: (1) structure, (2) OGD reform, (3) OGD ecosystem, and (4) interplay. These parts were divided into subparts by analyzing previous research and were further refined in the following steps. This step was iterative as I reflected on possible gaps and attempted to internally visualize an OGD reform and an OGD ecosystem. A metaphor is an assertion that something is like something else (Morgan, 1997). The advantages of metaphorical use are that metaphors can supplement vocabularies, enable people to understand intangible socio-technical phenomena, and act as an instrument to create new meanings (Black, 1955: Mészáros, 1966. Lakoff and Johnson, 2008). The disadvantages of metaphorical use are that the speaker and listener require shared knowledge, obscure knowledge-intensive situations can limit its usability, and it can influence reasoning around societal issues for the better or for the worse (Glucksberg, 1989. Hekkala, Stein, and Rossi, 2018. Thibodeau and Boroditsky, 2011). For the second step, I filled the skeleton framework with empirical material from my five included articles. In my doctoral research, I have collected a huge amount of empirical material, which could not be included in my five articles (cf. Myers, 2013). This step iterated between framework development and analysis of empirical material. I experienced that this step had the advantage of using my five articles as verified analytical notes with prepared concepts, familiarity with the empirical material and its internal complexities, and compare and synthesize empirical material that previously had not been analyzed together. I experienced its disadvantages are possible perceptual self-affirmation of deeper patterns between articles and empirical material, contextual details that need to be refreshed and remembered, and an even larger amount of qualitative empirical material to analyze compared to a single article. For the third step, I analyzed the filled framework and empirical material to identify interplay patterns that could affect the health of an OGD ecosystem. These patterns were identified by analyzing the interactions between actors and conditions with a focus on how they could affect each other's health. Ecosystem health is based on probable causes for dysfunctions and problems (Rapport, 1995). I also believe it encompasses probable causes for the functions and benefits of an OGD ecosystem. This analysis resulted in the RE-ECO framework. The step's advantages and disadvantages are similar to deductive content analysis and abduction, as mentioned above. For the fourth step, the RE-ECO framework was peer-reviewed by colleagues, which feedback helped to evaluate and continue the development of the RE-ECO framework.

\subsection{Limitations}

This doctoral thesis has some limitations, and I have divided them into the Swedish context and research limitations. The nascent OGD maturity of the Swedish OGD ecosystem contributed to a difficulty to identify mature providers, enrichers, and cul- 
tivators who could participate in my research. The scale was tipped towards a few mature providers but even fewer enrichers. For a while, there was an open data forum where providers, enrichers, cultivators, and researchers could meet, but it was discontinued around the 2017s. The lack of forums and national networks for providers and enrichers meant I had to navigate fragmented communities and follow advice or tips to find participants. I could often find participants on the Internet if they had made their relationship with OGD known, which meant it was easy to find enthusiasts. Providers were easier to identify than enrichers, as they created open data pages or registered their data on open data portals. On the other hand, some research participants had limited resources, which was a common impediment for enrichers, as they tended to work with OGD on the side or as a little part of their job. It was difficult to recruit them for longer and deeper research. Finally, there have been developments in the Swedish government with regards to the focus of leadership and roles, which has caused a bit of chaos. Therefore, Sweden has provided me with rich empirical material about the evolution and health of an OGD ecosystem and its related OGD reform. I was able to overcome some of the above limitations by verifying my research in Belgium.

Some of my empirical material was collected and analyzed in Belgium by colleagues. I am not fluent in French and had to rely on them for translation, data collection, and analysis. It is possible that this collaboration introduced biases or miscommunications. However, we have different backgrounds and are fluent in English, which should have negated this issue. We noted that some participants in the workshops ( Article E) experienced challenges understanding the concepts of information needs, which were resolved with explanations by the workshop facilitator. It is possible that this situation is a sign of a potential difference in culture (English academical vs. Belgian practical), which could be a limitation of the artifacts produced by my research.

My research has some limitations; most can be found in the included articles. I understand previous OGD research to be a young field birthed around the 2010s. Most of the literature is fragmented, and many of the used concepts are unclear. The first article of my licentiate thesis attempted to contribute towards a solution for this problem. A consequence is that I have used some duct tape when synthesizing different articles and assumed their practical meaning. This approach is based on the book of Adler and Van Doren (2014), which means that when the terminology in previous research is vague or uncertain, I have had to make a decision about its meaning and to include it or not. It could give rise to assumptions and speculations becoming findings, which were resolved by evaluating my research in practice and receiving feedback from peers.

While Article B went through a three-stage process and was completed, Article A reached the second stage of a similar planned three-stage process. A consequence is that the provider framework has been verified in other contexts from which it was created, but it needs further deductive verification with other providers. Similarly, Article E had its research process shortened because of difficulties finding participants in Belgium, the COVID pandemic, and I started to get close to the end of my doctoral research. This tentative framework needs further development and evaluation in other contexts, but also adds to previous research about the environment of 
providers, enrichers, and seekers. Article A and Article Eare published, based on rigorous and relevant research, and contribute to the knowledge body of OGD research.

I synthesized the RE-ECO framework based on empirical material from a nascent Swedish OGD ecosystem, previous research, and my five included articles. I have not collected new empirical material. The framework is in line with these sources. My articles have been verified in various ways, and four have been published. I believe they are of good research quality. When they have been synthesized as the RE-ECO framework, their theoretical and practical contributions have been evaluated against each other, which allowed further verification. However, the synthesization can also reveal gaps and soft spots (locations that need more empirical material) in the resulting framework. I have observed that my empirical material provides signs and expressions of energy flows, but not deeper details about these flows. The RE-ECO framework has received a small number of iterations compared to other frameworks I have created, which means potential avenues for future research can be discovered by comparing it to practice, through scrutiny, or a time-out to refresh one's perspective. The RE-ECO framework needs to be further developed and verified in other contexts than Sweden. The framework cannot be used to predict the evolution of an OGD ecosystem. It has not been created for mature OGD ecosystems where (I believe) an OGD reform would have subsided or is hibernating. Consequently, the RE-ECO framework can be used to describe and understand an OGD ecosystem, an OGD reform, and their interplay. I believe this description is limited to nascent and young OGD ecosystems. I also suspect that the identified interplay is contextual and limited to societies that favor collaboration and cooperation where cultivators possessing ample resources are active. 


\section{The RE-ECO Framework for Open Government Data}

This chapter presents the reform-ecosystem (RE-ECO) framework for open government data. The framework is a conceptual framework (Maxwell,2012a) and a knowledge contribution of my doctoral thesis. The synthesis of the framework is described in Section 4.4 and is based on previous research and my five included articles with some of their empirical material. The framework consists of a reciprocal structure, an OGD reform, an OGD ecosystem, and their interplay's affect on the health of the OGD ecosystem. Interplay is the actions between two or more things or the effects they have on each other (Interplay. 2021). Figure 5.1 gives an overview of the RE-ECO framework. The reciprocal structure is the foundation for the actions between an OGD reform and an OGD ecosystem. It represents how they can interplay. An OGD reform describes how this structure is supposedly transformed to realize a higher purpose. An OGD ecosystem coalesces from changes to this structure that produces certain outcomes that realize the higher purpose. The interplay between an OGD reform and an OGD ecosystem can affect the health of an OGD ecosystem. Especially, its evolution since an OGD reform seeks transformations, where both are a type of change.

In this chapter, I first present the reciprocal structure of an OGD reform and an OGD ecosystem, then an OGD reform, an OGD ecosystem, and, finally, how their interplay can affect the health of the OGD ecosystem. Their interplay is presented through the text with different focuses depending on the section. I also continuously cite my previous work to clarify the origin of the empirical material used to construct the framework and provide practical examples from my empirical material. When I quote my empirical material from the five included articles, I cite the original article with the abbreviation FEM (From Empirical Material). My previous work encompasses my five included articles (see Section 4.3), which are based on previous research and empirical material. Similarly, I also continuously cite previous research. 


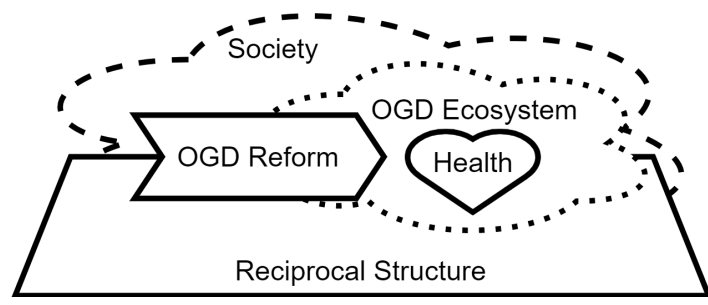

Figure 5.1: An overview of the RE-ECO framework.

\subsection{A Reciprocal Structure of an OGD Reform and an OGD Ecosystem}

OGD actors' work for an OGD ecosystem requires certain conditions (e.g., APIs and open licenses), which they can transform from other conditions (Zuiderwijk, Janssen, and Davis, 2014. Crusoe and Ahlin, 2019b. Crusoe, Simonofski, and Clarinval, 2020). This work is based on assumed solutions that are believed to contribute to the higher purpose of an OGD reform, which could be to resolve a societal problem or improve a society (see Section 2.3. If the conditions are impediments, they can obstruct or prevent certain actions, and, in turn, the work or the transformation (Barry and Bannister, 2014. Wang, Zhao, Zhao, and Chu, 2019: Crusoe, 2021a). This obstruction can mean the work is cumbersome or impossible but can also make interactions between OGD actors cumbersome or impossible. For example, providers might experience difficulties extracting data from IT-systems, as the IT-systems are not built with this function in mind; providers might be unable to publish data, as they lack resources; enrichers might need to spend hours on preparing low-quality data; and enrichers might not be able to find the data as OGD (Crusoe and Ahlin, 2019b Crusoe, 2021a). At the same time, the problem and the idea might be perceived as clear, but the solution is unknown and needs to be invented through iterations of design, development, and evaluation. For example, the various OGD principles (e.g., Tauberer and Lessig, 2007. Sunlight Foundation, 2014: Open Data Charter, 2015) or the development iterations of the Swedish OGD portal (see Section 5.4). Consequently, an OGD ecosystem coalesces through many actions and conditions where impediments can obstruct or prevent this process. The OGD actors have expectations about these actions and conditions, which helps to differentiate them from impediments. The configurations of actions and conditions that can coalesce to realize the higher purpose are not necessarily known by the OGD actors and need to be discovered. Here lies an important connection between actions and conditions and an OGD reform and an OGD ecosystem.

I believe the connection between conditions and actions and an OGD reform and an OGD ecosystem can be presented as a reciprocal structure (based on Davies, 2011. Lee, 2014 Zuiderwijk, Janssen, and Davis, 2014 Crusoe, Zuiderwijk, and Melin, 2020. Crusoe, 2021a). In this structure, the OGD reform provides top-down leeway 
(freedom to act within certain limitations (Leeway 2021)) and a higher purpose (e.g., Tauberer and Lessig, 2007) Sunlight Foundation, 2014. Open Data Charter, 2015), while the OGD ecosystem evolves and becomes from the bottom-up to realize this purpose (Crusoe and Ahlin, 2019b: Crusoe, Simonofski, and Clarinval, 2020). The leeway and the higher purpose determine the meaning of good and bad health for an OGD ecosystem. The leeway and the higher purpose are decided by OGD actors, which, in turn, need certain roles that require certain functions. The rudimental higher purpose is to share and reuse data for the realization of benefits (see Section 2.3. This purpose leads to a need for actors to become and be providers and reusers (enrichers and seekers). Providers share data following some OGD principles. This work requires them to perform functions of acquiring and providing data (Crusoe, Simonofski, and Clarinval,2020). For example, the Swedish National Space Agency acquired some of its data from the European Copernicus program. The data were shared through a satellite data tool called Swe 1 , the Swedish National Archives acquired data from other public organizations $2^{2}$ Some of its data were provided as OGD; and the Swedish Transport Administration collected data in collaboration with other actors ${ }^{3}$ Its data were filtered to then be shared in various channels (Crusoe, 2021a). On the other hand, enrichers follow some perceived needs to identify, acquire, and enrich data and to deploy related solutions (Crusoe and Ahlin, 2019b). For example, a group of Swedish data journalist ${ }^{4}$ aimed to automate the hunt for local news in statistics and data. The journalists identified data by gaining an overview of statistical sources, contacting public organizations, and probing search engines. They acquired the data by developing scrappers to semi-manually download and store the data. They enriched the data by cleaning and (sometimes) aggregating them. The prepared data were analyzed using an IT-system (named Newsworthy $\sqrt[5]{5}$, which was deployed in practice where seekers can register and subscribe to its service. If the IT-system detected a divergent trend or pattern, it created a notification for its subscribed seekers (Crusoe and Ahlin, 2019b). The functions, roles, and higher purpose of an OGD reform coalesce from the bottom-up as an OGD ecosystem. OGD actors of the OGD reform transform conditions to enable this coalescence by enabling certain actions. The conditions with actions can then realize functions, roles, and the higher purpose. However, if conditions and actions diverge from the leeway of functions, roles, and the higher purpose, they can be considered to contribute to the bad health of OGD actors and their OGD ecosystem (Crusoe, 2021a).

The work of OGD actors can be divided into various nodes spread out over a geographical area. An OGD ecosystem coalesces when nodes and their flows realize the higher purpose of an OGD reform. The flows exist between nodes (e.g., data production, data processing, and data provision) and meander distribution systems (e.g., the Internet) (Kalampokis, Tambouris, and Tarabanis, 2011a: Van Schalkwyk, Willmers, and McNaughton, 2016. Crusoe, Zuiderwijk, and Melin, 2020). For example, Linköping municipality collected data about bike traffic at 25 locations where the

\footnotetext{
${ }^{1}$ https://www.rymdstyrelsen.se/rymddata/tjanster-och-verktyg/satellitdataverktyget-swea/

2 https://riksarkivet.se/psidata

$3 \overline{\text { https://www.trafikverket.se/tjanster/data-kartor-och-geodatatjanster/las-om-vara-data/ }}$

${ }^{4}$ https://jplusplus.org/sv/

5 https://www.newsworthy.se/
} 
data were stored in a database and made accessible as OGD through an API ${ }^{6}$ (Crusoe, Simonofski, and Clarinval, 2020). I could download its data without physically visiting its server using the Internet and my computer. At the same time, a node could also be an IT-system and its related work, users, and developers (as in the case of the Newsworthy or, for example, the Swedish data porta 7). Nodes can contribute to health by ease the coalescence of flows and the provision of high-quality data, products, and services. They can give rise to bad health if it is difficult or impossible to coalesce flows or the data, products, and services impede other OGD actors (Crusoe, 2021a).

Nodes coalesce when elements interact as part of a certain role (e.g., provider, enricher, or seeker), meaning an actor can have various nodes that produce, process, and share data. Interactions happen within a node, can take many forms, and their tightness helps to separate a node from other nodes. I have observed in my research that the relationship between a collection of nodes and a specific role is based on the perceived identity of the actor and the present implementation of OGD principles, rather than the work of the nodes for an OGD ecosystem. For example, Davies (2010) and Lindman, Kinnari, and Rossi (2016) explain that enrichers can acquire data from providers, enrich them, and then provide them back to their OGD ecosystem. Similarly, the providers Swedish National Space Agency, Swedish National Archives, and Swedish Transport Administration acquired data from other actors that they enriched or stored and sometimes provided to anyone as OGD (Crusoe, 2021a). On the other hand, the GeoArchive of the City of Stockholm hired geo-technicians to measure geographical areas. Sometimes, the geo-technicians voluntarily contacted the GeoArchive and provided their data for free. The GeoArchive could then provide the data through an interactive map service. The service was based on data (as collected above) and acquired from other sources, such as the city planning office and the city archives. The data could help actors with city planning and construction (Crusoe, 2021a). As such, I suggest that an OGD actor is a tension point between the expected roles of an OGD reform and the realized nodes of an OGD ecosystem.

Elements coalesce when actions are combined with specific conditions of actors, artifacts, and resources to carry out a function. A function could be to download data manually and store them locally, to retrieve, clean them automatically, and store them, or to present a searchable list of data with metadata. I note that conditions populate much of the attention of OGD actors, as the OGD actors transform and work based on the conditions (Kucera, Chlapek, Klímek, and Necaskỳ, 2015: Charalabidis et al., 2018: Crusoe and Ahlin, 2019b; Crusoe, Simonofski, and Clarinval, 2020. Crusoe, 2021a). In my empirical material, an enricher participated at Hack for Sweden in 2017 for a weekend. Her goal was to develop an informative smartphone application (app) where seekers could search and tag educational programs. The app would combine data from the Swedish National Agency for Education, Statistics Sweden, and (possibly) the Swedish National Board of Health and Welfare. However, her weekend was mostly spent on gaining access to relevant data rather than developing her app. She needed to twist and turn search queries, explore six web-

\footnotetext{
6 https://www.linkoping.se/open/

7 https://www.dataportal.se/
} 
sites, study documentation, and learn to use the API of the Swedish National Agency for Education. She also needed to figure out the meaning of the filter keywords for the API and identify the connections between municipal codes and regional codes. For the latter, she visited Statistics Sweden to find a list of municipal codes, but the codes were not attached to names. She got a tip to look at another website where she found the municipal codes and names, but not how they relate to regions. Through guesswork based on extrapolation, she concluded that Swedish regional capitals end on " 80 ". She decided to continue her exploration to acquire relevant data by studying the EMIL standard from the Swedish Institute for Standards. This standard was free of charge but required registration and a buy ${ }^{8}$ She worked herself through the process and learned that the standard would arrive within 48 hours. She decided to continue to experiment and work with the API of the Swedish National Agency for Education (Crusoe and Ahlin, 2019b: Crusoe, 2021a). This example is a selection from the whole process. It shows some of the complexities involved in transforming and working with conditions an actor can experience. It is a recurrent theme I have encountered in practice and previous research (e.g., Hyland and Wood, 2011: Zuiderwijk, Janssen, and Davis, 2014: Crusoe and Ahlin, 2019b: Crusoe, Simonofski, and Clarinval, 2020: Crusoe, 2021a). I have observed in the Swedish OGD ecosystem that the great variety of conditions impeded the OGD ecosystem and its OGD reform (Crusoe, 2021a).

The described reciprocal structure is depicted in Figure 5.2. The figure's symbols with text act as their ledger, while curvy arrows represent relationships between concepts. The jellyfishes of the figure named higher purpose, roles, and functions represent the coalescence of smaller parts emerging into larger parts. I note that artifacts and resources have conditions. Some artifacts can conduct actions (e.g., IT-systems), while resources can change because of natural processes (e.g., deterioration and oxidation). As a result, nodes can coalesce as a mix of actors and artifacts, where resources can be used and transformed. However, resources alone cannot coalesce as nodes. Instead, resources can impede the coalescence of nodes by obstructing and preventing certain actions, interactions, and flows (e.g., low-quality data or lack of money (Crusoe, 2021a)). An OGD reform and an OGD ecosystem with their OGD actors are further described in the following sections.

\subsection{An OGD Reform}

Providers and enrichers work to transform their conditions for a higher purpose. They can be motivated and helped by cultivators as they attempt to coalesce an OGD ecosystem (Denis and Goëta, 2014: Hunnius and Krieger, 2014: Serra, 2014: Johnson and Greene, 2017. Crusoe, Zuiderwijk, and Melin, 2020). As such, I understand an OGD reform as a movement-game, which is a type of checkerboard game where players transform (move) conditions within or between squares to coalesce a system that achieves a certain purpose. Specifically, I have come to understand that an OGD reform perceives this (eco-)system as a collaborative factory simulation. The factory metaphor highlights the "production of data, products, and services to satisfy a mar-

\footnotetext{
${ }^{8}$ You buy it for the cost of 0 SEK.
} 


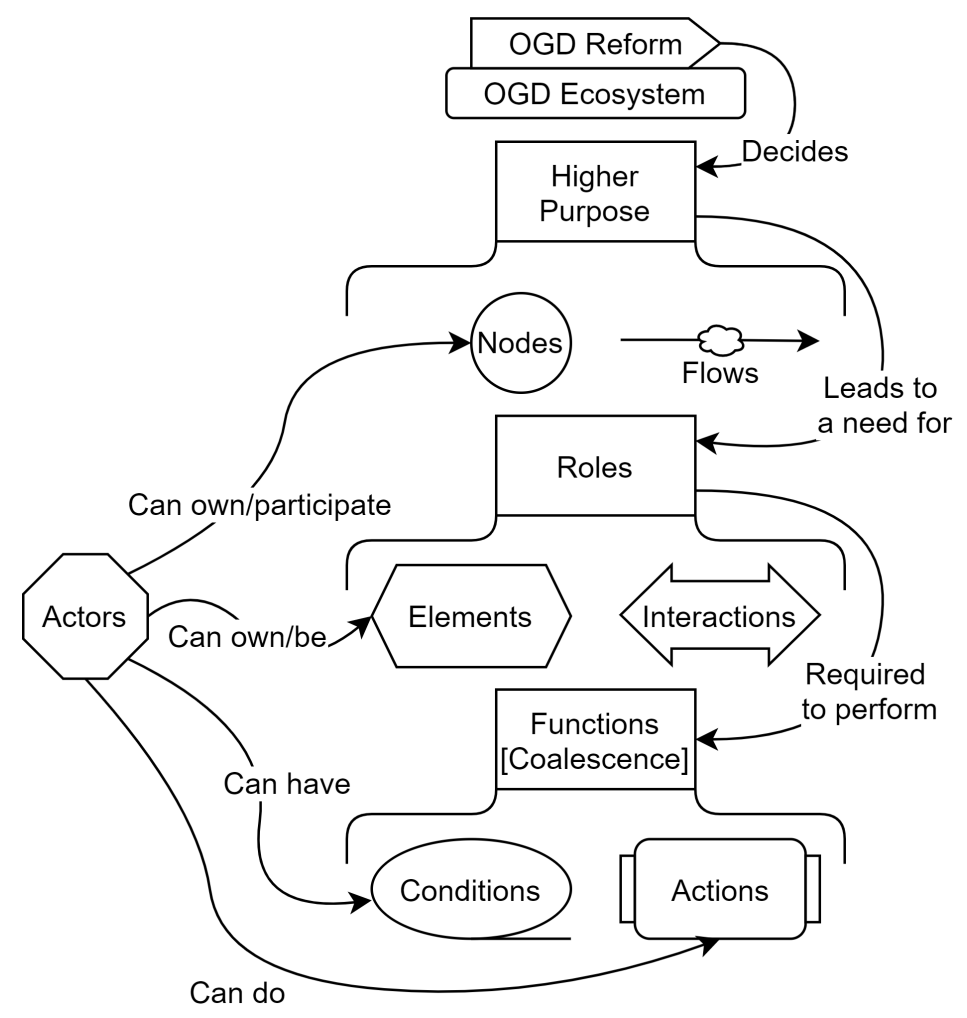

Figure 5.2: A reciprocal structure of an OGD reform and an OGD ecosystem.

ket" of an OGD ecosystem while reducing an actor's cognitive load by simplifying certain complexities (cf. Janssen, Charalabidis, and Zuiderwijk, 2012). In this type of simulation, players collaborate through division of labor to distribute and process resources into outputs using a combination of manual work and automated systems and logistics 9 The factory is divided into nodes of work and flows of resources (Lindman, Kinnari, and Rossi, 2016; Van Schalkwyk, Willmers, and McNaughton, 2016. Crusoe, Zuiderwijk, and Melin, 2020). Examples of this perspective in OGD are: (1) Sweden's Digital First governmental program where OGD was envisioned as a data value-chain of publishing, using, and matching (Crusoe, 2021a), (2) the provision and use perspective of previous OGD research (e.g., Davies, 2010 Zuiderwijk, Janssen, and Davis, 2014 Lindman, Kinnari, and Rossi, 2016), and (3) the OGD value chain (Carrara, Chan, Fischer, and Steenbergen, 2015). A consequence of this per-

${ }^{9}$ Factory simulation games include Factorio, Satisfactory, Dyson Sphere Program, and Factory Town. I base my definition on my studies of the games and an article written by Kuchera (2021). 
spective is that an OGD ecosystem is reduced to two sides of providers as supply and enrichers as demand, a chain that encompasses data to products and services (solutions), and a higher purpose of benefits and value based on processing. This simplification makes an OGD ecosystem easier to understand but hides complexities that originate in variations, quantities, and flows, such as the variations of how providers can own and structure multiple nodes with flows and the variations of how enrichers can reuse data from multiple providers to provide multiple products.

The main objective of the movement-game is the coalescence of an OGD ecosystem (the factory) that produces solutions while realizing the higher purpose of an OGD reform (e.g., Lee, 2014 Dawes, Vidiasova, and Parkhimovich, 2016; Tauberer and Lessig, 2007, Open Data Handbook, 2015). OGD actors play the game by persuading others to join their OGD reform or their OGD ecosystem, participating in different roles, and transforming conditions to coalesce nodes with flows. The OGD actors have at least one role in their OGD reform or their OGD ecosystem (e.g., Folmer et al., 2011. Martin, Turki, and Renault, 2017. Mokobombang, Gutierrez, and Petrova, 2020). For example, the Swedish Transport Administration provided data to its OGD ecosystem, contributed a sum of money to TrafficLab (organized and maintained by Samtrafiken), and participated in meet-ups at this lab. TrafficLab was an attempt to create a community around OGD and public transport (Crusoe, 2021a). I conclude that this community acts to germinate enricher nodes around the Swedish Transport Administration's data provision node, increasing its potential to realize benefits. Two other examples are (1) a data journalists who organized courses to teach other journalists the foundations of data journalism, but also courses to build a data team and (2) an enricher who developed smartphone applications (apps) also taught people how to use APIs, including some OGD (Crusoe, 2021a). I see that the two enrichers germinate the idea of OGD amongst their students, which could lead to new actors joining their OGD reform or their OGD ecosystem. I understand that OGD actors do not leave their original ecosystem; rather, they use an OGD reform to expand it with OGD (to include an OGD ecosystem).

I divide the OGD actors of an OGD reform into: cultivators, reformists, changers, and helpers. They can be people and organizations and are not exclusive or permanent for the actors who can morph between them. Their expressions can vary depending on the actor and its environment, and at least one cultivator, reformist, or helper is needed for an OGD reform to exist. My idea of cultivators originate from my licentiate thesis (Crusoe, 2019b) and draws on, for example, Folmer et al. (2011) and Mokobombang, Gutierrez, and Petrova (2020). Cultivators refer to actors who persuade others to join and participate in their OGD reform or an OGD ecosystem. They can also enable the work of others. They aim to transform conditions that impact several actors. They can coalesce nodes of their OGD reform rather than an OGD ecosystem. For example, Sweden's Innovation Agency funded several OGD projects, and the Swedish Meteorological and Hydrological Institute was the project leader of Hack for Sweden, where providers and enrichers could meet in 2017. Hack for Sweden was also arranged by the Swedish Mapping, Cadastral, and Land Registration Authority, the Swedish Public Employment Service, the Geological Survey of Sweden, Statistics Sweden, and the Swedish Environmental Protection Agency (Crusoe, 2021a). This type of node is, to my understanding, temporary as it exists for a cer- 
tain transformation of its OGD ecosystem and is then dismantled. Another example is given by Linköping municipality, which was part of arranging East Sweden Hack, discontinued in 2017. The aim of the hackathon was not to produce specific solutions. Rather, it aimed to produce several services, apps, and hardware as well as being a location where different actors could meet for a weekend (Crusoe, Simonofski, and Clarinval, 2020). I emphasize that the main workpieces of cultivators are actors rather than the nodes, flows, and resources of an OGD ecosystem.

My idea of reformists and changers originate in the work of Caiden (2017), my research of Crusoe, Simonofski, and Clarinval (2020), and the research of Lee (2014), Denis and Goëta (2014), Serra (2014), and Kucera, Chlapek, Klímek, and Necaskỳ (2015). Reformists accept a role, such as a provider or an enricher, and attempt to transform local conditions to coalesce elements and nodes so they may become part of an OGD ecosystem, which can involve persuading external actors to join. For example, the OGD manager of Linköping municipality was a reformist who persuaded public officials to publish their data and worked with them through the process while being responsible for the data flows to and from the municipality's data provision node (Crusoe, Simonofski, and Clarinval, 2020). On the other hand, actors may find themselves as reformists by chance. For example, the Swedish Transport Administration experienced dual conditions. First, it learned about OGD from a researcher. Second, developers were scrapping its website for data about trains that they shared through an API (according to the agency). The agency needed to decide between removing the train data from its website or publishing it as OGD. It decided for the latter and published the data (Crusoe, 2021a). I see that the agency was recruited by actors to join an OGD ecosystem, which then made it possible for them to join the agency's OGD ecosystem. Moreover, changers are actors who have been persuaded to join and work for an OGD reform or an OGD ecosystem but do not seek to spread the OGD reform. They can, for example, be public officials who work with data, lawyers who help to disentangle legal issues surrounding the data, or information owners who need to give consent to publish their data (Crusoe, Simonofski, and Clarinval, 2020: Crusoe, 2021a). I clarify that reformists are the builders of nodes and their flows within a local area, while changers can be catalysts in the transformations of nodes or participate in nodes.

Finally, my idea of helpers originates in my empirical material. Helpers work to persuade or help other actors join or become a role within their OGD reform or an OGD ecosystem. They can be support service providers (Lindman, Kinnari, and Rossi, 2016. Mokobombang, Gutierrez, and Petrova, 2020), consultants (e.g., Hagström Consulting) (Crusoe, 2021a), or researchers. I am an example of a research helper since I spread a popular science article describing the work of enrichers, which could help actors become or support enrichers (Crusoe and Ahlin, 2019b). I attempted to help providers and enrichers by creating a conceptual framework, which should support them in aligning the data of providers and the solutions of enrichers with the information needs of seekers (Crusoe, Gebka, and Ahlin, 2020b). It is also possible that helpers gain something from the OGD actors they are helping. For example, MetaSolutions offered providers local metadata catalogs for a monthly subscription fee but also offered educational courses about OGD (Crusoe, 2021a). I often got access to empirical material or opportunities for future collaborations. However, some helpers are 
also involved in an OGD ecosystem. For example, an enricher who was developing a price-searching site for train tickets helped a provider to publish its data by creating an API (Crusoe, 2021a). This type of helper leaves its role for a moment to help other actors transform their local conditions. I see that this help may also be good for the helper. In the above example, it is possible that the enricher can use the data from the API. I believe helpers are the factotum of an OGD reform or an OGD ecosystem, filling peculiar niches and smoothing thresholds of other OGD actors' work.

The OGD actors of an OGD reform interact within their movement-game, as seen in the above examples. I understand that cultivators act to recruit and enable reformists who, in turn, recruit changers (if needed). The actors need each other since they cannot do all the required transformations alone, as they can lack access, authority, resources, and knowledge. Helpers skitter around the legs of these giants, supporting them and sometimes pushing them towards OGD while, possibly, existing in symbiosis (Crusoe and Ahlin, 2019b: Crusoe, Simonofski, and Clarinval, 2020. Crusoe, 2021a). In sum and terms of the movement-game, cultivators and reformists are the players, while changers and helpers are supporters. Cultivators transform conditions in the squares of the metaphorical factory board that they hope positively impact many actors. They can host hackathons, declare laws (e.g., the PSI law), or found projects. Reformists transform local conditions in squares to coalesce elements with interactions and nodes with flows within a local area, involving the local actors as changers. They build the factory from the bottom-up. Helpers support the actors in the work of their OGD reform and their OGD ecosystem.

Together, the OGD actors' movement-game consists of four areas of activity (based on Caiden (2017), see Section 2.3): (1) persuasion, (2) collaboration, (3) transformation, and (4) evaluation. These areas can overlap and lead to each other. They can vary between actors who might invest differently in each and use various solutions. I claim that when there is high activity in each area, it means an OGD reform is ongoing, but it says little about its success. Persuasion is activities where OGD actors convince other actors to join their OGD reform or their OGD ecosystem. Collaboration happens when OGD actors create, distribute, and imitate innovations. Transformation refers to activities when OGD actors transform their conditions for some purpose. Evaluation occurs when OGD actors gauge the progress, success, development, or maturity compared to their expectations of OGD. They can evaluate themselves, others, their OGD ecosystem, and internationally. Persuasion and transformation are part of local reforms, as they focus on an actor joining an OGD reform or an OGD ecosystem or transforming conditions. On the other hand, collaboration and evaluation are part of collective reforms because OGD actors work together and look to each other.

Figure 5.3 depicts a movement-game of an OGD reform. It presents the movement from a society with potential data-information flows to a society with an OGD ecosystem. I note that enrichers before joining their OGD ecosystem are in the figure labeled precursors, and seekers can participate in an OGD reform as helpers and possibly cultivators. I have not identified in my empirical material or previous OGD research that seekers transform their local conditions. Thus, they are not reformists within an OGD 
reform, but I see that they could participate as helpers (activists) (Dawes, Vidiasova, and Parkhimovich, 2016. Mokobombang, Gutierrez, and Petrova, 2020.

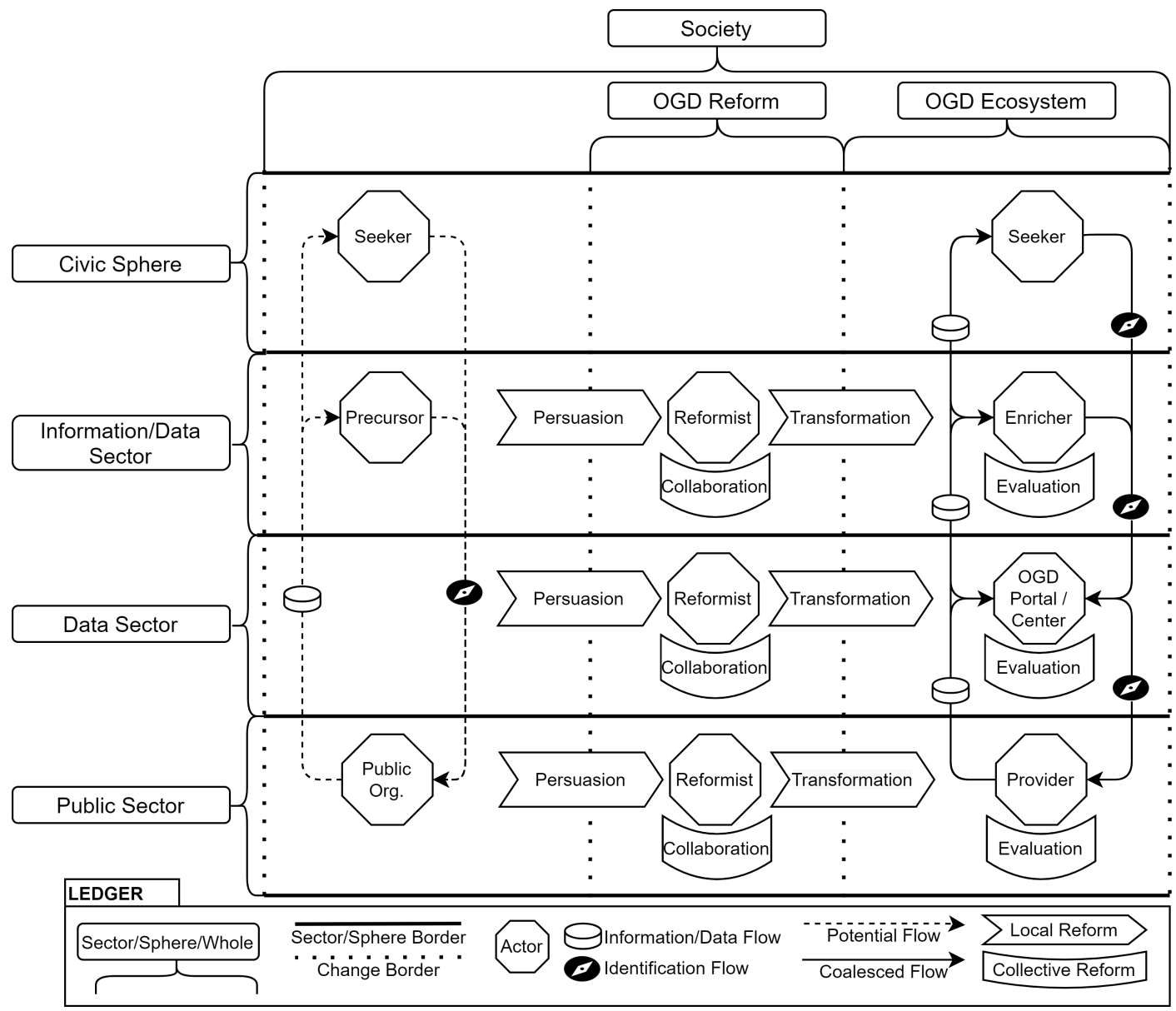

Figure 5.3: A movement-game of an OGD reform.

\section{Persuasion}

Actors tend to conduct reforms based on perceived societal needs (or illnesses) that need to be cured or a possibility to improve society (Caiden, 2017). For actors to join an OGD reform, they need to be aware of this need and accept it. Once persuaded to join an OGD reform, they can seek to remedy problems, such as incomplete and dysfunctional democracies, walled gardens of data and information only open to a small elite, the wasted potential of untapped data and information, and dysfunctional, obscure governments (Tauberer and Lessig, 2007: Sunlight Foundation, 2014. Open Data Charter, 2015: Open Data Handbook, 2015). An OGD reform 
also promises various political, social, economic, operational, and technical benefits (Janssen, Charalabidis, and Zuiderwijk, 2012), which OGD actors can seek to realize. For example, the OGD manager of Linköping municipality explained that the municipality worked with OGD because of the PSI directive, to promote innovation and transparency, to provide data, to develop applications and e-services, and OGD was part of the smart city concept (Crusoe, Simonofski, and Clarinval,2020). On the other hand, the OGD manager of the Swedish National Heritage Board explained that its board worked with OGD to enable external value creation. Therefore, OGD can help them to maximize its data's potential value. It was also driven by the fact that the board does not perceive itself to be the owner of its data (Crusoe, 2021a). I understand that persuasion gives OGD actors a purpose and reason to work with an OGD reform or an OGD ecosystem.

I have identified that the methods used to persuade actors to join an OGD reform or an OGD ecosystem can come in many forms, such as blog posts, books, meetings, hackathons, and contacts (Open Data Handbook, 2015 Crusoe, Simonofski, and Clarinval, 2020: Crusoe, 2021a Huyer, Van Knippenberg, Arriëns, and Blank, 2020). Therefore, I divide persuasion into direct persuasion and broadcast persuasion.

The direct persuasion is used by reformists and helpers to persuade actors to join their OGD reform or their OGD ecosystem. It could be citizen advocacy for OGD (Dawes, Vidiasova, and Parkhimovich, 2016, Reggi and Dawes, 2016). As the OGD manager of the Swedish National Archives notated in my research (Crusoe, 2021a), public organizations allocate resources to OGD if they know its purpose and function. His statement is supported by the findings of Yang, Lo, and Shiang (2015). Direct persuasion can take the form of actions (e.g., the developers scrapping the website of the Swedish Transport Administration) or communication. In Linköping municipality, at the start of its OGD journey, a politician had the role to ask for, encourage, nag, repeatedly ask questions, and push for OGD at the strategic level. Later, the municipality's OGD manager participated in meetings where he explained OGD, what it can and cannot do, and possible benefits and consequences for businesses and citizens (Crusoe, Simonofski, and Clarinval, 2020). Thus, direct persuasion involves a specific actor persuading a target actor to join its OGD reform or its OGD ecosystem.

The broadcast persuasion is used by cultivators to persuade several actors to join their OGD reform or an OGD ecosystem. For example, Scott (2020) argued in a blog post that OGD is good for democracy, can help fight crime, is good for people's health, can save lives, helps people get around their city as well as save their money, and it is gorgeous; Open Data Handbook (2015) was a digital open handbook that provided a section about why actors should join its OGD reform or an OGD ecosystem, including a section of 12 value stories; and Frick and Ainali (2017) from the Swedish Internet Foundation presented an OGD guide to decision-makers. The guide contained a section about who can benefit from OGD and why public organizations should work with OGD. Another example is the (previous) Swedish OGD portal that had a section for good examples, covering providers and enrichers (Crusoe, 2021a). As such, broadcast persuasion happens when an actor attempts to persuade a broader audience to join its OGD reform or an OGD ecosystem. The audience is not necessarily known by the actor and can be invited to participate (such as hackathons or open data 
forums). It is also visible in previous OGD research. For example, Lee (2014) defines five new OGD ecosystem principles and Harrison, Pardo, and Cook (2012) suggest public managers should engage in a strategic ecosystem thinking.

I have observed a middle-ground persuasion as between direct and broadcast persuasion. For example, Skövde municipality arranged internal meetings to talk about OGD, its OGD manager visited IT-committees to inform others about OGD, and hosted internal lectures. The municipality arranged a lecture about OGD at its egovernment days, where actors in the municipality and neighboring municipalities were invited for a day about e-governance. Similarly, the Swedish National Archives arranged lectures about OGD where, for example, the Swedish National Space Agency and I participated (Crusoe, 2021a). This middle-ground seems to be used when an actor attempts to persuade a specific group to join its OGD reform or an OGD ecosystem.

I have also identified that cultivators can arrange transformative nodes that confluence the areas of persuasion and collaboration. Confluence is a situation in which two things join or come together (Confluence 2021). The Swedish Environmental Protection Agency arranged the NextStep workshop where providers could meet and learn about how they could develop their data management. Providers from Denmark, Estonia, and the United Kingdom spoke at this workshop. Sweden's Innovation Agency and later the Swedish Internet Foundation arranged forums named the open data forum. At the forums, actors could meet to learn about OGD, exchange knowledge and experiences, and collaborate around OGD. In common, both the workshop and the forums allowed actors to persuade and collaborate, but they were also recorded and published online (Crusoe, 2021a). As a result, their presentations reached a specific group and brought attention to OGD for a broader audience.

\section{Collaboration}

As I explained in Section 2.3. an OGD reform gives rise to a series of problems and solutions. Collaborations between OGD actors are an approach to develop these solutions and spread them within an OGD community (Crusoe, Simonofski, and Clarinval, 2020: Crusoe, 2021a), such as data collaboratives, collaborative innovation (as ecosystem), and meet-ups (Lee, 2014: Susha, Janssen, and Verhulst, 2017. Kitsios, Papachristos, and Kamariotou, 2017). Collaborations within an OGD reform involve activities of innovation, distribution, and imitation. I have observed that reformists and helpers are often active participants in these activities, while cultivators can support, ease, help, or enable them.

A reformist or a helper who encounters a problem that it perceives to lack a solution or the existing solutions are not satisfactory, can innovate (e.g., Tauberer and Lessig, 2007, Hyland and Wood, 2011. Carrara, Oudkerk, Van Steenbergen, and Tinholt, 2018). For example, the Swedish Environmental Protection Agency developed two tools to help public organizations to publish and monitor their information management. The tools were developed through a project that started in 2016 with the NextStep workshop. One tool was a generic process for publishing OGD, and the other was a maturity model for information management. This project was financed 
by Sweden's Innovation Agency (Crusoe, 2021a). Another example is provided by the Swedish National Archives, which in 2012 developed a tool to publish OGD easier, as it could convert and clean data. The project was financed by Sweden's Innovation Agency (Crusoe, 2021a). A third example is provided by Sambruk (an association for municipal digitalization) that developed an information classification system based on the metaphor of a traffic light in a project financed by Sweden's Innovation Agency (Crusoe, 2021a). A fourth example is the "National Service for Open Data"-project that aimed to develop an OGD prototype to publish OGD. It was made in collaboration between Linköping municipality, Linköping university, and a company. This project was financed by Sweden's Innovation Agency (Melin, 2016; Crusoe, 2021a). The two tools from the Swedish Environmental Protection Agency and the classification of Sambruk are distributed solutions. The tools were available on the agency's website ${ }^{10}$, while the classification was presented at an open data forum in 2017 and recorded to be shared online 11

The Swedish Internet Foundation arranged the open data forum. A senior adviser at the Swedish Government Offices (as a cultivator) participated at this forum to explain how the Swedish Government worked with digitalization and OGD. He communicated a picture of OGD as publishing, matching, and using following a value chain. The advisor argued for a need to publish more OGD to realize an OGD ecosystem where the value of OGD reuse emerges from within it (Crusoe, 2021a). I believe his statement is a good reflection of the difference between an OGD reform and an OGD ecosystem. The open data forum acts as a location where OGD actors can distribute solutions and showcases OGD actors' ability to collaborate outside their OGD ecosystem to transform it.

I have experienced that it is common with the international and national distribution of solutions by cultivators, reformists, and helpers within an OGD reform. For example, the five-star provider scheme of Berners-Lee (2015), the goldbook for data managers and data holders of Carrara, Oudkerk, Van Steenbergen, and Tinholt (2018), and the cookbook for publishing linked data of Hyland and Wood (2011) are available online for free. Other examples include the numerous OGD principles that are (to a degree) rival to each other (e.g., Tauberer and Lessig, 2007, Sunlight Foundation, 2014: Open Data Charter, 2015: Open Data Handbook, 2015). In Sweden, a similar rivalry existed between tools describing the publishing process, such as ÖppnaData.SE (2018), Naturvårdsverket (2018), Kronofogden (2019), SKR (2017), and Södertälje (2019). A Swedish example of active rivalry was provided in a statement by Sambruk at the open data forum of 2017:

"[...] it is difficult to work according to the tools from the Swedish Environmental Protection Agency. The process is really good, but it looks expensive. It seems a bit costly to follow. How could we do this in a sensible way? I believe in AI in the long term. I also believe in the

\footnotetext{
10 https://www.naturvardsverket.se/Stod-i-miljoarbetet/Vagledningar/Oppna-data/

${ }^{11}$ The recorded presentation has since then been removed from its video hosting website.
} 
ability to classify information" - Coordinator for municipal OGD, Sambruk (FEM 12 Crusoe, 2021a).

The actor referred to the use of its information classification system (Crusoe, 2021a), and I understand that his statement was part of a sale pitch. The rivalry within an OGD reform or an OGD ecosystem tends to be supplementary, overlapping distributed solutions to similar problems. The use of distributed solutions also blurs the line between cultivators and reformists as well as helpers.

A reformist or a cultivator can choose to imitate and adapt distributed solutions, which could be a national OGD initiative signing up and following an international OGD action plan or an enricher using Google Chart API, Google Visualization, or Map Designer API to visualize data (Lee, 2014 Zuiderwijk, Janssen, and Davis, 2014). For example, Linköping municipality used GeoJSON for some of its data (Crusoe, Simonofski, and Clarinval, 2020); the Swedish Transport Administration and the Swedish Tax Agency used a modified form of the publishing process created by the Swedish Environmental Protection Agency; and the data value chain of the Swedish Digital First program was based on the OCDE data value chain (Crusoe, 2021a). Cultivators can study standards and best practices of other contexts to transform them to standards and best practices fit for their OGD reform. For example, the Swedish National Archives studied the DCAT-AP metadata standard to identify parts that could be relevant for Sweden (Crusoe, 2021a). At the same time, helpers can argue for the use of certain standards and best practices. For example, a helper (at the open data forum of 2017) argued that cultivators should introduce requirements for public agencies to work with metadata standards for all of their data (Crusoe, 2021a). As a result, reformists can imitate and adapt distributed solutions for their local contexts, while cultivators can adapt them for the context of their country. Helpers can encourage and push towards certain imitations and adaptions.

\section{Transformation}

There are clear distinctions between the transformation of an OGD reform and the evolution of an OGD ecosystem, such as when a public organization publishes data versus when it improves its data provision based on feedback. On the other hand, I have also experienced difficulties separating transformations and evolutions, as they are processes where an actor changes to become something else, and when they happen together, they form a confluence. This situation is notable for providers and enrichers since they participate in a transformation of themselves and as a new role in an OGD ecosystem (see Section 2.2.

I have identified that reformists have two sides of their transformation: the external and internal. For the external transformation, a reformist coalesces or dismantles a node to join or leave its OGD ecosystem. For providers, this type of transformation occurs when they implement their first OGD page and publish their first dataset (Folmer et al., 2011: Kucera, Chlapek, Klímek, and Necaskỳ, 2015: Crusoe, Simonofski, and Clarinval, 2020) or withdraw their final data provision from their

\footnotetext{
${ }^{12}$ (From Empirical Material)
} 
OGD ecosystem. For enrichers, it happens when they deploy products or services to seekers based on OGD (Davies, 2010: Crusoe and Ahlin, 2019b) or withdraw their final product or service from their OGD ecosystem. However, even if OGD actors have withdrawn their data, products, or services, they may still be actively used in society (Moore, 1997 Day, 2002. Ohlman, 2002). At the same time, it is possible that an enricher and a seeker are the same or different actors. For example, a Swedish researcher supplemented his electric bus simulation with timetable and route data for public traffic, which helped him to predict better where to place charging stations for buses; a Swedish researcher (as part of a pedagogical project) developed visualizations based on OGD that were presented on a website aimed towards high school students; and a data journalist created digital stories with visualizations based on OGD for seekers to experience (Crusoe and Ahlin, 2019b). With an external transformation, a reformist takes the final step to become or resign as a provider or an enricher.

For the internal transformation, a reformist transforms conditions within themselves to become a provider or an enricher (e.g., Janssen and Zuiderwijk, 2012: Zuiderwijk, Janssen, and Davis, 2014. Ayre and Craner, 2017). It coalesces nodes and flows to work with data and information for the higher purpose of an OGD reform. This type of transformation comes in two subtypes: preparatory and elastic. Preparatory transformations are the first changes of an OGD actor towards their first external transformation to join its OGD ecosystem. A provider conducts initiation processes (e.g., appoint an OGD manager and create a strategy) and inventory processes (e.g., identify the first data to publish) (Folmer et al.,2011. Carrara, Oudkerk, Van Steenbergen, and Tinholt, 2018: Crusoe, Simonofski, and Clarinval, 2020). For example, the Swedish National Archives and the Swedish Mapping, Cadastral, and Land Registration Authority used a pilot project to take the first steps of preparatory and external transformations. This approach was recommended by ÖppnaData.SE (2018). On the other hand, an enricher could be driven by an idea, curiosity, or a need to include OGD in its work for the first time. It needs to learn about OGD and how to identify, acquire, and enrich data (Crusoe and Ahlin, 2019b). For example, a consultant lived next to an inspector from the Environmental Administration of the City of Stockholm. The inspector told the consultant that they were interested in an app to show the statistics of their work in an app format and not only on their website. The consultant found it interesting and studied how the data were provided and could be acquired. $\mathrm{He}$ worked to untangle the situation and called public officials for more information. He later developed an app called Matkollen that was available on the App Store (Crusoe, 2021a). In addition, I believe an OGD actor could go through a preparatory transformation to leave its OGD ecosystem, but my empirical material does not cover such a case.

Elastic transformations can come after the first external transformation when a provider or an enricher seeks to expand or shrink its work by adding or removing nodes (Carrara, Oudkerk, Van Steenbergen, and Tinholt, 2018. Charalabidis et al., 2018). The concept is a variation of evolution within an OGD ecosystem. For expanding, a provider continues to search for and publish data, while an enricher continues to probe for and develop new types of solutions based on data. For example, Linköping municipality had the objectives to release 3-4 datasets per year and 
to develop its OGD portal (Crusoe, Simonofski, and Clarinval, 2020), while the data journalists wrote reports, articles, and blogs enriched with OGD. They also created data stories, analytical tools, and an e-service that automates the hunt for local news in statistics and data (Newsworthy)(Crusoe and Ahlin, 2019b). I have identified that the Swedish National Space Agency withdrew a dataset, but not to such a degree that it dismantled its provision node and left its OGD ecosystem. The agency still provided a PDF containing Swedish space objects that was last updated in June 2017. I have seen indications of an enricher leaving its OGD ecosystem since its app was last updated in 2014, and the app's Facebook group was removed.

I have above interweavingly presented most of the approaches cultivators can use for transformations of an OGD reform (see also Section 2.2. In sum, cultivators can delegate (e.g., the Swedish Government gave missions to different actors), support by developing tools (e.g., the publisher process of the EU-project "Increased Use of Open Data in the Stockholm Region"), transform societal conditions (e.g., the Swedish PSIlaw), engage actors (e.g., open data forums and Hackathons), fund projects and work (e.g., the funding from Sweden's Innovation Agency), give direction (e.g., the senior adviser at the Swedish Government Offices communicating a Swedish OGD value chain), and introduce conditions (e.g., the OGD portal created by Sweden's Innovation Agency, the Swedish National Archives, and the Swedish Agency for Digital Government). Therefore, I understand that cultivators are diverse in their roles and provide essential work for their OGD reform. Their presence permeates the work of reformists and helpers. Cultivators can divide their work and focus on specific problems, leading to several cycles of coordination, transformation, and evaluation. A strong cultivator, such as a government, can delegate its cultivation to other cultivators (e.g., the Swedish Government and Sweden's Innovation Agency), while smaller cultivators, such as activists, can work alone or in communities to apply direct persuasion on actors (e.g., the developers scrapping data from the website of the Swedish Transport Administration who convinced the agency to publish OGD and the data journalists who thought other journalists to use data germinated future enrichers).

\section{Evaluation}

From the perspectives of reformists and cultivators, an OGD reform needs to cause a permanent OGD ecosystem that realizes a higher purpose. If it cannot measure up to their expectations, it is inferior (based on Caiden, 2017). However, I have noticed that in some instances, perceived failures can fuel continual work with OGD and lead efforts of broadcast persuasion. For example, in a debate article of Computer Sweden (Nordmark et al., 2016), a mix of reformists and helpers argued that the Swedish Government must immediately make a large investment into OGD. They asked for national coordination that would ease management, increases competence, and promotes development. They gave examples of companies publishing open data (e.g., Spotify and Senion) and from other countries (e.g., the White House and the National Aeronautics and Space Administration of the United States). They also brought up Denmark as a leading country and Finland and the United Kingdom as good examples. Their need for action was based on a rapport presenting two challenges for Swedish OGD (lack of economic resources and policy) and Sweden's low position in the Global Open Data Index (2016). At the same time, a journalist helper from Com- 
puter Sweden gave voice to the impediments and needs of some Swedish enrichers. Her articles end with encouragements for certain transformations (Lindström, 2018a. Lindström, 2018b). As such, the evaluation of reformists and helpers can lead to persuasion and coordination activities. I have identified that reformists and cultivators can evaluate their work, the work of other actors, their OGD ecosystem, and internationally.

When reformists and cultivators evaluate their work, they can focus on the inputs, the processes, and the outputs (Janssen and Zuiderwijk, 2012 Lee, 2014: Carrara, Oudkerk, Van Steenbergen, and Tinholt, 2018). For example, Linköping municipality supplemented its OGD several times and sometimes enrichers suggested new datasets to publish. It aimed to be responsive to enrichers. It also collected statistics about calls to its APIs. For enrichers to use its APIs, they needed to register with an e-mail. This registration allowed the municipality to protect its APIs and to contact enrichers and ask about their work. The responses gave the municipality an insight into who and how its data are used (Crusoe, Simonofski, and Clarinval, 2020). Uppsala municipality explained that it is constantly working on publishing more data, improving the quality of its data, increasing the number of formats its data are available in, and facilitating the use of its data (Crusoe, 2021a). The Swedish National Archives and the Swedish Mapping, Cadastral, and Land Registration Authority published in small waves. The first time, they published a small amount of OGD to learn, stimulate innovation, and evince benefits (Crusoe, 2021a). However, I see that when actors evaluate their transformations, they can also evaluate potential risks. For example, Linköping municipality conducted a risk analysis with changers to assess risks of publishing certain data, and in Umeå municipality, a changer refused to publish her data because she was afraid of how seekers would react (Crusoe, 2021a). On the other hand, a developer developed an app that could help seekers with disabilities to travel using the public transport of Stockholm. The app was called Resledaren. The developer explained that he improved the quality of his application by removing bugs and usability problems (Crusoe, 2021a). Cultivators can recruit helpers to evaluate their work. For example, Arwidson and Kolsjö (2014) from PwC were granted project money from Sweden's Innovation Agency to evaluate 39 OGD projects from 2012. They studied demand, types of enrichers, use and application of data, project division amongst actors, contact between projects, results, and benefits. They also gave recommendations. As a result, I understand that this type of evaluation is part of the evolution of an OGD ecosystem towards betterment.

Reformists can evaluate the work other OGD actors and agree and disagree about different approaches or solutions (Zuiderwijk, Janssen, Choenni, Meijer, and Alibaks, 2012. Vetrò et al., 2016; Weerakkody, Irani, Kapoor, Sivarajah, and Dwivedi, 2017). For example, a CEO of an enricher explained:

"I do not think the [Swedish] Government is doing enough. There is much talk, but nothing happens. [...] There are no enforcing programs. Instead, there are goals and the PSI-law without any penalty." - CEO, Enricher (FEM. Crusoe,2021a).

The OGD manager of Uppsala municipality wanted to see more OGD work in Sweden, some kind of OGD manifest, a clear and more significant investment from the 
Swedish Government, and an arena to share good examples (Crusoe, 2021a). On the other hand, the OGD manager of the Swedish National Space Agency believed in investing in different types of hackathons and informational campaigns to help enrichers brainstorm ideas about data applications (Crusoe, 2021a). The OGD manager of Skövde municipality explained that the municipality had not participated in hackathons and open data forums. Instead, it worked more with direct persuasion and middle-ground persuasion (Crusoe, 2021a). A CEO of an enricher explained that he believed more in open data forums than hackathons (Crusoe, 2021a). A developer explained that it made him angry that actors wanted hackathons to produce something beneficial, as he thought they exist for actors to have fun (Crusoe, 2021a). At the same time, enrichers who attempt to use and combine data from several providers are also in a unique position to evaluate the access, quality, and availability of the data from various providers (Crusoe, 2021a). I understand that this type of evaluation relates to the evolution of an OGD ecosystem as co-evolution and multi-path evolution.

Reformists, cultivators, and helpers can evaluate their OGD ecosystem and their OGD reform (e.g., Lee, 2014; Welle Donker and Loenen, 2017). In 2017, at an open data forum, a data journalist presented eight problems the Swedish OGD reform and the Swedish OGD ecosystem were experiencing, but also eight possible solutions (Crusoe, 2021a). The Swedish Government gave the Swedish Agency for Public Management the mission to evaluate the impediments to reusing data from public agencies. The Swedish Agency for Public Management (Statskontoret, 2018) evaluated impediments experienced by enrichers based on empirical material from two other reports, supplementing with 19 interviews. Its evaluation resulted in a report identifying impediments for enrichers and challenges for public agencies to remove these impediments. The report ended with a conclusion and recommendations. Bisnode (2016) evaluated OGD in Sweden with support from Sweden's Innovation Agency. The report contained an analysis of the status of OGD in Sweden and an exploration of enrichers. It resulted in suggestions based on how businesses wanted OGD to be improved. Riksrevisionen (2016) presented an evaluation of the Swedish public sector's digitalization, including its status, challenges, possibilities, and needs of OGD. The report also highlighted that Sweden is falling behind in international rankings. OECD (2019a) evaluated institutional framework, policy funding, policy framework, and legal and regulatory framework. It also discussed the OURData Index with a focus on OGD availability, accessibility, and reuse. Frick (2015) from the Swedish Internet Foundation presented business intelligence and the status of OGD in the world from a Swedish perspective. Eriksson (2014), with support from Sweden's Innovation Agency, evaluated the status of OGD in Sweden with a focus on possible business models, public agencies, and the status in Sweden with strengths and weaknesses. This evaluation resulted in a list of needs for OGD improvements in Sweden. I understand that this type of evaluation attempts to influence the transformation of an OGD reform and the evolution of an OGD ecosystem.

OGD actors can conduct international evaluations (Styrin, Luna-Reyes, and Harrison, 2017: Zuiderwijk, Pirannejad, and Susha, 2021), which I have noticed can create a certain spark in Sweden. For example, Shekarabi (2017), who at the time was the Swedish Minister for Public Administration, argued that Sweden is no longer seen as a leading OGD country within the EU, and that is something that must be changed, 
as Sweden should be leading in issues of digitalization; and a senior adviser at the Swedish Government Offices explained that "the goal is to raise Sweden from the humiliating 28th rank of OCDE's OURData Index to a top-five or top-ten position" (FEM. Crusoe, 2021a). On the other hand, Sweden's Innovation Agency explained that the international rankings are relative to the helpers answering in each country (Crusoe, 2021a), as such, they should be taken with a pinch of salt. I identified that the international evaluations are often indexes, barometers, and rankings focusing on comparing the OGD maturity of countries. For example, the OURData Index evaluated countries based on data availability, data accessibility, and government support of data re-use (OECD, 2021); the European Data Portal measured the OGD maturity of EU-countries as policy, impact, portal, and quality (European Data Portal, 2021); the Open Data Barometer measured OGD maturity around the world with a focus on accountability, innovation, and social impact by measuring readiness, implementation, and impact (World Wide Web Foundation, 2021); and the Global Open Data Index evaluated the license, format, accessibility, relevancy, and cost of 15 datasets in countries (Global Open Data Index, 2016). I understand that this type of evaluation attempts to fuel a competitive spirit between countries by revealing the successes and failures of an OGD ecosystem compared to other OGD ecosystems. It is also an approach to understand how well an OGD ecosystem (factory) realizes the higher purpose of its OGD reform; an approach to understanding the health of an OGD ecosystem.

\subsection{An OGD Ecosystem}

I depict an OGD ecosystem as an ocean ecosystem where the public sector is the seafloor, then the data sector and information sector are the zones of water, and the information sphere and civic sphere are the air spheres (cf. Sverdrup and Kudela, 2013). The sectors focus on data-information work, while the spheres focus on the consumption of data and information to satisfy the needs in sectors outside the data and information sectors, but also the interstice between sectors (in everyday life of actors). Clines internally separate the sectors and spheres. I define ${ }^{13}$ a cline as an area where an important change is happening, which makes it a borderland within an area of similar characteristics (see Section 2.4). As such, a cline is an area that can act as an interstice and confluence between two similar sectors or two similar spheres. I draw this layering from Checkland and Holwell (1997) and Alter (2003a) and Davies (2011) and Sverdrup and Kudela (2013). The ocean ecosystem metaphor helps to structure the relationships and dependencies between the sectors and spheres. It highlights the distance between providers and seekers and the idea of the public sector as closed and the spheres as public, often expressed in OGD (e.g., walled garden or data as locked inside the government (Sunlight Foundation, 2014: Open Data Charter, 2015)). However, it embeds infrastructure as part of the environment and obscures geographical distances and complexities. In this metaphor, the public sector is a mountain range where some peaks reach the information sphere, and some valleys stretch into dark abyssal trenches. The ecosystem is populated with various nodes and their flows. An actor can own a collection of nodes spread through the ecosystem, creating a larger living structure where data and information flow from providers towards seekers,

\footnotetext{
${ }^{13}$ I define a cline within a socio-technical system and not a natural ecosystem.
} 
along the way, enrichers enrich them. Energy flows to or between these actors fueling their work. It is important to note that any flow can load (input) and export (output) resources, data, information, and energy for an OGD ecosystem. Figure 5.4 presents an overview of this OGD ecosystem, which is further explained through this section. I highlight that an OGD ecosystem helps and supports providers, enrichers, and seekers who are members of other ecosystems. The energy of an OGD ecosystem is loaded from other ecosystems, such as the civic sphere, information sphere, and public sector.

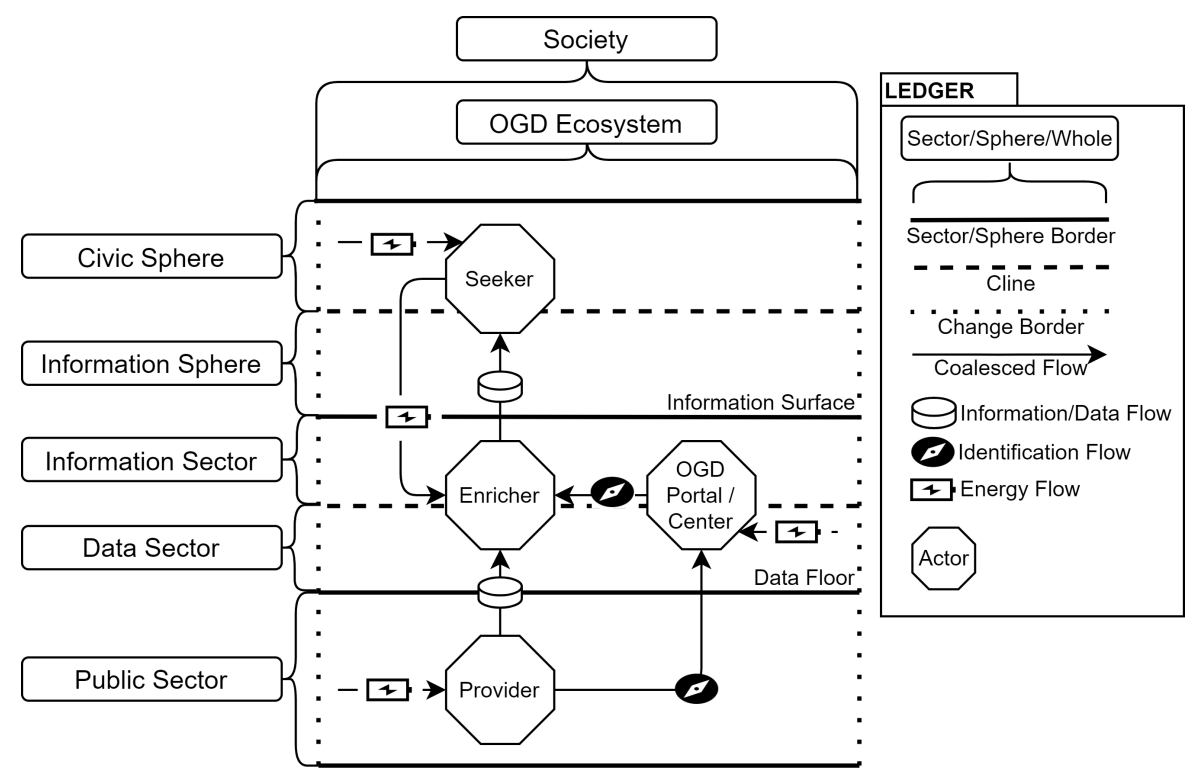

Figure 5.4: An overview of an OGD ecosystem

In the list below, I introduce each layer from top to bottom.

The civic sphere is the area furthest away from the ocean where seekers live in clouds of everyday life. Their information needs are not directly accessible to OGD actors; rather, they might need some help to express them (Westbrook, 1993: Crusoe, Gebka, and Ahlin, 2020b; Gebka, Crusoe, and Ahlin, 2020a). Seekers can, for example, use OGD when they travel public transport, partake in the news, or want to find public toilets (Bichard and Knight, 2012. Crusoe and Ahlin, 2019b. Crusoe, 2021a). This sphere is introduced in Section 2.5 as the civic sphere.

The information sphere is the area above the ocean where seekers can encounter and discover information solutions based on infrastructure. It encompasses, for example, roads with billboards, websites presenting customized advertisements, search engines, and libraries (based on Moore, 1997. Bernays, 
2005 Nicholas and Herman, 2010: Buckland, 2017). These solutions create an information surface that obfuscates the work behind them. Access to the solutions can be restricted and limited. This sphere is introduced in Section 2.5 as the information sector and the data-information society.

The information sector is the area below the information surface. It is populated with actors that work to create distribution infrastructure and information solutions (based on Moore, 1997; Ohlman, 2002: Day, 2002). Enrichers can be part of this sector, as they can acquire data from providers and enrich them to solutions, possibly adding them to the information surface. Enrichers also contribute to the creation of a cline between the information and data sectors, as they can have nodes to acquire data from providers in the data sector and nodes to deploy information solutions in the information sector (Crusoe and Ahlin, 2019b). This sector is introduced in Section 2.5 as the information sector.

The data sector is the area populated with actors that work with data, and I believe it to be the heart of an OGD ecosystem. It contains nodes and flows of providers and enrichers (based on Alter, 2003b: Crusoe, Zuiderwijk, and Melin, 2020. De Saulles, 2020. Lee and Cook, 2020). However, it is deep below the information surface and requires certain knowledge to navigate and know-how (Crusoe, 2021a). This sector is introduced in Section 2.5 as the data sector.

The public sector is the foundation of an OGD ecosystem deep below the information surface. Its mountains can stretch through the sectors into the spheres and deep into the ground to form dark trenches. On the data floor, data provision nodes pulse to share data with enrichers and seekers that visit them. Beneath this floor, public organizations work with data and information for their own purposes (based on Harrison, Pardo, and Cook, 2012. Heimstädt, Saunderson, and Heath, 2014. De Vries, 2016). This floor is introduced in Section 2.5 as the public sector.

An OGD ecosystem also has data-information cycles, energy flows, and health.

Data-Information Cycles. I understand an OGD ecosystem to contain several data-information cycles ${ }^{14}$ In a data-information cycle, the public sector provides data towards the information surface; along the way, enrichers can transform them into information (Ubaldi, 2013: Lindman, Kinnari, and Rossi, 2016: Berends, Carrara, Engbers, and Vollers, 2017). My perception adds two dimensions to each of the actions presented in the simple element cycle framework of Weathers, Strayer, and Likens (2012) (see Section 2.4): moving, sticking, and changing. My perception is also based on Section 2.1. Moving becomes copying and transferring. Copying happens when data and information are copied, such as when an enricher downloads data from a provider to process them locally. The original data are still stored on the servers of the provider, which allows others to access them (Crusoe and Ahlin, 2019b; Crusoe,

\footnotetext{
${ }^{14}$ I use cycles and flows as synonymous because of the reciprocal structure (see Section 5.1.
} 
Simonofski, and Clarinval, 2020). Transferring happens when data and information are moved from one location to another location without existing at the previous location. For example, the Swedish National Archives had the mission to receive and preserve data from other public organizations (Crusoe, 2021a). Sticking is divided into encoding and storing. Encoding happens when an actor records and encodes facts as data or information on a medium. For example, the Building and Environment Committee of Linköping municipality collected food data about organizations that produced food for consumers. Its inspectors visited organizations and, based on a checklist, took notes. The inspectors then recorded the notes in their IT-system as data that partly were made available as OGD. Storing happens when data and information are held within a medium for long-term preservation (Carrara, Oudkerk, Van Steenbergen, and Tinholt, 2018). Finally, changing is divided into processing and making. Processing happens when an actor works with the data and information to, for example, draw conclusions, clean them, or restructure them. Processing is also known as rawification for providers (Denis and Goëta, 2014) and enriching for enrichers (Crusoe and Ahlin, 2019b). Making happens when an actor creates a product or service with data or information. For example, visualizations, digital stories, and reports (Crusoe and Ahlin, 2019b). I perceive the assumed data-information cycle to be providers encode, process, and store data, enrichers process and make data into information, seekers process data or information. An underlying distribution system helps to copy data and information between the OGD actors (Crusoe, Zuiderwijk, and Melin, 2020). This cycle meanders through the public sector, data sector, information sector, information sphere, and civic sphere. I believe it could start and end with the same public organization that is both a provider and a seeker (Heimstädt, Saunderson, and Heath, 2014).

Energy Flow. OGD actors need the energy to build and maintain an OGD ecosystem against entropy (see Section 2.4. I understand that the energy within an OGD ecosystem is substituted by money and other resources (e.g., spare time). Hossain, Dwivedi, and Rana (2016) explain that acquiring and publishing data cost money while publishing data could lessen the income of a public organization. In my research of Crusoe (2021a), this substitution was captured in resource allocation and cumbersome use. In my research of Crusoe, Simonofski, Clarinval, and Gebka (2019), enrichers spent more time preparing data of low quality. Energy is not isolated within an OGD ecosystem and can be loaded from or exported to other ecosystems. For example, the developer of the Matkollen app worked with OGD as a side business within his consultancy, and the developer of Resledaren worked as a developer at a consultancy, and his OGD work happened in his spare time. His work has also been financed by two cultivators. The two apps were free to use by seekers (Crusoe, 2021a). I understand that energy can be generated, transported, stored, and consumed while always being captured in something (e.g., food or money) (see Section 2.4.

Health. I define health as the ability of an OGD ecosystem to achieve its higher purpose while benefiting its actors without harming society and actors (based on Rapport, Gaudet, Constanza, Epstein, and Levins, 2009. Iansiti and Levien, 2004. Mars, Bronstein, and Lusch, 2012; Wang, Zhao, Zhao, and Chu, 2019). Health has two sides: evolution and homeostasis. Evolution is transformations and changes to- 
wards better health (see Section 2.4, while homeostasis is the ability of actors and their OGD ecosystem to keep internal conditions the same despite any changes to external conditions (Homeostasis. 2021). Evolution consists of the dimensions of mutation ${ }^{15}$ and realization (Crusoe, 2021a). It is concerned with nodes and flows. It relates to self-evaluation as betterment and evaluation of others as co-evolution and can be influenced by evaluations of its OGD ecosystem. The two dimensions of evolution have different focuses. Mutation relates to unknowns and the persuasion and transformation of an OGD reform, while realization relates to the known and the collaboration, evaluation, and higher purpose of an OGD reform. Mutation is concerned with the ability of actors to adapt to permanent changes, growth in significant membership and resources, and capacity to self-organize ${ }^{16}$ (Iansiti and Levien, 2004 Mars, Bronstein, and Lusch, 2012. Welle Donker and Loenen, 2017. Manikas and Hansen, 2013. Shi, Rong, and Shi, 2018). I clarify that mutation is the ability of actors to become within an environment. It is, for example, concerned with the first external transformation an actor goes through to become a provider or an enricher, but also elastic transformations that introduce original changes to an OGD ecosystem (see Section 5.2. Mutation has good health when cultivation nodes persuade actors to join its OGD ecosystem and transform them in collaboration with providers or enrichers (see Section 5.2. Realization is concerned with the actors' basic functions, engagement, and embeddedness to realize the higher purpose, which includes a clear vision, leadership, control, and communication channels (Mars, Bronstein, and Lusch, 2012. Lee, 2014. Welle Donker and Loenen, 2017, Shi, Rong, and Shi, 2018). I clarify that realization is about the continual realization of an OGD reform's higher purpose. It relates to elastic transformations of an OGD reform and evaluations that lead to betterment. Realization has good health when providers continuously provide data to enrichers who continuously provide solutions to seekers. As such, it is concerned with bringing more of the same. On the other hand, homeostasis consists of the dimensions of resilience and stability (Crusoe, 2021a). Its metaphor is that of the immune and repair system for OGD actors and their OGD ecosystem. Resilience is concerned with actors' ability to adapt, recover, and overcome short-term shocks, disruptions, and changes in the ecosystem (Iansiti and Levien, 2004: Manikas and Hansen, 2013). Stability is concerned with the ability of the ecosystem to avoid permanent changes, shocks, and disruptions that can harm the ecosystem and its elements and actors (Heimstädt, Saunderson, and Heath, 2014: Crusoe, 2019b.

Health is tied to the reciprocal structure of an OGD ecosystem (see section 5.1), but also data-information cycles and energy flows. Impediments can make it challenging to coalesce nodes and flows (Zuiderwijk, Janssen, Choenni, Meijer, and Alibaks, 2012. Barry and Bannister, 2014), as such make the contribution to the health of an OGD ecosystem difficult. Enrichers are dependent on providers for data, while providers are dependent on enrichers to make solutions with their data, as such realize benefits.

${ }^{15}$ I have changed the name from evolution to mutation to fit the concept better with my doctoral thesis and avoid confusion. I think that evolution projects a process of multiple actors who change over time, while mutation describes the ability of these actors to change.

${ }^{16}$ Welle Donker and Loenen 2017) explain that the capacity of self-organizing is how supply matches demand. 
If providers cannot publish data (e.g., as of revenue loss or laws (Barry and Bannister, 2014)), this situation prevents enrichers from coalescing nodes. Similarly, if providers provide low-quality data or low-quality access to their data, this situation can increase a need for extra energy and resources of enrichers, which makes a node more expensive to coalesce (Crusoe, Simonofski, Clarinval, and Gebka, 2019). At the same time, if providers cannot observe or identify the added value of enrichers, they can find it difficult to motivate energy investments into publishing and providing data (Crusoe, Simonofski, and Clarinval, 2020. Crusoe, 2021a). The health crux of an OGD ecosystem is that providers invest energy and resources to acquire and provide data to enrichers without an immediate energy return; where enrichers can make the data into valuable solutions, investing their energy and resources, which they deploy to seekers who can return energy to them.

The following sections present the civic and information spheres, the information and data sectors, and the public sector.

\section{The Civic and Information Spheres}

I have used previous research to connect the information needs of seekers with the solutions of enrichers and data of providers (Crusoe, Gebka, and Ahlin, 2020b). My empirical material has not focused on the civic and information spheres (see Section 1.4. The civic sphere is the everyday of seekers where data and solutions are stored and processed to satisfy information needs (see Section 2.5). When providers and enrichers provide data and solutions, they need to consider seekers' previous knowledge, social roles, preferences, environment, level of expertise, and commonality of information needs (Crusoe, Gebka, and Ahlin, 2020b). For example, an innovative developer (enricher) explained that she wanted data that support every stage in life, solving everyday problems or everyday needs. She wanted to transform the data into "Ah! This is how these [data] affect or are important to me [as a seeker]!" (FEM. Crusoe and Ahlin, 2019b). She gave an example of a notification service that could help seekers avoid contaminated food (e.g., to help a pregnant woman avoid listeria) (Crusoe and Ahlin, 2019b). The information sphere is the area where data and solutions are discovered and copied or transferred from the information surface to the civic sphere for storing and processing (Westbrook, 1993: Moore, 1997; Nicholas and Herman, 2010). As such, this surface is a border between an OGD ecosystem and the rest of society, populated with data and solutions. For example, a data journalist explained that he often researches for bigger editors to provide a basis based on various data types, where one type is OGD. His basis can be used in the writing of articles and news (Crusoe and Ahlin, 2019b). Enrichers and providers should for this border consider technical and social integration, alternatives, type of subject, and intended use of their data and solutions (Crusoe, Gebka, and Ahlin, 2020b).

Energy can cross the information surface to load an OGD ecosystem (based on Weathers, Strayer, and Likens, 2012). This loading happens through the interactions between enrichers and seekers, where enrichers provide solutions to seekers who generate energy in return for enrichers to use. This generation can be realized by a thirdparty who acts like an intermediary ( $\mathrm{O}^{\prime} \mathrm{Neil}, 2016$; De Saulles, 2020). For example, the CEO of an enricher sold its solution to municipalities that seekers then used. The 
solution translated OGD into multiple languages (Crusoe, 2021a). In contrast, the developer of Matkollen explained he could see the excitement and interest to consume data but is doubtful about seekers' willingness to pay for the data (Crusoe, 2021a). A developer of public transport services reflected on the question of financing and explained:

"The question is to do it the old fashion way for apps. Namely, commercial financing where the app is free or one-time payment without commercials. I believe in the latter. It would be difficult with variable costs." - Developer of public transport services, Enricher (FEM. Crusoe and Ahlin, 2019b).

Therefore, the energy loading into the information and data sectors of an OGD ecosystem can vary, but also something that can be considered by enrichers.

The seekers of the spheres can load an OGD ecosystem with energy through different interactions and flows. This energy could then be used for evolution and homeostasis by enrichers. The potential utility of solutions and the possible number of seekers seem to play an essential role in how much energy an enricher believes can load from the spheres. For example, low availability of data as coverage of geographical areas within a country or a small perceived customer volume can be impediments for providers and enrichers (Crusoe, 2021a). The needs of seekers create leeway for what are considered valuable solutions. I see that enrichers who fail to create a sustainable and continuous energy loading from the spheres are forced to load their energy from other ecosystems (Crusoe, Gebka, and Ahlin, 2020b. Crusoe, 2021a). At the same time, the rawness of data can make seekers unable to use them for any meaningful purpose within their lives (Weerakkody, Irani, Kapoor, Sivarajah, and Dwivedi, 2017). Enrichers play a vital role in assisting seekers in using the data (Hunnius and Krieger, 2014). Thus, the health of an OGD ecosystem is partly constrained by its ability to match solutions of enrichers and data of providers to the needs of seekers (Crusoe, Gebka, and Ahlin, 2020b).

\section{The Information and Data Sectors}

The information and data sectors are populated with actors who work with information and data in nodes. Enrichers coalesce three types of nodes: deployment, enrichment, and acquisition nodes. They also participate in nodes of identification that coalesce around OGD portals, forums, and hackathons (Crusoe and Ahlin, 2019b). The nodes of enrichers can contribute to the creation of a cline between the information and data sectors. This layer emerges when an enricher acquires data from a provider to provide an information solution. Its enrichment node takes in data and outputs information; as such, the node becomes a location where a sector shift happens. In sum, an OGD ecosystem consists of two areas (see Figure 5.4. The first is the strands of data-information cycles that accrue from the work of providers, enrichers, and seekers. Each cycle is a strand in the health of its OGD ecosystem. The second is the identification nodes that help OGD actors discover data (Kalampokis, Tambouris, and Tarabanis, 2011a: Crusoe and Ahlin, 2019b). 
Enrichers can deploy solutions on the information surface or in the data sector (Johnson and Greene, 2017). Deployment nodes involve storing, transferring, and copying solutions from enrichers to seekers (based on Moore, 1997; Buckland, 2017). Solutions leave their OGD ecosystem, and in return, seekers can load enrichers with energy. Two examples of deployment on the Swedish information surface were (1) the data journalists who produced articles and Newsworthy and (2) the Swedish researcher who developed the electric bus simulator (Crusoe and Ahlin, 2019b: Crusoe, 2021a). Two examples of deployment in the data sector were (1) a developer who was developing a train ticket API (Crusoe, 2021a) and (2) a developer who took PDFs from providers, processed them to be stored in a database, and then developed a service on the database to calculate routes and distances between train stations (Crusoe and Ahlin, 2019b). Enrichers can use existing information infrastructure to distribute their solutions, such as the Google Play for Android, App Store for iPhone, and websites on the Internet. The solutions are made in the enrichment nodes of enrichers.

In the enrichment nodes, enrichers process data by preparing and concocting them to make various solutions (Davies, 2010: Lindman, Kinnari, and Rossi, 2016. Johnson and Greene, 2017, Crusoe and Ahlin, 2019b). Low-quality data can increase the amount of energy needed to prepare the data for enriching and making (Crusoe, Simonofski, Clarinval, and Gebka, 2019). I have identified that the great variation in formats, content, details, IDs in or between data acted as an impediment that contributed to cumbersome use Crusoe (2021a). Cumbersome use acts like an energy sink that enrichers need to fill before they can continue making a solution for their OGD ecosystem (Crusoe, Simonofski, Clarinval, and Gebka, 2019). Enrichers prepare data by extracting, casting, mapping, restructuring, and pruning them (Crusoe and Ahlin, 2019b). They can then concoct the data by analyzing or processing them, which can be captured in a solution. Alternatively, the created processes are developed into digital solutions, which helps to (semi-)automate them. The latter approach allows for interactive maps, e-services, and collaborative data tagging (Crusoe and Ahlin, 2019b. I understand that energy invested in filling an energy sink is not invested in increasing the realization and the homeostasis of an OGD ecosystem's health. The activity redirects energy from making solutions that could have loaded enrichers with energy.

In the acquisition nodes, enrichers copy data from providers to store or process them (Zuiderwijk, Janssen, and Davis, 2014 Lindman, Kinnari, and Rossi, 2016; Carrara, Oudkerk, Van Steenbergen, and Tinholt, 2018). This type of node involves access to, and delivery of data (Crusoe and Ahlin, 2019b), as such elements of a provider and elements of an enricher coalesce as a node. Providers can also allow enrichers to provide feedback so that they may improve the quality of their data provision (Charalabidis et al., 2018. Crusoe, Simonofski, and Clarinval, 2020). Enrichers need to consider the origin of data, the privacy of data, and the role of data in their solutions. Data can originate from seekers and other sources than providers (Crusoe, Gebka, and Ahlin, 2020b). I have identified that complexities in access and delivery in and between providers can contribute to cumbersome use (Crusoe, 2021a). However, the inability to access data can mean enrichers might need to abandon or change their idea about a possible solution (Crusoe, Simonofski, Clarinval, and Gebka, 2019). In contrast, difficulties in delivering the data can, for example, mean enrichers need to 
invest energy in reading documentation and developing software to connect to a data storage (a form of energy sink) (Crusoe and Ahlin,2019b). The inability to access data can lead to another type of problem than cumbersome use. A hobby programmer and nature conservation activist explained: "It may be that some data are very useful, but are not available everywhere, for example, different county administrative boards have different data available for their respective counties" (FEM. Crusoe and Ahlin, 2019b. Crusoe, 2021a). I understand that the lack of coverage and OGD can constrain the evolution of enrichers since their ideas may not be feasible, and low-quality data can be unreliable. For example, the previously mentioned notification service for contaminated food was impeded, as the underlying data were only available in notifications on the Swedish Food Agency's website and not as OGD (Crusoe and Ahlin, 2019b: Crusoe, 2021a). At the same time, enrichers need to decide if copied data should be locally stored for present and future use or only acquired, processed, and discarded once the solutions are made. In the case of digital solutions, solutions can acquire and process data and discard them once closed by their seekers (Crusoe and Ahlin, 2019b). If enrichers downloaded data to store them locally without using them, they would have an unused data storage element. Thus, acquisition nodes are couplings constructed by enrichers based on the data provision nodes of providers (see Section 2.2. I believe the life expectancy and structure of acquisition nodes vary depending on the recurrent need to acquire the data by enrichers.

In the identification nodes, providers can make their data discoverable to enrichers and seekers (Kalampokis, Tambouris, and Tarabanis, 2011a: Colpaert, Joye, Mechant, Mannens, and Walle, 2013). In Sweden, a common solution was various forms of OGD portals (Crusoe, 2021a), but I also identified an OGD center ${ }^{17}$ Hackathons, digital groups, and forums can also act as this type of node (Crusoe and Ahlin, 2019b). In Crusoe (2021a), four enrichers had experienced impediments when trying to discover data in Sweden. The developer of Matkollen explained:

"The big challenge is to find data. You have to google using various keywords and hope you get some hits on municipal websites. Then, you have to dig around on the websites and call

someone. The biggest challenge is to find data. Stockholm has an OGD portal. If such a portal existed for all of Sweden's public organizations, then it would have been much easier." - Developer, Enricher (FEM. Crusoe,2021a).

At the time, the Swedish OGD portal existed under the name "www.oppnadata.se". I believe the developer of the above quote did not know about the Swedish OGD portal. At the same time, I have experienced that providers do not always clearly state that their data are OGD. For example, the Swedish Board of Student Finance had a webpage for official statistics that were open and free for use by anyone ${ }^{18}$ However, the term "open data" was not mentioned on this webpage, while the data were registered on the Swedish OGD portal. Thus, I understand that identification nodes elucidate an OGD ecosystem by highlighting some data provision nodes for enrichers that distances and infrastructure would have obfuscated. Impediments of identification nodes can, thus, impede the evolution of an OGD ecosystem, as enrichers do

\footnotetext{
17 https://www.kolada.se/

${ }^{18}$ https://www.csn.se/om-csn/statistik-och-rapporter/officiell-statistik.html
} 
not discover data (Zuiderwijk, Janssen, Choenni, Meijer, and Alibaks, 2012: Crusoe, 2021a).

\section{The Public Sector}

In the public sector, public organizations work to provide public goods to the civic sphere (De Vries, 2016). Their work stretches deep within the public sector and, at some locations, breaks through the data floor. Their work consists of an extensive collection of various nodes, but for OGD, two types of nodes are interesting: (1) provision and (2) acquisition.

Provision nodes populate the data floor (see Figure 5.4. Each consists of a webpage or local OGD portal that highlights some access points of processes that connect with acquisition nodes (Hunnius and Krieger, 2014: Zuiderwijk, Janssen, and Davis, 2014. Carrara, Oudkerk, Van Steenbergen, and Tinholt, 2018). These processes copy and clean data from their acquisition nodes so that enrichers and seekers can copy the data at the access points. If the data are sensitive, a process can contain intermediary storage to protect the internal work of the provider (Denis and Goëta, 2014. Zuiderwijk, Janssen, and Davis, 2014: Carrara, Oudkerk, Van Steenbergen, and Tinholt, 2018. Crusoe, Simonofski, and Clarinval, 2020). For example, Linköping municipality had a local OGD portal where enrichers and seekers could search amongst 18 datasets 19 , read their metadata, visit their access points, and download the data. At the datas' access points, enrichers and seekers could read the documentation about how to understand and access the data and sometimes see the data on an interactive map layer ${ }^{20}$ One of the processes led to the municipality's statistical database where enrichers and seekers could access several datasets ${ }^{21}$ In addition, the municipality had recently developed a visualization tool for its $\mathrm{OGD}^{22}$, which could help enrichers and seekers understand its data (Crusoe, Simonofski, and Clarinval, 2020). When Linköping municipality published food data, its OGD manager involved a system manager (changer) in helping him build the cleaning of the data. The changer explained his role as follows:

"It is important to know what data are released. It is not so complicated. I am the bridge, but not the one that builds. Someone else slurps the data out from our IT-system and packages it.

There is a border between our database and OGD. It is what the OGD manager and his

colleagues work with." - System manager, Linköping municipality (FEM. Crusoe,

Simonofski, and Clarinval, 2020).

However, the benefits of provision nodes are not straightforward, as providers supply the data sector with data; this work requires an investment of energy (Hossain, Dwivedi, and Rana, 2016; Safarov, Meijer, and Grimmelikhuijsen, 2017, Zuiderwijk, Shinde, and Janssen, 2019. Jamieson, Wilson, and Martin, 2019. Crusoe, 2021a). On

\footnotetext{
19 https://www.linkoping.se/open/: Counted on 2021-05-26.

${ }_{2 C}$ http://kartan.linkoping.se/spatialmap?

${ }^{21}$ http://statistik.linkoping.se/

${ }^{22}$ https://www.linkoping.se/datavisualisering/
} 
the other hand, it could also release trapped energy. For example, the Swedish National Space Agency was forced to withdraw a dataset since it became too expensive to provide the data, and the Swedish Mapping, Cadastral, and Land Registration Authority was largely fee-founded, which meant releasing OGD would lower its energy loading. A lowering it could not afford. On the other hand, Uppsala municipality was able to save one year of full-time working hours in lowered administration by releasing map layer data about its territory, Linköping municipality was able to identify the utility of its data by contacting enrichers over e-mail, and the OGD manager of the Swedish Transport Administration explained "Of course it costs money to build APIs and maintain them, but nobody has protested that it has become too expensive" (FEM. Crusoe, 2021a). I understand that provider nodes are fundamental to the health of an OGD ecosystem, as they provide enrichers with the leeway to evolve within and a stable source of free data. Without these nodes, enrichers are forced to either give up or find alternative methods of acquiring data (Crusoe and Ahlin, 2019b: Crusoe, 2021a).

In the acquisition nodes, the members of public organizations participate in their day-to-day work and acquire data. The work of acquiring data can mean encoding facts as data on a medium, transferring data from one source to central storage, and copying data from one location to another. The members can then process and make solutions with the data in their work (Conradie and Choenni, 2014: Denis and Goëta, 2014. Carrara, Oudkerk, Van Steenbergen, and Tinholt, 2018). They might order a data delivery from consultants (like the GeoArchive of the City of Stockholm), receive archives from other public organizations (like the Swedish National Archives and the Swedish National Space Agency), collect data using sensors (e.g., about the bike traffic in Linköping municipality), or manually collect data (like the Building and Environment Committee of Linköping municipality) (Crusoe, Simonofski, and Clarinval, 2020: Crusoe, 2021a). Enrichers can notice and be impacted by how the data is acquired. For example, a hobby programmer and nature conservation activist explained:

"I have mostly worked with geodata, which is nationwide. The data can be varying in quality in different parts of the country. It is sometimes, for example, based on field studies and sometimes based on interpretations of orthophoto or satellite pictures." - Hobby programmer and nature conservation activist, Enricher (FEM. Crusoe, 2021a).

The process of copying data from the IT-system of an acquisition node can be difficult, as the system is old and not made for OGD or restricted because of IT-contracts (Crusoe, 2021a). The OGD manager of Umeå municipality had experienced problems with data disorder as administrators encode data differently (Crusoe, 2021a). The same OGD manager had also experienced impediments with IT-systems, as the logic of the data was not stored in the database. Instead, the logic was part of the software that used the database (Crusoe, 2021a). I have observed that impediments of data disorder, traditions, IT-systems, secrecy, security, and laws can increase the metaphorical size of an energy sink for providers (similar to the one experienced for enrichers) (Crusoe, 2021a). However, I see a difference between the energy sink of providers and enrichers. For example, let us assume that a group of providers fol- 
lows the first step of Berners-Lee (2015)'s five-star provider scheme to provide data in the format of PDF. An enricher copies the data from their PDFs and then enters them into a database to process them for some purpose (Crusoe and Ahlin, 2019b). On the other hand, if the providers instead used the second step of Berners-Lee (2015) to provide structured digital data, the enricher would have skipped the step to read and enter the data into the database, as it could have automated the extraction of data from the digital packages. A consequence is that a part of the providers' energy sinks was transferred to the enricher who wants to use the data in a digital format. I extrapolate that what is possibly good for a provider can mean more work for an enricher (Janssen, Charalabidis, and Zuiderwijk, 2012), as such, the health of an OGD ecosystem can contain conflicting needs.

\subsection{Interplay and Health}

This section focuses on how the interplay between an OGD reform and an OGD ecosystem can affect the health of the OGD ecosystem. Figure 5.5 gives an overview of this interplay. Providers and enrichers can own and participate in nodes of an OGD ecosystem (see section 5.3. The nodes of providers and the needs of seekers terraform the landscape of enrichers. Terraform means to change an environment to make it more hospitable or suitable for actors (Terraform. 2021). This landscape represents how easy or difficult it is for enrichers to bridge the gap between data provision of providers and the needs of seekers. Cultivators can arrange transformation nodes (e.g., hackathons and open data forums) and mutation-load OGD actors. OGD actors can step between transformation nodes, their nodes, and other nodes. Mutation-loading can encourage or enable certain mutations of OGD actors by introducing higher purposes, leeway, and energy to the OGD actors. Interwoven are purpose flows that motivate OGD actors to continue their OGD reform and their OGD ecosystem. In this section, I present the terraforming of OGD landscapes, the ability of actors to step between an OGD ecosystem and an OGD reform, mutation-loading, and purpose flows.

\section{Terraform OGD Landscapes}

An OGD landscape represents the degrees of adaptation for OGD actors in an environment towards the health of an OGD ecosystem (see Section 2.4. I argue that the landscape metaphor helps to reveal how the work of OGD actors and their environments can impact each other's work. However, I admit that the non-reflective use of the metaphor can create normative directions for transformations and evolutions and simplifying interactions. It connects back to the energy sinks explained above.

OGD actors can traverse an OGD landscape in an attempt to increase their health. They do this movement by transforming their local conditions, which consume energy and resources. The landscape's peaks and valleys are made from their environment and terraformed by other actors. High peaks represent better health, while deep valleys represent poor health. Their inclination represents the energy and resource costs to traverse their sides. An energy sink would contribute to making a peak steeper and a valley slipperier. In addition, actors can have expectations about 


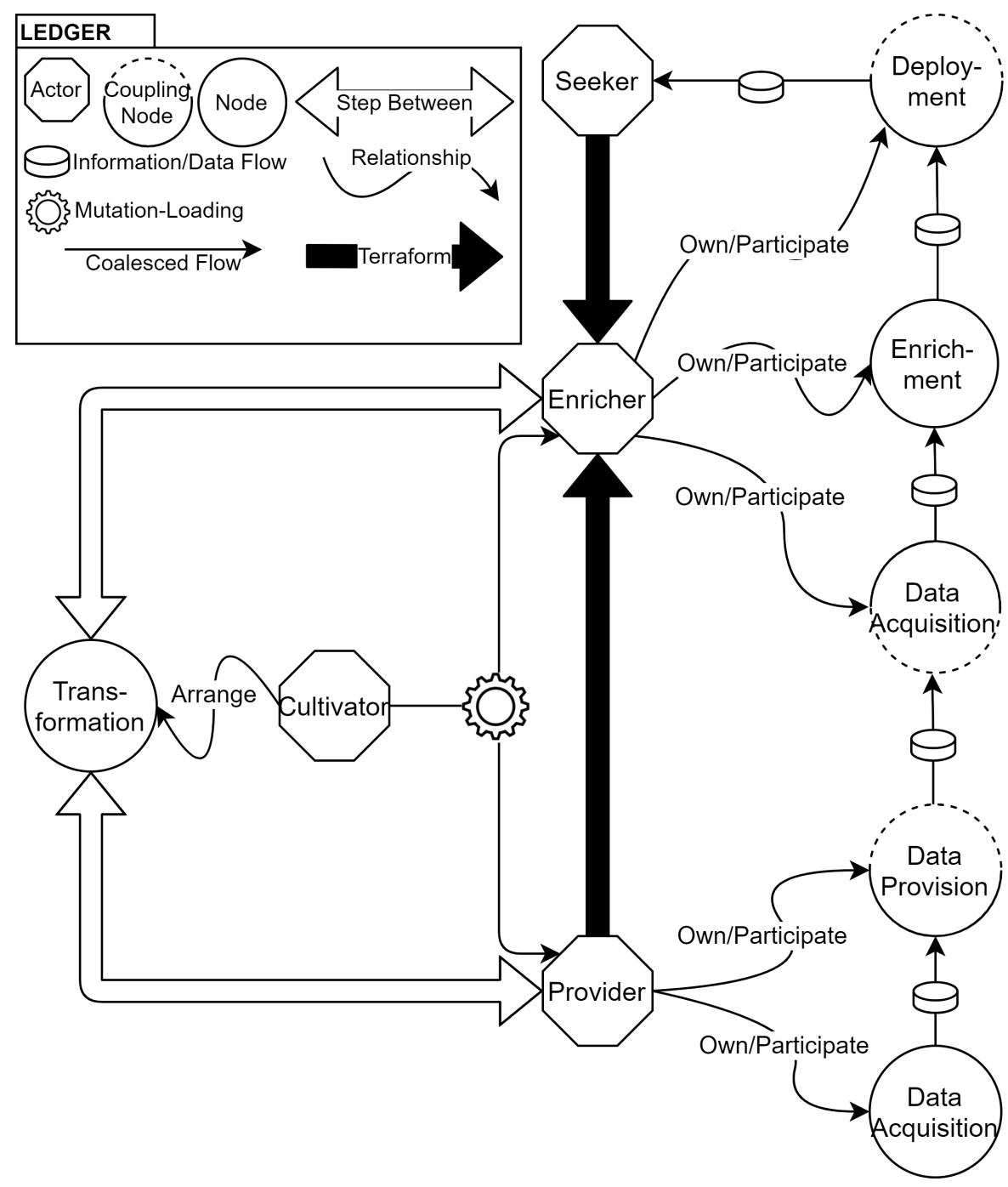

Figure 5.5: An overview of the interplay between an OGD reform and an OGD ecosystem that can affect the health of an OGD ecosystem. 
the topography of their landscape. Public organizations live within their public goods landscape (see Section 2.5 and can terraform the data landscape when they implement or develop their data provision nodes. This data landscape is the data floor within an OGD ecosystem (see Section 5.3. Seekers live within their civic landscape, and their needs can terraform the information landscape. The information landscape is the information surface of an OGD ecosystem (see Section 5.3. Enrichers live within the data landscape and seek to deploy solutions in the information landscape. They can terraform the data landscape by providing data (Davies, 2010. Lindman, Kinnari, and Rossi, 2016) or terraform the information landscape by conducting propaganda (see Section 2.5.

Providers and enrichers can have expectations on their landscapes, which can create expected peaks and valleys. These expectations are generated through persuasion and collaboration about conditions for certain elements where cultivators are main contributors (see Section 5.2). For example, enrichers can expect interoperability of data, machine-processable data, and open by default approaches from providers (Tauberer and Lessig, 2007; Open Data Charter, 2015: Open Data Handbook, 2015), while providers can expect enrichers to help seekers save lives, time, and resources and take better decisions (Carrara, Chan, Fischer, and Steenbergen, 2015). The digitalization director at Linköping municipality gave an example of a vision for OGD connected with the municipality's digital transformation:

"Now, when we plant our trees in the city, it is with moisture sensors. It means we patrol our trees less. Because, we only water them when they need it. We can basically ask if it is the role of the municipality to water the trees? If we plant the trees and publish the moisture data as OGD, then the district could water its own trees." - Digitalization director, Linköping municipality (FEM. Crusoe, Simonofski, and Clarinval, 2020).

Any divergence between OGD actors' expectations and their landscape can be experienced as impediments for them (Zuiderwijk, Janssen, Choenni, Meijer, and Alibaks, 2012. Beno, Figl, Umbrich, and Polleres, 2017; Zuiderwijk and Janssen, 2014a), such as social distance for enrichers and OGD as sidecar work for providers (Crusoe, 2021a). This situation means OGD actors are tension points between the expectations of an OGD reform and the reality of an OGD ecosystem. This tension can be seen in the information landscape and the data landscape.

In the information landscape, islands with mountains are terraformed based on certain information needs of seekers (e.g., know the weather of today for dressing (Crusoe, Gebka, and Ahlin, 2020b) or avoid contaminated food (Crusoe and Ahlin, 2019b)). The islands are populated with alternative solutions that can compete against the solutions of enrichers. For example, the Swedish Meteorological and Hydrological Institute's website compete with the weather app of an enricher (Sveriges meteorologiska och hydrologiska institut, 2021: Kron, 2021) and enrichers' public transport can compete against each other (e.g., City Mapper, 2020. Nilsson, 2020. Skjutsgruppen, 2020). An island's mountains rise based on complex combinations of seekers' previous knowledge, social roles, preferences, environment, level of expertise, and commonality of information need (Crusoe, Gebka, and Ahlin, 2020b). I have observed that these combinations can make a mountain rises several peaks. 
For example, the mountain of journey planning at the island of public transport has at least two peaks. One peak is for people with disabilities climbed by the app of Resledaren (Resledaren, 2021) and the other peak is for carpooling climbed by the app of Skjutsgruppen (Skjutsgruppen, 2020). I claim that solutions that climb towards a peak generate more energy while being easier to discover and more beneficial to seekers. A solution on a peak assumably contributes to realizing the higher purpose of an OGD ecosystem. The commonality of information needs limits the height of a peak (Crusoe, Gebka, and Ahlin, 2020b. Crusoe, 2021a). I have also learned that cultivators can guide enrichers toward deploying solutions on certain mountains, meaning some islands can be considered more legitimate than others. This legitimization is based on the higher purpose of an OGD reform, such as the realization of innovation, transparency, public engagement, or improved solutions (Janssen, Charalabidis, and Zuiderwijk, 2012. Hartog, Mulder, Spée, Visser, and Gribnau, 2014. Kucera and Chlapek, 2014: Schrier, 2014. Safarov, Meijer, and Grimmelikhuijsen, 2017). For example, a senior adviser at the Swedish Government Offices stated that, in 2017, the Swedish Government decided to fund Hack for Sweden, but required that some public agencies presented challenges to solve. He explained that this approach introduced social needs and moved away from Hackathons as only something fun. He continued that, in 2018, the Swedish Government added the requirement to the Swedish Public Employment Service to work with innovative procurement methods, which would help new enrichers to create sustainable solutions. These requirements changed Hack for Sweden from a yearly hackathon to Hack for Sweden 365. The hackathon became an innovation system to build a data-driven culture where public agencies could present new challenges every day (Crusoe, 2021a). I understand that these requirements were introduced by the Swedish Government (as a cultivator) to better anchor the cultivation of enrichers in certain needs of seekers and increase the evolutionary health of their OGD ecosystem based on the higher purpose of the Swedish OGD reform. As a result, in the information landscape, the tension experienced by OGD actors can take the forms of competition between solutions and the legitimization of information islands.

The data landscape is populated by enrichers while being terraformed by providers when they traverse their public goods landscape. OGD actors persuade public organizations to accept transformations to their public goods landscape, such as data provision and possibly the need to be a cultivator (Crusoe, Simonofski, and Clarinval, 2020. Crusoe, 2021a). They attempt to add new peaks and valleys to the public goods landscape based on distributed solutions that providers need to climb and avoid. The peaks' and valleys' inclinations change based on the impediments experienced by providers. At the same time, their government has defined the height of the public goods landscape (see Section 2.5), which an OGD reform could attempt to influence. I claim that providers who climb towards a peak increase the utility of their data while decreasing the energy cost to maintain the provision and acquisition nodes 23 This climb is done by providers transforming local conditions, which requires energy and resources. This climb also terraforms the landscape of enrichers, such as increasing the availability of data and the size of energy sink (Crusoe and Ahlin, 2019b: Crusoe,

${ }^{23}$ I want to clarify that it is possible that a peak can reach the summit before the utility of data reaches $100 \%$ and energy cost of maintenance reaches $0 \%$. 
2021a). In sum, providers become part of enrichers' data landscape by transforming within their own public goods landscape, which can deviate from enrichers' expectations about their data landscape. The expectations of an OGD reform contribute to the height and slope of the mountains for providers but could smooth them for enrichers. However, steeper mountains mean reformists need to invest more resources and time to transform their conditions. I have formulated this problem as energy sinks of enrichers and providers (see Section 5.3 and Section 5.3. I see that this situation raises a question of the division of labor between providers and enrichers. At the same time, providers and enrichers can experience impediments that prevent their ability to climb or increase the energy cost by increasing the incline of the mountains (Crusoe, 2021a). They can, as such, get stuck somewhere between the feet or peak of a mountain, which means the health of an OGD ecosystem can be impeded. Consequently, I understand that providers are health makers of an OGD ecosystem, but they could be in a position where an OGD reform gives unrealistic promises to enrichers. I have observed that the gap between promises and data provision can create impediments for enrichers and contributes to friction and frustration in the collaborations of an OGD reform (Crusoe, 2021a). As a result, in the data landscape, the tension experienced by OGD actors can take the form of public goods versus OGD expectations.

\section{Step Out and Into}

OGD actors can participate in nodes as elements without being permanent parts of them (see Section 5.1). They have the ability to step out of one node to step into another node. At the same time, they can carry things with them. As a result, an OGD actor could step between a node of its OGD ecosystem and a node of its OGD reform while bringing solutions and ideas with it. The solutions and ideas can then be shared with other OGD actors (Crusoe, Simonofski, and Clarinval, 2020: Crusoe, 2021a).

When OGD actors step out from their OGD ecosystem and into a node of their OGD reform, they can avoid some of its rules. These rules are not laws. For example, providers are supposed to allow for anonymous access to their data (Tauberer and Lessig, 2007), which the OGD manager of Linköping municipality explained is the case, but the municipality also asked for e-mail addresses from enrichers to give them API-keys. This setup allowed the municipality to cut the connect for a single enricher if anything weird would start to happen to its APIs (Crusoe, Simonofski, and Clarinval, 2020). On the other hand, the anonymity means providers have limited insight into how they contribute to data-information cycles and if their OGD ecosystem realizes the higher purpose of their OGD reform. Enrichers can also experience difficulties seeing the work of providers. For example, an enterprise architect of an enricher described providers as isolated behind a firewall with small slots used for communication, and a developer complained about anonymous web-forms and an inability to communicate with real people (Crusoe, 2021a). An OGD reform can overcome this problem by coalescing transformative nodes (e.g., open data forums). OGD actors can then step out of their nodes to step into a transformative node. Here, OGD actors can deliberate, provide feedback, and distribute solutions. In addition, external 
actors can enter to be persuaded to join an OGD reform or an OGD ecosystem and allow helpers to reach a wider audience.

OGD actors can refuse to participate in transformative nodes or prefer one format over another. For example, the OGD manager of Umeå municipality experienced disinterest from a developer community towards hackathons and students aimed more for fun than the realization of value; the CEO of an enricher criticized hackathons and wanted some kind of forum; and the OGD manager of the Swedish Board of Student Finance explained that he does not actively participate in transformative nodes, but he had previously participated in Hack for Sweden and one open data forum of Sweden's Innovation Agency to present the organization's work with OGD (Crusoe, 2021a).

Thus, I understand that cultivators can coalesce transformative nodes, but they require the participation of reformists. The nodes can help OGD actors see the various nodes of their OGD ecosystem and how their nodes contribute to their OGD reform's higher purpose. It is also an opportunity to persuade other actors to join their OGD reform or their OGD ecosystem. As a result, transformative nodes can encourage the evolution of an OGD ecosystem and be a location for the creation of stability (homeostasis). I believe that open communication can help OGD actors understand how their actions can impact each other and, in turn, affect the health of their OGD ecosystem. However, a developer explained that there is no natural place to continue these types of discussions after the transformative node is dismantled (Crusoe, 2021a). As such, once OGD actors step out of an OGD reform and step into an OGD ecosystem, they may leave certain matters behind.

The OGD actors' ability to step out and into nodes can merge the collaboration, transformation, and evaluation of an OGD reform as a confluence. For example, the National Service for Open Data (Melin, 2016), Open North, and the Swedish OGD portal (Crusoe, 2021a) were collaborative projects between actors that acted to produce something for their OGD ecosystem. The National Service for Open Data is explained above (see Section 5.2. . Open North was a north regional OGD portal developed in collaboration between Umeå municipality, Skellefteå municipality, Luleå University of Technology, and Umeå University 24. The Swedish OGD portal was (according to me) a good example of an IT-artifact that has iterated several times between collaboration, transformation, and evaluation and been carried between nodes. The first version of the Swedish OGD portal was procured as a beta-portal in 2012 by Sweden's Innovation Agency. It acted foremost as a basis for evaluation and a point of departure for dialogue. The agency collected insights about the possible future design of an OGD portal through dialogues and personal use. It hosted a workshop to evaluate the current OGD portal and support future developments in 2013. The agency procured a new OGD portal based on the open-source solution of CKAN. This type of portal provides a catalog of metadata that links to data, which (according to the agency) was in line with the majority of the OGD portals within the EU. Sweden's Innovation Agency then procured the development for the OGD portal to include the recommended DCAT-AP metadata standard, which made it possible to harvest metadata from providers automatically. In 2016, Sweden's Innovation Agency

24 https://www.ltu.se/centres/cdt/Projekt/Pagaende-projekt/Open-North-1.121038 
(based on a mission from the government) gave the Swedish National Archives the Swedish OGD portal. The archives evaluated the OGD portal, and a new version of the Swedish OGD portal was launched in 2017. The old OGD portal was merged with a guidance platform for providers and then included a section for a blog, good examples of providers and enrichers, and make-a-wish for data publication. In 2018, the OGD portal was taken over by the Swedish Agency for Digital Government. The new owner replaced the OGD portal in 2020 with an OGD portal that included a data catalog, news section, and community forum section (https://www.dataportal.se/) (Crusoe, 2021a). Similar reform work has run its course for a general OGD publishing process in Sweden. I have mentioned most of the distribution previously in this chapter as it has traveled from the Swedish Environmental Protection Agency to the Swedish Transport Administration, the Swedish Tax Agency, and other providers. The latest project in this series is the EU-project "Increased Use of Open Data in the Stockholm Region" (Crusoe, Simonofski, and Clarinval, 2020). As a result, I see that an OGD reform is not uniform. It consists of multiple transformation nodes that form a metaphorical bubbling primordial soup within an OGD ecosystem. The soup means the evolution of an OGD ecosystem happens at several locations simultaneously, could influence each other, and diverge or converge the transformation of nodes. These nodes blur the line between an OGD reform and an OGD ecosystem. Thus, the health of an OGD reform and the health of an OGD ecosystem may be intertwined.

\section{Mutation-Loading and Purpose Flow}

An OGD reform introduces mutation-loading and purpose flow to an OGD ecosystem. Cultivators can mutation-load an OGD ecosystem by introducing rules, giving direction, and providing energy to OGD actors. Mutation-loading can, as such, introduce leeway and give higher purposes to govern mutation (see Section 5.1 and Section 5.3 and provide OGD actors with energy needed for transformations of their local conditions (see Section 5.2). Rules and leeway can, for example, be standards, open licenses, OGD principles, and value chains (Berners-Lee, 2015: Open Data Charter, 2015. Open Knowledge Foundation, 2020: Carrara, Chan, Fischer, and Steenbergen, 2015). OGD actors decide how to put rules and leeway into practice and if they want to follow them (e.g., Linköping municipality used e-mail registration, which could reduce anonymity of enrichers (Tauberer and Lessig, 2007. Crusoe, Simonofski, and Clarinval, 2020). Cultivators can give directions to OGD actors. For example, Huyer, Van Knippenberg, Arriëns, and Blank (2020) presented opportunities for value creation of OGD in Europe, Sweden's Digital First governmental program encouraged behaviors to match demand and supply (Crusoe, 2021a), Nordmark et al. (2016) demanded certain changes and actions, and Hack for Sweden 365 presented problems to be solved (Crusoe, 2021a). Cultivators can also provide OGD actors with energy to support the development of tools or conduct projects and work. For example, Sweden's Innovation Agency had the mission from the Swedish Government to stimulate OGD from 2012 to 2016. The agency financed about 130 projects and arranged several meet-ups, conferences, and meetings (Crusoe, 2021a). It has mutationloaded projects into, for example, the Swedish Environmental Protection Agency to produce two tools, Sambruk to develop an information classification system, and a 
developer to implement the first version of his public transport app for people with disabilities (Crusoe, 2021a). The OGD manager of Umeå municipality explained that almost all of the municipality's OGD projects had been funded by Sweden's Innovation Agency. He added "Sweden's Innovation Agency can finance $50 \%$ of a project, but it is often difficult to get the last $50 \%$. I wish the Swedish Government could co-finance to at least $75-80 \% "$ (FEM. Crusoe, 2021a). Therefore, I understand that mutation-loading allows an OGD ecosystem to evolve before it can internally generate enough energy to drive its evolution. It is like the umbilical cord between a mother and her child. It also governs the mutation of OGD actors towards a higher purpose of an OGD reform led by cultivators.

The purpose flow is human motivational energy that waxes and wanes as an OGD reform iterates between transformations and evaluations (see Section 5.2. The cycle exists in the interplay between an OGD reform and an OGD ecosystem. Reformists are charged through persuasion, collaborations, and previous evaluations. For example, the value stories of Open Data Handbook (2015), the debate articles of Computer Sweden (Nordmark et al., 2016. Lindström, 2018a Lindström, 2018b) and the argument of Shekarabi (2017). This charge can lead them to invest energy and resources into transforming local conditions to coalesce nodes. Actors can experience impediments that prevent their transformation or require extra energy to overcome (e.g., energy sink). The result is evaluated to identify how well it realized the higher purpose. I believe that success can further charge reformists, while perceived failures could disincentivize further work but sometimes charge it instead ${ }^{25}$ For example, the OGD manager of the Swedish Transport Administration explained that good examples and easy to use distributed solutions help to reduce impediments; the OGD manager of Skövde municipality explained it is difficult to motivate costs without an enricher who had promised to develop a solution or solve a problem; the OGD manager of Uppsala municipality considered than an arena to show good examples could help fuel the Swedish OGD reform; and a cultivator from Sweden's Innovation Agency explained that the nescience of OGD actors mean there are few good examples and role models (Crusoe, 2021a). In common, I have observed that an OGD reform is dependent on an OGD ecosystem to generate proof of its ability to realize the higher purpose of the OGD reform. As a result, the health of an OGD ecosystem could determine the fate of an OGD reform.

\subsection{A Summary of the RE-ECO Framework}

This chapter presented the reform-ecosystem (RE-ECO) framework for open government data developed in this doctoral thesis (see Section 4.4 and Figure 5.1. The framework is mainly conceptual and descriptive and, secondly, normative. Its purpose is to describe and help OGD researchers and OGD practitioners understand an OGD reform, an OGD ecosystem, and how their interplay can affect the health of the OGD ecosystem (Section 1.2. An OGD reform transforms a reciprocal structure to coalesce an OGD ecosystem (see Section 5.1 and Figure 5.2). This structure is part of society. The reforming actors decide and provide leeway and a higher purpose

\footnotetext{
${ }^{25}$ Why it varies my empirical material does not explain.
} 
to other actors, which, in turn, need certain roles that require certain functions. The rudimental higher purpose is to share and reuse data to realize benefits. The roles are providers, enrichers, seekers, OGD portals, and OGD centers.

An OGD reform transforms society through persuasion, collaboration, transformation, and evaluation (see Figure 5.3. OGD actors use persuasions to recruit actors to their OGD reform or their OGD ecosystem. It can be directed towards specific actors, broadcasted to an audience, or middle-grounded where actors are invited or participate in semi-private events (see Section 5.2). OGD actors use collaboration to solve problems and spread solutions. It can be to innovate solutions, distribute solutions, or imitate distributed solutions (see Section 5.2. OGD actors use transformations when they transform local conditions to coalesce their OGD ecosystem. It can be external or internal. Through an external transformation, OGD actors join or leave an OGD ecosystem. On the other hand, internal transformations can be preparatory towards external transformations or elastic to expand or shrink their work in their OGD ecosystem (see Section 5.2). The OGD actors can evaluate their work to transform it, the work of other OGD actors, their OGD ecosystem, and the OGD ecosystems of other countries. Evaluations help them to understand the status of their OGD ecosystem but could also fuel arguments to further their OGD reform (see Section 5.2.

An OGD ecosystem consists of two areas based on common infrastructure (that they share with other ecosystems) (see Section 5.3 and Figure 5.4). First, identification nodes enable the data from providers to be discovered by enrichers and seekers. These nodes help OGD actors to identify and understand data and their access points. Second, strands of data-information cycles copy and enrich data from the public sector to other sectors and the civic sphere. Each data-information cycle is a strand in the health of an OGD ecosystem, which means their ability to realize benefits or detriments affects this health. A consequence is that an OGD ecosystem can have a mix of strands in good and poor health. A data-information cycle consists of copying, transferring, encoding, storing, processing, and making data and information (see Section 5.3. These cycles meander through an OGD ecosystem, starting in the public sector and ending in the data sector, information sector, public sector, or civic sphere. As data are copied and transferred, they are exported from one ecosystem to be loaded into another ecosystem passing through borderlands, such as provision nodes or distribution infrastructure. The data can, through their cycles, be enriched to information. These cycles are sustained by energy flows, which an OGD ecosystem loads from other ecosystems (see Section 5.3). Providers should not sell their data. As such, they need to load energy to maintain their data provision from other ecosystems. Enrichers can generate energy from seekers using their solutions, but not directly by acquiring and enriching data.

The interplay between an OGD reform and an OGD ecosystem can affect the health of the ecosystem. The RE-ECO framework presents at least three possible ways (see Figure 5.5): (1) the terraforming of OGD landscapes, (2) actors step out and into nodes, and (3) mutation-loading.

OGD actors can terraform each other's landscapes when they transform their local conditions. A landscape represents the degrees of adaption for actors in an environment towards the health of an OGD ecosystem (see Section 5.4. Enrichers acquire 
data by adapting to the data landscape and can deploy solutions in the information landscape. The data landscape is terraformed when providers publish or withdraw data, while the information landscape is terraformed following seekers' needs.

OGD actors can step between nodes in their OGD reform and their OGD ecosystem (see Section 5.4). They can carry mutations, experiences with impediments, solutions, energy, motivations, identifications, data, and information. It also allows them to avoid certain rules of an OGD ecosystem and see the work of other OGD actors. Cultivators can coalesce transformative nodes for this purpose, which can act as a location for contributing to the stability of an OGD ecosystem.

Cultivators can mutation-load by (1) introducing rules, (2) giving direction, and (3) loading energy (see Section 5.4. Cultivators can introduce rules to an OGD ecosystem by cultivating and distributing standards, open licenses, OGD principles, value chains, and laws. Actors of an OGD ecosystem can decide to follow the rules or not. If they follow the rules, they need to decide how to put them into practice, leading to variations in application. Cultivators can give direction by distributing the possibilities of OGD (e.g., save lives and money), encouraging certain behaviors (e.g., match demand and supply), fueling motivation and purpose (e.g., demand certain changes and actions), and present problems to be solved (e.g., Hack for Sweden 365). Cultivators can also load an OGD ecosystem by, for example, financing projects of reformists and helpers. This loading can help OGD actors create tools and solutions for distribution or go through their first external transformation to become providers or enrichers. 



\section{Discussion}

This chapter discusses my disentanglement of an OGD reform and an OGD ecosystem, tension points of an OGD reform and an OGD ecosystem, cycles and flows, and then the interplay and its affect on the health of an OGD ecosystem. The discussion highlights some contributions of the RE-ECO framework and their importance in relation to previous OGD research. The concept of evolution is revisited through the discussion as it is related to an OGD reform and the health of an OGD ecosystem (see Section 5.2 and Section 5.3. I end the chapter with a summary of the discussion.

\subsection{My Disentanglement of an OGD Reform and an OGD Ecosystem}

I contribute to previous OGD research by disentangling an OGD reform and an OGD ecosystem. Previous OGD research tends to conflate an OGD reform and an OGD ecosystem by enveloping the elements of an OGD reform within an OGD ecosystem. For example, Dawes, Vidiasova, and Parkhimovich (2016) include activities within data provision to prepare and publish data for public use, and Lee (2014) includes data audits and data access in an OGD ecosystem. I introduce the reciprocal structure (see Section 5.1) to clarify the interplay between an OGD reform and an OGD ecosystem. My research also involves conceptual developments of an OGD reform and an OGD ecosystem. While the concepts of cultivation, stimulation, and social infrastructure are not new (e.g., Harrison, Pardo, and Cook, 2012; Martin, Turki, and Renault, 2017. Crusoe, 2019b), I argue that the concept of an OGD reform is original to previous OGD research.

In an OGD reform, OGD actors work to persuade other actors to join, collaborate to create and distribute solutions, transform conditions, and evaluate their OGD ecosystem (see Section 5.2. The concept of an OGD reform adds a new layer of complexity to an OGD ecosystem where OGD actors can work outside their OGD ecosystem to transform it (see Section 5.4). Previous OGD research has included an OGD reform 
as a localized part of an OGD ecosystem, such as building a community or collaborations (Folmer et al., 2011. Charalabidis et al., 2018). The problem with this inclusion is that it obfuscates the work invested outside an OGD ecosystem to transform it and inflates the work of an OGD ecosystem. It is, as such, difficult to gauge the requirements and resource costs of organizing an OGD ecosystem. My research reveals this gap but also presents an approach to fill it.

The disentanglement of an OGD reform and an OGD ecosystem contributes to the conceptual developments of an OGD ecosystem. In my research, I have experienced two problems from the multitudinous nature of an OGD ecosystem. Previous OGD research divides an OGD ecosystem along the line of, for example, (1) ecosystem and infrastructure, (2) sectors, roles, and infrastructure, and (3) sectors, resources, and roles (Davies, 2011: Zuiderwijk, Janssen, and Davis, 2014 Van Schalkwyk, Willmers, and McNaughton, 2016). The first problem is the issue of infrastructure. Van Schalkwyk, Willmers, and McNaughton (2016) explain that one of the limitations of their ecosystem perspective is the invisibility of the Internet as a key facilitator of change. I overcome this problem by including infrastructure as part of an OGD ecosystem's environment and as conditions similar to Zuiderwijk, Janssen, and Davis (2014). The infrastructure is treated similar to the terrain of a natural ecosystem, which means the RE-ECO framework assumes a developed information infrastructure and distribution system is existing as part of a data-information society (see Section 2.5. This inclusion is illustrated in Section 5.3 .

The second problem is the issue of dividing an OGD ecosystem into different interacting areas. Ubaldi (2013) suggests an OGD ecosystem consisting of ecosystems of providers, enrichers, and seekers. Similarly, Harrison, Pardo, and Cook (2012) suggest to understand an OGD ecosystem to encompass smaller, localized ecosystems. I agree that an OGD ecosystem needs to be further divided, as I have seen in my empirical material that providers and enrichers can interact within their OGD reform or their OGD ecosystem (see Section 5.2. Section 5.3. and Section 5.4. I disagree with the ecosystem-of-ecosystems approach, as I perceive it to cause confusion and difficulties in communication. It opens for recursive thinking of everything being an ecosystem. At the same time, Van Schalkwyk, Willmers, and McNaughton (2016) divide an OGD ecosystem following resources, sectors, and actors. I agree that this type of division is appropriate to an OGD ecosystem, but it flattens the reciprocal structure (e.g., actors can work with resources and both can be part of sectors) (see Section 5.1). I resolve the division problem by drawing on previous research from ecology and oceanography (e.g., Weathers, Strayer, and Likens, 2012: Sverdrup and Kudela, 2013). Their approach to zoning made it possible to understand and explain the various areas of OGD work that exchange resources and energy within an OGD ecosystem (see Section 5.3). I believe this approach fits better with how Swedish OGD actors work, as, I have noted in my research, Swedish OGD actors tend to step between OGD nodes and other nodes but are also influenced by these areas (see Section 5.4). This approach is in line with my diagnosis of the Swedish OGD ecosystem (Crusoe, 2021a) and my studies of providers and enrichers (Crusoe and Ahlin, 2019b: Crusoe, Simonofski, and Clarinval, 2020). The approach should be generalizable to other national OGD ecosystems where it can help researchers analyze and explain them. 
In the RE-ECO framework (see Chapter 5), I include the public sector, data sector, information sector, and civic sphere, meaning an expansion of the concept of an OGD ecosystem (see Section 5.3. In previous OGD research, an OGD ecosystem is often depicted to involve providers, enrichers, and sometimes seekers with data at the core or base (e.g., Ding et al., 2011, Zuiderwijk, Janssen, and Davis, 2014. Lindman, Kinnari, and Rossi, 2016). I understand that previous OGD research with its abstractions has to some degree decoupled an OGD ecosystem from its society. This separation is notable in the light attention given to the variations of provider roles and seeker roles and rich focuses on the variations of enricher roles (see Section 2.2). In my empirical material, I identify that an OGD reform transforms actors to providers or enrichers while being part of their original ecosystems (see Section 5.2) (Crusoe and Ahlin, 2019b Crusoe, Simonofski, and Clarinval, 2020). I have also identified the possibility for solutions from providers and enrichers to compete for seekers (see Section 5.4. In addition, Zuiderwijk, Janssen, Poulis, and Kaa (2015) explain that one way to add value to OGD is for enrichers to include data and information from other sources than providers, which I similarly note in my research of Crusoe, Gebka, and Ahlin (2020b). Consequently, I understand that this expansion dislodges and loosens the concept of an OGD ecosystem with clear borders and data or enrichers as a core or base. Therefore, I conclude that an OGD ecosystem refers to new data flows between new or old nodes of preexisting organizational ecosystems. It is similar to a corridor between ecosystems, which I collectively have described as a foundational data flow (Crusoe, Zuiderwijk, and Melin, 2020). It acts like a borderland where data and information travel from the public sector to other sectors and spheres. An OGD ecosystem can be understood, explained, and developed as new loadings and exports (flows) of data and information between already existing ecosystems where OGD portals and OGD centers help OGD actors reveal access points to data.

The loosening of an OGD ecosystem's borders also impacts its relationship with society. For example, value generation in previous OGD research tends to be included within an OGD ecosystem (e.g., Attard, Orlandi, and Auer, 2016; Lindman, Kinnari, and Rossi, 2016, Berends, Carrara, Engbers, and Vollers, 2017), while the benefits have been admitted to be part of other organizational ecosystems, such as optimization of administrative processes, improvement in public policies, and channel to better inform seekers (Janssen, Charalabidis, and Zuiderwijk, 2012: Kucera and Chlapek, 2014). I have identified that the nodes of an OGD ecosystem are often embedded in other organizational ecosystems where their flows permeate them (see Section 5.3. At the same time, energy is loaded into an OGD ecosystem from other ecosystems (see Section 5.3. Consequently, the health of an OGD ecosystem is rooted in how well it can support and help actors of other organizational ecosystems. This rooting extends the interplay between an OGD reform and an OGD ecosystem to include other ecosystems. An OGD reform transforms parts of other ecosystems to coalesce an OGD ecosystem. Therefore, the other ecosystems become part of determining the higher purpose and leeway of the OGD reform, thus, affecting the health of the OGD ecosystem. I conclude that an OGD ecosystem is an ancillary, symbiotic ecosystem. 


\subsection{OGD Actors as Tension Points}

In the reciprocal structure (see Section 5.1), I suggest that an OGD actor is a tension point of an OGD reform and an OGD ecosystem. I develop this statement in relation to previous research and identify possible tensions between (1) expectations and realizations and (2) an OGD reform and missions of actors.

First, OGD actors can experience tensions between what other actors expect of them and how they have implemented OGD (see Section 5.1. Caiden (2017) explains that a reform is likelier to be accepted if it is tailored to local conditions and implemented through existing institutions. For example, the five-star scheme of Berners-Lee (2015) and Colpaert, Joye, Mechant, Mannens, and Walle (2013) give freedom for providers to chose an OGD approach fitting to their local conditions. Similarly, the vagueness of the OGD principles, such as accessible (data is available to the widest range of users for the widest range of purposes) and machine-processable (data is reasonably structured to allow automated processing) (Tauberer and Lessig, 2007), give broad leeway for providers in their data provision (Crusoe, 2021a). I understand that an OGD reform allows providers to chose to transform conditions based on what fits their context and environment while giving a future direction for their work. On the other hand, the interoperability of an OGD ecosystem requires specific, homogeneous, widespread conditions of the used technology and infrastructure. For example, (1) the technical level (data exchange between systems) needs to overcome compatibility issues between systems (Janssen, Estevez, and Janowski, 2014: Charalabidis et al., 2018), and (2) the syntactic level (standards in exchange formats) requires, for example, XML and JSON (Janssen, Estevez, and Janowski, 2014 Charalabidis et al., 2018). Evans, Martin, and Poatsy (2008) explain that the linking of datasets requires common identifiers, which helps to connect two related data (e.g., a student with his courses). Great variations in these conditions can contribute to energy sinks for enrichers (Crusoe, 2021a).

Second, OGD actors (as people) can experience tensions between the expectations of other actors and their missions. Caiden (2017) explains that reforms are likelier to be accepted if they invite local participation and are implemented through existing institutions. For example, Folmer et al. (2011) argue that providers should act to build a community around their data to foster its use and have a community manager. Harrison, Pardo, and Cook (2012) argue that providers must find ways to cultivate synergies between data and enrichers, such as civic hackathons, data paloozas, and data jams. Carrara, Oudkerk, Van Steenbergen, and Tinholt (2018) encourage providers to engage enrichers to make their initiatives a broader success. Similarly, in my empirical material, I identify some Swedish providers who cultivate an OGD ecosystem. On the other hand, I also identify sporadic user engagement where some Swedish providers believe in it, and others leave it be (Crusoe, 2021a). This difference could be explained through a perceived difference in the missions of public organizations. De Vries (2016) explains that public organizations provide public goods through policies and programs. They put politics into practice, implement laws, and organize and manage the public sector. De Vries (2016) adds that the hierarchical relations between public organizations differ based on how power and authority are divided. The public organizations can differ in role, tasks, responsibilities, authority, and power (De 
Vries, 2016). World Wide Web Foundation (2021) states that governments are investing little resources into national data infrastructure and community building. In my research of Crusoe (2021a), I provide an example of an enricher that experienced that a provider only cared for their region.

Therefore, I conclude that there is a tension between the persuasiveness of an OGD reform and the needed exactness of an OGD ecosystem (see Section 5.1. This tension means an OGD reform can promulgate persuasive solutions by using broad leeway, which can contradict the standardized needs of an OGD ecosystem's health. I note that OGD actors can disagree about what is good and poor health and, as such, perceive the needs for standards differently. This variation can make it challenging to combine and use data for enrichers (Crusoe, Simonofski, Clarinval, and Gebka, 2019. Crusoe, 2021a). I also conclude that there is a tension between providers as public organizations with public goods and an OGD reform's perception of providers as cultivators (see Section 5.1. I see that the cultivation of an OGD ecosystem can be outside public organizations' roles, tasks, responsibilities, authority, power, and provision of public goods.

\subsection{Cycles and Flows}

Previous OGD research tends to base an OGD ecosystem on the concepts of value chains or flows where their parts vary between researchers (e.g., Kalampokis, Tambouris, and Tarabanis, 2011a Jaakkola, Mäkinen, and Eteläaho, 2014: Lindman, Kinnari, and Rossi, 2016. Van Schalkwyk, Willmers, and McNaughton, 2016). This OGD research uses various labels for similar elements to describe data flows, which can make it difficult to understand and compare research findings as well as developing knowledge. My doctoral research contributes to this research by conceptually refining a data flow as a meandering data-information cycle of copying, transferring, encoding, storing, processing, and making data and information (see Section 5.3. The refinement proposes an action terminology that can describe the work of providers, enrichers, and seekers with a focus on data and information. At the same time, the term cycle emphasizes the energy invested by enrichers to make the data into something valuable for OGD actors from an ecosystem perspective. The refinement allows data and information to be understood and explained as flowing between and within various areas of ecosystems and having the ability to transform to each other. Similar to the complex flows of Van Schalkwyk, Willmers, and McNaughton (2016) and the potential cyclical behaviors of Heimstädt, Saunderson, and Heath (2014). It moves away from an OGD reform's factory perspective of a progressive, straight flow similar to Ubaldi (2013), Lindman, Kinnari, and Rossi (2016), and Mokobombang, Gutierrez, and Petrova (2020).

The data-information cycles of the RE-ECO framework (see Section 5.1. Section 5.2 and Section 5.3 are a step towards answering the call from Hossain, Dwivedi, and Rana (2016) for OGD research from an economic perspective. Hossain, Dwivedi, and Rana (2016) request more OGD research on how to finance the data provision of providers since data are not free to collect, store, maintain, and provide. The datainformation cycles highlight the need for energy and resources to maintain an OGD 
ecosystem and the energy and resources needed for the transformations of an OGD reform. In these transformations, OGD actors can experience impediments that create metaphorical energy sinks, which can only be removed by filling them with energy or resources (see Section 5.3. Therefore, I argue that an ecosystem perspective can feasibly include an economic perspective.

Some OGD researchers add cyclic behaviors to their OGD ecosystem, which can include activities of feedback, discussions, and searching (e.g., Folmer et al., 2011: Janssen and Zuiderwijk, 2012 Zuiderwijk, Janssen, and Davis, 2014: Charalabidis et al.,2018). I agree that these activities of an OGD ecosystem are essential for providers and enrichers. However, I disagree as they conflate the activities of actors with the activities of a data-information cycle while hiding the export of data or information to other ecosystems. I see it as a generative approach to describe interactions between providers and enrichers, which is only a small part of an OGD ecosystem. The RE-ECO framework recognizes these activities as nodes of an OGD ecosystem or an OGD reform, such as identification nodes and forum nodes (see Chapter 5). While the framework separates an OGD ecosystem and an OGD reform, it welcomes confluences between the two.

Dawes, Vidiasova, and Parkhimovich (2016) add global and national influences towards openness, motivation for OGD development, and advocacy and interactions to their OGD ecosystem. I agree with the authors that benefits could lead to OGD advocacy and motivation for an OGD reform. Global and national influences towards openness could fuel motivation for an OGD reform. Based on Section 5.2 and Section 5.4. I find a need to question that they are part of the same cycles and flows. In my empirical material, I observe that some providers search for good examples to generate motivation to further allocate resources to their OGD reform (Crusoe, 2021a) (see Section 5.2. However, this type of motivation generation is based on a datainformation cycle, but not a continuation of it (see Section 5.3. As such, the RE-ECO framework includes global and national influences towards openness, motivation for OGD development, and advocacy as part of purpose flows (see Section 5.4. I understand that purpose flows are unique to an OGD reform, as they contain the energy that encourages energy allocations and transformations.

\subsection{Interplay and Health}

In my doctoral thesis, I identify how the interplay between an OGD ecosystem and an OGD ecosystem (as an important finding) can affect the health of an OGD ecosystem (see Section 5.4. However, it is worth noting that I perceive the Swedish OGD ecosystem to be in its infancy, as internal energy generation is limited and the ecosystem is experiencing several impediments (Crusoe, 2021a). Consequently, my conclusions about the interplay's affect on the health of an OGD ecosystem can vary based on the maturity level of an OGD ecosystem. I understand that the young age means the interplay between the Swedish OGD reform and the Swedish OGD ecosystem mainly affects the ecosystem's mutation. Homeostasis is framed as something the Swedish OGD actors attempt to realize through mutation (Crusoe, 2021a). An OGD reform fuels the early evolution of an OGD ecosystem to realize homeostasis through 
the creation of internal energy generation. However, as I note in Crusoe (2021a), this approach can, with weak governance elements (e.g., laws, OGD principles, and leadership that provide broad leeway), lead to an OGD ecosystem sprawling into a wilderness, but also be challenging to conduct if basic infrastructure is not in order. In this section, I discuss the affect of OGD landscapes, step out and step into ecosystems, and mutation-loading on the health of an OGD ecosystem.

\section{OGD Landscapes}

I understand that OGD landscapes reveal complexities tucked into the expectations of and interactions between OGD actors (see Section 5.4), but also in the ability of actors in organizational ecosystems to plan and act (Mars, Bronstein, and Lusch, 2012). Previous OGD research explains that impediments can traverse an OGD ecosystem, give rise to new impediments, and vary in severity for different OGD actors (Zuiderwijk and Janssen, 2014a: Beno, Figl, Umbrich, and Polleres, 2017 Huang, Lai, and Zhou, 2017). I have also identified that acceptable solutions can together become impediments for enrichers (Crusoe, 2021a). While previous OGD research has understood obstructing or preventing phenomena as impediments, risks, and barriers (e.g., Zuiderwijk, Janssen, Choenni, Meijer, and Alibaks, 2012: Barry and Bannister, 2014: Wang, Zhao, Zhao, and Chu, 2019), I understand them as part of OGD landscapes that have been terraformed and traversed by OGD actors (see Section 5.4). This metaphor reveals how the work of an OGD actor can be understood to impact the work of other OGD actors, constraining the health of others and their OGD ecosystem. I conclude that the metaphor of landscapes can be used to understand and analyze impediments from an OGD ecosystem perspective.

Janssen, Charalabidis, and Zuiderwijk (2012) explain that two myths of OGD are: (1) publishing data will automatically yield benefits and (2) it is a matter of simply publishing OGD. I understand that their explanation in combination with the "open by default" principle (e.g., Tauberer and Lessig, 2007. Open Data Charter, 2015), the "raw data, now" principle (Berners-Lee, 2009), and my empirical material (see Section 5.2 highlights a problem. The problem is that an OGD reform obfuscates the multiple interactions between OGD actors within their OGD ecosystem. These actors are dependent on each other to realize health but also work within preexisting landscapes. It is, as I note in Section 5.2. a blind spot of the collaborative factory simulation perspective. As a result, I conclude that the concept of OGD landscape raises two questions for an OGD actor: (1) how does its work impact the work of others in terms of ease and impede their evolution? And (2) are the expectations on it feasible to implement? A provider has the additional question of how does its work align with the work of other providers to create a data pool (see Section 2.2.?

\section{Step Out and Into Ecosystems}

The disentanglement of an OGD reform and an OGD ecosystem reveals a new type of interplay where OGD actors can step between their OGD reform and their OGD ecosystem. This ability allows actors to recruit and persuade actors to join their OGD reform or their OGD ecosystem, discuss and distribute solutions, and coordinate and 
collaborate (see Section 5.4. Zuiderwijk, Shinde, and Janssen (2019) explain that OGD programs mainly deliver operational and technical benefits then economic and last societal. The authors report a mismatch between the objectives of these OGD initiatives and their realized benefits, which they believe originate in OGD initiatives mimicking each other. The ability of OGD actors to step gives credence to their belief (see Section 5.2). In the Swedish OGD ecosystem, it was common for OGD actors to participate in various social events and use distributed solutions. I understand, as such, that distributed solutions of an OGD reform can converge the expected landscapes of various OGD actors between OGD ecosystems in different countries. At the same time, I believe this ability to step allows OGD actors to bypass certain rules and the isolation of their OGD ecosystem. For example, in the case of Linköping municipality, its OGD manager explained that anyone who uses OGD is supposed to be anonymous (see Section 5.4), which is supported by some OGD principles (e.g., Tauberer and Lessig, 2007). However, when I participated at the Swedish open data forums (as part of Crusoe (2021a)), I saw providers and enrichers socializing and sharing experiences. In addition, I also identify that OGD actors can step from their OGD reform or their OGD ecosystem into other ecosystems (see Section 5.4. This ability to step allows them to generate energy in an external ecosystem that they can then be loaded into their OGD reform or their OGD ecosystem, which is a form of mutationloading (see Section 5.4. I understand that energy loading and generation are core concepts of an OGD ecosystem, as they fuel evolution and maintain homeostasis, and, in turn, sustain health. Figure 6.1 presents an OGD actor stepping between nodes of its OGD reform, its OGD ecosystem, and other ecosystems. The OGD actor can carry with it mutations (e.g., OGD principles and visions for OGD), experiences with impediments (e.g., low-quality data or inability to find data), solutions (e.g., publisher processes or information classification systems), energy (e.g., resources and money), motivations (e.g., good examples and possibilities of OGD), identifications (e.g., who can provide certain data or who is using the data), data, and information. Figure 6.1 is based on this paragraph and Section 5.4 This figure presents an OGD actor's ability to step out and into its OGD reform, its OGD ecosystem, and other ecosystems.

\section{Mutation-Loading}

I see that the inclusion of cultivation or stimulation as roles into the concept of OGD ecosystem is young and needs further developments (e.g., Martin, Turki, and Renault, 2017. Crusoe, 2019b). Previous OGD research has identified work to foster demand, reveal user paths, advocate for OGD, and attempts to increase motivations for publishing of using OGD (Harrison, Pardo, and Cook, 2012; Ubaldi, 2013: Zuiderwijk, Janssen, and Davis, 2014: Dawes, Vidiasova, and Parkhimovich, 2016). I add to this stream of research the concept of mutation-loading (see Section 5.4). Mutationloading seems important to the early stages of an OGD ecosystem as it germinates the first transformations of an OGD reform. It provides rules, direction, and energy to the early evolution of an OGD actor, which could lead to further transformations or give rise to energy generation that can contribute to homeostasis. However, I have been unable to identify the switch between evolution dependent on mutation-loading and evolution based on internal energy generation. This gap, together with the perceived lack of good examples for Swedish providers and cumbersome use of Swedish en- 


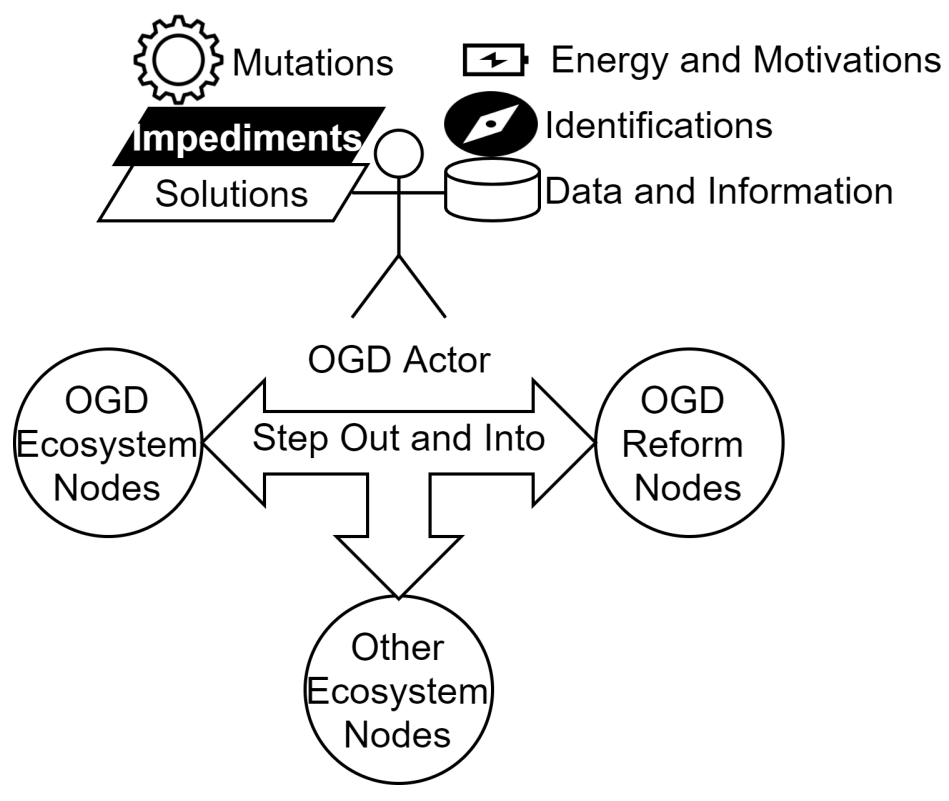

Figure 6.1: A representation of an OGD actor step between nodes of its OGD reform, its OGD ecosystem, and other ecosystems.

richers (Crusoe, 2021a) mean that I believe the Swedish OGD ecosystem is still in its infancy.

\subsection{Summary of Discussion}

In this section, I summarize the above discussion where I have argued that:

- Previous OGD research encompasses an OGD reform into an OGD ecosystem, which obfuscates the work invested outside an OGD ecosystem to transform it and inflates the work of an OGD ecosystem. My disentanglement of an OGD reform and an OGD ecosystem has loosened the borders of an OGD ecosystem and highlighted its relationship to its society. An OGD ecosystem is an ancillary, symbiotic ecosystem (see Section 6.1.

- OGD actors can be tension points between their OGD reform and their OGD ecosystem. For example, they might experience tensions between the persuasiveness of their OGD reform and the needed exactness of their OGD ecosystem; and tensions between providers as public organizations with public goods and an OGD reform's perception of providers as cultivators (see Section 6.2. The tensions can be expressed as impediments. 
- The data-information cycles, energy flows, and purpose flows can be used to understand the interplay between transformations, work, and costs of OGD actors (see Section 6.3) and describe an OGD ecosystem.

- OGD landscapes reveal complexities tucked into the expectations of and interactions between OGD actors and their ability to plan and act. An OGD reform has a blind spot for how the interactions and transformations of OGD actors can impact each other (see Section 6.4). The metaphor of landscapes reveals that the work of OGD actors can constrain the work of others, as such constrain the health of their OGD ecosystem.

- OGD actors can step between their OGD reform and their OGD ecosystem, explaining how and why OGD actors mimic each other (and, as such, realize similar benefits). In addition, OGD actors can carry things with them that can help them in their work (see Section 6.4).

- Cultivators can mutation-load an OGD ecosystem by introducing rules, giving direction, and loading energy. It seems to be important to the early stages of the OGD ecosystem, as it can germinate the first transformations of an OGD reform. Mutation-loading could lead to further transformations or give rise to energy generation (and, in turn, homeostasis) (see Section 6.4). 


\section{Conclusions and Implications}

In this chapter, I present my conclusions in relation to my doctoral thesis's main research question (see Section 1.2. The sub-questions have been responded by my five included articles and previous research section (see Section 4.2 and Chapter 2). My main response to the purpose of my thesis is the RE-ECO framework (see Chapter 5), which is to disentangle the interplay between an OGD reform and an OGD ecosystem from the perspective of evolution and health. I then give my theoretical contributions and implications accompanied by practical implications and recommendations to OGD actors. I derive the theoretical contributions from my framework and discussion while drawing the implications from my empirical research. I end my doctoral thesis by reflecting on my doctoral research process, thesis contribution, and research quality, as well as suggesting future research.

\subsection{How can the Interplay Between an OGD Reform and an OGD Ecosystem Affect the Health of an OGD Ecosystem?}

I have, based on my doctoral research, identified that the interplay between an OGD reform and an OGD ecosystem could affect the health of an OGD ecosystem in at least the five following ways:

1. An OGD ecosystem is an ancillary, symbiotic ecosystem; meaning its health is rooted outside of it and extends the interplay to include other ecosystems (that can affect the health by partly determining the higher purpose and the leeway of the OGD reform), 
2. Cultivators can use mutation-loading to apply some control and fuel the mutations of an OGD ecosystem,

3. OGD actors can step between nodes of their OGD reform, their OGD ecosystem, and other ecosystems, carrying energy and solutions with them and possibly bypassing rules,

4. The metaphor of landscapes reveals how an OGD reform and a society can constrain the health of an OGD ecosystem,

5. OGD actors can experience tensions between their OGD reform and their OGD ecosystem.

First, an OGD ecosystem embeds and permeates preexisting organizational ecosystems, which means its nodes can be confluences between OGD and other practices, such as journalism, research, and the building and environment committee of a municipality. An OGD ecosystem is an ancillary, symbiotic ecosystem to other organizational ecosystems, which means its health is rooted in how well it can support and help actors of other ecosystems (see Section 5.3 and Section 6.1. This conclusion extends the interplay between an OGD reform and an OGD ecosystem to include other organizational ecosystems. An OGD reform transforms parts of other ecosystems to coalesce an OGD ecosystem, which then become part of both. It deepens the meaning of interplay and how it can affect the health of an OGD ecosystem. It also stresses the need for an OGD ecosystem to be valuable or beneficial to other organizational ecosystems.

Second, cultivators of an OGD reform can load energy and solutions over the borders of an OGD ecosystem. This mutation-loading allows cultivators to apply some control over and fuel the mutation of their OGD ecosystem (see Section 5.4 and Section 6.4. This loading seems to be important for begetting an OGD ecosystem, as it provides some of the energy needed for the first transformations of reformists (see Section 5.2).

Third, an OGD reform consists of multiple transformative nodes within or outside an OGD ecosystem (see Section 5.2 and Section 5.4. Cultivators can load these nodes with energy to then load the exports of these nodes into other nodes (e.g., OGD portals or publishing processes), possibly contributing to their OGD reform. OGD actors can step between these nodes and the nodes of their OGD ecosystem and other ecosystems. It allows them to carry energy and solutions that they can share but also possibly avoiding some rules of their OGD ecosystem (see Section 6.4). It could give rise to convergent evolution.

Fourth, the metaphor of landscapes reveals how an OGD reform and a society can constrain the health of an OGD ecosystem (see Section 5.4). OGD actors' transformations of their local conditions or their needs can constrain other OGD actors' ability to realize good health. Providers transform their local conditions, which, in turn, can terraform the landscape of enrichers. The terraforming raises or lowers the height or inclination of peaks, meaning it changes the energy and resources needed by enrichers to realize good health. Providers of low-quality data can create energy sinks, which enrichers need to fill before enriching the data into a product or service for seekers. This situation redirects energy and resources that could have been used to develop solutions. At the same time, the needs of seekers terraform a landscape populated by solutions, 
which can compete to satisfy the needs of seekers. Some of these solutions are from enrichers. Cultivators can guide enrichers towards deploying solutions on certain peaks, meaning some needs can be considered more legitimate than others.

Fifth, actors can experience tensions between an OGD reform and an OGD ecosystem (see Section 5.1). I have identified two types of tensions; actors can experience tensions between (1) persuasiveness of their OGD reform and the required standards of their OGD ecosystem and (2) their mission and the expectations of their OGD reform (see Section 6.2). The first tension means an OGD reform can promulgate solutions that persuade actors through the use of broad leeway, which can be contradictory to the conditions needed to coalesce and accrue strands of data-information cycles. The second tension means that the cultivation of an OGD ecosystem can be outside the mission of public organizations. At the same time, I recognize there may be more tensions to identify.

\subsection{Theoretical Contribution and Recommendations}

My research has contributed to previous OGD research by disentangling an OGD reform and an OGD ecosystem and developing the concept of ecosystem health. My research provides concepts that can help researchers within OGD and possibly IS and e-government who study reforms and organizational ecosystems. It gives the RE-ECO framework (see Chapter 5 with rich empirical descriptions based on a methodology that other OGD researchers could draw inspiration from when they study OGD reforms and OGD ecosystems. My contributions are primarily aimed towards e-government researchers who study digital reforms and digital ecosystems of the public sector, IS researchers who study the digital transformations of organizations within information-based organizational ecosystems, and OGD researchers who study OGD reforms and OGD ecosystems in other contexts and countries.

Disentangle an OGD Reform and an OGD Ecosystem. My research makes an original contribution to previous OGD research of OGD ecosystems (see Section 6.1 with the RE-ECO framework (see Chapter 5). The framework loosens the borders of an OGD ecosystem and divides it into strands of data-information cycles and identification nodes. It is a step away from an OGD ecosystem as an object towards it as a corridor. The strands meander through an OGD ecosystem and coalesce through the work of providers, enrichers, and seekers. The identification nodes allow providers to make their data access points discoverable and understandable to enrichers and seekers. An OGD ecosystem as an ancillary, symbiotic attachment to other ecosystems is similar to Van Schalkwyk, Willmers, and McNaughton (2016). My research is a step away from an OGD ecosystem as a whole (e.g., Heimstädt, Saunderson, and Heath, 2014 Shah, Peristeras, and Magnisalis, 2020: Gelhaar, Groß, and Otto, 2021) and the factory view of value chain with two sides (e.g., Carrara, Chan, Fischer, and Steenbergen, 2015: Lindman, Kinnari, and Rossi, 2016: Mokobombang, Gutierrez, and Petrova, 2020). My research recognizes the values of, but is critical towards life cycle and cyclical perspectives of ecosystems (e.g., Folmer et al., 2011; Attard, Orlandi, Scerri, and Auer, 2015; Dawes, Vidiasova, and Parkhimovich, 2016: Charal- 
abidis et al., 2018). I propose that OGD researchers who study an OGD ecosystem should (1) beware of the interplay between an OGD reform and an OGD ecosystem, (2) investigate the transformations and work of OGD actors, and (3) explore strands of data-information cycles with energy flows to analyze the relationship between acquisition nodes, deployment nodes, and seekers' use of data and solutions. Similarly, I suggest that e-government researchers and IS researchers who study digital reforms could (1) investigate the interplay between previous work and reforms and (2) explore how the reforms transform data-information cycles.

Ecosystem Health. My research theoretically contributes to the concept of ecosystem health in previous OGD research (e.g., Lee, 2014: Zuiderwijk, Janssen, and Davis, 2014 Heimstädt, Saunderson, and Heath, 2014: Oliveira, Lima, and Lóscio, 2019). It presents a definition of health with health dimensions in relation to datainformation cycles and energy flows permeating sectors and spheres of society. It integrates the health concept with other concepts relevant to an OGD ecosystem. At the same time, my research is a step away from the idea of a successful OGD ecosystem (Welle Donker and Loenen, 2017) and the idea of progressive development often found in international OGD indexes and rankings (e.g., Global Open Data Index, 2016. World Wide Web Foundation, 2021. OECD, 2021). More of the same does not necessarily lead to good health, as data-information cycles require energy to coalesce and maintain. I advise that OGD researchers who study ecosystem health should (1) gauge the maturity of their OGD ecosystem and consider potential implications to its health, (2) consider the conflict between expectations of a higher purpose, the health of OGD actors, and the health of their OGD ecosystem, and (3) identify and define bad and good health for their OGD ecosystem. On the other hand, I suggest that e-government researchers and IS researchers who study digital, organizational ecosystems could (1) ponder the health concept and its potential applications and (2) consider maturation as self-induced meandering transformations rather than DNA scripted instructions.

\subsection{Implications and Recommendations for Practice}

My doctoral research provides concepts that can help practitioners who work with OGD as providers, enrichers, or cultivators or seek to become any of these roles. It has contributed to practice by naming roles, describing their work, their OGD reform, and their OGD ecosystem, and presenting how they could work to affect the health of their OGD ecosystem. My recommendations are aimed towards providers, enrichers, reformists, and cultivators in countries with developed information infrastructure and governments that own extensive semi-closed data. These countries should also seek to conduct an OGD reform or have a nascent OGD ecosystem. I believe, based on OECD (2020), these countries could, for example, be Belgium, Denmark, Finland, Germany, Norway, Sweden, and the United Kingdom. Providers are public organizations, enrichers are anyone who seeks to develop solutions for citizens based on OGD, seekers use data and solutions to satisfy their needs, reformists are people who change local conditions to organize an OGD ecosystem, and cultivators are anyone 
who persuades other actors to join an OGD reform or an OGD ecosystem or enable the work of others by transforming conditions that have broad impact. My practical implications and recommendations are:

- I recommend cultivators arrange forums and workshops where providers and enrichers can discuss harmonizing their work and defining the benefits of their OGD ecosystem. It can ease their OGD reform and make it more effective and directed.

- I suggest the introduction of a data governor to an OGD ecosystem. The role could work to maintain the homeostasis of an OGD ecosystem. It can bring sustainability and stability to an OGD ecosystem and enable the continual realization of benefits.

- I recommend providers and enrichers to follow principles of "high-value, high-impact" and "publish with purpose" (Ubaldi, 2013. Calderon, 2018). This recommendation is contrary to the "open by default" and "raw data, now" principles (Open Data Charter, 2015. Berners-Lee, 2009). In the short term, "open by default" and "raw data, now" might build momentum and experience, at the risk of OGD that is not used and of low quality. In the long term, the hurried publishing of all data can act as an argument against OGD, as costs and impediments outweigh the benefits.

\subsection{Reflections}

This section presents my reflection of my doctoral research process, my contributions, and my research quality. I use the reflection of my licentiate thesis as a point of departure since it has been a step in my doctoral research (Crusoe, 2019b). In the first subsection, I reflect on my research approach, methodologies and methods, metaphors, and multi-disciplinary research. In the second subsection, I reflect on my contribution to health, OGD reform and OGD ecosystem, and OGD. In the third subsection, I reflect on my research quality as relevancy, internal validity, generalizability, reliability, and delimitations and limitations.

\section{Reflections on the Doctoral Research Process}

Research Approach. I initiated my doctoral research in 2016 through an exploratory pilot study. I participated in the Swedish OGD community and completed two case studies. My case studies resulted in an exploration of the Swedish OGD ecosystem and my compilation licentiate thesis (Crusoe, 2019b). The change from licentiate to doctoral thesis represented a change in my research approach, as I started to collaborate with other researchers nationally and internationally. I wrote a thesis proposal in 2019, which was presented and discussed at the Ph.D. Colloquium of the EGOV-CeDEM-ePART conference (in Italy) with international collaboration in mind. My research process has involved many decisions about methods, philosophy, methodology, and scope, where the main contribution of my doctoral research became the RE-ECO framework (see Chapter 5). At the start of my doctoral research, I remember feeling excited and curious to embark on an expedition into OGD. Ulf 
had the magical ability to fuel my curiosity through the five years of research. It is one reason I drew on knowledge from multiple disciplines and continues to read books. However, the religious tones of the Swedish OGD community and previous OGD research deterred me, which I think increased my critical attitude towards the phenomenon. At the same time, the vagueness and openness of previous research concerning methods and methodology combined with conflicting feedback and comments from researchers stressed me and made me feel inadequate. My licentiate thesis and collaborations were a breakthrough that dispelled my feelings of inadequacy and gave me an idea about what research is and is not. The explorations of other research contexts (e.g., Belgium and the Netherlands) also broadened my horizon and emphasized the need for collaborations to conduct high-quality research. Overall, my experience with research has been a rollercoaster ride. I cherish the incredible peaks, such as excellent supervisors, friendly colleagues, an opportunity to learn, and freedom of choice. Thou, I wonder about the low valleys, such as inconsistencies in feedback and comments, the difficulties to combine and use previous research, and the many gaps in methodological texts. I understand that my experiences result from the rapid growth of the IS discipline and its move from positivistic to interpretivist research, where researchers have not fully realized the distance between being and not being a researcher. Most of the texts I have read were written as if the reader was a professor or as if the discipline had consilience (Wilson, 1999), while it has diversity (Benbasat and Weber, 1996). This behavior is also known as the curse of knowledge (a cognitive bias where an expert assumes their common knowledge is common to all, while others still need to learn it) (King, 2019). In one way, I have had to rediscover the experiences that make previous research understandable, but it also has made me wonder how I am similarly cursed with knowledge.

Through my research, I made several decisions about methods and methodology. In hindsight, I see a possible alternative to my research approach (see Chapter 4 . I recognize that an early, systematic exploration of previous research to identify theories and create a conceptual map of OGD would have benefited my work. I could then have studied a provider and its enrichers to understand how they become and work. I could have focused my research on exploring this part of an OGD ecosystem to identify various important phenomena and their interactions. The result would have been a rich case study with increased research quality, as I could have triangulated and verified my empirical material and followed how OGD could have developed over time. It would have allowed me to explore emerging interpretations and make local practical contributions. However, it could have limited my ability to contextually generalize my conclusions to other cases, but I believe the ability to analytically generalize would stay similar (Walsham, 1995 Yin, 2018). As a result, I have learned that there are multiple approaches to research a phenomenon, and it is worth taking the time to explore and investigate various research approaches before diving into practice. It is also valuable to take your time to read up on a topic to identify knowledge gaps and construct conceptual maps.

Moreover, I have, for example, discovered the administrative reform, data-driven society, and public utility theories (Bylund et al., 2016; McNabb, 2016; Caiden, 2017) by iterating between my empirical material and previous research. At the start of my doctoral thesis, I embarked on synthesizing a design and action theory for an OGD 
ecosystem. A theory of design and action describes "how to do" something (Gregor, 2002. Gregor, 2006). I sought to explain to OGD researchers and OGD practitioners how to organize healthily, sustainable OGD ecosystems through their OGD reform. However, as I was researching the work of OGD actors, cultivation activities and transformative activities kept appearing. They seemed too important to ignore as the OGD actors tended to stress them or be gaps in the logical chain to arrive at certain local conditions or work. This situation made me ponder and create the idea of an OGD reform by reading the book of Caiden (2017). As a result, I believe my research provides an original contribution by tweaking previous OGD research and including previous research from other disciplines, such as administrative reform, business, ecology, ecosystems, health, information science, information systems, oceanography, and public utilities (e.g., Alter, 2003b Iansiti and Levien, 2004 Nicholas and Herman, 2010: Mars, Bronstein, and Lusch, 2012: Weathers, Strayer, and Likens, 2012: McNabb, 2016. Sverdrup and Kudela, 2013: Caiden, 2017). I have learned that decisions about methods, methodology, and theory need to be informed through iterations between previous research and practice.

Methodologies and Methods. I have, through my doctoral research, read more books than in my entire life before I said yes to my doctoral position. I have often read far and wide to explore research paradigms, methodologies, and methods. I read out of curiosity, as when I encountered new concepts or phenomena, I usually want to know more about them. I think of myself as a jack of all trades and a generalist. Epstein (2021) explains that generalization can lead to original, creative approaches and solutions, while generalists tend to be on a journey to find the best fit between them and some work. The author adds that a generalization is a good approach to wicked environments where rules are obfuscated or unclear. I recognize the author's explanation in my experience of OGD research. I have tried various approaches to synthesize an approach that I find usable and allowed my knowledge of other disciplines to fuel my research. I have explored dead-ends and revisited old paths with reflections and mistakes. I have collaborated with researchers from different backgrounds to, for example, conduct mixed-method research (Crusoe, Simonofski, Clarinval, and Gebka, 2019) or verify my conceptual frameworks (Crusoe and Ahlin, 2019b) (see Section 4.3). As a result, a personal research approach has emerged through my doctoral research. I, with colleagues, tend to create a skeleton framework that we fill with empirical material. This process creates a tentative conceptual framework (Maxwell, 2012a) that we evaluate in another context and submit to an e-government workshop. I believe the evaluation is best done in another research constellation than the first one. We use feedback and comments to improve the framework. It is then evaluated in practice and finally submitted to a journal. I believe the step-wise iterative nature of my research helps explore organizational ecosystems and create high-quality research, even if it is resource-intensive. My research draws on, for example, engaged scholarship, design research, grounded theory, and case studies (see Section 4.1) (Peffers, Tuunanen, Rothenberger, and Chatterjee, 2007; Ven et al., 2007; Saldana, 2015. Yin, 2018). However, my exploration and experimentation with methodologies and methods within my research have caused some frustration and overwork. I admit that my adventure has been a learning experience, fitting a research education, and I would gladly do it again if given the 
opportunity. I have noticed that studying an OGD ecosystem is resource-intensive since multiple methods are needed to acquire empirical material, and the analytical methods grow in complexity as with quantity and interactive complexity of empirical material. I have studied documents, recorded presentations, reports, laws, PPT presentations, news articles, websites, and blogs. I have used semi-structured interviews over e-mail, phone, Skype, and face-to-face. I have verified empirical material and analysis at multiple stages with various actors. It has taken time and resources to figure out what methods work and not in what context and for what phenomenon. It is also about whom to contact and where to look for OGD actors. A consequence is that my research has provided me with good knowledge about the status of OGD in Sweden and the world in different ways. Alternatively, I could have focused on a policy or law and then studied how various actors interpret and implement it or studied actors around a specific artifact or event. The first approach would have allowed me to study how cultivators through policy or law can cultivate their OGD ecosystem, while the second approach would allow me to study how OGD actors act outside their OGD ecosystem to coalesce it. I could have invested my resources and time in digging deeper and identify underlying patterns in both approaches. Most likely, even been able to develop a tentative theory. However, I would only have studied localized parts of an OGD ecosystem. I believe my approach has allowed me to find a usable methodology and develop my skills as a researcher. I think this methodology can also be used to study and understand ecosystems.

Metaphors. I use various metaphors to depict my findings, contributions, and ideas. It has been a challenge to find a representation that makes OGD less abstract and more understandable. Metaphors have been a handy tool but a bit recalcitrant. Morgan (1997) explains that metaphors are an approach to see and think about social systems, which emphasizes certain explanations and obfuscates alternatives. They can add to vocabularies and help to create new interpretations (Black, 1955: Lakoff and Johnson, 2008). Metaphors can be used to understand intangible socio-technical phenomena because they enable people to apply their previous knowledge to new phenomena (Mészáros, 1966). Longaker and Walker (2011) add that metaphors are, within rhetoric, figures of speech or tropes, which can increase the persuasiveness of an argument and ease its communication. However, metaphors can have a strong influence on how people understand and approach societal problems. People tend to look for information in line with their metaphors while seldom recognizing the influence they have on their decisions and behaviors (Thibodeau and Boroditsky, 2011). I understand that metaphors are a double-edged sword. They can work well when they capture and explain new phenomena but can bring misunderstandings and confusion. Previous OGD research is rich in metaphors, everything from building ecosystems to value chains. I contribute to this pool with my doctoral thesis. I have learned that a complex social phenomenon might need several metaphors to be understood; even if it creates some complexity in the text, it makes it easier to think about it in the end. For example, I use transformation and collaborative factory simulation for OGD reform and ocean ecosystem and landscapes for an OGD ecosystem. I bridge the two with a structure connecting conditions with an ecosystem, and actors can step out and into nodes. However, I note that the landscape metaphor became more complex than first thought since humans can plan and have expectations, while an OGD 
ecosystem coalesces from actions and interactions. Consequently, an organizational landscape emerges from an actor's environment, expectations, and interactions with other actors. I understand that metaphors can be a tool to reveal and explore these kinds of complexities.

Multi-disciplinary Research. I am defending my dissertation as a researcher in the IS discipline. The IS discipline is multi-disciplinary and trans-disciplinary (Galliers, 2003). It has drawn knowledge from disciplines, such as agriculture, artificial intelligence, cognitive psychology, computer science, economics, information science, linguistics, management, marketing, and sociology (Davis, 1991: Khazanchi and Munkvold, 2000: Baskerville and Myers, 2002). I have drawn knowledge from administrative reform, biology, business, cognitive psychology, computer science, ecology, ecosystems, evolution, gatekeeping, health, history, information science, information society, metaphors, oceanography, organizations, public administration, public relations (propaganda), public utilities, sociology, and software (e.g., Morgan, 1997; Day, 2002. Ohlman, 2002: Pickett and Cadenasso, 2002 Alter, 2003b: Pinker, 2003b. Iansiti and Levien, 2004: Bernays, 2005: McGhee, 2006 Rapport, Gaudet, Constanza, Epstein, and Levins, 2009. Shoemaker and Vos, 2009. Nicholas and Herman, 2010. Durant and Durant, 2012: Mars, Bronstein, and Lusch, 2012: Weathers, Strayer, and Likens, 2012: Manikas and Hansen, 2013: Dawkins, 2016; De Vries, 2016: McNabb, 2016. Sverdrup and Kudela, 2013: Buckland, 2017. Caiden, 2017 Lee and Cook, 2020). I have used this knowledge to supplement other knowledge and understand as well as explain phenomena. Its use has varied depending on my perceived need and empirical material, but also my ability to pedagogically present my research (cf. Crusoe, Zuiderwijk, and Melin, 2020. Crusoe, 2021a). I started my doctoral research focusing on IS and OGD but have, through the process, broaden the use of knowledge from different disciplines, which has contributed to my research and created some challenges. Multi-disciplinary research allowed me to use knowledge to explain phenomena I encountered without needing to research them. It also gave me a richer vocabulary and picture of the phenomena and their possible complexities. However, it is difficult to apply, study, and criticize knowledge outside your disciplinary boundaries (e.g., psychology and public utilities). The difficulty is rooted in the need for expert knowledge to know and understand alternatives to the knowledge in front of me. Consequently, it becomes important to select literature and scrutinize authors. This selection is a hand-picked dissection to extract, what I understand as, the most valuable and usable knowledge. This knowledge could, within the discipline, be considered less relevant or outdated. It can be difficult to identify the relevancy of knowledge within a discipline, as this knowledge is often ingrained in its research community (in my experience). I determine the relevancy of knowledge external to my discipline by comparing it to the phenomenon under study. The authenticity is determined by scrutinizing the authors. At the same time, when I use studies from other disciplines, they can be part of other paradigms and research traditions. This situation opens for questions about the compatibility of research and if other research is metaphors or descriptions. These questions came to me as I was writing this reflection. I have resolved these questions by synthesizing frameworks that I, in iterations, develop and evaluate in previous research and practice. I have learned that in multidisciplinary research, it is important to (1) explore and discover concepts that can 
explain a phenomenon, (2) select and generalize the literature, (3) synthesize conceptual frameworks, and (4) evaluate the frameworks through iterations in various contexts of practice and academia. I have also found collaboration necessary, as it is easy to get lost in multi-disciplinary research, and deliberative reflections can reveal opportunities and problems.

\section{Reflections on Thesis Contributions}

Reform and Ecosystem. In my doctoral research, I have used the concepts of reform and ecosystem to construct the RE-ECO framework (see Chapter 5). It is an odd duo because of the political and transformative nature of reforms and the natural and lifeness of ecosystems. It was, for example, partly expressed as tension points between persuasion versus realization as well as expectations versus missions (see Section 5.1 and Section 6.2. I think they capture the ideas of change and order as a metaphorical yin-yang relationship. The transformation of a reform and the evolution of an ecosystem are two sides of the same coin, as they revolve around change. I understand that they differ in their origin and continuation. A reform comes and goes while an ecosystem continues until it disintegrates. The RE-ECO framework is created to understand periods where an OGD reform and an OGD ecosystem interplay without explaining how this interplay starts or ends. At the same time, there is no denying that humans live within and terraform ecosystems (Rapport, Gaudet, Constanza, Epstein, and Levins, 2009. Weathers, Strayer, and Likens, 2012), which means a reform is a natural part of a human ecosystem. On the other hand, a reform is based on the spread and acceptance of ideas to change conditions, making it similar to a transformative force that can blow through several ecosystems, causing havoc and creation. A reform could, from this perspective, almost be understood as an invasion or intrusion into an ecosystem, which is visible when actors resist it (Crusoe, 2021a). Therefore, I see the potential duo of reform and ecosystem could be used to understand phenomena like smart cities, OGD, and digitalization. The REECO framework could be adapted to them and expanded to include explanations for when the interplay between a reform and an ecosystem starts and stops.

Health. The health metaphor has its origin in research about organisms and populations, which has been extended to ecosystems (many species interacting within an environment). Organisms, unlike ecosystems, have clearly defined boundaries, reproduce, and evolve through genetic selection. Thus, even if health is of organisms, its metaphorical use does not make an ecosystem an organism (Rapport, Gaudet, Constanza, Epstein, and Levins, 2009). I find health an interesting concept since it encompasses realization, stability, repair, and harm. Even if it is possible to measure health with objective criteria (Rapport, Gaudet, Constanza, Epstein, and Levins, 2009), it is not a progressive spectrum; more of the same is not a guarantee for better health. It recognizes that within an ecosystem, not every actor will perform optimally, even in good health. I understand that health is a step away from open data indexes and rankings that claim the more, the better for certain criteria. Examples of indexes and rankings include European Data Portal (2021), OECD (2021), and World Wide Web Foundation (2021). The downside of ecosystem health is that the health of an ecosystem can differ from the health of actors. There is no guarantee that they are 
synchronized or harmonized. I can see that the two types of health could be conflicting, as the ecosystem needs one thing and the actors need other things. At the same time, health brings continual and static thinking about assumed perfect health, which can conflict with a reform because of the invention and growth of a new ecosystem. How could we know the perfect health of an ecosystem that we have never organized before? In addition, an ecosystem evolves and changes with its environment, which could bring changes to what defines its health. Consequently, I see that ecosystem health is an important concept to research that opens many avenues for future research. It is important to note that the young age of the concept within previous OGD research means that many of its strengths and weaknesses are to be created by researchers.

My Contribution, my Role, and Open Government Data. In my licentiate thesis (Crusoe, 2019b), I reflected that OGD as a term connects with various phenomena ranging from a normative idea about a social system to a certain type of data shared by providers. This spectrum contributes to difficulty when it comes to discerning the meaning of certain OGD concepts. Normative ideas can by mistake be transferred into research as descriptive. It took me three years and a doctoral thesis to disentangle the origin of this spectrum but also understand some of its problems. The origin is the interplay between an OGD reform and an OGD ecosystem. For example, an OGD manager can maintain data provision and persuade others to publish their data, and enrichers can be activists who persuade others to use OGD. Similarly, I have encountered OGD proponents in previous OGD research. I am not surprised that an OGD reform has been able to persuade researchers to join it, as one of its areas of activity is persuasion (see Section 5.2. Walsham (1995) explains that it is important that qualitative researchers have a view of their role in the complex human process of social research. Ven et al. (2007) divide the roles into four forms of research: informed basic research, collaborative basic research, design and evaluation research, and action/intervention research. Hirschheim and Klein (1989) present four roles of IS development that I think apply to researchers, as they are based on the idea of practice-oriented paradigms. Their roles are: expert, facilitator, partisan, and emancipator. I roughly connect the forms with the roles as: (1) experts conduct informed basic research (outside observers who describe and explain phenomena with advice from participants), (2) facilitators do collaborative basic research (involved observers who describe or explain phenomena with feedback and comments from participants who receive the produced knowledge in turn), (3) emancipators use design and evaluation research (helpers who help OGD actors understand how they can better design and implement OGD), and (4) partisans lead intervention research (reformists or cultivators who participate or lead an OGD reform). I think OGD researchers of an OGD reform or an OGD ecosystem need to discuss and decide their role within their research and their relationship with practice. My research is use-inspired basic research (Stokes, 2011), and I believe my role has been mostly that of the facilitator. I have used open-ended questions in my interviews to allow participants to express their experiences, but I have also sent knowledge to them for verification and feedback. Some participants presented my research and asked if they agree with my findings to allow them to input their experiences. I have seldom spent extended periods within a single case. On the other hand, I see that my role has oscillated between expert and 
emancipator for certain periods. For example, in my research Crusoe, Gebka, and Ahlin (2020b), I studied the information needs of seekers without the usual feedback and comment cycles, which made me an expert, while in my research Crusoe (2021a), I diagnosed the Swedish OGD ecosystem and shared a popular science article with my findings to practitioners, which made me an emancipator. However, I am skeptical of the emancipator and partisan roles. I think they risk changing my role from a research helper to a cultivator who persuades rather than gives critical advice. I do not think it is wise to lead something that you are studying as your actions could help verify your findings. At the same time, it makes me wonder if social research is supposed to lead social reforms or participate in them. No one has voted for me, and the recommendations I give can direct the actions and attention of practitioners. I have certain expert authority, broad leeway, and can hide my presence from the public. I can draw on a continuously growing pool of arguments for why we should reform society and continue to work for a reform for years by finding and solving problems. If my research would harm society or make actors prodigal with their resources, I do not believe I would be held accountable. If I leave research, another researcher could pick up my work and continue the reform. Even if OGD could lead to benefits, it is not fair to citizens who do not want the reform, lack resources and time to sustain their reform, are not represented by research, and do not benefit from the reform where the invested resources could have been used to improve their quality of life. Therefore, my OGD research has left me wondering if it is ethical to research OGD and be part of an OGD reform. This issue is a question that should be addressed by future research.

\section{Reflections on Research Quality}

My idea of research quality is grounded in my axiological element (see Section 3.5) as the concepts of relevance and rigor.

Relevancy. Relevant research solves practical problems, produces popular science articles and provides practical contributions (Myers, 2013). My research is based on practical problems, even if it is not directly written into the text of my articles and doctoral thesis. The practical problems I have considered are captured as: (1) the lack of OGD use (e.g., Hellberg and Hedström, 2015. Safarov, Meijer, and Grimmelikhuijsen, 2017) and (2) the slow and stagnate state of OGD in Sweden and the world (e.g., Shekarabi, 2017) World Wide Web Foundation, 2021). One of my colleagues summarized the practical problems as a question of "why is OGD not working as intended?" I sought answers to this question in previous OGD research, which made me discover knowledge gaps. This activity acted as a bridge between relevance and rigor. The first problem led to my research of Crusoe and Ahlin (2019b) and Crusoe, Gebka, and Ahlin (2020b), as I wanted to know how people could transform OGD into solutions and who would like to use these solutions. The second problem led me to my research of Crusoe, Simonofski, and Clarinval (2020) and Crusoe (2021a) since I wanted to know what providers are doing and why the work of providers and enrichers are slow or stagnating. In the research of Crusoe and Ahlin (2019b) and Crusoe (2021a), I wrote popular science articles that I shared with Swedish OGD practitioners. I have also presented the research of Crusoe and Ahlin (2019b) at a 
workshop to practitioners. The distributed research has received positive feedback, and some practitioners have sought further engagement with me. My research also provides practical implications (e.g., providers can use the enricher framework to understand how enrichers can work with data and what enrichers can expect of them (Crusoe and Ahlin, 2019b), which could be followed by practitioners. My doctoral thesis is based on perceived practical problems and provides practical implications (see Section 7.3) but has not yet been distributed as popular science. I see that my research has good practical relevance, but I have not evaluated its practical use or impact. Therefore, I deem that my research has high potential relevance for practice.

Rigorous research is considered scientific research following scientific standards where the results are peer-reviewed and published in journals. Its emphasis is on theoretical contributions (Myers, 2013). Rigor covers validity and reliability. Validity is divided into internal and external validity (Saunders and Lewis, 2012).

Internal Validity. Internal validity is concerned with the representatives of the findings for the studied phenomenon and related data collection methods. It is influenced by (1) participant invitations, (2) case history, (3) researchers-participants interactions, (4) drop-off, and (5) ambiguity about event flows ${ }^{1}$ (Saunders and Lewis, 2012). First, I have invited people who have publicly shown their OGD work to participate in my research (Crusoe and Ahlin, 2019b: Crusoe, Simonofski, and Clarinval, 2020. Crusoe, 2021a), which risks recruiting mostly enthusiasts. On the other hand, in the research of Crusoe, Gebka, and Ahlin (2020b), we openly invited participants, which attracted students who had free time or wanted to express their experiences. Second and third, my research is not a longitudinal study. It has not followed the history of OGD actors. It is a snapshot of how OGD actors can work. Consequently, I have spent little time interacting with practitioners, which limits my ability to influence them. I see that they may have been unable or unwilling to tell me everything they have experienced (which is relevant to my study). It is also possible that the short time has made it difficult for them to construct and understand the researcherparticipant relationship and, as such, found it difficult to express their experiences or know what is relevant to explain. On the other hand, I have used open-ended questions in my interviews (Whiting, 2008) (e.g., "Tell me how you have been working with OGD" or "Why are you working with OGD?") and when appropriate, I have sought feedback and comments on my analysis and findings to ensure I have not misunderstood the participants (member checking) (Mays and Pope, 2000). Similarly, I have used documents that I perceive to be authentic, credible, representative, and understandable (Myers, 2013). Fourth, I managed drop-off in my research through broad invitation of participants (Crusoe and Ahlin, 2019b: Crusoe, Gebka, and Ahlin, 2020b Crusoe, Simonofski, and Clarinval, 2020. Crusoe, 2021a). Participants could, as such, leave without impacting my research to a greater extent, as I had others who could share their experiences. Fifth, I resolved the ambiguity about event flows by comparing empirical material (Crusoe and Ahlin, 2019b. Crusoe, Gebka, and Ahlin,

\footnotetext{
${ }^{1}$ I have changed some of the names to make them less strong and fit them within my paradigmatic worldview. The original list is: (1) subject selection, (2) history, (3) testing, (4) mortality, and (5) ambiguity about casual direction (Saunders and Lewis, 2012).
} 
2020b Crusoe, Simonofski, and Clarinval, 2020: Crusoe, 2021a). The comparisions allowed me to identify gaps and oddities. I could return to and ask participants about the gaps and oddities. It also allowed me to probe about future participants in interviews (Whiting, 2008). As a result, the internal validity compensates for its lacking longitudinal dimension through the use of comparisons. I have also used open-ended and exploitative data collection methods with a mix of inductive and deductive approaches to allow the empirical material to express itself and verify previous research (Crusoe and Ahlin, 2019b: Crusoe, Gebka, and Ahlin, 2020b: Crusoe, 2021a). I judge the internal validity of my research to be good but could have been improved with longitudinal studies and invitations of OGD actors who are just about to start working with OGD or have decided not to work with it.

Generalizability. External validity refers to the generalizability of my findings (Saunders and Lewis, 2012). My research uses analytical generalizations to expand and generalize theories (Walsham, 1995: Yin, 2018). Walsham (1995) explains that analytical generalizations can be the development of concepts, generation of theory, drawing of specific implications, and contribution of rich insight. My research mainly focuses on the development of concepts and generation of theory (see Chapter 5). I increased my research's ability to generalize by drawing on previous research from multiple countries and evaluating my findings in Belgium (Crusoe and Ahlin, 2019b. Crusoe, Simonofski, and Clarinval, 2020). My research has produced knowledge that is descriptive, explanatory, and guiding with elements of normative and prospective (Goldkuhl, 1998). The general OGD reform introduces the normative and prospective elements (e.g., the need for providers and enrichers and the possible benefits). My research is not predictive or critical (Goldkuhl, 1998), as such, it should not be used to predict patterns or behaviors or be used to question OGD. My research is generalizable to countries with developed information infrastructure; active cultivators who seek or encourage cooperation and collaboration amongst OGD actors; governments that own extensive pools of semi-closed data; and activists that seek to expand the data work of society for some higher purpose while making this work more effective. At the same time, I want to clarify that it should be possible to identify the four areas of an OGD reform and the data-information cycles and energy flows of an OGD ecosystem in other countries (see Chapter 5). However, the structures of the OGD ecosystem, the specific activities of OGD actors, and the interplay can vary based on context. The RE-ECO framework is based on Swedish empirical material, and previous research from other countries but has not been evaluated in Sweden or another country. Its quality is good, but it requires further conceptual developments, such as purpose flows, energy flows, variations of providers and enrichers, and seekers.

Reliability. Reliability refers to the extent data collection methods and analysis produces consistent or similar findings, but also the clarity of how I came to my conclusions. Errors and biases of subjects and observers can influence reliability (Saunders and Lewis, 2012). My research has iterated between previous research and empirical material. I have returned to my empirical material and previous research to verify conclusions (Crusoe and Ahlin, 2019b: Crusoe, Gebka, and Ahlin, 2020b: Crusoe, Simonofski, and Clarinval, 2020: Crusoe, Zuiderwijk, and Melin, 2020: Crusoe, 2021a). I believe the iterations with comparisons and member checking (see above) 
have minimized biases and errors. However, I noted that some respondents in Crusoe, Gebka, and Ahlin (2020b) and Crusoe (2021a) either found it difficult to understand certain concepts or put words to their experiences. An OGD reform transforms society to coalesce an OGD ecosystem, containing phenomena never encountered by participants. I have myself struggled with this problem and focused my attention on conceptual developments (see Chapter 5). At the same time, I have had my articles and doctoral thesis peer-reviewed by colleagues, who have evaluated the clarity of my reasoning for conclusions. I deem the data and analytical methods of my research reliable.

Delimitations and Limitations. I give the delimitations and limitations of my research at Section 1.4 and Section 4.5 which have influenced the quality of my research and, in turn, my contributions. I understand the nascent Swedish OGD ecosystem to be a good context for my research, but the enthusiasm of an OGD reform blurs the line between descriptions and possibilities, which makes the RE-ECO framework (see Chapter 5) inherently lean towards a positive view of OGD. I have, through my research, reflected on and evaluated my findings, which should lessen it, but the framework may contain normative and prospective elements. At the same time, I delimited myself not to study the development of an OGD reform and its related OGD movement and siblings (e.g., public sector information and mydata). My decision has created a blind spot in the framework and empirical material for how the interplay between an OGD reform and other reforms could shape an OGD ecosystem. On the other hand, my attention has been guided by practitioners towards interesting OGD phenomena. I have learned that this approach tends to lead to things that evoke excitement or frustration for the participants or things that they are supposed or encouraged to say (often based on the Swedish OGD reform). I have noticed that these behaviors tend to obfuscate everyday things that are plainer but just as important. Moreover, I have sometimes duct-taped previous research. I have learned that this decision is risky when reading multi-disciplinary research, as I cannot always know the full research context and misapply the concepts. This risk was lessened through comparisons and empirical explorations, and evaluations. As a result, my research and the RE-ECO framework align with previous research and have made theoretical contributions and practical contributions. My research has also resulted in future research avenues.

\subsection{Future Research}

My doctoral research has identified avenues for further research. Generally, the REECO framework (see Chapter 5) could be supplemented with gatekeeping theory (e.g., Shoemaker and Vos, 2009; Vos and Heinderyckx, 2015), role theory (e.g., Biddle, 2013), and mega-project theory (e.g., Flyvbjerg, 2017. Sarkheyli and Sarkheyli, 2019). Future research is needed about mutation-loading and purpose flows (see Section 5.4 and Section 6.4. My research has specifically lead to the following three avenues for future research. 
Seekers and the Public Sector. My research has focused on the work of providers and enrichers, leaving the work of seekers described by previous research. I believe the information needs of seekers could partly determine the health of an OGD ecosystem by demanding certain data (Crusoe, Gebka, and Ahlin, 2020b). Ubaldi (2013) explains that high-value, high-impact data should be published. On the other hand, the acquisition and provision nodes for providers can vary in structures (e.g., how data are collected and cleaned). It is possible that their structures can impact their OGD ecosystem by constraining the work of enrichers and seekers. I perceive it to be possible that data matching the need of seekers are published, but the used collection methods make the data unable to satisfy the need of the seekers (Crusoe, 2021a). At the same time, OGD can also realize detriments and harm actors and society (Wang, Zhao, Zhao, and Chu, 2019). The dark side of an OGD ecosystem (Zuiderwijk and Janssen, 2014b) could fuel anti-democratic movements, criminals, and information warfare. This avenue raises the three following questions: what OGD has high-value and high-impact for seekers within a certain context? How can OGD contribute to the dark side of an OGD ecosystem? How can acquisition nodes constrain their OGD ecosystem and its health?

An OGD Reform and its Development. My research has focused on the work of providers and enrichers (e.g., Crusoe and Ahlin, 2019b Crusoe, Simonofski, and Clarinval, 2020), which has left the developments of an OGD reform a limitation. In my research, I have encountered several OGD principles, changes in Swedish OGD leadership and solution ownership, developments and changes in the legal system, and several approaches to evaluate an OGD ecosystem. However, these phenomena indicate that an OGD reform develops as its OGD ecosystem develops. It is possible that the Swedish OGD reform has gone through stages as its Swedish OGD ecosystem has evolved. This avenue also involves future possibilities of OGD, such as its use with big data, machine learning, and artificial intelligence, and new types of collaborations between the public and private sectors. This research avenue wonders: How can an OGD reform develop in relation to the cultivation of its OGD ecosystem? What are the possibilities of OGD with regards to machine learning and AI? How can new types of collaborations between OGD actors contribute to an OGD reform and an OGD ecosystem?

The Future of OGD in the Public Sector. An OGD reform seeks to transform the public sector to beget an OGD ecosystem. It comes with its own moral purpose and values where some are captured in OGD principles, such as "open by default" and "public input" (Tauberer, 2014. Open Data Charter, 2015). For example, the Swedish Tax Agency has explained that an OGD reform involves a cultural journey for their employees (Kronofogden, 2019). It adds new work to public organizations, providing data to enrichers and seekers. However, the public sector has previous morals and values where Rose, Persson, Heeager, and Irani (2015) have identified four value positions: (1) professionalism, (2) efficiency, (3) service, and (4) engagement. De Vries (2016) explains that the public sector is authorized to allocate collectively binding values and services in society, and it serves public goods to the civic sphere but also has certain tasks, authority, and responsibilities. I understand that these morals, values, tasks, authority, and responsibilities can be understood as 
the mission of the public sector. I recognize that this mission could vary between countries but also interplay with an OGD reform. My research brings the question about where within this mission OGD falls; is or will OGD be a public good (see Section 2.5, a public utility (see Crusoe, Zuiderwijk, and Melin (2020)), or something else? 



\section{References}

Abella, Alberto, Marta Ortiz-de Urbina-Criado, and Carmen DePablos-Heredero (2019). "The process of open data publication and reuse". In: Journal of the Association for Information Science and Technology 70.3, pp. 296-300.

Adam, Frederic and Brian Fitzgerald (2000). "The status of the information systems field: historical perspective and practical orientation". In: Information Research 5.4, pp. 1-17.

Adler, Mortimer J and Charles Van Doren (2014). How to read a book: The classic guide to intelligent reading. Simon and Schuster.

Agrawal, Deepti, William Kettinger, and Chen Zhang (2014). The openness challenge: why some cities take it on and others don't. Tech. rep. AMCIS 2014.

Akhlaghpour, Saeed, Jing Wu, Liette Lapointe, and Alain Pinsonneault (2013). "The ongoing quest for the IT artifact: Looking back, moving forward". In: Journal of Information Technology 28.2, pp. 150-166.

Al-Shbail, Tariq and Aini Aman (2018). "E-government and accountability". In: Transforming Government: People, Process and Policy 12.2, pp. 155-190.

Alter, Steven (2003a). "18 Reasons Why IT-Reliant Work Systems Should Replace" The IT Artifact" as the Core Subject Matter of the IS Field". In: Communications of the Association for Information Systems 12.1, p. 23. 
- (2003b). "Sidestepping the IT Artifact, Scrapping the IS Silo, and Laying Claim to" Systems in Organizations""'. In: Communications of the Association for Information Systems 12.1, pp. 494-526.

Angelopoulos, Michail K and Yannis A Pollalis (2020). "Use of open data as a tool for successful lean management in public services: evidence from Greece". In: SPOUDAI-Journal of Economics and Business 70.1-2, pp. 117-127.

Archer, Margaret, Roy Bhaskar, Andrew Collier, Tony Lawson, and Alan Norrie (2013). Critical realism: Essential readings. Routledge.

Arwidson, Jon and Magnus Kolsjö (2014). Öppna data i Sverige. PricewaterhouseCoopers (PwC). URL: https://www.pwc.se/sv/pdf-reports/ oppna-data-i-sverige-2014-low.pdf (Accessed: 18 May 2021).

Ascher, Kate, Wendy Marech, and Isley Alexander (2005). The works: anatomy of a city. Penguin Press New York, NY.

Attard, Judie, Fabrizio Orlandi, and Sören Auer (2016). "Value creation on open government data". In: 2016 49th Hawaii International Conference on System Sciences (HICSS). Ed. by Tung X. Bui and Ralph H. Sprague. IEEE, pp. 2605-2614.

- (2017). "Exploiting the value of data through data value networks". In: Proceedings of the 10th international conference on theory and practice of electronic governance. Ed. by Rehema Baguma, Rahul De, and Tomasz Janowski. Association for Computing Machinery, pp. $475-484$.

Attard, Judie, Fabrizio Orlandi, Simon Scerri, and Sören Auer (2015).

"A systematic review of open government data initiatives". In: Government Information Quarterly 32.4, pp. 399-418.

Ayre, Lori Bowen and Jim Craner (2017). “Open Data: What It Is and Why You Should Care". In: Public Library Quarterly 36.2, pp. 173184.

Bannister, Frank and Regina Connolly (2012). "Forward to the past: Lessons for the future of e-government from the story so far". In: Information Polity 17.3-4, pp. 211-226.

Barry, Emily and Frank Bannister (2014). "Barriers to open data release: A view from the top". In: Information Polity 19.1-2, 129-152. Baskerville, Richard L and Michael D Myers (2002). "Information systems as a reference discipline". In: MIS Quarterly 26.1, pp. 1-14.

Baum, Christopher and Andrea Di Maio (2000). Gartner's four phases of e-government model. Gartner Group. URL: https://www.gartner.com/ 
en / documents / 317292/ gartner-s-four-phases-of-e-government-model (Accessed: 29 June 2021).

Becker, Howard S (2008). Writing for social scientists: How to start and finish your thesis, book, or article. University of Chicago Press.

Belkin, Nicholas J and Alina Vickery (1985). Interaction in information systems: A review of research from document retrieval to knowledgebased systems. Wetherby (United Kingdom), British Library.

Benbasat, Izak and Ron Weber (1996). "Research commentary: Rethinking "diversity" in information systems research". In: Information systems research 7.4, pp. 389-399.

Benbasat, Izak and Robert W Zmud (2003). "The identity crisis within the IS discipline: Defining and communicating the discipline's core properties". In: MIS quarterly 27.2, pp. 183-194.

Bengtsson, Mariette (2016). "How to plan and perform a qualitative study using content analysis". In: NursingPlus Open 2, pp. 8-14.

Beno, Martin, Kathrin Figl, Jürgen Umbrich, and Axel Polleres (2017). "Open data hopes and fears: determining the barriers of open data". In: E-Democracy and Open Government (CeDEM). Ed. by Peter Parycek and Noella Edelmann. IEEE, pp. 69-81.

Berends, Jorn, Wendy Carrara, Wander Engbers, and Heleen Vollers (2017). Re-using Open Data. European Data Portal. URL: https:// www.europeandataportal.eu/sites/default/files /re-using \_open \_data.pdf (Accessed: 19 April 2019).

Berger, Peter and Thomas Luckmann (1966). The social construction of reality. Anchor Books.

Bernays, Edward L (2005). Propaganda. Ig publishing.

Bernecker, Sven and Duncan Pritchard (2011). The Routledge companion to epistemology. Routledge.

Berners-Lee, Tim (2009). The next web. URL: https://www.ted.com/talks/ tim_berners $\backslash$ lee $\backslash$ the $\backslash \_n e x t \backslash w e b($ Accessed: 25 June 2021).

- (2015). 5-Star Open Data. URL: http://5stardata.info/en (Accessed: 24 August 2020).

Berntzen, Lasse, Marius Rohde Johannessen, Kim Normann Andersen, and Jonathan Crusoe (2019). "Parliamentary Open Data in Scandinavia". In: Computers 8.3, pp. 1-18.

Bhaskar, Roy (2013). A realist theory of science. Routledge.

Bichard, Jo-Anne and Gail Knight (2012). "Improving public services through open data: public toilets". In: Proceedings of the Institu- 
tion of Civil Engineers-Municipal Engineer. Ed. by Matthew Lugg. Vol. 165. 3. Thomas Telford Ltd, pp. 157-165.

Biddle, Bruce J (2013). Role theory: Expectations, identities, and behaviors. Academic Press.

Bisnode (2016). ÖPPNA DATA = INNOVATION! Bisnode. URL: https:

/ / www.bisnode.se / kunskap / vara-tankar-om / white-paper-oppna-data /

(Accessed: 18 May 2021).

Black, Max (1955). "XII-METAPHOR". In: Proceedings of the Aristotelian Society. Vol. 55. 1. Oxford University Press Oxford, UK, pp. 273294.

Bloom, Paul N and Gregory Dees (2008). "Cultivate your ecosystem". In: Stanford social innovation review 6.1, pp. 47-53.

Boell, Sebastian K (2017). “Information: Fundamental positions and their implications for information systems research, education and practice". In: Information and Organization 27.1, pp. 1-16.

Boell, Sebastian K and Dubravka Cecez-Kecmanovic (2014). "A hermeneutic approach for conducting literature reviews and literature searches". In: Communications of the association for information systems 34.1, pp. 257-286.

Boulton, Geoffrey, Michael Rawlins, Patrick Vallance, and Mark Walport (2011). "Science as a public enterprise: the case for open data". In: The Lancet 377.9778, pp. 1633-1635.

Bounabat, Bouchaiib (2017). "From e-government to digital Government". In: Electronic Journal of Information Technology.

Bowen, Glenn A (2009). "Document analysis as a qualitative research method". In: Qualitative research journal 9.2, 27-40.

Brix, Andrew C. (2017). Postal system. URL: https://www.britannica.com/ topic/postal-system (Accessed: 03 October 2020).

Brodie, Richard (2009). Virus of the mind: The new science of the meme. Hay House, Inc.

Buchanan, Robert Angus (1990). Public utilities. In: An encyclopaedia of the history of technology. Ed. by Ian McNeil. 1st ed. London and New York: ROUTLEDGE. Chap. 20, pp. 949-966.

Buckland, Michael (2017). Information and society. MIT Press.

Bylund, Markus et al. (2016). Det Datadriona Samhället - Temarapport

2016:1. URL: https: / / www. regeringen . se / rattsliga - dokument / statens offentliga-utredningar/2016/12/sou-201685/(Accessed: 28 June 2021).

Caiden, Gerald E (2017). Administrative Reform. Routledge. 
Calderon, Ania (2018). Publishing with Purpose. URL: https : / / opendatacharter. medium . com / publishing - with - purpose - introducing - our 2018-strategy-ddbf7ab46098 (Accessed: 25 June 2021).

Callon, Michel (1999). "Actor-network theory-the market test". In: The Sociological Review 47.1_suppl, pp. 181-195.

Carrara, W, F Oudkerk, E Van Steenbergen, and D Tinholt (2018). Open Data Goldbook for Data Managers and Data Holders. European Data Portal. URL: https: / / www. europeandataportal.eu / sites / default / files / goldbook.pdf (Accessed: 27 August 2019).

Carrara, Wendy, Wae-San Chan, Sander Fischer, and E van Steenbergen (2015). Creating value through open data: Study on the impact of re-use of public data resources. European Commission. URL: https:// data.europa.eu/sites/default/files/edp \_creating $\backslash$ _value $\backslash \_t h r o u g h \backslash$ open $\backslash$ _data $\_$0.pdf (Accessed: 28 June 2021).

Chalmers, Alan F (2013). What is this thing called science? Hackett Publishing.

Charalabidis, Yannis et al. (2018). The World of Open Data. Springer International Publishing.

Checkland, Peter and SE Holwell (1997). Information, systems and information systems. John Wiley and Sons Ltd.

City Mapper (2020). City Mapper. URL: https: / / citymapper.com/ (Accessed: 01 July 2020).

Colborne, Adrienne and Michael Smit (2020). "Characterizing Disinformation Risk to Open Data in the Post-Truth Era". In: Journal of Data and Information Quality (JDIQ) 12.3, pp. 1-13.

Colpaert, Pieter, Sarah Joye, Peter Mechant, Erik Mannens, and Rik Van de Walle (2013). "The 5 stars of open data portals". In: Proceedings of the 7th International Conference on Methodologies, Technologies and Tools Enabling E-Government. Ed. by Luis Álvarez Sabucedo and Luis Anido Rifón. Servizo de Publicacións da Universidade de Vigo, 2013, pp. 61-67.

Confluence (2021). In: The Cambridge Dictionary. Cambridge University Press. URL: https://dictionary.cambridge.org/dictionary/english/confluence (Accessed: 30 May 2021).

Conradie, Peter and Sunil Choenni (2014). "On the barriers for local government releasing open data". In: Government Information Quarterly 31, S10-S17.

Cortada, James W (2011). Information and the modern corporation. MIT Press. 
Creswell, John W and J David Creswell (2017). Research design: Qualitative, quantitative, and mixed methods approaches. Sage publications.

Crusoe, Jonathan (2016). Open data ecosystem: the data market between municipalities and businesses. Tech. rep. [Master's Thesis]. Linköping University.

- (2019a). Organizing Open Government Data - Exploring Data as a Public Utility. [Thesis Plan]. Colloquium of the EGOV-CeDEM-ePART conference (in Italy).

- (2019b). Why is it so challenging to cultivate open government data?: Understanding impediments from an ecosystem perspective. Vol. 124. [Licentiate Thesis]. Linköping University Electronic Press.

- (2021a). "Diagnose a National Open Data Ecosystem - The Countrywide Exploration of Open Data in Sweden". In: [In Preparation and Peer Reviewed].

- (2021b). "Information Systems - Inklings toward a fundamental framework". In: Scandinavian Workshop of e-Government SWEG 2021, the IT University of Copenhagen, Denmark, 27-28 January. [In Preparation and Peer Reviewed].

Crusoe, Jonathan and Karin Ahlin (2019a). “Users' activities and impediments from motivation to deployment in Open Government Data-a process framework". In: Scandinavian Workshop of e-Government SWEG 2019, the University of South-Eastern Norway (USN), Campus Vestfold, 30-31 January. [Developed and Published].

- (2019b). “Users' activities for using open government data-a process framework". In: Transforming government: People, process and policy 13.3-4, pp. 213-236.

- (2020). "Publisher' activities for working with Open Government Data - a process framework". In: Scandinavian Workshop of eGovernment Scandinavian Workshop of e-Government SWEG 2020, the University of Gothenburg, Campus Lindholmen, 29-30 January. [Developed and Published].

Crusoe, Jonathan, Elisabeth Gebka, and Karin Ahlin (2020a). "Do we need open data in our lives?" In: Scandinavian Workshop of eGovernment Scandinavian Workshop of e-Government SWEG 2020, the University of Gothenburg, Campus Lindholmen, 29-30 January. [Developed and Published].

- (2020b). "Open Government Data from the Perspective of Information Needs - A Tentative Conceptual Model". In: Electronic Govern- 
ment. Ed. by Gabriela Viale Pereira et al. Cham: Springer International Publishing, pp. 250-261.

Crusoe, Jonathan and Ulf Melin (2017). "Exploring actor's roles within an Open Data Ecosystem - Reflexive Conceptual Development". In: Scandinavian Workshop of e-Government SWEG 2017, the Mid Sweden University, Sundsvall, 1-2 February 1-2. [In Preparation and Peer Reviewed].

- (2018a). "Investigating open government data barriers". In: International Conference on Electronic Government. Ed. by Peter Parycek et al. Springer, pp. 169-183.

- (2018b). "The Bigger Picture of Open Government Data Barriers A Literature Review and Conceptualization". In: The 15th Scandinavian Workshop of e-Government SWEG, Copenhagen Business School, Copenhagen, January 31-February 1. [Developed and Published].

Crusoe, Jonathan, Anthony Simonofski, and Antoine Clarinval (2020). "Towards a Framework for Open Data Publishers: A Comparison Study Between Sweden and Belgium". In: Electronic Government. Ed. by Gabriela Viale Pereira et al. Cham: Springer International Publishing, pp. 262-274.

Crusoe, Jonathan, Anthony Simonofski, Antoine Clarinval, and Elisabeth Gebka (2019). "The impact of impediments on open government data use: Insights from users". In: 2019 13th International Conference on Research Challenges in Information Science (RCIS). Ed. by Manuel Kolp, Jean Vanderdonckt, Monique Snoeck, and Yves Wautelet. IEEE, pp. 1-12.

Crusoe, Jonathan, Anneke Zuiderwijk, and Ulf Melin (2020). “Open Government Data Systems: Learning from a Public Utility Perspective". In: Electronic Government. Ed. by Gabriela Viale Pereira et al. Cham: Springer International Publishing, pp. 275-289.

Cursus Publicus (2020). In: Nationalencyklopedin. NE Nationalencyklopedin AB. URL: https: / / www.ne.se/ uppslagsverk / encyklopedi / 1 \%C3 \ \%A5ng/cursus-publicus (Accessed: 03 October 2020).

Daft, Richard L and Robert H Lengel (1986). "Organizational information requirements, media richness and structural design". In: Management science 32.5, pp. 554-571.

Damasio, Antonio (1994). Descartes' Error: Emotion, Reason, and the Human Brain Paperback.

Davies, Tim (2010). Open data, democracy and public sector reform - A look at open government data use from data.gov.uk. Open Data Impacts. 
URL: http:/ /www.opendataimpacts.net/report/wp-content/uploads / 2010/ 08/How-is-open-government-data-being-used-in-practice.pdf (Accessed: 28 June 2021).

Davies, Tim (2011). Open Data: Infrastructures and ecosystems. Open

Data Research. URL: https: / / wiki.ikmemergent.net/sites / default / files / ikmemergent_archive/Social_Life_of_Data_-_Infrastructure_and_Ecosystem_ Paper.pdf (Accessed: 28 June 2021).

- (2012). 5-Stars of Open Data Engagement. URL: http : / / www . opendataimpacts.net/engagement/ (Accessed: 09 October 2020).

Davis, Gordon B (2006). "Information systems as an academic discipline". In: IFIP World Computer Congress, TC 8. Ed. by David Avison, Steve Elliot, John Krogstie, and Jan Pries-Heje. Springer, pp. 11-25.

Davis, Gordon Bitter (1991). The emergence of Information Systems as a business function and academic discipline. Management Information Systems Research Center, Curtis L. Carlson School of ...

Davison, RM, MC Munro, and DW Straub (2004). "AIS Code of Research Conduct". In: Communications of the Association for Information Systems 13, pp. 9-16.

Dawes, Sharon S, Lyudmila Vidiasova, and Olga Parkhimovich (2016). "Planning and designing open government data programs: An ecosystem approach". In: Government Information Quarterly 33.1, pp. 15-27.

Dawkins, Richard (2016). The selfish gene. Oxford university press.

Day, Lance (2002). "Language, writing, printing and graphic arts". In: An Encyclopedia of the History of Technology. Ed. by Ian McNeil. Routledge. Chap. 14, pp. 665-685.

De Rosnay, Melanie Dulong and Katleen Janssen (2014). “Legal and institutional challenges for opening data across public sectors: Towards common policy solutions". In: Journal of Theoretical and Applied Electronic Commerce Research 9.3, 1-14.

De Saulles, Martin (2020). The Business of Data: Commercial Opportunities and Social Challenges in a World Fuelled by Data. Routledge.

De Vries, Michiel S (2016). Understanding public administration. Macmillan International Higher Education.

den Hartigh, Erik, Michiel Tol, and Wouter Visscher (2006). "The health measurement of a business ecosystem". In: Proceedings of the European Network on Chaos and Complexity Research and Management Practice Meeting, pp. 1-39. 
Denis, Jérôme and Samuel Goëta (2014). "Exploration, Extraction and 'Rawification'. The Shaping of Transparency in the Back Rooms of Open Data". In: The Shaping of Transparency in the Back Rooms of Open Data 2014.February, pp. 1-8.

DESI (2019). Digital Economy and Society Index (DESI) 2019 ranking. URL: https:/ /ec.europa.eu/digital-single-market/en/countries-performancedigitisation (Accessed: 02 July 2021).

Dickson, Gary W (1968). "Management information-decision systems: A new era ahead?" In: Business Horizons 11.6, pp. 17-26.

Ding, Li et al. (2011). "TWC LOGD: A portal for linked open government data ecosystems". In: Journal of Web Semantics 9.3, pp. 325333.

Downer, MC, FA Teagle, and JG Whittle (1979). "Field testing of an information system for planning and evaluating dental services". In: Community Dentistry and Oral Epidemiology 7.1, pp. 11-16.

Dresch, Aline, Daniel Pacheco Lacerda, and José Antônio Valle Antunes (2015). "Design science research". In: Design Science Research. Ed. by Aline Dresch, Daniel Pacheco Lacerda, and José Antônio Valle Antunes. Springer. Chap. 4, pp. 67-102.

Durant, Will and Ariel Durant (2012). The lessons of history. Simon and Schuster.

Eisenhardt, Kathleen M (1989). "Building theories from case study research". In: Academy of management review 14.4, pp. 532-550.

Ellis, David, Deborah Cox, and Katherine Hall (1993). “A comparison of the information seeking patterns of researchers in the physical and social sciences". In: Journal of documentation 49.4, pp. 356-369.

Elo, Satu and Helvi Kyngäs (2008). "The qualitative content analysis process". In: Journal of advanced nursing 62.1, pp. 107-115.

Emamjome, Fahame, Alison Gable, Wasana Bandara, and Guy Gable (2018). "Re-thinking the ontology of information". In: Proceedings of the 39th International Conference on Information Systems (ICIS) 2018 Conference: AIS Electronic Library, pp. 1-17.

Epstein, David (2021). Range: Why generalists triumph in a specialized world. Penguin.

Erdelez, Sandra (1999). "Information encountering: It's more than just bumping into information". In: Bulletin of the American Society for Information Science and Technology 25.3, pp. 26-29. 
Eriksson, Ola (2014). Öppna data 2014 - Nulägesanalys. Vinnova and Generic Systems Sweden AB. URL: https: / / publector.org / uploads / publications/Oppna-data-2014/vr_14_04.pdf(Accessed: 18 May 2021).

European Data Portal (2020). What is open data? URL: https: / / www. europeandataportal . eu / elearning / en / \# / id / co-01 (Accessed: 08 June 2020).

- (2021). Open Data Maturity. URL: https://www.europeandataportal.eu/ en/impact-studies/open-data-maturity (Accessed: 26 February 2021).

Evans, Alan, Kendall Martin, and Mary Anne Poatsy (2008). Technology in action. Pearson Prentice Hall.

Fath-Allah, Abdoullah, Laila Cheikhi, Rafa E Al-Qutaish, and Ali Idri (2014). "E-government maturity models: A comparative study". In: International Journal of Software Engineering \& Applications 5.3, pp. 71-91.

Fieser, James and Bradley Dowden (2011). "Ethics". In: Internet encyclopedia of philosophy.

Finger, Matthias (2009). "e-gov and public sector reform: what roles for government in e-government?" In: Proceedings of the 3rd international conference on Theory and practice of electronic governance. Ed. by Tomasz Janowski and Jim Davies. Association for Computing Machinery, pp. 1-4.

Fitzgerald, Brian and Debra Howcroft (1998). "Competing dichotomies in IS research and possible strategies for resolution". In: International Conference on Information Systems. AIS Electronic Library, pp. 155-164.

Fleck, Ludwik (2012). Genesis and development of a scientific fact. University of Chicago Press.

Flyvbjerg, Bent (2017). The Oxford handbook of megaproject management. Oxford University Press.

Folmer, Erwin et al. (2011). "Walking the extra byte: A lifecycle model for linked open data". In: Linked Open Data - Pilot Linked Open Data Nederland. Ed. by Erwin Folmer, M. Reuvers, and W. Quak. Remwerk, pp. 95-111.

Frick, Anders (2015). Öppna data - En omvärldsanalys med nulägesstatus. Internetstiftelsen. URL: https:/ / internetstiftelsen.se / kunskap/rapporteroch-guider/oppna-data-en-omvarldsanalys-med-nulagesstatus/ (Accessed: 18 May 2021).

Frick, Anders and Jan Ainali (2017). Öppna Data - En Guide för beslutsfattare. Internetstiftelsen. URL: https: / / internetstiftelsen . se / 
kunskap / rapporter-och-guider / oppna-data-guide-for-beslutsfattare/ (Accessed: 18 May 2021).

Froese, Rainer (1990). "FISHBASE: an information system to support fisheries and aquaculture research". In: Fishbyte 8.3, pp. 21-24.

Funk, Ken (2001). What is a worldview? URL: http://web.engr.oregonstate. edu/ funkk/Personal/worldview.html (Accessed: 28 June 2021).

Galliers, Robert D (2003). "Change as crisis or growth? Toward a trans-disciplinary view of information systems as a field of study: A response to Benbasat and Zmud's call for returning to the IT artifact". In: Journal of the Association for Information Systems 4.1, pp. 337-351.

Gannon, Brian (2013). "Outsiders: an exploratory history of IS in corporations". In: Journal of Information Technology 28.1, pp. 50-62.

Gebka, Elisabeth, Antoine Clarinval, Anthony Simonofski, and Jonathan Crusoe (2019). "Generating value with open government data: Beyond the programmer". In: 2019 13th International Conference on Research Challenges in Information Science (RCIS). Ed. by Manuel Kolp, Jean Vanderdonckt, Monique Snoeck, and Yves Wautelet. IEEE, pp. 1-2.

Gebka, Elisabeth, Jonathan Crusoe, and Karin Ahlin (2020a). “Open data reuse and information needs satisfaction: a method to bridge the gap". In: Proceedings of Ongoing Research, Practitioners, Posters, Workshops, and Projects at EGOV-CeDEM-ePart 2020. Ed. by Shefali Virkar et al. CEUR-WS, pp. 41-49.

- (2020b). "Open data reuse and information needs satisfaction: a method to bridge the gap". In: the Scandinavian Workshop of $e$ Government Scandinavian Workshop of e-Government SWEG 2020, the University of Gothenburg, Campus Lindholmen, 29-30 January. [Developed and Published as Research in Progress].

Geddes, Rick (1998). Public utilities. In: The Encyclopedia of Law and Economics. Ed. by Boudewijn Bouckaert and Gerrit De Geest. 1st ed. Edward Elgar. Chap. 5940, pp. 1162-1205.

Gelhaar, Joshua, Tobias Groß, and Boris Otto (2021). “A Taxonomy for Data Ecosystems". In: Proceedings of the 54th Hawaii International Conference on System Sciences. Ed. by Tung X. Bui. ScholarSpace, pp. 6113-6122.

Gleick, James (2011). The information: A history, a theory, a flood. Vintage. Global Open Data Index (2016). Global Open Data Index. URL: https:// index.okfn.org/(Accessed: 23 May 2021). 
Glucksberg, Sam (1989). "Metaphors in conversation: How are they understood? Why are they used?" In: Metaphor and Symbol 4.3, pp. 125-143.

Goldkuhl, Göran (1998). Kunskapande. Inst. för datavetenskap.

- (2008). "Artefact science vs. practice science: seeking information systems identity". In: Proceedings of the 5th International Conference on Action in Language, Organisations and Information Systems. Ed. by Ågerfalk Pär J., Lind Mikael, and Jacucci Gianni. University of Trento, pp. 1-15.

- (2012). "Pragmatism vs interpretivism in qualitative information systems research". In: European journal of information systems 21.2, pp. 135-146.

Gorski, Philip S (2013). "What is critical realism? And why should you care?" In: Contemporary sociology 42.5, pp. 658-670.

Gray, Jonathan, Carolin Gerlitz, and Liliana Bounegru (2018). "Data infrastructure literacy". In: Big Data \& Society 5.2, pp. 1-13.

Greenhalgh, Trisha (1997). "How to read a paper: Papers that summarise other papers (systematic reviews and meta-analyses)". In: Bmj 315.7109, pp. 672-675.

Gregor, Shirley (2002). "A theory of theories in information systems". In: Information Systems Foundations: building the theoretical base. Ed. by S. Gregor and D. Hart. Australian National University, Canberra, pp. 1-20.

- (2006). "The nature of theory in information systems". In: MIS quarterly 30.3, pp. 611-642.

Grönlund, Åke and Thomas A Horan (2005). "Introducing e-gov: history, definitions, and issues". In: Communications of the association for information systems 15.1, pp. 1-19.

Guba, Egon G, Yvonna S Lincoln, et al. (1994). "Competing paradigms in qualitative research". In: Handbook of qualitative research. Ed. by N. K. Denzin and Y. S. Lincoln. 163-194. California, Sage Publications. Chap. 6, pp. 105-117.

Guchteneire, Paul de (2006). Code of conduct social science research UNESCO. URL: http://www.unesco.org/new/fileadmin/MULTIMEDIA/HQ/ SHS/pdf/Soc_Sci_Code.pdf (Accessed: 29 June 2021).

Gurstein, Michael B (2011). "Open data: Empowering the empowered or effective data use for everyone?" In: First Monday 16.2, 1-8.

Haidt, Jonathan (2012). The righteous mind: Why good people are divided by politics and religion. Vintage. 
Halonen, Antti (2012). Being open about data - Analysis of the UK Open Data Policies and Applicability of Open Data. Tech. rep. London: Finnish Institute in London. URL: http://www.fininst.uk/wp-content/ uploads/2017/09/being-open-about-data.pdf (Accessed: 29 June 2021).

Harrison, Teresa M., Theresa A. Pardo, and Meghan Cook (2012). "Creating Open Government Ecosystems: A Research and Development Agenda". In: Future Internet 4.4, 900-928.

Hartog, Martijn, Bert Mulder, Bart Spée, Ed Visser, and Antoine Gribnau (2014). "Open data within governmental organisations - Effects, Benefits and Challenges of the Implementation Process". In: eJournal of eDemocracy \& Open Government 6.1, 49-61.

Heeks, Richard (1998). Public Sector Accountability: Can IT Deliver? The University of Manchester. URL: https: / / www.researchgate.net/ publication/334637966 \_Public \_Sector \_Accountability \_Can \_IT \_Deliver (Accessed: 28 June 2021).

Heimstädt, Maximilian, Fredric Saunderson, and Tom Heath (2014). "Conceptualizing Open Data ecosystems: A timeline analysis of Open Data development in the UK". In: Conference for E-Democracy and Open Government. Ed. by Peter Parycek and Noella Edelmann. sn. Edition Donau-Universität Krems, pp. 245-255.

Heimstädt, Maximilian, Fredric Saunderson, and Tom Heath (2014). "From Toddler to Teen: Growth of an Open Data Ecosystem". In: eJournal of eDemocracy \& Open Government 6.2, 123-135.

Hekkala, Riitta, Mari-Klara Stein, and Matti Rossi (2018). “Metaphors in managerial and employee sensemaking in an information systems project". In: Information Systems Journal 28.1, pp. 142-174.

Hellberg, Ann-Sofie and Karin Hedström (2015). "The story of the sixth myth of open data and open government". In: Transforming Government: People, Process and Policy 9.1, pp. 35-51.

Hey, Jonathan (2004). "The data, information, knowledge, wisdom chain: the metaphorical link". In: Intergovernmental Oceanographic Commission 26, pp. 1-18.

Higman, Rosie and Stephen Pinfield (2015). "Research data management and openness: the role of data sharing in developing institutional policies and practices". In: Program 49.4, pp. 364-381.

Hirschheim, Rudy (1985). "Information systems epistemology: An historical perspective". In: Research methods in information systems. Elsevier Publishers. Chap. 2, pp. 9-33. 
Hirschheim, Rudy and Heinz K Klein (1989). "Four paradigms of information systems development". In: Communications of the ACM 32.10, pp. 1199-1216.

- (2011). "Tracing the history of the information systems field". In: The Oxford handbook of management information systems: Critical perspectives and new directions. Ed. by Robert D. Galliers and Wendy Currie. OUP Oxford. Chap. 2, pp. 16-61.

- (2012). "A glorious and not-so-short history of the information systems field". In: Journal of the association for information systems 13.4, p. 5.

Homeostasis. (2021). In: The Cambridge Dictionary. Cambridge University Press. URL: https: / / dictionary. cambridge.org / dictionary / english / homeostasis (Accessed: 25 May 2021).

Hong, Sun-ha (2020). Technologies of speculation: The limits of knowledge in a data-driven society. NYU Press.

Hossain, Mohammad Alamgir, Yogesh K Dwivedi, and Nripendra P Rana (2016). "State-of-the-art in open data research: Insights from existing literature and a research agenda". In: Journal of organizational computing and electronic commerce 26.1-2, pp. 14-40.

Hsieh, Hsiu-Fang and Sarah E Shannon (2005). "Three approaches to qualitative content analysis". In: Qualitative health research 15.9, pp. 1277-1288.

Huang, Ruhua, Tong Lai, and Lihong Zhou (2017). "Proposing a framework of barriers to opening government data in China". In: Library Hi Tech 35.3, pp. 421-438.

Huijboom, Noor and Tijs Van den Broek (2011). “Open data: an international comparison of strategies". In: European journal of ePractice 12.1, pp. 4-16.

Hunnius, Sirko and Bernhard Krieger (2014). "The social shaping of open data through administrative processes". In: Proceedings of The International Symposium on Open Collaboration. Ed. by Dirk Riehle et al. Association for Computing Machinery, pp. 1-5.

Huyer, Esther, Laura Van Knippenberg, Eline Arriëns Lincklaen, and Marit Blank (2020). The Economic Impact of Open Data - Opportunities for value creation in Europe. European Data Portal. URL: https: //www.europeandataportal.eu/sites/default/files/the-economic-impact- ofopen-data.pdf (Accessed: 01 July 2020).

Hyland, Bernadette and David Wood (2011). "The joy of data-a cookbook for publishing linked government data on the web". In: Link- 
ing government data. Ed. by David Wood. Springer. Chap. 1, pp. 326.

Hyrynsalmi, Sami and Sonja M Hyrynsalmi (2019). "Ecosystem: A Zombie Category?" In: 2019 IEEE International Conference on Engineering, Technology and Innovation (ICE/ITMC). Ed. by Marc Pallot, Alain Zarli, Abdul Rahman Abdel Razek, and Adrien Lecossier. IEEE, pp. 1-8.

Iansiti, Marco and Roy Levien (2004). The keystone advantage: what the new dynamics of business ecosystems mean for strategy, innovation, and sustainability. Harvard Business Press.

Iivari, Juhani and Kalle Lyytinen (1999). "Research on information systems development in Scandinavia". In: Rethinking management information systems - An Interdisciplinary Perspective. Ed. by Wendy Currie and Bob Galliers. Oxford: Oxford University Press. Chap. 2, pp. 57-102.

Immonen, Anne, Marko Palviainen, and Eila Ovaska (2014). "Requirements of an open data based business ecosystem". In: IEEE access 2, pp. 88-103.

Ingwersen, Peter (1982). "Search Procedures in the Library-Analysed from the Cognitive Point of View." In: Journal of documentation 38.3, pp. 165-191.

Innis, Harold Adams (2007). Empire and communications. Rowman \& Littlefield.

Interplay. (2021). In: The Cambridge Dictionary. Cambridge University Press. URL: https:// dictionary.cambridge.org/dictionary/english/interplay (Accessed: 30 May 2021).

Jaakkola, Hannu, Timo Mäkinen, and Anna Eteläaho (2014). “Open data: opportunities and challenges". In: Proceedings of the 15th International Conference on Computer Systems and Technologies. Ed. by Boris Rachev and Angel Smrikarov. Association for Computing Machinery, pp. 25-39.

Jaakkola, Hannu, Timo Mäkinen, Jaak Henno, and Jukka Mäkelä (2014). “Open" ${ }^{\mathrm{n}}$. In: 2014 37th International Convention on Information and Communication Technology, Electronics and Microelectronics (MIPRO). Ed. by Petar Biljanovic et al. IEEE, pp. 608-615.

Jamieson, David, Rob Wilson, and Mike Martin (2019). "The (im) possibilities of open data?" In: Public Money E Management 39.5, pp. 364-368. 
Janssen, Marijn, Yannis Charalabidis, and Anneke Zuiderwijk (2012). "Benefits, adoption barriers and myths of open data and open government". In: Information systems management 29.4, pp. 258-268.

Janssen, Marijn, Elsa Estevez, and Tomasz Janowski (2014). "Interoperability in big, open, and linked data-organizational maturity, capabilities, and data portfolios". In: IEEE Computer Architecture Letters 47.10 , pp. 44-49.

Janssen, Marijn and Anneke Zuiderwijk (2012). "Open data and transformational government". In: Proceedings of the Transforming Government Workshop 2012. Ed. by The Information Systems Evaluation and Integration Group. Brunel University, pp. 1-7.

- (2014). "Infomediary business models for connecting open data providers and users". In: Social Science Computer Review 32.5, pp. 694-711.

Jax, Kurt (2002). Zur Transformation ökologischer fachbegriffe beim Eingang in verwaltungsnormen und rechtstexte: das beispiel des ökosystembegriffs. na.

- (2006). "Ecological units: definitions and application". In: The Quarterly Review of Biology 81.3, pp. 237-258.

- (2007). "Can we define ecosystems? On the confusion between definition and description of ecological concepts". In: Acta Biotheoretica 55.4, pp. 341-355.

Jetzek, Thorhildur (2016). "Managing complexity across multiple dimensions of liquid open data: The case of the Danish Basic Data Program". In: Government Information Quarterly 33.1, pp. 89-104.

Jetzek, Thorhildur, Michel Avital, and Niels Bjørn-Andersen (2013). "The generative mechanisms of open government data". In: ECIS 2013 Proceedings - 21st European Conference on Information Systems. AIS Electronic Library, 47-56.

Jetzek, Thorhildur, Michel Avital, and Niels Bjorn-Andersen (2019). "The sustainable value of open government data". In: Journal of the Association for Information Systems 20.6, pp. 702-734.

Johnson, Peter A and Sarah Greene (2017). "Who Are Government OpenData Infomediaries? A Preliminary Scan and Classification of Open Data Users and Products." In: Journal of the Urban $\mathcal{E}$ Regional Information Systems Association 28.1, pp. 9-18.

Kahneman, Daniel (2011). Thinking, fast and slow. Macmillan.

Kalampokis, Evangelos, Efthimios Tambouris, and Konstantinos Tarabanis (2011a). “A classification scheme for open government data: 
towards linking decentralised data". In: International Journal of Web Engineering and Technology 6.3, pp. 266-285.

- (2011b). "Open government data: A stage model". In: Electronic Government. Ed. by Marijn Janssen, Hans J. Scholl, Maria A. Wimmer, and Yao-hua Tan. Springer, pp. 235-246.

Kassen, Maxat (2013). “A promising phenomenon of open data: A case study of the Chicago open data project". In: Government information quarterly 30.4, pp. 508-513.

- (2019). "Open data and e-government-related or competing ecosystems: a paradox of open government and promise of civic engagement in Estonia". In: Information Technology for Development 25.3, pp. 552-578.

Khazanchi, Deepak and Bjørn Erik Munkvold (2000). "Is information system a science? an inquiry into the nature of the information systems discipline". In: ACM SIGMIS Database: the DATABASE for Advances in Information Systems 31.3, pp. 24-42.

King, Timothy (2019). “THE CURSE OF KNOWLEDGE”. In: Professional Safety 64.3, pp. 61-61.

Kitchenham, Barbara (2004). Procedures for performing systematic reviews. Tech. rep. Keele, UK, Keele University.

Kitchin, Rob (2014). The data revolution: Big data, open data, data infrastructures and their consequences. Sage.

Kitsios, Fotis, Nikolaos Papachristos, and Maria Kamariotou (2017). "Business models for open data ecosystem: Challenges and motivations for entrepreneurship and innovation". In: 2017 IEEE 19th Conference on Business Informatics (CBI). Ed. by Peri Loucopoulos, Yannis Manolopoulos, Oscar Pastor, Babis Theodoulidis, and Jelena Zdravkovic. Vol. 1. IEEE, pp. 398-407.

Kron, Niclas (2021). Vädret. URL: https: / / play.google.com / store / apps / details?id=fi.kroon.vadret\&gl=SE (Accessed: 04 March 2021).

Kronofogden (2019). Hur gjorde vi? URL: https:/ / www. kronofogden.se/ erfarenhetpsidata.html (Accessed: 30 May 2021).

Kucera, Jan and Dusan Chlapek (2014). "Benefits and Risks of Open Government Data". In: Journal of Systems Integration 5.1, 30—41.

Kucera, Jan, Dusan Chlapek, Jakub Klímek, and Martin Necaskỳ (2015). "Methodologies and Best Practices for Open Data Publication." In: Databases, Texts, Specifications, Objects. Ed. by Martin Necasky, Jaroslav Pokorny, and Pavel Moravec. MATFYZPRESS, pp. 52-64. 
Kuchera, Ben (2021). Strip-mining the galaxy has never been so satisfying. URL: https: / / www. polygon.com / 2021 / 1 / 29 / 22255096 / dyson - sphereprogram-pc-steam (Accessed: 18 May 2021).

Kuhlthau, Carol C (1991). "Inside the search process: Information seeking from the user's perspective". In: Journal of the American society for information science 42.5, pp. 361-371.

Kunz, Werner and Horst WJ Rittel (1970). Issues as elements of information systems. Tech. rep. Berkeley, California: Institute of Urban and Regional Development, University of California.

Lakoff, George and Mark Johnson (2008). Metaphors we live by. University of Chicago press.

Land, Frank (2014). The story of LEO-the World's First Business Computer. URL: https://warwick.ac.uk/services/library/mrc/archives_online/ digital/leo/story (Accessed: 24 September 2020).

Langefors, Borje (1968). System för företagsstyrning. [Studentlitteratur]. Lund, Sweden.

Leavitt, HJ and TL Whisler (1958). "Management in the 1980's November". In: Brighton, MA: Harvard Business Review NovemberDecember, pp. 41-48.

Lee, Ashlin J and Peta S Cook (2020). "The myth of the "data-driven" society: Exploring the interactions of data interfaces, circulations, and abstractions". In: Sociology Compass 14.1, e12749.

Lee, Deirdre (2014). "Building an Open Data Ecosystem: An Irish Experience". In: Proceedings of the 8th International Conference on Theory and Practice of Electronic Governance. Ed. by Elsa Estevez, Marijn Janssen, and Luís Soares Barbosa. Association for Computing Machinery, 351-360.

Lee, Gwanhoo and Young Hoon Kwak (2012). "An open government maturity model for social media-based public engagement". In: Government information quarterly 29.4, pp. 492-503.

Leeway (2021). In: The Cambridge Dictionary. Cambridge University Press. URL: https: / / dictionary.cambridge.org / dictionary / english / leeway (Accessed: 23 May 2021).

Lewis, Clive Staples (1978). "The poison of subjectivism". In: Religion in life 47.3, pp. 288-296.

- (2001). The abolition of man. Zondervan.

Lin, Kenneth (2019). Range: Why Generalists Triumph in a Specialized World. Riverhead Books. 
Lindman, Juho, Tomi Kinnari, and Matti Rossi (2016). "Business roles in the emerging open-data ecosystem". In: IEEE Software 33.5, pp. 54-59.

Lindström, Karin (2018a). Företag frustrerade över öppna data - motarbetas aktivt av myndigheterna. URL: https://computersweden.idg.se/2.2683/ 1.695727/oppna-data-myndigheter (Accessed: 29 June 2021).

- (2018b). Svårt för utvecklare att använda myndigheters öppna data. URL: https: / / computersweden.idg. se / 2.2683 / 1.699357 / svart - anvanda oppna-data (Accessed: 29 June 2021).

Liston, Michael (2016). Scientific realism and antirealism. In: Internet Encyclopedia of Philosophy.

Longaker, Mark Garrett and Jeffrey Walker (2011). Rhetorical analysis: A brief guide for writers. Pearson Longman.

Lucas Jr, Henry C (1973). “A descriptive model of information systems in the context of the organization". In: ACM SIGMIS Database: the DATABASE for Advances in Information Systems 5.2-3-4, pp. 27-39.

Machi, Lawrence A and Brenda T McEvoy (2016). The literature review: Six steps to success. Corwin Press Inc.

Magalhaes, Gustavo, Catarina Roseira, and Laura Manley (2014). "Business models for open government data". In: Proceedings of the 8th International Conference on Theory and Practice of Electronic Governance. Ed. by Elsa Estevez, Marijn Janssen, and Luís Soares Barbosa. Association for Computing Machinery, pp. 365-370.

Manikas, Konstantinos and Klaus Marius Hansen (2013). “Reviewing the health of software ecosystems-a conceptual framework proposal". In: Proceedings of the 5th International Workshop on Software Ecosystems. Ed. by Carina F. Alves, Geir K. Hanssen, Jan Bosch, and Slinger Jansen. Citeseer, pp. 33-44.

March, Salvatore T and Gerald F Smith (1995). "Design and natural science research on information technology". In: Decision support systems 15.4, pp. 251-266.

Mars, Matthew M, Judith L Bronstein, and Robert F Lusch (2012). "The value of a metaphor: Organizations and ecosystems". In: Organizational Dynamics 41.4, pp. 271-280.

Martin, Sébastien, Slim Turki, and Samuel Renault (2017). “Open data ecosystems - Introducing the Stimulator Function". In: International Conference on Electronic Government and the Information Systems Perspective. Ed. by Andrea Ko and Enrico Francesconi. Springer, pp. 49-63. 
Mason, Richard O and Ian I Mitroff (1973). "A program for research on management information systems". In: Management science 19.5, pp. 475-487.

Maxwell, Joseph A. (2012a). “Conceptual framework: What do you think is going on?" In: Qualitative research design: An interactive approach. Ed. by Joseph A. Maxwell. Sage. Chap. 3, pp. 49-82.

Maxwell, Joseph A (2012b). Qualitative research design: An interactive approach. Sage Publications.

Mayer-Schönberger, Viktor and Zarino Zappia (2011). Participation and power: intermediaries of open data. Tech. rep. 1st Berlin Symposium on Internet and Society, Berlin, Germany.

Mays, Nicholas and Catherine Pope (2000). "Assessing quality in qualitative research". In: Bmj 320.7226, pp. 50-52.

McCoyd, Judith LM and Toba Schwaber Kerson (2006). "Conducting intensive interviews using email: A serendipitous comparative opportunity". In: Qualitative Social Work 5.3, pp. 389-406.

McGhee, George R (2006). The geometry of evolution: adaptive landscapes and theoretical morphospaces. Cambridge University Press.

McKinney Jr, Earl H and Charles J Yoos (2010). "Information about information: A taxonomy of views". In: MIS quarterly 34.2, pp. 329344.

McNabb, David E (2002). Research methods in public administration and nonprofit management. ME Sharpe.

- (2016). Public Utilities: Old Problems, New Challenges. Edward Elgar Publishing.

Meadows, Donella H (2008). Thinking in systems: A primer. chelsea green publishing.

Melin, Ulf (2016). "Challenges and benefits in an open data initiativea local government case study of myths and realities". In: 15th IFIP Electronic Government and the 8th Electronic Participation Conference (EGOV ePart 2016). Ed. by Efthimios Tambouris et al. Vol. 23, pp. 111-122.

Mingers, John, Alistair Mutch, and Leslie Willcocks (2013). "Critical realism in information systems research". In: MIS quarterly 37.3, pp. 795-802.

Mokobombang, N, Jairo Gutierrez, and Krassie Petrova (2020). "Value-creating Roles Played by the Actors in Open Government Data: A Systematic Literature Review". In: 31st Australasian Conference on Information Systems. ACIS, pp. 1-11. 
Möller, Knud (2013). "Lifecycle models of data-centric systems and domains". In: Semantic Web 4.1, 67-88.

Mooers, Calvin N (1959). "The next twenty years in information retrieval: some goals and predictions". In: Papers presented at the the March 3-5, 1959, western joint computer conference. Ed. by R. R. Johnson. Association for Computing Machinery, pp. 81-86.

Moore, Nick (1997). "The information society". In: World information report 1997/98. Ed. by Yves Courrier and Andrew Large. UNESCO Publishing. Chap. 20, pp. 271-284.

Morgan, Gareth (1997). Images of organization. SAGE Publications.

Myers, Michael D (2013). Qualitative research in business and management. Sage Publications Limited.

Myers, Michael D and Michael Newman (2007). "The qualitative interview in IS research: Examining the craft". In: Information and organization 17.1, pp. 2-26.

Mészáros, István (1966). "Metaphor and Simile: Preliminary Notes to a Discussion of Norms and Values". In: Proceedings of the Aristotelian Society. Vol. 67. JSTOR, pp. 127-144.

Nardi, Bonnie A, Vicki O'Day, and Vicki L O'Day (1999). Information ecologies: Using technology with heart. Mit Press.

Naturvårdsverket (2018). Tillgängliggöra data och följa upp informationshantering. URL: https:/ / www. naturvardsverket.se/Stod-i-miljoarbetet/ Vagledningar/Oppna-data/(Accessed: 10 October 2019).

Nicholas, David and Eti Herman (2010). Assessing information needs in the age of the digital consumer. Routledge.

Nilsson, Johan (2020). STHLM Traveling. URL: http:/ / sthlmtraveling.se/ (Accessed: 01 July 2020).

Nolan, Richard L and James C Wetherbe (1980). "Toward a comprehensive framework for MIS research". In: MIS Quarterly 4.2, pp. 119.

Nordmark, Ingrid et al. (2016). "Vi kräver att regeringen storsatsar på öppna data". In: URL: https:// computersweden.idg.se/2.2683/1.664888/ regeringen-oppna-data $\ 204 / 4$ (Accessed: 29 June 2021).

Novick, Gina (2008). "Is there a bias against telephone interviews in qualitative research?" In: Research in nursing E health 31.4, pp. 391398.

OECD (2019a). Digital Government Review of Sweden. OECD, pp. 1-124. URL: https:// www.oecd-ilibrary.org/content/publication/4daf932b-en (Accessed: 18 May 2021). 
OECD (2019b). Government at a Glance 2019. Paris. DOI: https://doi.org/ $10.1787 / 8 \mathrm{ccf} 5 \mathrm{c} 38$-en.

- (2020). Open, Useful and Re-usable data (OURdata) Index: 2019 - Policy Paper. OECD. URL: https: / / www. oecd.org / gov / digital-government / policy-paper-ourdata-index-2019.htm (Accessed: 18 May 2021).

- (2021). Open Government Data. The Organisation for Economic Cooperation and Development (OECD). URL: https://www.oecd.org/ digital / digital - government / open - government - data .htm (Accessed: 26 February 2021).

Ohlman, Herbert (2002). "Information: timekeeping, computing, telecommunications and audiovisual technologies". In: An Encyclopedia of the history of technology. Ed. by Ian McNeil. Routledge. Chap. 15, pp. 686-758.

Oliveira, Marcelo Iury S, Glória de Fátima Barros Lima, and Bernadette Farias Lóscio (2019). "Investigations into Data Ecosystems: a systematic mapping study". In: Knowledge and Information Systems 61.2, pp. 589-630.

Oliveira, Marcelo Iury S and Bernadette Farias Lóscio (2018). "What is a data ecosystem?" In: Proceedings of the 19th Annual International Conference on Digital Government Research: Governance in the Data Age. Ed. by Anneke Zuiderwijk and Charles C. Hinnant. Association for Computing Machinery, pp. 1-9.

O'Neil, Cathy (2016). Weapons of math destruction: How big data increases inequality and threatens democracy. Broadway Books.

Open Data Charter (2015). Principles. URL: https: / / opendatacharter.net/ principles/(Accessed: 08 June 2020).

Open Data Handbook (2015). What is open data? URL: http : / / opendatahandbook.org/guide/en/what-is-open-data/ (Accessed: 08 June 2020).

Open Knowledge (2005). Open Knowledge Definition 1.0. URL: http:// opendefinition.org/od/1.0/en/(Accessed: 08 June 2020).

- (2015). Open Knowledge Definition 2.1. URL: http://opendefinition.org/ (Accessed: 08 June 2020).

Open Knowledge Foundation (2020). What is open? URL: https://okfn. org/opendata/ (Accessed: 08 June 2020).

ÖppnaData.SE (2018). Skapa E publicera öppna data - Den nationella portalen för öppna data och PSI. URL: https://oppnadata.se/skapa-publiceraoppna-data/(Accessed: 27 August 2019). 
Orlikowski, Wanda J and Jack J Baroudi (1991). "Studying information technology in organizations: Research approaches and assumptions". In: Information systems research 2.1, pp. 1-28.

Orlikowski, Wanda J and C Suzanne Iacono (2001). "Research commentary: Desperately seeking the "IT" in IT research - A call to theorizing the IT artifact". In: Information systems research 12.2, pp. 121-134.

Peffers, Ken, Tuure Tuunanen, Marcus A Rothenberger, and Samir Chatterjee (2007). "A design science research methodology for information systems research". In: Journal of management information systems 24.3, pp. 45-77.

Pentland, Alex "Sandy" (2013). "The data-driven society". In: Scientific American 309.4, pp. 78-83.

Pereira, Gabriela Viale, Marie Anne Macadar, Edimara M Luciano, and Maurício Gregianin Testa (2017). "Delivering public value through open government data initiatives in a Smart City context". In: Information Systems Frontiers 19.2, pp. 213-229.

Peterson, Jordan B (1999). Maps of meaning: The architecture of belief. Psychology Press.

Petrou, Irene, Marios Meimaris, and George Papastefanatos (2014). "Towards a methodology for publishing linked open statistical data". In: eJournal of eDemocracy \& Open Government 6.1, pp. 97105.

Petrou, Irene and George Papastefanatos (2014). "Publishing Greek Census Data as linked open data". In: ed. by Vassilis Christophides and Dan Vodislav, pp. 1-3.

Petter, Stacie, Michelle Carter, Adriane Randolph, and Allen Lee (2018). "Desperately Seeking the Information in Information Systems Research". In: ACM SIGMIS Database: the DATABASE for Advances in Information Systems 49.3, pp. 10-18.

Pfeffer, Jeffrey and Gerald R Salancik (2003). The external control of organizations: A resource dependence perspective. Stanford University Press.

Pickett, Steward TA and Mary L Cadenasso (2002). "The ecosystem as a multidimensional concept: meaning, model, and metaphor". In: Ecosystems 5.1, pp. 1-10.

Pinker, Steven (2003a). The blank slate: The modern denial of human nature. Penguin. 
Pinker, Steven (2003b). The language instinct: How the mind creates language. Penguin UK.

- (2007). The stuff of thought: Language as a window into human nature. Penguin.

Pollock, Rufus (2011). Building the (open) data ecosystem. URL: https:// blog.okfn.org/2011/03/31/building-the-open-data-ecosystem/ (Accessed: 28 June 2021).

Purwanto, Arie, Anneke Zuiderwijk, and Marijn Janssen (2020). "Citizen engagement with open government data: A systematic literature review of drivers and inhibitors". In: International Journal of Electronic Government Research (IJEGR) 16.3, pp. 1-25.

Rachels, James and Stuart Rachels (2012). The Elements of Moral Philosophy. 7th. Mc Graw Hill Education.

Rapport, David J (1995). "Ecosystem health: More than a metaphor?" In: Environmental values 4.4, pp. 287-309.

Rapport, David J, Connie L Gaudet, R Constanza, PR Epstein, and R Levins (2009). Ecosystem health: principles and practice. John Wiley \& Sons.

Real, Leslie A and James H Brown (2012). Foundations of ecology: classic papers with commentaries. University of Chicago Press.

Reggi, Luigi and Sharon Dawes (2016). “Open government data ecosystems: Linking transparency for innovation with transparency for participation and accountability". In: International Conference on Electronic Government. Ed. by Hans Jochen Scholl et al. Springer, pp. 74-86.

Resledaren (2021). Resledaren. URL: https://www.resledaren.se/ (Accessed: 30 May 2021).

Riksrevisionen (2016). Den offentliga förvaltningens digitalisering. Riksrevisionen. URL: https : / / www . riksrevisionen . se / rapporter / granskningsrapporter / 2016 / den - offentliga - forvaltningens - digitalisering --en-enklare-oppnare- och- effektivare-forvaltning.html (Accessed: 18 May 2021).

Rogers, Everett M (2003). Diffusion of innovations. Free Press.

Rohunen, Anna, Jouni Markkula, Marikka Heikkila, and Jukka Heikkila (2014). "Open traffic data for future service innovation: Addressing the privacy challenges of driving data". In: Journal of theoretical and applied electronic commerce research 9.3, pp. 71-89. 
Rose, Jeremy, John Stouby Persson, Lise Tordrup Heeager, and Zahir Irani (2015). "Managing e-Government: value positions and relationships". In: Information Systems Journal 25.5, pp. 531-571.

Rose, Richard and William James Millar Mackenzie (1991). "Comparing forms of comparative analysis". In: Political studies 39.3, pp. $446-462$.

Royal Mail Group (2020). Royal Mail Group - Our story. URL: https:// www.royalmailgroup.com/en/about-us/our-story/(Accessed: 04 October 2020).

Safarov, Igbal, Albert Meijer, and Stephan Grimmelikhuijsen (2017). "Utilization of open government data: A systematic literature review of types, conditions, effects and users". In: Information Polity 22.1, pp. 1-24.

Saldana, Johnny (2015). The Coding Manual for Qualitative Researchers. SAGE.

Sandoval-Almazan, Rodrigo and J Ramon Gil-Garcia (2016). “Toward an integrative assessment of open government: Proposing conceptual lenses and practical components". In: Journal of Organizational Computing and Electronic Commerce 26.1-2, pp. 170-192.

Sarkheyli, Azadeh and Elnaz Sarkheyli (2019). "Smart Megaprojects in Smart Cities, Dimensions, and Challenges". In: Smart Cities Cybersecurity and Privacy. Ed. by Danda B. Rawat and Kayhan Zrar Ghafoor. Elsevier. Chap. 19, pp. 269-277.

Saunders, Mark NK and Philip Lewis (2012). Doing research in business $\mathcal{E}$ management: An essential guide to planning your project. Pearson.

Schrier, Bill (2014). "Government Open Data: Benefits, Strategies, and Use". In: The Evans School Review.

Scott, Anna (2020). What is 'open data' and why should we care? -- The ODI. Open Data Institute. URL: https://theodi.org/article/what-is-opendata-and-why-should-we-care/ (Accessed: 08 June 2020).

Sector (2021). In: The Cambridge Dictionary. Cambridge University Press. URL: https: / / dictionary. cambridge. org / dictionary / english / sector (Accessed: 29 January 2021).

Serra, Lluís Esteve Casellas (2014). "The mapping, selecting and opening of data: The records management contribution to the Open Data project in Girona City Council". In: Records Management Journal 24.2, pp. 87-98.

Shah, S, Vasilis Peristeras, and Ioannis Magnisalis (2020). "Government (Big) data ecosystem: definition, classification of actors, and 
their roles". In: International Journal of Computer and Information Engineering 14.4, pp. 102-114.

Shekarabi, Ardalan (2017). Regeringen vill snabba på arbetet med öppna data. URL: https:/ / www.regeringen.se/debattartiklar/2017/05/ regeringenvill-snabba-pa-arbetet-med-oppna-data/ (Accessed: 18 May 2021).

Shi, Xianwei, Ke Rong, and Yongjiang Shi (2018). "Conceptualising Entreprenurial Ecosystems: Definition, Configurations and Health". In: 2018 IEEE International Symposium on Innovation and Entrepreneurship (TEMS-ISIE). Ed. by Michael Condry, Jin Chen, Xiaohong Quan, and Xielin Liu. IEEE, pp. 1-11.

Shoemaker, Pamela J and Timothy Vos (2009). Gatekeeping theory. Routledge.

Sidorova, Anna, Nicholas Evangelopoulos, Joseph S Valacich, and Thiagarajan Ramakrishnan (2008). "Uncovering the intellectual core of the information systems discipline". In: MIS Quarterly 32.3, pp. 467-482.

Sipior, Janice C (1996). “Congratulations to our ACM fellows!" In: ACM SIGMIS Database: the DATABASE for Advances in Information Systems 28.1, pp. 14-16.

Skjutsgruppen (2020). Skjutsgruppen. URL: https://play.google.com/store/ apps/details?id=nu.skjutsgruppen.skjutsgruppen (Accessed: 01 July 2020).

SKR (2017). Ramverk, öppna data - SKR. URL: https : / / skr . se / skr / naringslivarbetedigitalisering / digitalisering / informationsforsorjningdigitalinfrastruktur / skrsoppnadata / stodoppnadata / ramverketforoppnadata.1184.html (Accessed: 30 May 2021).

Smith, Göran and Johan Sandberg (2018). "Barriers to innovating with open government data: Exploring experiences across service phases and user types". In: Information Polity 23.3, pp. 249-265.

Södertälje (2019). Södertäljes öppna data. URL: https:/ / www.sodertalje.se/ kommun-och-politik/for-medborgare/oppna-data (Accessed: 26 August 2019).

Sowell, Thomas (2019). The vision of the anointed: Self-congratulation as a basis for social policy. Hachette UK.

Sphere (2021). In: The Cambridge Dictionary. Cambridge University Press. URL: https: / / dictionary.cambridge.org / dictionary / english / sphere (Accessed: 29 January 2021).

Starmans, Barbara J. (2015). Royal Mail History. URL: https: / / www. thesocialhistorian.com/royal-mail-history/(Accessed: 04 October 2020). 
Statskontoret (2018). Hinder för att använda myndigheternas öppna data. Statskontoret. URL: https://www.statskontoret.se/nyheter/hinder-for-attanvanda-myndigheternas-oppna-data/(Accessed: 18 May 2021).

Stokes, Donald E (2011). Pasteur's quadrant: Basic science and technological innovation. Brookings Institution Press.

Strauss, William and Neil Howe (2009). The fourth turning: What the cycles of history tell us about America's next rendezvous with destiny. Crown.

Styrin, Evgeny, Luis Felipe Luna-Reyes, and Teresa M. Harrison (2017). "Open data ecosystems: an international comparison". In: Transforming Government: People, Process and Policy 11.1, 132-156.

Sunlight Foundation (2014). TEN PRINCIPLES FOR OPENING UP GOVERNMENT INFORMATION. URL: https: / / sunlightfoundation. com / policy / documents / ten- open- data - principles/ (Accessed: 08 June 2020).

Susha, Iryna, Åke Grönlund, and Marijn Janssen (2015). “Organizational measures to stimulate user engagement with open data". In: Transforming Government: People, Process and Policy 9.2, pp. 181-206. Susha, Iryna, Marijn Janssen, and Stefaan Verhulst (2017). "Data collaboratives as "bazaars"? A review of coordination problems and mechanisms to match demand for data with supply". In: Transforming Government: People, Process and Policy 11.1, pp. 157-172.

Sverdrup, Keith and Raphael Kudela (2013). Investigating oceanography. McGraw-Hill Higher Education.

Sveriges meteorologiska och hydrologiska institut (2021). Väder Väderprognoser Klimat- $\mathcal{E}$ Vädertjänster i Sverige. URL: https://www.smhi.se/ (Accessed: 04 March 2021).

Tananbaum, Greg (2008). "Adventures in open data". In: Learned Publishing 21.2, pp. 154-156.

Tansley, Arthur G (1935). “The use and abuse of vegetational concepts and terms". In: Ecology 16.3, pp. 284-307.

Tauberer, Joshua (2014). Open Government Data: The Book. URL: https: //opengovdata.io/ (Accessed: 08 June 2020).

Tauberer, Joshua and Larry Lessig (2007). The 8 principles of open government data. URL: https://opengovdata.org/(Accessed: 28 June 2021).

Terraform. (2021). In: The Cambridge Dictionary. Cambridge University Press. URL: https:/ / dictionary.cambridge.org/dictionary/english/terraform (Accessed: 05 July 2021). 
Thibodeau, Paul H and Lera Boroditsky (2011). "Metaphors we think with: The role of metaphor in reasoning". In: PLOS ONE 6.2, pp. 111.

Turki, Slim, Sébastien Martin, and Samuel Renault (2017). “How open data ecosystems are stimulated?" In: Proceedings of the Internationsl Conference on Electronic Governance and Open Society: Challenges in Eurasia. Ed. by Dmitrii Trutnev. Association for Computing Machinery, pp. 179-187.

Ubaldi, Barbara (2013). Open Government Data - Towards Empirical Analysis of Open Government Data Initiatives. 22. OECD, pp. 1-61. URL: https:// www.oecd-ilibrary.org/governance / open-government-data 5k46bj4f03s7-en (Accessed: 28 June 2021).

Van Schalkwyk, François, Michelle Willmers, and Maurice McNaughton (2016). “Viscous Open Data: The Roles of Intermediaries in an Open Data Ecosystem". In: Information Technology for Development 22.November, 68-83.

Ven, Andrew H Van de et al. (2007). Engaged scholarship: A guide for organizational and social research. Oxford University Press on Demand.

Vetrò, Antonio et al. (2016). "Open data quality measurement framework: Definition and application to Open Government Data". In: Government Information Quarterly 33.2, pp. 325-337.

Vos, Timothy and François Heinderyckx (2015). Gatekeeping in transition. Routledge.

Walsham, Geoff (1995). "Interpretive case studies in IS research: nature and method". In: European Journal of information systems 4.2, pp. 7481.

Wang, Fang, An Zhao, Hong Zhao, and Jun Chu (2019). "Building a Holistic Taxonomy Model for OGD-Related Risks: Based on a Lifecycle Analysis". In: Data Intelligence 1.4, pp. 309-332.

Weathers, Kathleen C, David L Strayer, and Gene E Likens (2012). Fundamentals of ecosystem science. Academic Press.

Weerakkody, Vishanth, Zahir Irani, Kawal Kapoor, Uthayasankar Sivarajah, and Yogesh K Dwivedi (2017). "Open data and its usability: an empirical view from the Citizen's perspective". In: Information Systems Frontiers 19.2, pp. 285-300.

Welle Donker, Frederika and Bastiaan van Loenen (2017). "How to assess the success of the open data ecosystem?" In: International Journal of Digital Earth 10.3, pp. 284-306. 
Wennberg, John and Alan Gittelsohn (1973). "Small area variations in health care delivery: a population-based health information system can guide planning and regulatory decision-making". In: Science 182.4117, pp. 1102-1108.

Westbrook, Lynn (1993). "User needs: a synthesis and analysis of current theories for the practitioner". In: RQ 32.4, pp. 541-549.

Whiting, Lisa S (2008). "Semi-structured interviews: Guidance for novice researchers." In: Nursing standard 22.23, pp. 35-40.

Williamson, Oliver E (1991). "Comparative economic organization: The analysis of discrete structural alternatives". In: Administrative science quarterly 36.2, pp. 269-296.

Wilson, Edward O (1999). Consilience: The unity of knowledge. Vol. 31. Vintage.

Wilson, Tom D (1981). “On user studies and information needs". In: Journal of documentation 37.1, pp. 3-15.

Wilson, Woodrow (1886). "The study of public administration". In: Communication Researchers and Policy-making (2003). Ed. by Sandra Braman. MIT Press. Chap. 3, pp. 61-84.

Wirtz, Bernd W. and Steven Birkmeyer (2015). "Open Government: Origin, Development, and Conceptual Perspectives". In: International Journal of Public Administration 38.5, 381-396.

Wirtz, Bernd W, Robert Piehler, Marc-Julian Thomas, and Peter Daiser (2016). "Resistance of public personnel to open government: A cognitive theory view of implementation barriers towards open government data". In: Public Management Review 18.9, pp. 13351364.

World Wide Web Foundation (2021). The Open Data Barometer. URL: https://opendatabarometer.org/ (Accessed: 26 February 2021).

Yang, Tung-Mou, Jin Lo, and Jing Shiang (2015). "To open or not to open? Determinants of open government data". In: Journal of Information Science 41.5, pp. 596-612.

Yin, Robert K (2018). Case study research and applications: Design and methods. Sage publications.

Zuiderwijk, Anneke and Marijn Janssen (2013). "A coordination theory perspective to improve the use of open data in policy-making". In: the 12th IFIP WG 8.5 International Conference on Electronic Government 2013 (EGOV 2013) (Koblenz, Germany). Ed. by Maria Wimmer, Marijn Janssen, and Hans Jochen Scholl. Heidelberg, Berlin: Springer, pp. 38-49. 
Zuiderwijk, Anneke and Marijn Janssen (2014a). "Barriers and development directions for the publication and usage of open data: A socio-technical view". In: Open government - Opportunities and Challenges for Public Governance. Ed. by Mila Gascó-Hernández. Springer, pp. 115-135.

- (2014b). "The negative effects of open government datainvestigating the dark side of open data". In: Proceedings of the 15th Annual International Conference on Digital Government Research. Ed. by Gabriel Puron-Cid, Scott Robertson, Jing Zhang, and J. Ramon Gil-Garcia. Association for Computing Machinery, pp. 147152.

Zuiderwijk, Anneke, Marijn Janssen, Sunil Choenni, and Ronald Meijer (2014). "Design principles for improving the process of publishing open data". In: Transforming Government: People, Process and Policy 8.2, pp. 185-204.

Zuiderwijk, Anneke, Marijn Janssen, Sunil Choenni, Ronald Meijer, and Roexsana Sheikh Alibaks (2012). "Socio-technical Impediments of Open Data". In: Electronic Journal of e-Government 10.2, pp. 156-172.

Zuiderwijk, Anneke, Marijn Janssen, and Chris Davis (2014). "Innovation with open data: Essential elements of open data ecosystems". In: Information Polity 19.1, 2, pp. 17-33.

Zuiderwijk, Anneke, Marijn Janssen, Kostas Poulis, and Geerten van de Kaa (2015). “Open data for competitive advantage: insights from open data use by companies". In: Proceedings of the 16th Annual International Conference on Digital Government Research. Ed. by Karen Mossberger, Natalie Helbig, Jing Zhang, and Yushim Kim. Association for Computing Machinery, pp. 79-88.

Zuiderwijk, Anneke, Euripides Loukis, Charalampos Alexopoulos, Marijn Janssen, and Keith Jeffery (2014). "Elements for the development of an open data marketplace". In: Conference for EDemocracy and Open Governement. Ed. by Peter Parycek and Noella Edelmann. sn. Edition Donau-Universität Krems, pp. 309-322.

Zuiderwijk, Anneke, Ali Pirannejad, and Iryna Susha (2021). “Comparing open data benchmarks: Which metrics and methodologies determine countries' positions in the ranking lists?" In: Telematics and Informatics 62, pp. 1-23.

Zuiderwijk, Anneke, Rhythima Shinde, and Marijn Janssen (2019). "Investigating the attainment of open government data objectives: 
Is there a mismatch between objectives and results?" In: International Review of Administrative Sciences 85.4, pp. 645-672. 



\section{My Articles and Works}

\section{A.1 Included Articles}

Article A Crusoe, Jonathan, Anthony Simonofski, and Antoine Clarinval (2020). "Towards a Framework for Open Data Publishers: A Comparison Study Between Sweden and Belgium". In: Electronic Government. Ed. by Gabriela Viale Pereira, Marijn Janssen, Habin Lee, Ida Lindgren, Manuel Pedro Rodríguez Bolívar, Hans Jochen Scholl, and Anneke Zuiderwijk. Cham: Springer International Publishing, pp. 262-274

Article B Crusoe, Jonathan and Karin Ahlin (2019b). “Users' activities for using open government data-a process framework". In: Transforming government: People, process and policy $13.3-4$, pp. 213-236

Article C Crusoe, Jonathan (2021a). “Diagnose a National Open Data Ecosystem The Countrywide Exploration of Open Data in Sweden". In: [In Preparation and Peer Reviewed]

Article D Crusoe, Jonathan, Anneke Zuiderwijk, and Ulf Melin (2020). “Open Government Data Systems: Learning from a Public Utility Perspective". In: Electronic Government. Ed. by Gabriela Viale Pereira, Marijn Janssen, Habin Lee, Ida Lindgren, Manuel Pedro Rodríguez Bolívar, Hans Jochen Scholl, and Anneke Zuiderwijk. Cham: Springer International Publishing, pp. 275-289

Article E Crusoe, Jonathan, Elisabeth Gebka, and Karin Ahlin (2020b). “Open Government Data from the Perspective of Information Needs - A Tentative Conceptual Model". In: Electronic Government. Ed. by Gabriela Viale Pereira, Marijn Janssen, Habin Lee, Ida Lindgren, Manuel Pedro Rodríguez Bolívar, Hans Jochen Scholl, and Anneke Zuiderwijk. Cham: Springer International Publishing, pp. 250-261 


\section{A.2 Additional Articles}

Crusoe, Jonathan and Ulf Melin (2017). “Exploring actor's roles within an Open Data Ecosystem - Reflexive Conceptual Development". In: Scandinavian Workshop of e-Government SWEG 2017, the Mid Sweden University, Sundsvall, 1-2 February 1-2. [In Preparation and Peer Reviewed]

Crusoe, Jonathan and Ulf Melin (2018b). "The Bigger Picture of Open Government Data Barriers - A Literature Review and Conceptualization". In: The 15th Scandinavian Workshop of e-Government SWEG, Copenhagen Business School, Copenhagen, January 31-February 1. [Developed and Published]

Crusoe, Jonathan and Ulf Melin (2018a). "Investigating open government data barriers". In: International Conference on Electronic Government. Ed. by Peter Parycek, Olivier Glassey, Marijn Janssen, Efthimios Jochen Scholl Hans Tambouris, Evangelos Kalampokis, and Shefali Virkar. Springer, pp. 169-183

Berntzen, Lasse, Marius Rohde Johannessen, Kim Normann Andersen, and Jonathan Crusoe (2019). "Parliamentary Open Data in Scandinavia". In: Computers 8.3, pp. 1-18

Crusoe, Jonathan (2019b). Why is it so challenging to cultivate open government data?: Understanding impediments from an ecosystem perspective. Vol. 124. [Licentiate Thesis]. Linköping University Electronic Press

Crusoe, Jonathan, Anthony Simonofski, Antoine Clarinval, and Elisabeth Gebka (2019). "The impact of impediments on open government data use: Insights from users". In: 2019 13th International Conference on Research Challenges in Information Science (RCIS). ed. by Manuel Kolp, Jean Vanderdonckt, Monique Snoeck, and Yves Wautelet. IEEE, pp. 1-12

Crusoe, Jonathan and Karin Ahlin (2019a). “Users' activities and impediments from motivation to deployment in Open Government Data-a process framework". In: Scandinavian Workshop of e-Government SWEG 2019, the University of South-Eastern Norway (USN), Campus Vestfold, 30-31 January. [Developed and Published]

Gebka, Elisabeth, Antoine Clarinval, Anthony Simonofski, and Jonathan Crusoe (2019). "Generating value with open government data: Beyond the programmer". In: 2019 13th International Conference on Research Challenges in Information Science (RCIS). ed. by Manuel Kolp, Jean Vanderdonckt, Monique Snoeck, and Yves Wautelet. IEEE, pp. 1-2

Crusoe, Jonathan (2019a). Organizing Open Government Data - Exploring Data as a Public Utility. [Thesis Plan]. Colloquium of the EGOV-CeDEM-ePART conference (in Italy)

Crusoe, Jonathan, Elisabeth Gebka, and Karin Ahlin (2020a). “Do we need open data in our lives?" In: Scandinavian Workshop of e-Government Scandinavian Workshop of e-Government SWEG 2020, the University of Gothenburg, Campus Lindholmen, 29-30 January. [Developed and Published]

Gebka, Elisabeth, Jonathan Crusoe, and Karin Ahlin (2020b). “Open data reuse and information needs satisfaction: a method to bridge the gap". In: the Scandinavian Workshop of e-Government Scandinavian Workshop of e-Government SWEG 2020, the University of Gothenburg, Campus Lindholmen, 29-30 January. [Developed and Published as Research in Progress]

Gebka, Elisabeth, Jonathan Crusoe, and Karin Ahlin (2020a). “Open data reuse and information needs satisfaction: a method to bridge the gap". In: Proceedings of 
Ongoing Research, Practitioners, Posters, Workshops, and Projects at EGOV-CeDEMePart 2020. Ed. by Shefali Virkar, Marijn Janssen, Ida Lindgren, Ulf Melin, Francesco Mureddu, Peter Parycek, Efthimios Tambouris, Gerhard Schwabe, and Hans Jochen Scholl. CEUR-WS, pp. 41-49

Crusoe, Jonathan and Karin Ahlin (2020). "Publisher' activities for working with Open Government Data - a process framework". In: Scandinavian Workshop of e-Government Scandinavian Workshop of e-Government SWEG 2020, the University of Gothenburg, Campus Lindholmen, 29-30 January. [Developed and Published]

Crusoe, Jonathan (2021b). "Information Systems - Inklings toward a fundamental framework". In: Scandinavian Workshop of e-Government SWEG 2021, the IT University of Copenhagen, Denmark, 27-28 January. [In Preparation and Peer Reviewed] 



\section{Articles}

The articles associated with this thesis have been removed for copyright reasons. For more details about these see:

http://urn.kb.se/resolve?urn=urn:nbn:se:liu:diva-177827 


\section{FACULTY OF ARTS AND SCIENCES}

Linköping Studies in Arts and Sciences Dissertations, No. 810, 2021

Department of Management and Engineering

Linköping University

SE-581 83 Linköping, Sweden

www.liu.se 